Portland State University

PDXScholar

$11-11-2020$

\title{
Investigation of Prussian Blue Analogues as Cathode Materials for Next Generation Batteries
}

Neal Walters Kuperman

Portland State University

Follow this and additional works at: https://pdxscholar.library.pdx.edu/open_access_etds

Part of the Physics Commons

Let us know how access to this document benefits you.

\section{Recommended Citation}

Kuperman, Neal Walters, "Investigation of Prussian Blue Analogues as Cathode Materials for Next Generation Batteries" (2020). Dissertations and Theses. Paper 5614.

https://doi.org/10.15760/etd.7486

This Dissertation is brought to you for free and open access. It has been accepted for inclusion in Dissertations and Theses by an authorized administrator of PDXScholar. Please contact us if we can make this document more accessible: pdxscholar@pdx.edu. 


\title{
Investigation of Prussian Blue Analogues as Cathode Materials for \\ Next Generation Batteries
}

by

Neal Walters Kuperman

\begin{abstract}
A dissertation submitted in partial fulfillment of the requirements for the degree of
\end{abstract}

\section{Doctor of Philosophy}

in

Applied Physics

\author{
Dissertation Committee: \\ Raj Solanki, Chair \\ Gary Goncher \\ Drake Mitchell \\ Tami Lasseter Clare \\ Andrea Goforth
}

\author{
Portland State University \\ 2020
}


(C) 2020 Neal Walters Kuperman 


\begin{abstract}
Since the beginning of the indusial revolution, the average global temperature has risen about $1{ }^{\circ} \mathrm{C}$ due increases in anthropogenic greenhouse gases emitted into the atmosphere. Of all human produced greenhouse gases, carbon dioxide is the most prevalent, with the production of electricity from fossil fuels being the major contributor.

Solar and wind power are promising net zero emission energy sources but only accounted for $\sim 5 \%$ of global electricity generation in 2016 . The most significant hurdle hindering their widespread adoption is the intermittent nature of the electricity generation. To overcome this limitation, significant resources need to be put into the development and implementation of energy storage systems (ESS). Rechargeable batteries are one possible solution to the demand for storage, with the lithium ion battery (LIB) being the current standard. However, due to the cost, safety concerns, and toxicity of LIBs, new battery technologies are needed to fully utilize renewable energy sources, such as wind and solar.
\end{abstract}

Metal hexacyanoferrates, or Prussian blue (PB) and Prussian blue analogues (PBAs), are one family of materials whose electrochemical and physical properties make them intriguing candidates for electrode materials for non-lithium ion-based technologies. In particular, their open framework structure, high specific capacity, good ionic conductivity, facile synthesis, and tunability. The work in this dissertation examines 
four different PBAs as cathode materials in both aqueous and nonaqueous electrolytes with the aim of achieving the following objectives:

1. Develop cathode materials for non-lithium ion based batteries, with a particular focus on divalent ion systems.

2. Determine if the physical and electrochemical storage properties of a PBA could be improved if two binary metal hexacyanoferrates are incorporated into a hybrid metal hexacyanoferrate composite.

These objectives were achieved via performing the following investigations.

In the first study, Prussian blue $\left(\mathrm{KFe}^{3+}\left[\mathrm{Fe}^{2+}(\mathrm{CN})_{6}\right]\right)$ is adopted as a cathode material for a nonaqueous calcium ion battery. The work demonstrated for the first time the use of PB in a Ca based system. The cathode delivered a specific capacity of 150 mAhg $^{-1}$ at a current density of $23 \mathrm{mAg}^{-1}$.

The second study examined manganese-cobalt hexacyanoferrate in an aqueous $\mathrm{Zn}^{2+}$ electrolyte. The inclusion of $\mathrm{Mn}$ and $\mathrm{Co}$ in the same compound prevent the dissolution of $\mathrm{Mn}$ in the aqueous electrolyte. Additionally, the addition of $\mathrm{Mn}$ provided a $21 \%$ increase $\left(29 \mathrm{mAhg}^{-1}\right)$ in storage capacity compared to CoHCF. However, the mixed metal system suffered from increased capacity loss compared to CoHCF.

The effects of coordinated and zeolitic $\mathrm{H}_{2} \mathrm{O}$ on a $\mathrm{Cu}\left[\mathrm{Fe}(\mathrm{CN})_{6}\right]$ cathode in a nonaqueous $\mathrm{Mg}^{2+}$ electrolyte are examined in the third study. Water was shown to play 
an important role in maximizing the specific capacity of copper hexacyanoferrate. Maintaining water within the CuHCF lattice resulted in a $25 \%$ increase in specific capacity compared to the dehydrated sample. However, both samples displayed strong rate capability and exhibited comparable $\mathrm{Mg}^{2+}$ diffusion coefficients.

The last experimental study presents $\mathrm{Mn}_{x} \mathrm{Ni}_{1-\mathrm{x}}\left[\mathrm{Fe}(\mathrm{CN})_{6}\right]$ as a cathode material in a nonaqueous $\mathrm{K}^{+}$electrolyte. $\mathrm{Mn}_{0.50} \mathrm{Ni}_{0.50}\left[\mathrm{Fe}(\mathrm{CN})_{6}\right]$ displayed superior performance compared to all other materials investigated in this work. By combing $\mathrm{Mn}$ and $\mathrm{Ni}$, the mixed metal system was able to overcome the poor $\mathrm{K}^{+}$diffusion kinetics of $\mathrm{Mn}\left[\mathrm{Fe}(\mathrm{CN})_{6}\right]$ while delivering specific capacity $25 \%$ greater than $\mathrm{Ni}\left[\mathrm{Fe}(\mathrm{CN})_{6}\right]$.

Analysis of the FTIR and electrochemical data of $\mathrm{Mn}_{\mathrm{x}} \mathrm{Ni}_{1-\mathrm{x}}\left[\mathrm{Fe}(\mathrm{CN})_{6}\right]$ suggested substitution of $\mathrm{Mn}$ for $\mathrm{Ni}$ in the PBA lattice caused a shift in electron density away from the nitrogen coordinated transition metal (either $\mathrm{Mn}$ or $\mathrm{Ni}$ ) towards the Fe-C end of the cyanide. Density functional theory (DFT) calculations were performed to further study the effect of incorporation of $\mathrm{Mn}$ on the electronic properties of the mixed manganese-nickel hexacyanoferrate system. Initial computational results appeared to confirm the experimental hypothesis about the shifts in electron density with respect to manganese. 


\section{Dedication}

To my Grandmother.

Thank you for always seeing in me the person I strive be. 


\section{Acknowledgements}

The mere fact that I have the privilege to write the acknowledgements page of my dissertation is a testament to all of the guidance, support, and comradery I have received over the past six and a half years. Countless people within the Portland State University community, especially in the physics department, have contributed to my growth and development as a learner, thinker, and researcher, and I want to acknowledge a few people in particular.

First and foremost, I want to thank Dr. Raj Solanki for providing me the opportunity to become a member of his group. He provided both the scaffolding and autonomy that allowed me to forge my own path and explore my passions. His continued love for science and desire to learn created the foundation for my doctoral research, and are two qualities I hope to display throughout career and life. I would also like to thank Dr. Gary Goncher, without his vital insight and mentorship my research would have not have been as fulfilling and fruitful. Thank you to my other committee members: Dr. Tami Clare, Dr. Andrea Goforth, and Dr. Drake Mitchell for taking the time to provide advice and feedback on my research throughout my graduate career.

My lab mates, Dr. Sudhaprasanna Kumar Padigi, Dr. Michael Adventure Hopkins, and soon to be doctors Bao Nguyen and Joseph Thiebes, thank you for creating a wonderful community over the years in the Solanki lab. I owe a particular gratitude to Dr. 
Padigi, his mentorship introduced me to the world of electrochemistry and Prussian blue analogues.

Along with the fantastic community at Portland State, none of my work would have been possible without the support from my family.

Mom and Dave, thank you for everything, you have been the foundation of my support for this entire journey. In particular, I need to thank my wonderful, nosey, loving, and overly proud mother, for providing me with the figurative and literal fuel that powered me through the writing of my dissertation.

Uncle lee, thank you for providing the spark that ignited my passion for physics. You are a guiding influence for me in my scientific journey. From Thursday nights at Alameda brewing helping with my high school physics homework to editing my dissertation, you have always been an enormous source of encouragement and motivation.

Julia, you are my best friend, sounding board, and rock. Thank you for the countless sacrifices you have made that have allowed me to get to this point. From the long nights working together to the little sticky notes with words of love and support. Grad school has been a wild journey, but it has been immensely more fun and exciting going through it with you. 
Investigation of Prussian Blue Analogues as Cathode Materials for Next Generation Batteries

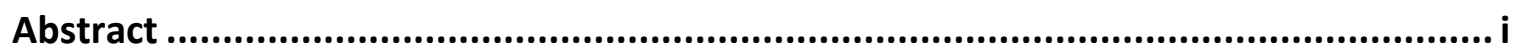

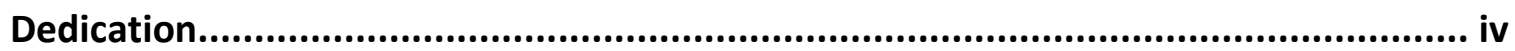

Acknowledgements ............................................................................................ v

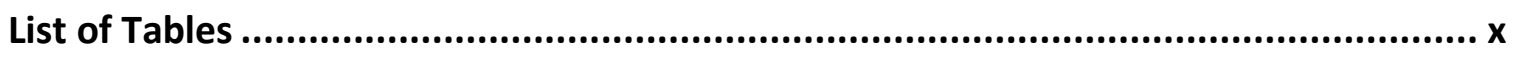

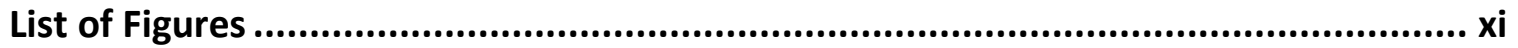

Chapter 1. Introduction ............................................................................ 1

1.1 Global Warming and Electricity Production .................................................. 1

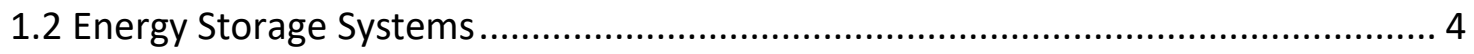

1.2.1 Pumped Hydro energy storage ............................................................... 5

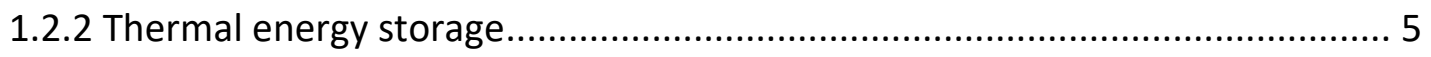

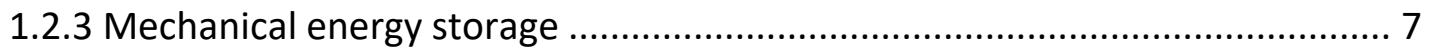

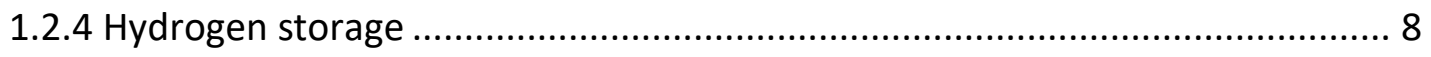

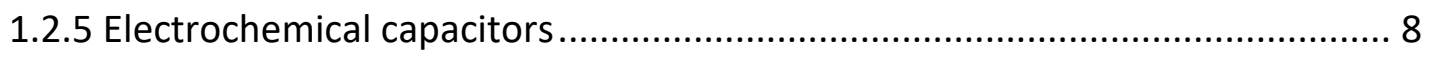

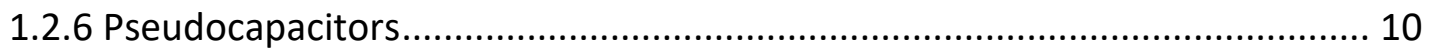

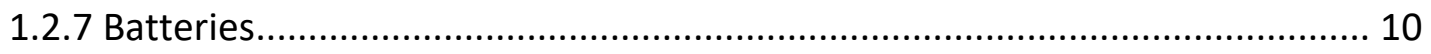

1.3 Solid Electrode Batteries as an Energy Storage Solution................................... 12

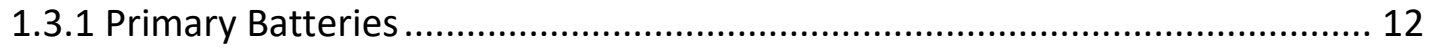

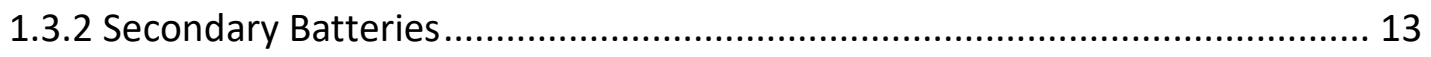

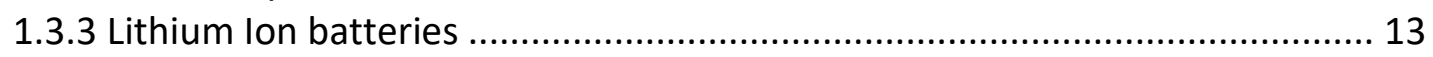

1.3.4 Moving Beyond Lithium Ion Batteries ..................................................... 18

1.4 Prussian Blue (PB) and its Analogues (PBAs) .................................................... 19

1.4.1 Prussian Blue and Prussian Blue Analogues Chemical Composition ............... 20

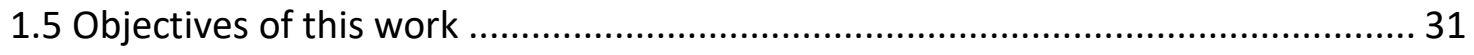

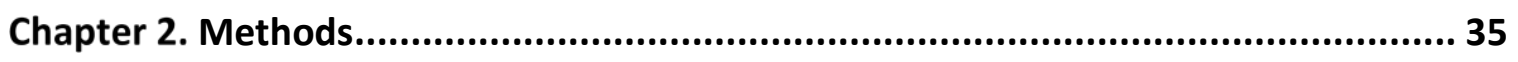

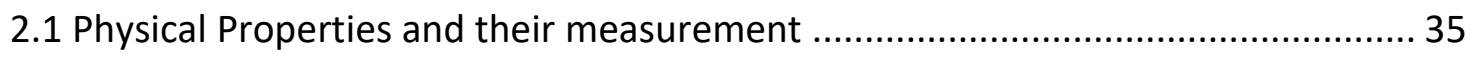

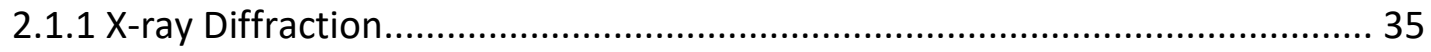

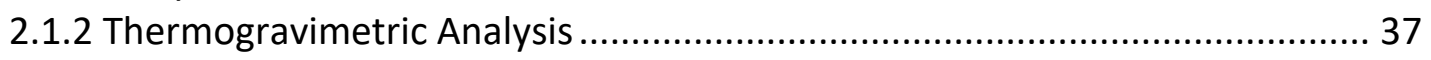

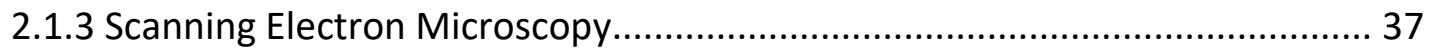

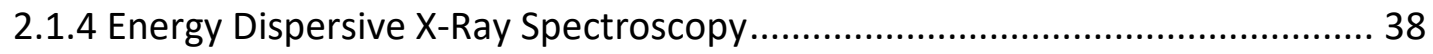

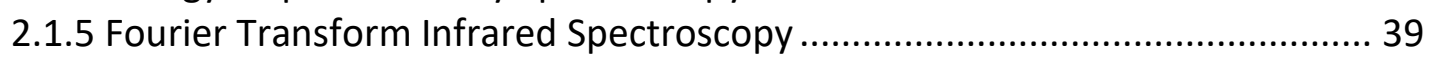




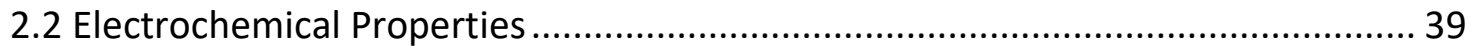

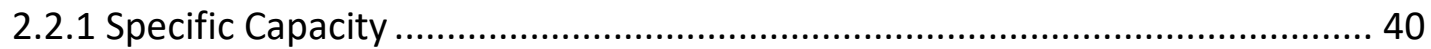

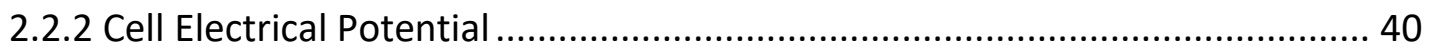

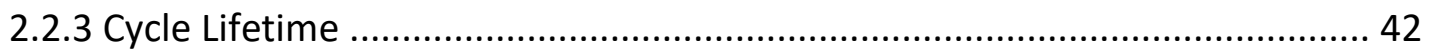

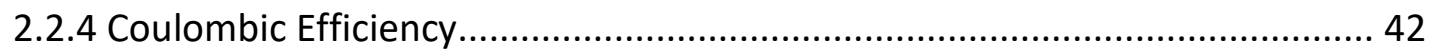

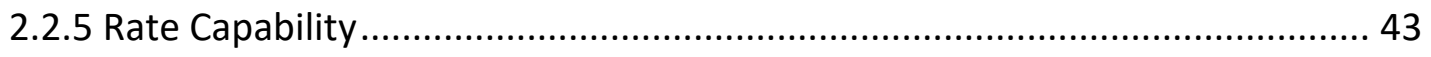

2.3 Measurement of Electrochemical Properties .................................................... 43

2.3.1 Three-Electrode Measurements............................................................... 43

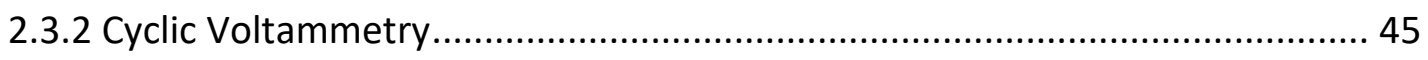

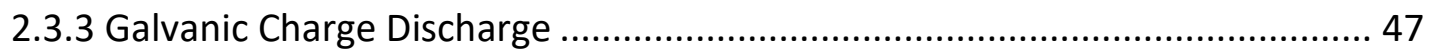

Chapter 3. High performance Prussian blue as a cathode material for nonaqueous calcium ion batteries ................................................................................. 48

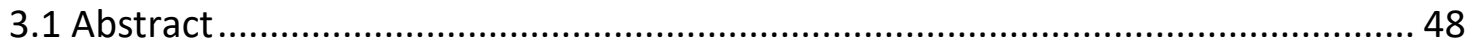

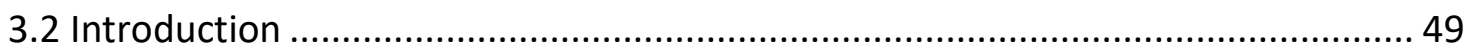

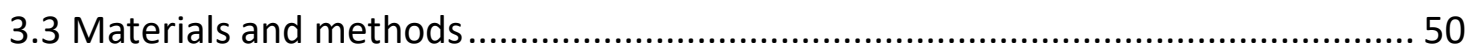

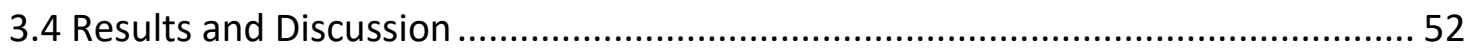

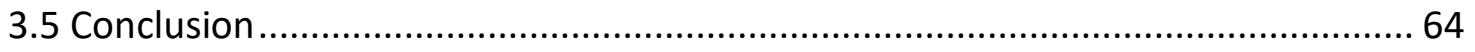

3.6 Additional Commentary on Published Work .................................................... 65

Chapter 4. Manganese-Cobalt Hexacyanoferrate as a Cathode Material for Aqueous

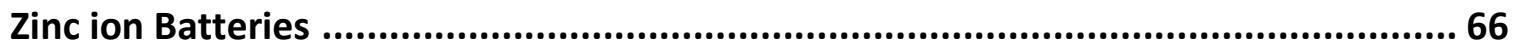

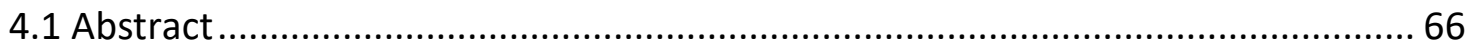

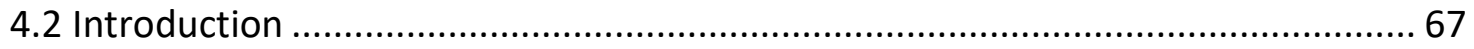

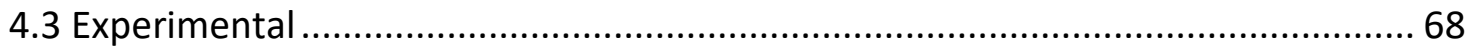

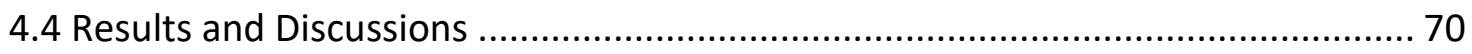

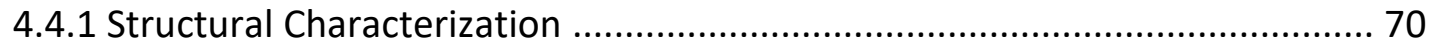

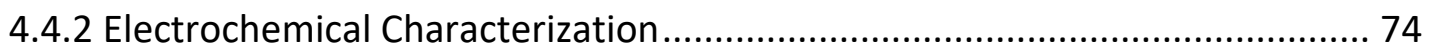

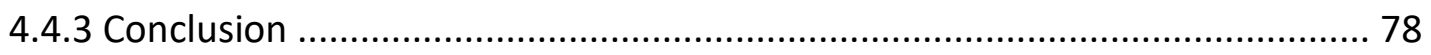

4.5 Additional Commentary on Published Work ..................................................... 79

Chapter 5. Copper Hexacyanoferrate as a cathode material for magnesium ion batteries. ............................................................................................... 81

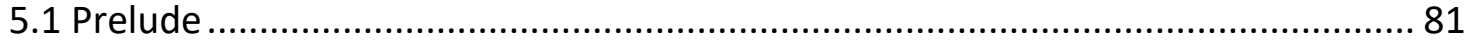

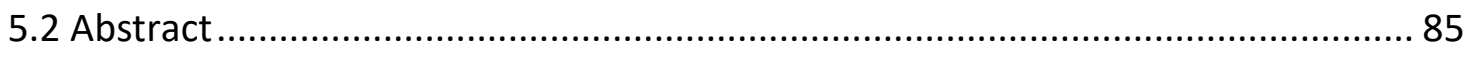

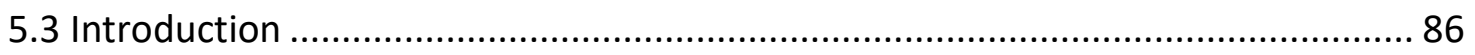

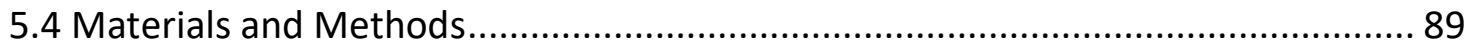

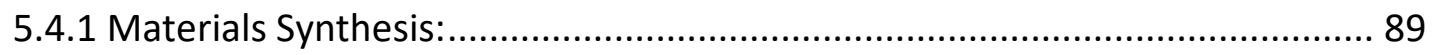

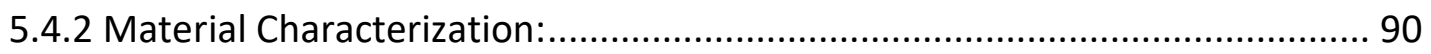

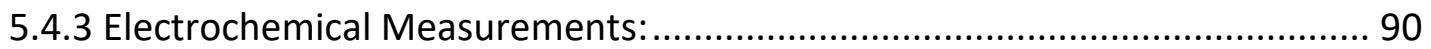

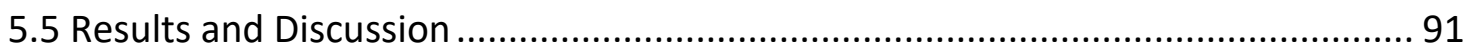

5.6 Conclusion: 
5.7 Additional Commentary on Published Work

Chapter 6. Manganese-Nickel Hexacyanoferrate and its Application as a Cathode Material for Nonaqueous Potassium Ion Batteries ............................................... 112

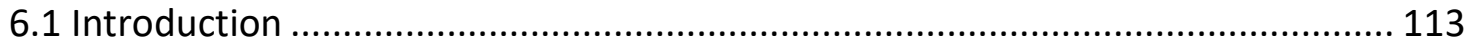

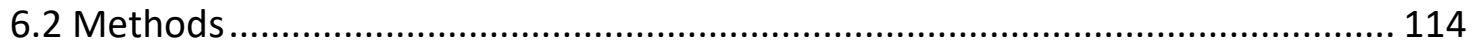

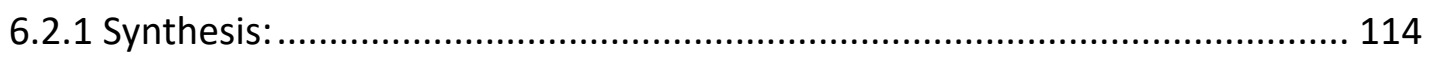

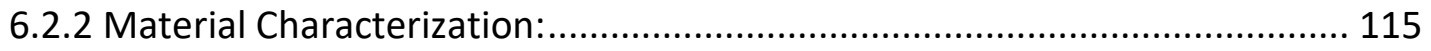

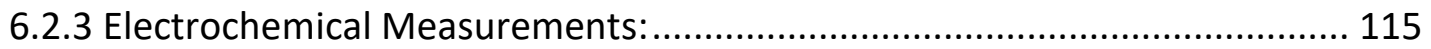

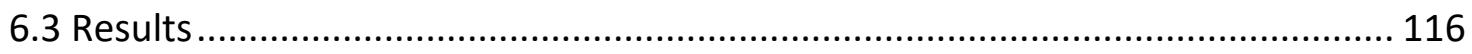

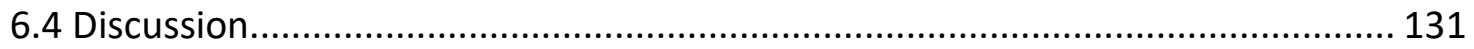

6.5 Additional Commentary on Manganese-Nickel Hexacyanoferrate and its Application as a Cathode Material for Nonaqueous Potassium Ion Batteries ........... 134

Chapter 7. Calculating Electron Density Distribution in $\mathrm{Mn}_{\mathrm{x}} \mathrm{Ni}_{1-\mathrm{x}}\left[\mathrm{Fe}(\mathrm{CN})_{6}\right] \ldots . . . . . . . . . .135$

7.1 Computational Parameters............................................................................ 138

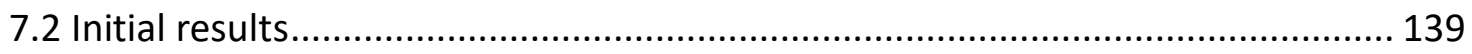

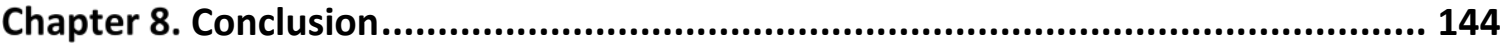

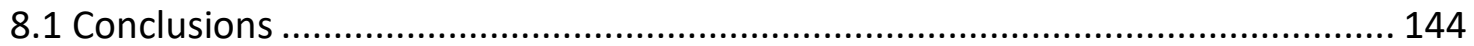

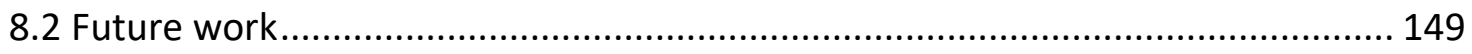

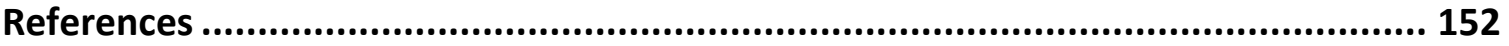

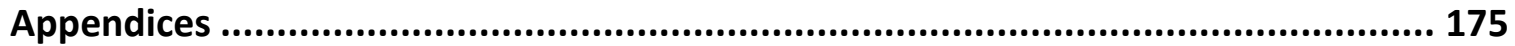

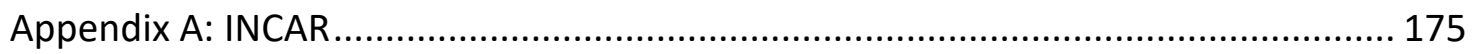

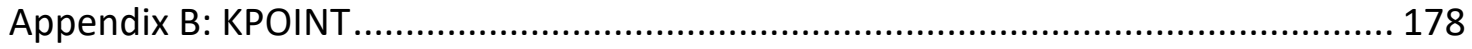

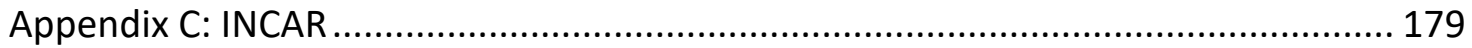




\section{List of Tables}

Table 1.1 Mixed metal hexacyanoferrates as tested as battery cathodes................... 30

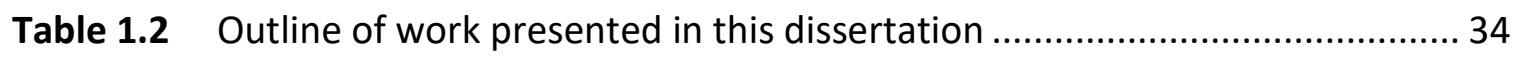

Table 4.1 Lattice parameters and space group assignment for each sample ............. 72

Table 6.1 Lattice parameters for the as-synthesized and annealed $\mathrm{Na}_{2} \mathrm{Mn}_{\mathrm{x}} \mathrm{Ni}_{1-\mathrm{x}}\left[\mathrm{Fe}(\mathrm{CN})_{6}\right]$

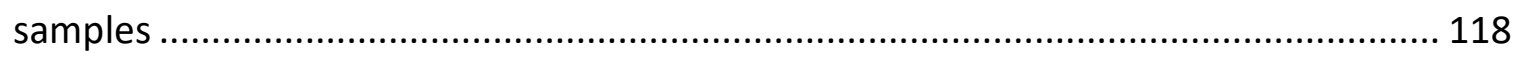

Table 6.2 Summary of zeolitic and coordinated water content as determined by

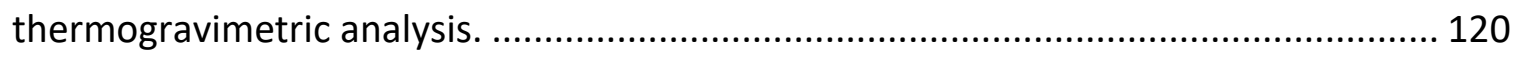

Table 6.3 Slopes determined from best fit lines in Figure $6.2 \mathrm{e}-\mathrm{h}$ and the calculated anodic and cathode $\mathrm{K}^{+}$diffusion coefficients for the $\mathrm{Fe}^{2+} / \mathrm{Fe}^{3+}$ redox reaction of

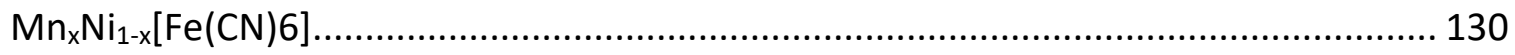

Table 7.1 Experimental and theoretical lattice parameters for $\mathrm{Na}_{2} \mathrm{Mn}_{\mathrm{x}} \mathrm{Ni}_{1-\mathrm{x}}\left[\mathrm{Fe}(\mathrm{CN})_{6}\right]$ 140 


\section{List of Figures}

Figure 1.1 Schematic of a charge electrochemical double layer capacitor ................... 9

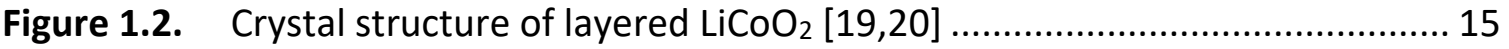

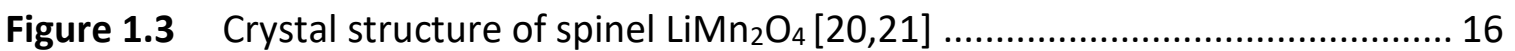

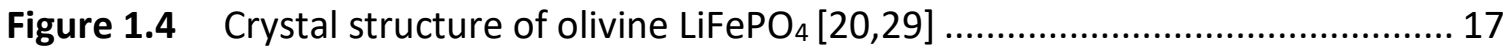

Figure 1.5 Schematic depiction of charge and discharge mechanisms of Prussian blue. 21

Figure 1.6 $\mathrm{Zn}[\mathrm{Fe}(\mathrm{CN}) 6]$ nanostructures with different macroscopic geometries (a) Rhombohedral cuboctahedron (C-RZnHCF), (b) truncated octahedron (T-RZnHCF), and

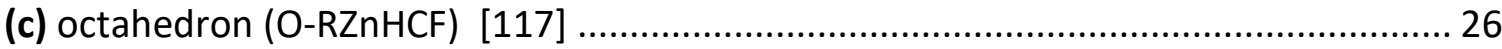

Figure 2.1 Standard powder X-ray diffraction profile........................................... 36

Figure 2.2 Three-electrode electrochemical cell [181] ........................................... 45

Figure 2.3 standard cyclic voltammogram for a single redox reaction [182] .............. 46

Figure 3.1 XRD pattern of pre and post annealed Prussian blue................................ 53

Figure 3.2 Powder XRD pattern for annealed PB. The experimental x-ray spectrum is shown in red and the Rietveld fit with the solid black line .......................................... 53

Figure 3.3 SEM image of as prepared PB nanocubes ranging between $20-200 \mathrm{~nm} . .54$

Figure 3.4 $\mathrm{CV}$ for $\mathrm{PB}$ with $\mathrm{Ca}\left(\mathrm{ClO}_{4}\right)_{2}$ in dry $\mathrm{AN}$ with the ferrocene reference added to the electrolyte. The ferrocene redox potential is $-0.068 \mathrm{~V}$ against $\mathrm{Ag} / \mathrm{Ag}^{+}$. To report everything against $\mathrm{Fc} / \mathrm{Fc}^{+}$, all potentials were adjusted by adding $68 \mathrm{mV}$ to each. The ferrocene redox potential was taken to be the half-wave potential of the $\mathrm{Fc} / \mathrm{Fc}^{+}$redox couple $\left(\mathrm{E}_{1 / 2}\right)$. $\mathrm{E}_{1 / 2}$ was estimated from $E_{1 / 2}=\left(E_{a p}+E_{c p}\right) / 2$, where $E_{a p}$ and $E_{c p}$ are the anodic and cathodic peak potentials, respectively. 55

Figure 3.5 (a) $\mathrm{CV}$ of $\mathrm{PB}$ in $1 \mathrm{M} \mathrm{KPF}_{6}$ in acetonitrile at a scan rate of $0.5 \mathrm{mVs}^{-1}$. Cycled between $[-0.68 \mathrm{~V}, 1.17 \mathrm{~V}]$ with respect to $\mathrm{Fc} / \mathrm{Fc}^{+}$. (b) $\mathrm{CV}$ of $\mathrm{PB}$ in $1 \mathrm{M} \mathrm{Ca}\left(\mathrm{ClO}_{4}\right)_{2}$ in dry acetonitrile at a scan rate of $0.5 \mathrm{mVs}^{-1}$. Cycled between $[-0.53 \mathrm{~V}, 1.27 \mathrm{~V}]$ with respect to $\mathrm{Fc} / \mathrm{Fc}^{+}$. Reference electrode for each is $\mathrm{Ag} / \mathrm{Ag}^{+}$in acetonitrile, corrected to $\mathrm{Fc} / \mathrm{Fc}^{+}$using a ferrocene reference. 56 
Figure 3.6 CV for carbon-carbon symmetric cell with $\mathrm{Ca}\left(\mathrm{ClO}_{4}\right)_{2}$ in dry $\mathrm{AN}$. Both the anode and the cathode were graphite rods, identical to the anodes used in the PB cells. 57

Figure 3.7 (a) Charge-discharge profile of $\mathrm{PB}$ in $1 \mathrm{M} \mathrm{KPF}_{6}$ in acetonitrile at a current density of $31 \mathrm{mAg}^{-1}$. [-.42 V, .917 V] with respect to $\mathrm{Fc} / \mathrm{Fc}^{+}$. (b) Charge-discharge profile of $\mathrm{PB}$ in $1 \mathrm{M} \mathrm{Ca}\left(\mathrm{ClO}_{4}\right)_{2}$ in acetonitrile at a current density of $23 \mathrm{mAg}^{-1}$. [-0.07 $\left.\mathrm{V}, 1.07 \mathrm{~V}\right]$ with respect to $\mathrm{Fc} / \mathrm{Fc}^{+}$. Reference electrode for each is $\mathrm{Ag} / \mathrm{Ag}^{+}$in acetonitrile, corrected to $\mathrm{Fc} / \mathrm{Fc}^{+}$using a ferrocene reference. 58

Figure 3.8 Reversible specific capacity vs. the number of charge/discharge cycles with $\mathrm{Ca}^{2+}$ at three different current densities. Cut-off voltages were $-0.07 \mathrm{~V}$ and $1.07 \mathrm{~V}$ with respect to the $\mathrm{Fc} / \mathrm{Fc}^{+}$redox couple. 59

Figure 3.9 First 6 charge-discharge cycles of $\mathrm{PB}$ in $1 \mathrm{M} \mathrm{Ca}\left(\mathrm{ClO}_{4}\right)_{2}$ in acetonitrile at a current density of $23 \mathrm{mAg}^{-1}$. [-0.07 V, $1.07 \mathrm{~V}$ ] with respect to $\mathrm{Fc} / \mathrm{Fc}^{+}$. Reference electrode for each is $\mathrm{Ag} / \mathrm{Ag}^{+}$in acetonitrile, corrected to $\mathrm{Fc} / \mathrm{Fc}^{+}$using a ferrocene reference........ 60

Figure 3.10 EDX spectra of an as synthesized PB electrode, fully charged electrode, and fully discharge. All spectra normalized to the Fe peak intensity for the PB after different stages of charge-discharge cycling. 61

Figure 3.11 Reversible specific capacity vs. the number of charge/discharge with $\mathrm{Ca}^{2+}$ at $125 \mathrm{mAg}^{-1}$. Upper cut-off potential of $1.37 \mathrm{~V} \mathrm{vs.} \mathrm{Fc} / \mathrm{Fc}^{+}$. 63

Figure 4.1 (a) XRD pattern of CoHCF, MnCoHCF0.50 and MnHCF (b) Highlighted shift in the 202 and 404 peaks for MnCoHCF0.50. 71

Figure 4.2 SEM images of (a) CoHCF (b) MnCoHCF0.50 (c) MnHCF ......................... 73

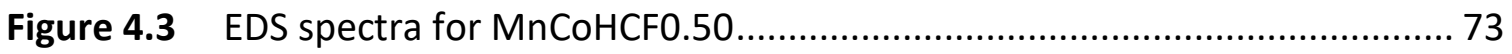

Figure 4.4. $\quad$ CV profile at $25 \mathrm{mV} / \mathrm{s}$ (a) CoHCF (b) MnCoHCF0.50 ................................. 75

Figure 4.5 (a) 1st Galvanic Charge Discharge cycles for CoHCF and MnCoHCF0.50

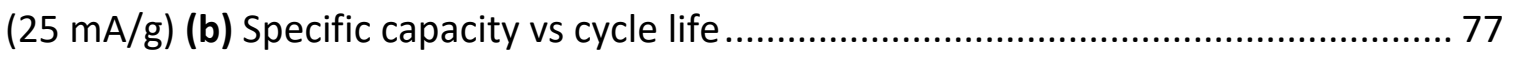

Figure 5.1 XRD profiles for the hydrated samples of copper hexacyanoferrate (CuHCF), manganese-copper hexacyanoferrate (MnCuHF0.50), and manganese hexacyanoferrate (MnHCF) 81

Figure 5.2 XRD profiles for hydrothermal synthesis of MnCuHCF0.50 with sodium citrate (blue) and sodium sulfate (orange). Both samples crystalized into a single phase. 82 
Figure 5.3 (a) SEM image of C-MnCuHCF0.50 (b) EDS elemental map of C-MnCuHCF0.50.

Figure 5.4 Depiction of the cubic structure of $\mathrm{CuCHF}$ (a) A pristine lattice where intercalated ions can reside at A lattice sites (8c). (b) B lattice site (24e) of CuHCF at a $\left[\mathrm{M}_{2}(\mathrm{CN})_{6}\right]^{3-/ 4-}$ vacancy and the resulting coordinated water molecules bonded to the dangling $\mathrm{Cu}^{2+}$ atoms. 88

Figure 5.5 Physical characterization of $\mathrm{H}$ - and D-CuHCF. (a) Powder x-ray diffraction patterns for D-CuHCF and H-CuHCF. (b) Thermogravimetric curves for the CuHCF powders. $\mathrm{H}$-CuHCF undergoes a $34 \%$ mass loss due to the removal of both zeolitic and coordinated water between $50{ }^{\circ} \mathrm{C}<\mathrm{T}<115^{\circ} \mathrm{C}$. D-CuHCF experiences an $8 \%$ mass loss over the same temperature range. (c) FTIR spectra (between $600-3800 \mathrm{~cm}^{-1}$ ) confirm the removal of surface water $\left(3350 \mathrm{~cm}^{-1}\right)$, and partial removal of coordinated and zeolitic water (1650 and $1610 \mathrm{~cm}^{-1}$, respectively). (d) FTIR spectra in the far IR range (between 90 $-690 \mathrm{~cm}^{-1}$ ) demonstrate the effect of dehydration on the Fe-CN and Cu-N bond. ........ 92

Figure 5.6 XRD profile fittings for (a) The cubic structure of H-CuHCF with lattice parameter $10.03 \AA$ (b) The orthorhombic structure of D-CuHCF with lattice parameters a $=10.32 \AA, b=10.21 \AA, c=9.88 \AA$. 93

Figure 5.7 Powder $\mathrm{x}$-ray diffraction patterns for CuHCF after different thermal treatments: annealed under vacuum at $150{ }^{\circ} \mathrm{C}$, annealed under vacuum at $100{ }^{\circ} \mathrm{C}$ (D-CuHCF), untreated ( $\mathrm{H}-\mathrm{CuHFC}$ ) and the crystalline structure breaks down after the high temperature anneal. 94

Figure 5.8 Standard SEM image of CuHCF. CuHCF crystalizes into nano-sized particles on the order of 25-100 nm, and further aggregate into large agglomerations. 95

Figure 5.9 FTIR spectra of $\mathrm{H}$-CuHCF pre- and post-curing at $100{ }^{\circ} \mathrm{C}$ under vacuum, confirming coordinated and zeolitic water are not removed from the H-CuHCF electrodes. The stability of the coordinated and zeolitic water is attributed to the presence of the PVDF binder. 97

Figure 5.10 Cyclic voltammograms at a scan rate of $0.5 \mathrm{mV} \mathrm{s}^{-1}$ in $1 \mathrm{M} \mathrm{Mg}\left(\mathrm{ClO}_{4}\right)_{2}$ in PC/EC = 50/50. (a) H-CuHCF. (b) D-CuHCF 98

Figure 5.11 CV of $\mathrm{H}-\mathrm{CuHCF}\left(\mathrm{vs} \mathrm{Ag} / \mathrm{Ag}^{+}\right.$) in $1 \mathrm{M} \mathrm{Mg}\left(\mathrm{ClO}_{4}\right)_{2}$ in $\mathrm{PC} / \mathrm{EC}=50 / 50$ with ferrocene added to calibrate the $\mathrm{Ag} / \mathrm{Ag}^{+}$pseudo-reference. $\mathrm{The} \mathrm{Fc} / \mathrm{Fc}^{+}$potential was determined to be $-0.365 \mathrm{~V}$ vs $\mathrm{Ag} / \mathrm{Ag}^{+}$. 98

Figure 5.12 multiple cyclic voltammograms of $\mathrm{H}$ - and D-CuHCF at $10 \mathrm{mVs}^{-1}$ and $0.5 \mathrm{mVs}^{-1}$. (a) H-CuHCF at $10 \mathrm{mVs}^{-1}$ (b) D-CuHCF at $10 \mathrm{mVs}^{-1}$ (c) $1^{\text {st }}$ cycle at $0.5 \mathrm{mVs}^{-1}$ of H- 
CuHCF (d) $1^{\text {st }}$ cycle at $0.5 \mathrm{mVs}^{-1}$ of D-CuHCF (e) $2^{\text {st }}$ cycle at $0.5 \mathrm{mVs}^{-1}$ of H-CuHCF (f) $2^{\text {st }}$ cycle at $0.5 \mathrm{mVs}^{-1}$ of D-CuHCF 99

Figure 5.13 Confirmation of $\mathrm{Mg}^{2+}$ intercalation/deintercalation. Ex situ EDS spectra for fully charged and fully discharged (a) H-CuHCF (b) D-CuHCF. 101

Figure 5.14 (a) Galvanostatic charge/discharge profiles of $\mathrm{H}$ - and D-CuHCF at $25 \mathrm{~mA} \mathrm{~g}^{-1}$ in $1 \mathrm{M} \mathrm{Mg}\left(\mathrm{ClO}_{4}\right)_{2}$ in $\mathrm{PC} / \mathrm{EC}=50 / 50$. All current densities and capacities are calculated by considering the total mass of the electrode coating. (b) Differential capacity plots of charge/discharge profiles at $25 \mathrm{~mA} \mathrm{~g}^{-1}$. H-CuHCF exhibits two reduction steps, while DCuHCF only displays a single step. The higher potential redox process observed in $\mathrm{H}$-CuHCF accounts for $25 \%$ of its total specific capacity. 102

Figure 5.15 Cyclic voltammograms vs differential capacity plots for (a) D-CuHCF. (b) HCuHCF. The difference in redox potentials as measured by the two methods range from 1 $\mathrm{mV}$ to $102 \mathrm{mV}$. 103

Figure 5.16 Electrochemical and charge storage characterization of $\mathrm{H}$ - and D-CuHCF in $1 \mathrm{M} \mathrm{Mg}\left(\mathrm{ClO}_{4}\right)_{2}$ in $\mathrm{PC} / \mathrm{EC}=50 / 50$. All current densities and capacities are calculated taking total electrode mass into account. (a) Rate capability tests for $\mathrm{H}$ - and D- CuHCF. (b) Capacity retention of $\mathrm{H}$ - and D-CuHCF cathodes over 500 cycles at $300 \mathrm{~mA} \mathrm{~g}^{-1}$. Neither sample experienced any capacity loss after the extended cycling...... 103

Figure 5.17 Gavanostatic discharge profiles at different current densities in $1 \mathrm{M}$ $\mathrm{Mg}\left(\mathrm{ClO}_{4}\right)_{2}$ in $\mathrm{PC} / \mathrm{EC}=50 / 50$ to determine the rate capabilities. (a) Discharge profiles of $\mathrm{H}$ CuHCF. (b) Discharge profiles of D- CuHCF. 104

Figure 5.18 (a,d) Cyclic voltammograms of $\mathrm{H}$ - and D-CuHCF at scan rates from 10 to 50 $\mathrm{mV} \mathrm{s}^{-1}$ in $1 \mathrm{M} \mathrm{Mg}\left(\mathrm{ClO}_{4}\right)_{2}$ in $\mathrm{PC} / \mathrm{EC}=50 / 50$. (b,e) the corresponding log (peak current density) vs log (sweep rate) plots used to calculate the b coefficients. (c, f) the corresponding peak current density vs square root of the scan rate plots used to estimate $\mathrm{Mg}^{2+}$ diffusion coefficients. 106

Figure 5.19 Ex situ FTIR analysis of H-CuHCF. The interstitial and zeolitic water peak at $1628 \mathrm{~cm}^{-1}$ does not change between fully charge and fully discharged, demonstrating the water does not leave the lattice. 108

Figure 6.1 Schematic of $\mathrm{Na}_{2} \mathrm{Mn}_{x} \mathrm{Ni}_{1-x}\left[\mathrm{Fe}(\mathrm{CN})_{6}\right]$ 113

Figure 6.2 (a) XRD profile for the as-synthesized, unannealed, $\mathrm{Na}_{2} \mathrm{Mn}_{\mathrm{x}} \mathrm{Ni}_{1-\mathrm{x}}\left[\mathrm{Fe}(\mathrm{CN})_{6}\right]$ powders. NiHCF, MnNiHCF-2, and MnNiHCF-2 all crystallized into a cubic structure, and MnHCF crystallized into a monoclinic structure. (b) (200) reflection for as synthesized 
samples. The decreasing $2 \theta$ indicates an increasing lattice parameter with increasing $\mathrm{Mn}$ concentration.

Figure 6.3 (200) reflection for the as-synthesized (dotted lines) and the annealed (solid lines) samples

Figure 6.4 Thermogravimetric curves for as-synthesized $\mathrm{Na}_{2} \mathrm{Mn}_{x} \mathrm{Ni}_{1-\mathrm{x}}\left[\mathrm{Fe}(\mathrm{CN})_{6}\right]$ samples. The zeolitic water contentment for each sample increases with Mn concentration, while the percentage of coordinated water for each sample is $9 \%$.

Figure 6.5 a) FTIR of the as-synthesized $\mathrm{Na}_{2} \mathrm{Mn}_{\mathrm{x}} \mathrm{Ni}_{1-\mathrm{x}}\left[\mathrm{Fe}(\mathrm{CN})_{6}\right]$. b) $v(\mathrm{C} \equiv \mathrm{N})$ of the as-synthesized samples. The downward shift in $v(\mathrm{C} \equiv \mathrm{N})$ with increasing $\mathrm{Mn}$ concentration indicates a weakening of the cyanide bond. 122

Figure 6.6 FTIR spectra of the $100{ }^{\circ} \mathrm{C}$ annealed samples of $\mathrm{Na}_{2} \mathrm{Mn}_{x} \mathrm{Ni}_{1-x}\left[\mathrm{Fe}(\mathrm{CN})_{6}\right] \ldots 122$

Figure 6.7 a) Far IR FTIR spectra for the as-synthesized $\mathrm{Na}_{2} \mathrm{Mn}_{x} \mathrm{Ni}_{1-\mathrm{x}}\left[\mathrm{Fe}(\mathrm{CN})_{6}\right]$ samples. b) $v(\mathrm{Fe}-\mathrm{C})$ of the as-synthesized samples. The upward shift in $v(\mathrm{Fe}-\mathrm{C})$ with increasing $\mathrm{Mn}$ concentration indicates a strengthening of the Fe-C bond.

123

Figure 6.8 Relationships between the effective polarizing power of the nitrogen coordinated metals and the stretching frequencies for $v(\mathrm{C} \equiv \mathrm{N})$ and $v(\mathrm{Fe}-\mathrm{C})$. $\sigma_{\text {eff }}$ decreases with increasing Mn concentration, which in a decrease in $v(C \equiv N)$ and increase in $v(F e-C)$. These trends are indicative of a weakening of the cyanide bond and a strengthening of the iron-carbon bond. 123

Figure 6.9 (a) Plot of $\mathrm{Fe}^{3+} / \mathrm{Fe}^{2+}$ discharge potential verses percent $\mathrm{Mn}$. (b) Plot of $\mathrm{Fe}^{3+} / \mathrm{Fe}^{2+}$ discharge potential verses $v(\mathrm{Fe}-\mathrm{C})$ 125

Figure 6.10 Galvanostatic charge discharge, at $25 \mathrm{mAg}^{-1}$, of a) $\mathrm{NiHCF}$, b) MnNiHCF-1, c) MnNiHCF-2, and d) MnHCF. e) Rate data for $\mathrm{Na}_{2} \mathrm{Mn}_{x} \mathrm{Ni}_{1-x}\left[\mathrm{Fe}(\mathrm{CN})_{6}\right]$. f) Normalized capacity vs current density for $\mathrm{Na}_{2} \mathrm{Mn}_{x} \mathrm{Ni}_{1-x}\left[\mathrm{Fe}(\mathrm{CN})_{6}\right]$. The rate capability of a material is inversely related to the percentage of $\mathrm{Mn}$. g) Cycle lifetimes of $\mathrm{Na}_{2} \mathrm{Mn}_{x} \mathrm{Ni}_{1-x}\left[\mathrm{Fe}(\mathrm{CN})_{6}\right]$. Each cathode displays excellent performance over extended cycling at $300 \mathrm{mAg}^{-1}$. 126

Figure 6.11 Cyclic voltammograms at $0.1 \mathrm{mV} \mathrm{s}^{-1}$ of a) NiHCF, b) MnNiHCF-1, c) $\mathrm{MnNiHCF}-2$, and d) MnHCF 128

Figure 6.12 Cyclic voltammograms from $0.1-1.0 \mathrm{mV} \mathrm{s}^{-1}$ and the corresponding peak current vs (scan rate) $)^{1 / 2}$ for $(\mathbf{a}, \mathbf{e}) \mathrm{NiHCF},(\mathbf{b}, \mathbf{f}) \mathrm{MnNiHCF}-1, \mathbf{( c , g )} \mathrm{MnNiHCF}-2$, and (d,h) MnHCF 129

Figure 6.13 Specific capacity vs. Log (current density) of $\mathrm{Na}_{2} \mathrm{Mn}_{x} \mathrm{Ni}_{1-\mathrm{x}}\left[\mathrm{Fe}(\mathrm{CN})_{6}\right]$. The slopes provide a quantitative value related to the rate capability of the different materials. 
A larger slope corresponds to worse rate performance. By extrapolating the best fit lines to the $y$-intercept (zero current), a theoretical zero-current capacity can be obtained. At zero current, MnHCF has the highest theoretical capacity followed by MnNiHCF-2, $\mathrm{MnNiHCF}-1$, and NiHCF, respectively.

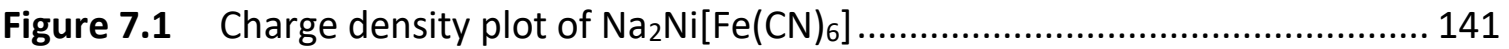

Figure 7.2 Charge density plot of $\mathrm{Na}_{2} \mathrm{Mn}_{0.25} \mathrm{Ni}_{0.75}\left[\mathrm{Fe}(\mathrm{CN})_{6}\right]$ along the (200) plane .... 142

Figure 7.3 Charge density plot of $\mathrm{Na}_{2} \mathrm{Mn}_{0.25} \mathrm{Ni}_{0.75}\left[\mathrm{Fe}(\mathrm{CN})_{6}\right]$ along the (010) plane .... 143 


\section{Chapter 1.}

\section{Introduction}

\subsection{Global Warming and Electricity Production}

Eighty-four countries signed the Kyoto protocol in 1992 [1], signaling a worldwide acknowledgment that human production of greenhouse gases (GHG) had caused the average temperature of the Earth to increase about $1{ }^{\circ} \mathrm{C}$ since the beginning of the industrial revolution in 1763. Since 1992 an additional 107 countries have joined the Kyoto agreement and climate change has been widely accepted as one of the largest existential threats to the global community. Nevertheless, greenhouse gas emissions have continued to rise and nine of the hottest years on record, dating to 1880 , have occurred since 2005 [2].

The relationship between climate change and greenhouse gases is well understood. When visible and ultraviolet (UV) radiation from the sun reach the Earth, $30 \%$ is reflected back into space, $23 \%$ is absorbed by particles in the atmosphere, and $47 \%$ is absorbed by land and ocean [3]. Much of the energy absorbed by land and ocean water is re-radiated back into the atmosphere as infrared (IR) radiation, i.e. heat. Greenhouse gas molecules in the atmosphere, although transparent to the sun's visible and UV radiation, absorb significant amounts of the IR radiation emanating from the Earth's surface. 
Greenhouse gases absorb IR radiation through excitation of stretching and bending modes of molecular bonds. Absorbed IR light is re-emitted in all directions, with about half escaping into outer space and the other half being directed back down to the earth's surface, resulting in warming of the Earth and lower atmosphere. This warming of the Earth through absorption and remission of IR light is called the greenhouse effect.

Naturally occurring greenhouse gases in the atmosphere include water vapor, $\mathrm{CO}_{2}$, methane $\left(\mathrm{CH}_{4}\right)$, and nitrous oxide $\left(\mathrm{N}_{2} \mathrm{O}\right)$. These gases maintain the Earth at a temperature about $35{ }^{\circ} \mathrm{C}$ higher than it would be if these gases were not present, i.e. $14{ }^{\circ} \mathrm{C}$ rather than $-2{ }^{\circ} \mathrm{C}[4,5]$. The most important of the greenhouse gases is $\mathrm{CO}_{2}$, due to its relative abundance in the upper regions of the atmosphere. Between $~ 800,000 \mathrm{BCE}$ and $1763 \mathrm{CE}$, atmospheric $\mathrm{CO}_{2}$ levels fluctuated within a relatively narrow range, between 173 and 299 ppm [6].

In contrast, since the start of the industrial revolution in 1763, average atmospheric $\mathrm{CO}_{2}$ concentrations have risen to 320 ppm, with a peak of 408 ppm in 2018 [7]. This increase in $\mathrm{CO}_{2}$ is attributed to the combustion of fossil fuels as energy sources, the production of cement, and deforestation with an associated decrease in photosynthesis. Additionally, man-made GHGs such as hydrofluorocarbons (HFCs), perfluorocarbons (PFCs), and sulfur hexafluoride $\left(\mathrm{SF}_{6}\right)$ have been introduced into the environment. 
In addition to global warming, increased GHG emissions are having other negative climatic effects including increased ocean acidity, eradication of ecosystems and increased glacier melting [8]. In 2018 the United Nations' international Panel on Climate Change (IPCC) warned that if the increase, from pre-industrial values, in average global temperature exceeds $1.5^{\circ} \mathrm{C}$ by 2050 , considerable and potentially irreversible damage to the environment and humanity will become inevitable [2,3]. With their warning, the IPCC also set out goals and emission targets, specifically calling for a "fundamental transformation of the energy supply system" to stave off a climatic catastrophe [9].

The production of electricity from fossil fuels is a major contributor to atmospheric $\mathrm{CO}_{2}$ and accounted for $32 \%$ of all man-made $\mathrm{CO}_{2}$ emissions in 2016 [9]. To dramatically decrease the emissions of the energy supply sector, which includes energy extraction, conversion, storage, transmission, and distribution processes, a radical shift in how we produce and consume energy is needed. One key piece in any energy solution will be a major growth in electricity production from sources that produce little or no atmospheric $\mathrm{CO}_{2}$.

The main energy sources used to produce electricity with minimal or no $\mathrm{CO}_{2}$ production are nuclear, hydroelectric (water), solar, wind and geothermal. These sources cause much less $\mathrm{CO}_{2}$ production than the combustion of fossil fuels, even when one accounts for the $\mathrm{CO}_{2}$ produced during the manufacturing and distribution of the equipment needed for ongoing electricity generation. 
Solar and wind power accounted for only $\sim 9 \%$ of global electricity generation in 2020, in spite of their favorable $\mathrm{CO}_{2}$ footprint [10]. The most significant hurdle hindering the widespread adoption of solar and wind is the intermittent nature of the electricity generation. To overcome this limitation, significant resources need to be put into the development and implementation of energy storage systems (ESS).

\subsection{Energy Storage Systems}

There are numerous methods to store energy, each with its own set of benefits and weaknesses. When comparing the different available storage technologies for a particular application or community, some of the key considerations are:

1. The amount of energy that can be stored per unit volume or unit mass (energy density),

2. The power that can be delivered per unit volume or unit mass (power density),

3. The energy efficiency,

4. The lifetime, and

5. How long the energy can be stored without significant loss, i.e. self-discharge.

For example, if a particular application requires that energy be delivered sparsely over long durations, then a storage system with high energy density would be desirable. 
However, if large amounts of energy are required quickly, then power density is the most important factor.

\subsubsection{Pumped Hydro energy storage}

Pumped hydro storage (PHS) systems store energy in the form of gravitational potential energy by moving water between a low elevation reservoir and a high elevation reservoir. PHS is typically charged during times of low energy demand and low costs, and discharged during high cost and high demand times. As of 2020, PHS accounts for $95 \%$ of all deployed energy storage systems in the world [11]. The main benefit of pumped hydro is its very low self-discharge rate, allowing energy to be stored for long periods of time. However, low energy density, high upfront capital costs and geographic limitations restrict the construction of new pumped hydro systems.

\subsubsection{Thermal energy storage}

Thermal energy storage (TES) systems store energy in the form of heat. Common materials used in TES systems include rocks, concrete, water, and salts. The heat stored can be generated naturally, e.g. heating water with sunlight, or can be man-made, e.g. waste heat from industrial processes. TES is categorized into three systems depending on the way heat is stored: sensible, latent, and thermochemical systems.

Sensible heat storage is the oldest and most common form of TES, in which thermal energy is stored by raising the temperature of the storage medium. The amount of energy stored is described by Equation 1.1. 


$$
q=m C_{p}\left(T_{H}-T_{C}\right)
$$

where $q$ is the heat stored $(J), m$ is the mass of the material storing the heat $(k g), C_{p}$ is the material's specific heat at constant pressure $\left(\mathrm{J} \mathrm{kg}^{-1} \mathrm{~K}^{-1}\right)$, and $\mathrm{T}_{\mathrm{H}}$ and $\mathrm{T}_{\mathrm{C}}$ are the hot and cold temperatures $(\mathrm{K})$.

Latent heat storage capitalizes on the energy required to induce a phase change in a material. Phase changes occur at constant temperatures in the material of interest, absorbing heat during solid $\rightarrow$ liquid or liquid $\rightarrow$ gas transitions, and releasing heat during the opposite transitions. The equation for latent heat for a solid to liquid phase change at the melting point is given in equation 1.2.

$$
q=m L
$$

where $q$ is heat $(\mathrm{J}), \mathrm{m}$ is the mass $(\mathrm{kg})$ of the material undergoing the phase change and $\mathrm{L}$ is the latent heat of fusion $\left(\mathrm{J} \mathrm{kg}^{-1}\right)$.

The last form of thermal storage is thermochemical storage, in which energy is stored in a reversible endothermic chemical reaction. Some examples include magnesium sulfate/water, calcium sulfate/water, calcium hydroxide/water and iron oxide (FeO)/carbon dioxide [12]. The major benefits of thermochemical storage are its ability to be implemented in a wide variety of settings, and store energy with minimal loss over long periods of time. 
Each of the thermal energy storage technologies has drawbacks. Sensible and latent heat storage both have slow discharge times, limiting the power output, while thermochemical is a nascent technology that is currently cost prohibitive.

\subsubsection{Mechanical energy storage}

Mechanical energy storage systems convert electrical energy into either mechanical potential energy or kinetic energy. Two examples are the flywheel and compressed air energy storage.

A flywheel is an electromechanical device that uses a motor to rotate a wheel to very high speeds. The energy stored is given by equation 1.3.

$$
E_{\text {kinetic }}=I \omega^{2}
$$

where $E_{\text {kinetic }}$ is rotational kinetic energy, $I$ is the moment of inertia of the rotating object and $\omega$ is its angular velocity. Flywheel technology is still not mature enough for mass deployment, but is theoretically suitable for high power applications.

Compressed air energy storage technology (CAES) stores energy in the elastic potential energy of a compressed gas. CAES systems typically use off-peak, low cost energy to compress a gas in underground caverns or in above-ground mechanical tanks. Energy is recovered when the stored, high pressure gas is used to drive a turbinegenerator. Low energy efficiency, around 70\%, is a major drawback to compressed air storage. 


\subsubsection{Hydrogen storage}

Energy can be stored through the production of $\mathrm{H}_{2}$ by electrolysis, as shown in the reaction that follows.

$$
2 \mathrm{H}_{2} \mathrm{O}(\mathrm{aq})+2 e^{-} \rightarrow \mathrm{H}_{2}(g)+2 \mathrm{OH}^{-}(a q)
$$

There are numerous different ways to store the hydrogen gas once it is produced, including as a compressed gas, as liquid hydrogen (stored at $-253 \mathrm{C}$ ), absorbed within a solid or stored in an alternative chemical bond. Energy can be reclaimed, as electricity, by oxidizing the hydrogen gas, such as occurs in the reaction between $\mathrm{O}_{2}$ and $\mathrm{H}_{2}$ in a fuel cell. Hydrogen energy storage has the highest theoretical energy density of the storage methods discussed [13]. However, problems with loss of hydrogen gas during storage, low efficiency and safety concerns currently limit adoption of this method. Most notable, the round trip efficiency of current hydrogen storage technology is on the order of $35 \%$ $[14,15]$

\subsubsection{Electrochemical capacitors}

Conventional parallel plate capacitors, which store energy in the electric field between two oppositely charged species some distance $d$ away from each other, are of very limited use as large scale energy storage systems due to their low energy densities. This limitation spurred the development of higher energy density electrochemical doublelayer capacitors (EDLC), in which the electrostatic interactions occur at the electrode/electrolyte interface between adsorbed charged species in the electrolyte and 
the conducting electrodes (Figure 1.1). The region of ion accumulation is known as the Helmholtz layer. The simplest estimation of the capacitance of an EDLC is given by

$$
C=\frac{Q}{V}=\frac{\epsilon_{0} \epsilon_{r} A}{d}
$$

where $\mathrm{C}$ is the capacitance, $\mathrm{Q}$ is the charge stored, $\mathrm{V}$ is the potential between an electrode and the charged ions, $\varepsilon_{0}$ is the dielectric constant of vacuum, $\varepsilon_{r}$ is the dielectric constant of the electrolyte, $A$ is the electrode-electrolyte surface area, and $d$ is the charge separation distance. The energy stored in an EDCL with a capacitance $C$ that can be estimated by

$$
U=\frac{1}{2} C V^{2}
$$

where $U$ is the energy stored in the capacitor, and $C$ and $V$ are as previously defined. EDLCs have extremely fast charge and discharge rates, making them desirable for highpower applications. However, EDCLs suffer from high self-discharge rates and their

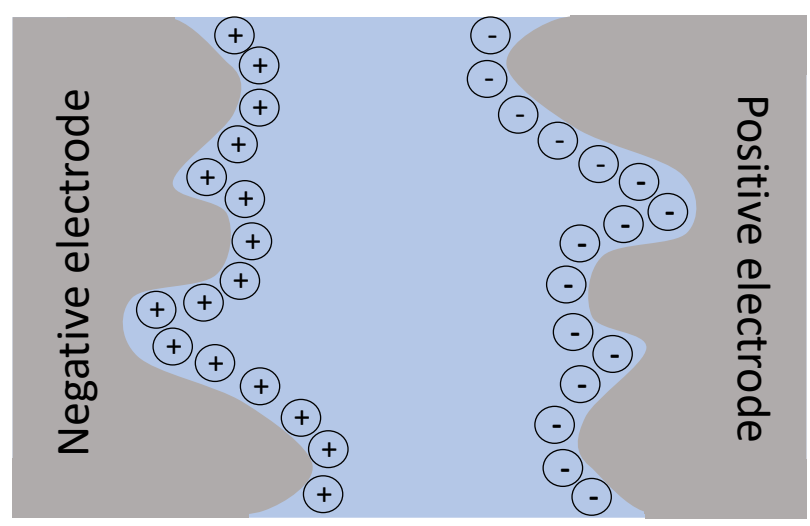

Figure 1.1 Schematic of a charge electrochemical double layer capacitor 
energy density is much lower than other non-capacitor technologies, making them unsuitable for long term energy storage.

\subsubsection{Pseudocapacitors}

Pseudocapacitors are a hybrid between traditional batteries and EDCLs. The majority of charge storage occurs through reversible charge transfer reactions at the electrode/electrolyte interface, with some additional storage in an electrochemical double-layer. Because the reactions take place entirely at the surface of the electrode, pseudocapacitors offer charge and discharge rates much higher than batteries. However, because they do not utilize the entire volume of a material, the energy density of pseudocapacitors is relatively low.

\subsubsection{Batteries}

Batteries interconvert electrical energy and chemical energy through electrochemical redox reactions. Compared to other electrochemical storage systems, batteries offer high energy densities and relatively low power densities. However, the power density of modern batteries is high enough to make them suitable for a wide range of applications, ranging from powering portable electronics to storing gigawatts of wind and solar energy. Under the umbrella of battery technologies, there are two overarching groups: flow batteries and solid electrode batteries.

Flow batteries allow for the decoupling of power and storage capacity, unlike other electrochemical storage systems. Electrolytes, representing stored chemical 
energy, are housed in large external tanks and are pumped into cell stacks when electricity needs to be generated. Storage capacity can be increased by increasing the size of the tanks or the concentrations of reactive redox species. Total power output can be modulated by adjusting the number of stacks or changing the electrolyte flow rate. Some of the most promising flow battery chemistries are based on all-iron, all-vanadium, ironchromium mixtures and zinc-bromine mixtures. The major drawbacks to flow batteries are low energy density, high self-discharge rates, and system stability.

A solid electrode battery is a completely closed system with an anode, cathode and electrolyte all in the same cell. During charging and discharging, positively charged ions in the electrolyte migrate back and forth between the anode and cathode, where oxidation and reduction reactions occur. Mirroring the flow of ions through the electrolyte, electrons are transferred through an external circuit to maintain charge balance. Energy capacity is dependent on the total amount of redox active species in the electrodes; the electrolyte acts solely as a transport medium for charged ions.

By utilizing the entire volume of an electrode material, solid electrode batteries have high energy densities, making them suitable for a wide range of applications. However, difficulties delivering high voltages and currents prevent solid electrode batteries from being used in applications that require rapid charge-discharge cycling or very high power. Despite their limitations, the mix of high energy density, scalability, and 
stability make solid electrode batteries one of the most promising technologies for long term energy storage.

\subsection{Solid Electrode Batteries as an Energy Storage Solution}

\subsubsection{Primary Batteries}

A primary (non-rechargeable) battery is an electrochemical cell designed for single use without the ability to be recharged. The first primary battery was discovered in 1799 by the Italian physicist Alessandro Volta. By stacking alternating copper and zinc plates separated by paper discs soaked in salt water, Volta realized that an electrical current could be generated that was proportional to the number of metal plates [16]. The half reactions for Volta's battery, aptly named the Voltaic pile, are shown in equations 1.7 and 1.8.

$$
\begin{aligned}
& Z n^{0}(s) \rightarrow Z n^{2+}(a q)+2 e^{-} \\
& 2 H^{+}(a q)+2 e^{-} \rightarrow H_{2}(g)
\end{aligned}
$$

The copper plates did not participate in the electrochemical reaction, and acted only as a current collector. Batteries based on Volta's work were the predominant source of electricity for nearly 70 years until the dynamo, an electric generator, was introduced into the electricity industry. 


\subsubsection{Secondary Batteries}

60 years after the invention of the Voltaic pile, French physicist Gaston Planté revolutionized the energy world by inventing the first secondary (rechargeable) battery. The lead acid battery, as constructed by Planté, consisted of two rolled sheets of lead separated by rubber and submerged in $10 \%$ sulfuric acid. Each lead acid cell provides nearly $2 \mathrm{~V}$. The positive and negative plate half reactions, and the full-cell discharge reaction are shown in equations $1.9-1.11$, respectively:

$$
\begin{gathered}
\mathrm{Pb}^{4+} \mathrm{O}_{2}+\mathrm{HSO}_{4}^{-}+3 \mathrm{H}^{+}+2 e^{-} \rightarrow \mathrm{Pb}^{2+} \mathrm{SO}_{4}+2 \mathrm{H}_{2} \mathrm{O} \\
\mathrm{Pb}^{0}+\mathrm{HSO}_{4}^{-} \rightarrow \mathrm{Pb}^{2+} \mathrm{SO}_{4}+\mathrm{H}^{+}+2 e^{-} \\
\mathrm{Pb}^{4+} \mathrm{O}_{2}+\mathrm{Pb}^{0}+2 \mathrm{H}_{2} \mathrm{SO}_{4} \rightarrow \mathrm{Pb}^{2+} \mathrm{SO}_{4}+2 \mathrm{H}_{2} \mathrm{O}
\end{gathered}
$$

To charge the battery, a potential is applied to promote the reverse reactions. Because of the long lifetime, good power, and stability, the lead acid battery is still widely used across numerous industries.

\subsubsection{Lithium Ion batteries}

Secondary lithium ion batteries (LIBs) have become the primary battery technology due to their relatively high energy density, good cycle lifetime and ability to be scaled to meet the needs of a specific application. LIBs were first invented in the 1970s 
by Dr. Michael Whittingham, but did not become a reliable energy storage option until 1985. It was the work of Dr. John Goodenough in 1980, who first demonstrated layered $\mathrm{LiCoO}_{2}$ as an intercalation cathode [17], and Dr. Akira Yoshino in 1985, who developed a safe and energy dense graphitic carbon anode [18], that introduced the world to the modern LIB. Since commercialization in 1991 by Sony, LIB research has largely focused on the discovery of new cathode materials, as the cathode is the bottleneck to increased energy density.

LIB cathodes are categorized as either conversion or intercalation electrodes, depending on the chemistry underlying the storage of Li ions. Conversion electrodes store energy by breaking and creating chemical bonds during the insertion and extraction of $\mathrm{Li}$ ions. The high theoretical energy densities of conversion reaction cathodes, such as $\mathrm{Li}_{2} \mathrm{O}_{2}$ and $\mathrm{Li}_{2} \mathrm{~S}$, have made them of great interest. However, problems such as large structural expansions during charging and discharging, and dissolution of the active material have made them unusable in a commercial battery.

Intercalation electrodes charge and discharge as $\mathrm{Li}^{+}$ions migrate through the interstitial spacing of the host lattice, occupying vacancies while transition metals in the electrode undergo oxidation and reduction. Three classes of materials have garnered the most interest as intercalation cathodes for LIBs: layered transition metal oxides, spinel transition metal oxides, and polyanion oxides. 


\subsubsection{Layered Transition Metal Oxides}

Layered transition metal oxides (LTMO) with the general formula $\mathrm{LiMO}_{2}(\mathrm{M}=$ transition metal) crystallize in a rock salt structure with alternating layers of the sequence O-Li-O-M-O (Figure 1.2). Insertion/extraction of Li ions occur between the covalently bonded $\mathrm{MO}_{2}$ layers. The crystallographic configuration of LTMOs allows for fast twodimensional ionic migration. The lithium pillars between the $\mathrm{MO}_{2}$ layers are integral to the integrity of the rock salt layered structure. For $\mathrm{LiCoO}_{2}$, the original $\mathrm{LIB}$ cathode and an example of a LMTO, the structural Li ions will de-intercalate upon charging above 4.2V, resulting in a phase transition and degradation of the material. This limits the operating potential of LMTOs, and thus the potential of the overall battery cell.

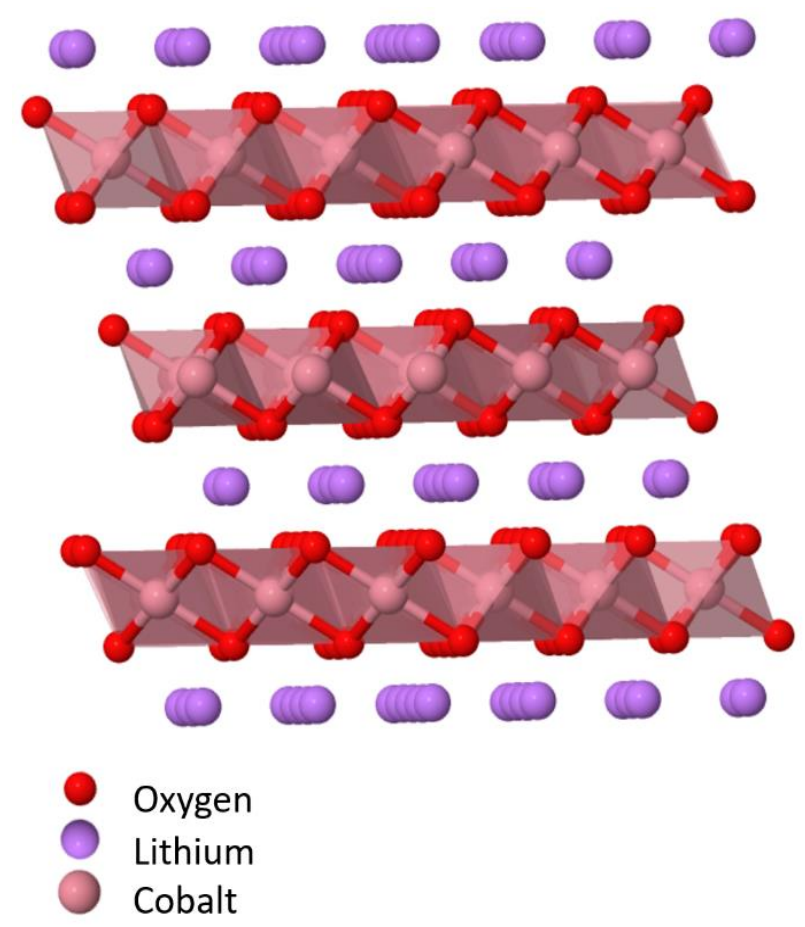

Figure 1.2. Crystal structure of layered $\mathrm{LiCoO}_{2}[19,20]$ 


\subsubsection{Spinel Transition Metal Oxides:}

Spinel transition metal oxides (STMO) possess the general formula $\mathrm{LiM}_{2} \mathrm{O}_{4}(\mathrm{M}=$ transition metal) and crystalize in a tetragonal spinel structure with space group Fd3-m where the $\mathrm{Li}$ and $\mathrm{M}$ are tetrahedrally and octahedrally coordinated to the oxygen, respectively. The $\left[\mathrm{M}_{2}\right] \mathrm{O}_{4}$ edge-shared octahedrons form intercalation/deintercalation pathways for $\mathrm{Li}$ ions. $\mathrm{LiMn}_{2} \mathrm{O}_{4}$ was the first STMO studied and displays a two-step intercalation/deintercalation process at $4 \mathrm{~V}$ and $3 \mathrm{~V}\left(\mathrm{vs} \mathrm{Li} / \mathrm{Li}^{+}\right)$. Figure 1.3 shows the crystal structure for $\mathrm{LiMn}_{2} \mathrm{O}_{4}$. The redox reaction at $3 \mathrm{~V}$ induces a cubic to tetragonal phase shift and causes structural instabilities. Because of this only the redox reaction at $4 \mathrm{~V}$ can be utilized effectively, eliminating half of the storage capacity of $\mathrm{LiMn}_{2} \mathrm{O}_{4}$. Further problems

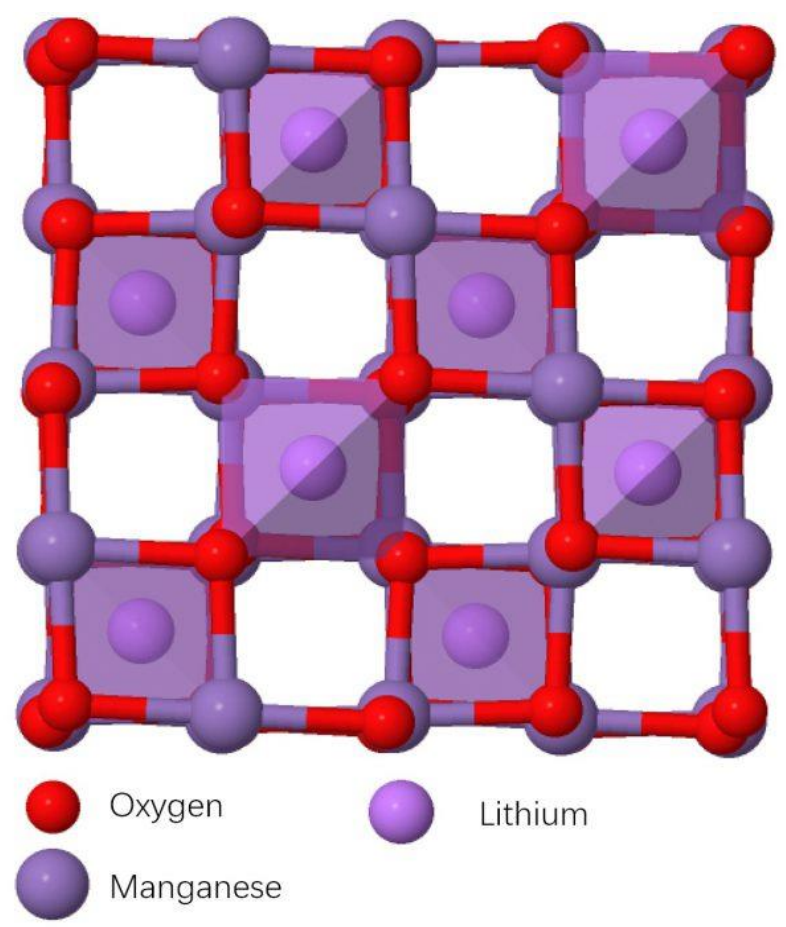

Figure 1.3 Crystal structure of spinel $\mathrm{LiMn}_{2} \mathrm{O}_{4}[20,21]$ 
occur from the dissolution of $\mathrm{Mn}$ during operation. Mixed metal STMOs ( $\left.\mathrm{LiMn}_{2}-\mathrm{xMxO}_{4}\right)$ have been studied with the hope of overcoming the Mn dissolution. Although $\mathrm{Mn}$ dissolution can be suppressed, the substitution of other metals for $\mathrm{Mn}$ increases the operating potential of the $\mathrm{LiMn}_{2}-\mathrm{xMxO}_{4}$, making them unusable with current nonaqueous electrolytes.

\subsubsection{Polyanion Oxides}

Polyanion oxides of type $\mathrm{LiM}_{y}\left(\mathrm{XO}_{4}\right)_{\mathrm{n}}(\mathrm{X}=\mathrm{S}, \mathrm{Mo}, \mathrm{P}$, and $\mathrm{W}$; and $\mathrm{M}=$ transition metal) were first investigated in an effort to find a set of transition metal oxides that were stable during $\mathrm{Li}$ intercalation/deintercalation [22-27]. The materials crystallize in the

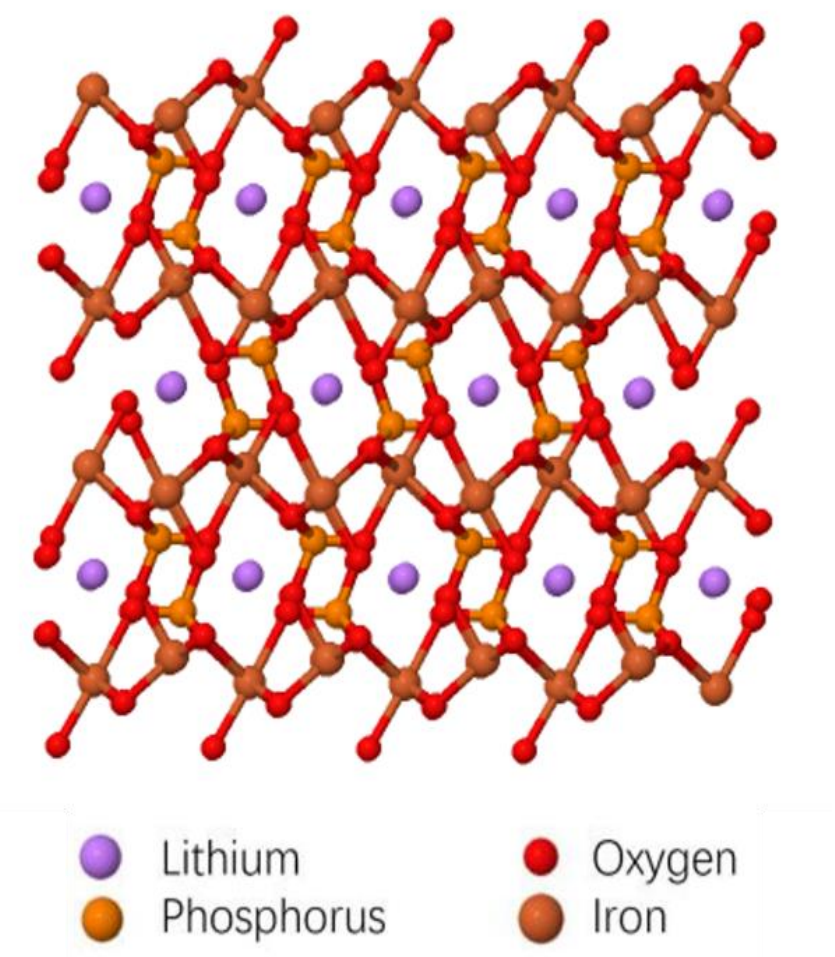

Figure 1.4 Crystal structure of olivine $\mathrm{LiFePO}_{4}[20,29]$ 
orthorhombic olivine structure with space group Pnma (Figure 1.4) [28]. The goal of replacing the oxygen with a polyanion was to utilize lower-valent transition metals to suppress the structural distortions observed with $\mathrm{LiCoO}_{2}\left(\mathrm{Co}^{3+/ 4+}\right)$ and $\mathrm{LiMn}_{2} \mathrm{O}_{4}\left(\mathrm{Mn}^{3+/ 4+}\right)$. $\mathrm{LiFePO}_{4}\left(\mathrm{Fe}^{2+/ 3+}\right)$ was shown to successfully undergo charge/discharge cycling with Li ions. By replacing $\mathrm{O}$ with $\mathrm{PO}$, the $\mathrm{Fe}^{2+/ 3+}$ redox potential could be elevated from $2.5 \mathrm{~V}$ v $\mathrm{Li} / \mathrm{Li}^{+}$ (for $\mathrm{Fe}_{2} \mathrm{O}_{3}$ ) to $4.1 \mathrm{~V}$ vs $\mathrm{Li} / \mathrm{Li}^{+}$(for $\mathrm{LiFePO}_{4}$ ). The challenge of polyanion oxides, and $\mathrm{LiFePO}_{4}$ in particular, is their poor performance at high currents. This limits the power density and limits high charging/discharging capacities to low current densities.

\subsubsection{Moving Beyond Lithium Ion Batteries}

Despite their widespread adoption, lithium ion batteries have significant limitations with regards to cost, safety, and toxicity, restricting their potential for grid scale storage. New lithium chemistries such as lithium-air [30-36] and lithium-sulfur [3740] are being explored due to their high energy densities, however neither have been shown to be stable or offer lifetimes greater than a few charge/discharge cycles. The mass deployment of any lithium ion storage technology is further constrained by the scarcity of lithium salts in the Earth's crust $\left(1.6 \times 10^{7}\right.$ tons, $\left.20 \mathrm{ppm}\right)$ [41]. To meet the storage needs of intermittent solar and wind powered electricity production, novel, low cost, storage solutions must be designed that prioritize the use of non-toxic, safe, and abundant materials while maintaining long lifetimes. 
In recent years, battery chemistries based on abundant elements such as sodium [42-49], potassium [50-56], magnesium [57-63], calcium [56,64-70], or aluminum [7176] have emerged as low-cost alternatives to LIBs. Attempts to transition cathodes from lithium ion batteries to alternate systems has proven difficult. The relatively narrow interstitial pathways of the cathodes that worked well with lithium ion have prohibitively slow diffusion with larger or more highly charged ions that are present in non-lithium systems [77]. Thus, developing alternative cathode materials is paramount to the success of non-lithium ion technology. One class of materials that has garnered a lot of attention is Prussian blue analogues (PBAs).

\subsection{Prussian Blue (PB) and its Analogues (PBAs)}

Iron hexacyanoferrate, also known as Prussian blue, was first discovered in 1704 by the German colormaker Diebach of Berlin while attempting to make a crimson paint [78]. By happenstance, Diebach combined "animal oil", a distillation of animal blood that unknowingly contained cyanide, with a solution of iron sulfate and produced Prussian blue [79]. Between 1704 and 1977, Prussian blue was used in numerous applications ranging from early photocopying to gas purification. It was not until the work of Vernon Neff in 1978 that the electrochemical properties of Prussian blue were first explored [80]. Since Neff, Prussian blue and its analogues (PBAs) have continued to provide promising results in the search for cathode materials for secondary batteries, due to several properties that are desirable for energy storage: large interstitial pathways, high specific capacity, good ionic conductivity, facile synthesis and tunability. 


\subsubsection{Prussian Blue and Prussian Blue Analogues Chemical Composition}

\subsubsection{Prussian blue}

Prussian blue is a mixed valence coordination compound with the general chemical formula $\mathrm{AFe}^{3+}\left[\mathrm{Fe}^{2+}(\mathrm{CN})_{6}\right]$, where $\mathrm{A}$ is a monovalent alkali cation, $(\mathrm{CN})$ is the cyanide anion, low spin (LS) $\mathrm{Fe}^{2+}$ is coordinated to $\mathrm{C}$, and high spin (HS) $\mathrm{Fe}^{3+}$ is coordinated to cyanide N. The PB framework consists of $(\mathrm{C} \equiv N)^{-}$anions bridging the $\mathrm{FeN}_{6}$ and $\mathrm{FeC}_{6}$ octahedra, which form a face-centered cubic structure with space group Fm3m and a lattice parameter of $10.2 \AA$ [81]. The open framework of PB allows for the reversible intercalation of a large variety of monovalent and multivalent cations, including $\mathrm{Na}^{+}$ [47,49,55,82-97], $\mathrm{K}^{+}[98-109], \mathrm{Mg}^{2+}[110-115], \mathrm{Ca}^{2+}[56,66,87,113,116,117], \mathrm{Zn}^{2+}[118-$ 122] and $\mathrm{Al}^{3+}[71,72,123,124]$. Charging and discharging of $\mathrm{PB}$ is a two-step process as shown in

Figure 1.5, with the C-coordinated Fe and N-coordinated Fe undergoing redox at different potentials. This asymmetry arises from differences in the ligand field strengths at opposite ends of the cyanide, causing the high-spin (HS) FeN6 octahedra and low-spin (LS) FeC6 octahedra. 


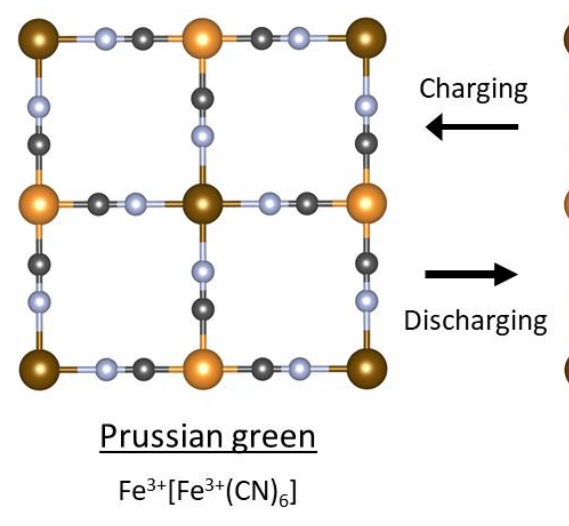

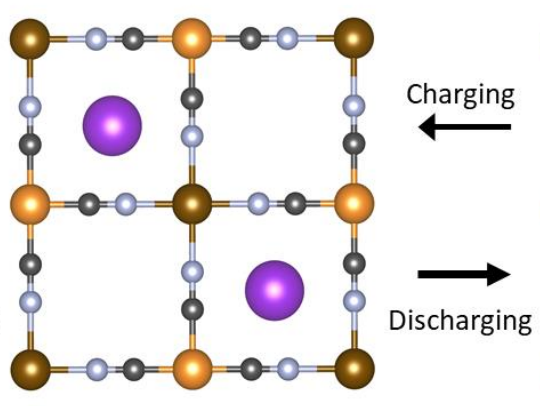

Prussian Blue

$\mathrm{AFe}^{3+}\left[\mathrm{Fe}^{2+}(\mathrm{CN})_{6}\right]$

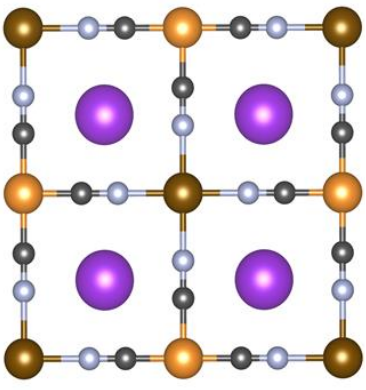

Prussian White

$\mathrm{A}_{2} \mathrm{Fe}^{2+}\left[\mathrm{Fe}^{2+}(\mathrm{CN})_{6}\right]$

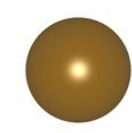

$\mathrm{Fe}$ (HS)

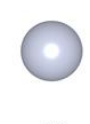

N

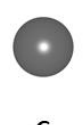

C

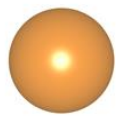

$\mathrm{Fe}$ (LS)

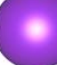

K

Figure 1.5 Schematic depiction of charge and discharge mechanisms of Prussian blue.

\subsubsection{Prussian Blue Analogues}

Prussian blue analogues (PBAs) are a class of mixed valence compounds that result from the substitution of a transition metal in place of one or both of the coordinated irons in PB. PBAs have the general formula

$$
\mathrm{A}_{\mathrm{x}} \mathrm{M}_{\mathrm{a}}^{\prime}\left[\mathrm{M}(\mathrm{CN})_{6}\right]_{\mathrm{y}} \cdot \square_{1-\mathrm{y}} \cdot \mathrm{nH}_{2} \mathrm{O}
$$

where $A$ is an alkali cation, $M^{\prime}$ is the $N$-coordinated transition metal; $M$ is the C-coordinated transition metal, $\mathrm{M}(\mathrm{CN})_{6}$ is the hexacyanometallate anion, $\square$ is a $\left[\mathrm{M}^{\prime}(\mathrm{CN})_{6}\right]^{3 / 4-}$ vacancy, and $0<\mathrm{x}<2 ; 0<\mathrm{y}<1$. Water molecules can be present in two unique crystallographic environments: either coordinated to unbonded $\mathrm{M}^{\prime}$ atoms 
(coordinated water), or residing in interstitial spacing of the crystal (zeolitic water) $[81,125-127]$. The substitution of different metals into the PB framework creates a large family of materials with varying physical and crystallographic properties that affect electrochemical properties.

\subsubsection{Lattice Vacancies and Structural Water in PBAs}

Hexacyanometallate vacancies, as well as both coordinated and zeolitic water, have been shown to play integral roles in the electrochemical properties of a PBA, with both disadvantageous and advantageous effects.

\section{Disadvantageous Effects of Vacancies and Water}

One of the most important properties of a battery is total energy storage. Specific capacity $\left(\mathrm{mAhg}^{-1}\right)$ is a measure of the capacity, or energy stored, per unit weight. Early PBA cathodes failed to deliver specific capacities above $100 \mathrm{mAhg}^{-1}$ despite high theoretical capacities of $\sim 170 \mathrm{mAhg}^{-1}[128,129]$. Cathodes of $\mathrm{Mn}^{2+}, \mathrm{Fe}^{2+}, \mathrm{Co}^{2+}, \mathrm{Ni}^{2+}, \mathrm{Cu}^{2+}$ or $\mathrm{Zn}^{2+}$ PBAs, synthesized via co-precipitation, experienced poor coulombic efficiencies and a maximum reversible capacity of $70 \mathrm{mAhg}^{-1}$ [128]. These low values were thought to be due to structural instabilities and side reactions caused by lattice vacancies and coordinated water molecules introduced during synthesis [130-135]. Vacancies can also cause low specific capacities, as missing redox active hexacyanometallate anions are replaced by water molecules. Thus, numerous studies have tried to eliminate defects and 
control the coordinated water content through novel synthesis procedures $[131,132,136-$ 138].

In order to limit the formation of defects, a single precursor synthesis has been proposed, where PB is synthesized from ferrocyanide in an acid solution $[134,138,139]$. High quality PB (HQ-PB) particles were produced using this method, and compared with low quality PB (LQ-PB) synthesized under the unmodified co-precipitation technique [134]. Although the structures of the HQ-PB and LQ-PB were identical, they had $6 \%$ and $32 \%$ vacancies by weight, and $15 \%$ and $20 \%$ water content by weight, respectively. By limiting defects and reducing coordinated water, the HQ-PB exhibited superior electrochemical properties with a high specific capacity $\left(170 \mathrm{mAhg}^{-1}\right)$, no apparent capacity loss over 150 cycles and a coulombic efficiency near $100 \%$.

Wu et al. produced a low vacancy $\mathrm{NaCo}\left[\mathrm{Fe}(\mathrm{CN})_{6}\right]$ through a citrate-assisted synthesis [130]. With the addition of trisodium citrate as a chelating agent, the reaction rate and crystallization process were slowed, allowing for a more controlled growth. The resulting material showed reductions in lattice defects and water content of $11 \%$ and $52 \%$ respectively when compared to a control synthesized without citrate ions. The pristine $\mathrm{NaCo}\left[\mathrm{Fe}(\mathrm{CN})_{6}\right]$ displayed a higher specific capacity $\left(150 \mathrm{mAhg}^{-1}\right)$ than the control (115 mAhg-1), attributed to suppressed defects and coordinated lattice water. Other reports of citrate-assisted synthesis have also delivered high capacities and lifetimes $[130,140-145]$. 
In addition to the above procedures, other methods to reduce the water content of PBAs have been proposed including synthesis of carbon/PB composites $[131,136,146,147]$ mixed solution synthesis [148], and annealing as-synthesized PBAs at elevated temperatures [149]. All of these techniques have resulted in increased capacity and cathode lifetime, highlighting the importance of synthetic conditions.

\section{Advantageous Effects of Vacancies and Water}

Whereas the above studies demonstrated undesirable electrochemical effects of hexacyanometallate vacancies and coordinated or zeolitic water, other studies have demonstrated that these effects are not strictly negative. For aqueous electrolytes, water offers charge screening between the lattice and the intercalating ions, which allows for high ionic mobilities on the order of $10^{-7} \mathrm{~cm}^{2} \mathrm{~s}^{-1}$ [150]. Additionally, zeolitic and nitrogen coordinated water can facilitate the migration of ions in PBAs [87]. Padigi et al. and others have demonstrated the use of hybrid aqueous/nonaqueous electrolytes can lead to improved electrochemical performances and increase specific capacities by more than $45 \%[65,151-153]$. Xiao et al. carried out a theoretical study on the impacts of structural and zeolitic water to $\mathrm{Na}_{2} \mathrm{FeMn}(\mathrm{CN})_{6}$, proposing water caused a phase change and an increase in redox potentials [154]

\subsubsection{Crystal Structure of PBAs}

The crystal structures of PBAs have been shown to affect their energy storage capacities. Recently, rhombohedral PBAs have become of interest, displaying superior 
performance when compared to their cubic counterparts [47-49,130,134,141]. Wang et al. determined that the induced phase change for $\mathrm{Mn}\left[\mathrm{Fe}(\mathrm{CN})_{6}\right]$ occurred with increased $\mathrm{Na}^{+}$ions in the lattice [48]. Although the rhombohedral and cubic $\mathrm{Mn}\left[\mathrm{Fe}(\mathrm{CN})_{6}\right]$ have similar discharge capacities, the rhombohedral phase has a higher operating voltage and thus higher energy density. A similar effect on the operating voltage of $\mathrm{Ni}\left[\mathrm{Fe}(\mathrm{CN})_{6}\right]$ was observed, where the cubic and rhombohedral materials had a $120 \mathrm{mV}$ offset in operating potential [141]. It was proposed that in the rhombohedral structure, the intercalated sodium atoms caused a dramatic polarization of the electron density in the crystal lattice away from the $\mathrm{Ni}-\mathrm{N}$ bond towards the Fe-C bond. This polarization in turn raised the redox potential of the iron in the rhombohedral nickel hexacyanoferrate.

In addition to the effect of the microcrystalline structure of a PBA on its battery performance, the macro structure plays an important role in a material's electrochemical properties. Zhang et al. synthesized rhombohedral cuboctahedron (C-RZnHCF), truncated octahedron (T-RZnHCF), octahedron (O-RZnHCF) and $\mathrm{Zn}[\mathrm{Fe}(\mathrm{CN}) 6]$ nanostructures by varying the rate of mixing of the reactants during synthesis [122]. Each material crystallized with the same phase and lattice parameter, but displayed different macroscopic geometries (Figure 1.6). The initial specific capacities were the same for each sample, however after 100 cycles at $300 \mathrm{mAg}^{-1} \mathrm{C}-\mathrm{RZnHCF}$ maintained a higher percentage of its initial capacity than the other two materials. By adjusting the macro and micro crystallographic properties of a PBA, the electrochemical properties of the materials can be improved. 


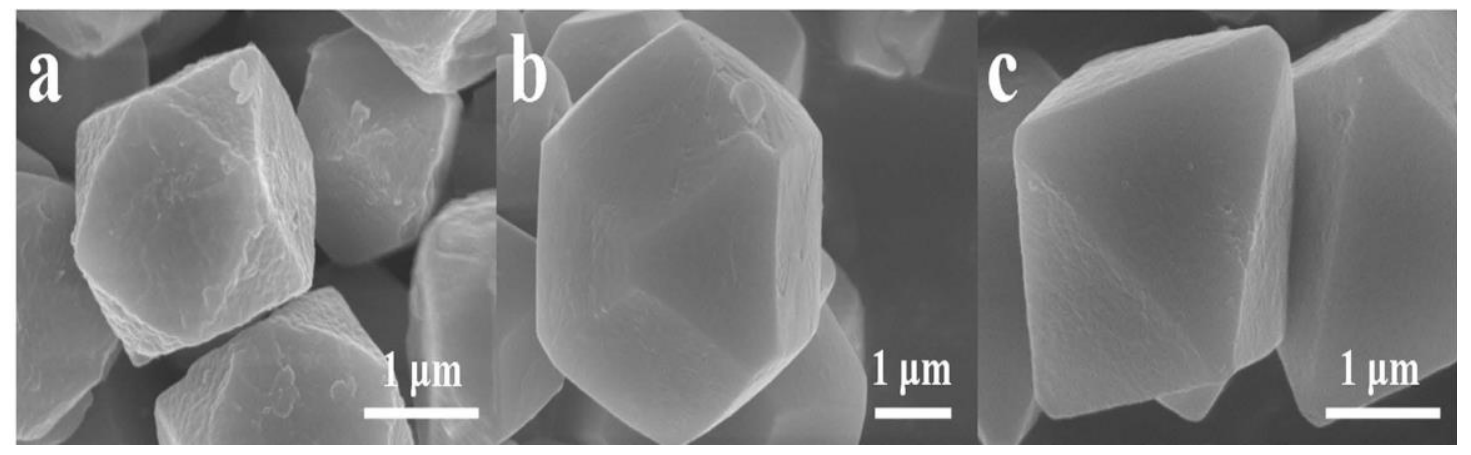

Figure 1.6 $\mathrm{Zn}[\mathrm{Fe}(\mathrm{CN}) 6]$ nanostructures with different macroscopic geometries (a) Rhombohedral cuboctahedron (C-RZnHCF), (b) truncated octahedron (T-RZnHCF), and (c) octahedron (O-RZnHCF) [117]

\subsubsection{PBA Crystal Redox Active Elements}

To maximize the theoretical capacity of a PBA, both C-coordinated and $\mathrm{N}$ coordinated transition metals must be redox active. However, when PBAs such as $\mathrm{Fe}\left[\mathrm{Fe}(\mathrm{CN})_{6}\right], \mathrm{Mn}\left[\mathrm{Fe}(\mathrm{CN})_{6}\right]$ and $\mathrm{Co}\left[\mathrm{Fe}(\mathrm{CN})_{6}\right]$ undergo redox, the lattice expands and contracts, which may result in structural deterioration [155]. This in turn causes the capacity to quickly fade. By introducing a non-redox active element, it is possible to reduce the stress and strain on the lattice and improve stability over time. You et al. reported on $\mathrm{Ni}[\mathrm{Fe}(\mathrm{CN}) 6]$ as a zero-strain insertion cathode, where $\mathrm{Ni}$ did not undergo redox [156]. Under the insertion and extraction of $\mathrm{Na}$ ions, the change in lattice parameters was less than $1 \%$. This structural stability was associated with a capacity retention of $99.7 \%$ over 200 cycles and a coulombic efficiency of $100 \%$. Theoretical calculations were performed for NiHCF, in which the volume variation for $\mathrm{Na}^{+}$ intercalation was predicted to be $0.72 \%[141]$. 


\subsubsection{Mixed Metal Hexacyanoferrates (MMHCFs)}

The electrochemical and physical properties of PBAs are distinct from PB due to effects arising from the different transition metals that are present in PBAs. Additional variations in properties can be induced by partially substituting a third metal atom into a PBA, resulting in a mixed-metal, or ternary, hexacyanometallate. Maintaining the ferrocyanide anion and varying the nitrogen coordinated metal results in a mixed-metal hexacyanoferrate with the chemical formula

$$
A_{x} M^{\prime}{ }_{1-z} M^{\prime \prime}{ }_{z}\left[M(C N)_{6}\right]_{y} \cdot{ }_{1-y} \cdot n H_{2} O
$$

where $\mathrm{M}$ is $\mathrm{Fe}$, and $\mathrm{M}^{\prime}$ and $\mathrm{M}^{\prime \prime}$ are two different nitrogen bonded transition metals. By varying the ratio of $\mathrm{M}^{\prime}$ to $\mathrm{M}^{\prime \prime}$, it becomes possible to tune specific properties of a PBA. This feature of MMHCFs has been utilized in areas such chemical sensing [157-160], magnetic materials [161-164], and catalysis [165-169]. The application of ternary hexacyanoferrates to energy storage has mainly focused on sodium ion batteries $[83,91,96,97,150,170-174]$, with minimal reports on other chemistries $[71,100,107,175-$ 178].

Bharathi et al. investigated the redox behavior of mixed metal hexacyanoferrates by substituting Ni or Mn for some of the Fe in PB [179]. In the study, the three binary systems $\left(\mathrm{Mn}\left[\mathrm{Fe}(\mathrm{CN})_{6}\right], \mathrm{Ni}\left[\mathrm{Fe}(\mathrm{CN})_{6}\right]\right.$ and $\mathrm{Fe}\left[\mathrm{Fe}(\mathrm{CN})_{6}\right]$ were compared to the mixed metal hexacyanoferrates $\left(\mathrm{MnFe}\left[\mathrm{Fe}(\mathrm{CN})_{6}\right]\right.$ and $\left.\mathrm{NiFe}\left[\mathrm{Fe}(\mathrm{CN})_{6}\right]\right)$. Differences in the redox properties between the two binary parent systems and the tertiary mixed metals were 
observed. Most interestingly, while $\mathrm{Mn}[\mathrm{Fe}(\mathrm{CN})]_{6}$ was unstable the incorporation of $\mathrm{Mn}$ into the PB lattice stabilized the Mn-C-N-Fe chain. However, a critical concentration of Mn was identified where increased $M n$ led to dissolution of the material.

The electrodeposited materials studied by Bharathi et al. did not allow for crystal analysis due to the limited amount of product produced. XRD analysis was possible on the $\mathrm{Fe}_{x} \mathrm{Ni}_{1-x}\left[\mathrm{Fe}(\mathrm{CN})_{6}\right]$ system, synthesized in sufficient quantities via coprecipitation [180]. A linear relationship between the materials' lattice constants and the percentage of nickel was observed. The authors proposed the formation of a single mixed phase, as only one voltammetric response was observed instead of the two systems present when both binary HCFs were mixed together.

The first comprehensive investigation into the structural properties of mixed metal hexacyanoferrates was performed for $\mathrm{Fe}^{3+} \mathrm{Cd}^{2+}\left[\mathrm{Fe}(\mathrm{CN})_{6}\right]$ by varying the $\mathrm{Cd}^{2+}$ concentration [181]. It was discovered that for products with a molar ratio $\mathrm{m}_{\mathrm{Cd}}=\mathrm{n}_{\mathrm{Cd}} /\left(\mathrm{n}_{\mathrm{Cd}}+\mathrm{n}_{\mathrm{Fe}}\right)$ less than $0.126, \mathrm{Cd}$ only resided in the interstitial space of the Prussian blue lattice. For samples with $\mathrm{m}_{\mathrm{cd}} \leq 0.4$, the cubic phase of PB was maintained with partial $\mathrm{Fe}^{2+}$ replaced by $\mathrm{Cd}^{2+}$, whereas those with higher ratios underwent a phase change to an orthorhombic structure. Coinciding with the phase transition from cubic to orthorhombic, a partial oxidation of the low-spin irons occurred.

The transition energies, or band gap energies, of the nickel iron $\mathrm{Fe}_{x} \mathrm{Ni}_{3-\mathrm{x}}\left[\mathrm{Fe}(\mathrm{CN})_{6}\right]_{2}$ system were studied by Ishizaki et al. [182]. It was reported that the color of the solid 
precipitants gradually changed from blue to yellow with increasing $\mathrm{Ni}$ concentration. Employing vis-near-IR absorption spectra, a linear correlation between composition ratio $(0.6<x<3.0)$ and a material's absorption was identified. The transition energies were estimated to be $1.44 \mathrm{eV}(\mathrm{x}=3), 1.36 \mathrm{eV}(\mathrm{x}=2.4), 1.27 \mathrm{eV}(\mathrm{x}=1.5)$ and $1.2 \mathrm{eV}(\mathrm{x}=0.6)$. Although Ni has been shown to be redox inactive in PBAs $[156,183,184]$, a linear shift in potential between $0.58 \mathrm{~V}$ and $0.87 \mathrm{~V}$ for the first redox couple $\left(\mathrm{Fe}^{2+} / \mathrm{Fe}^{3+}\right)$ was observed with increasing $\mathrm{Ni}$ concentration. The authors showed that the energy levels of $\mathrm{Fe}_{x} \mathrm{Ni}_{3-\mathrm{x}}\left[\mathrm{Fe}(\mathrm{CN})_{6}\right]_{2}$ could be systematically tuned by adjusting the Ni concentration.

As briefly highlighted above, the addition of a third transition metal into the PBA lattice leads to novel structural, chemical, and electrical properties that can be tuned based on the material's composition. Table 1.1 provides a different published mixed metal hexacyanoferrate systems that have been investigated for electrochemical energy applications. 
Table 1.1 Mixed metal hexacyanoferrates as tested as battery cathodes

\begin{tabular}{|c|c|c|}
\hline Material & Intercalating ion & Ref \\
\hline $\mathrm{NiCo}\left[\mathrm{Fe}(\mathrm{CN})_{6}\right]$ & K & {$[100,185-187]$} \\
\hline $\mathrm{NiCo}\left[\mathrm{Fe}(\mathrm{CN})_{6}\right]$ & $\mathrm{Na}$ & {$[83,91,188,189]$} \\
\hline $\mathrm{MnCu}\left[\mathrm{Fe}(\mathrm{CN})_{6}\right]$ & $\mathrm{Li}$ & {$[190]$} \\
\hline $\mathrm{MnCo}\left[\mathrm{Fe}(\mathrm{CN})_{6}\right]$ & $\mathrm{Li}$ & {$[191]$} \\
\hline $\mathrm{MnCo}\left[\mathrm{Fe}(\mathrm{CN})_{6}\right]$ & $\mathrm{K}$ & {$[192]$} \\
\hline $\mathrm{MnCo}\left[\mathrm{Fe}(\mathrm{CN})_{6}\right]$ & $\mathrm{Na}$ & {$[150,153,192,193]$} \\
\hline $\mathrm{CuNi}\left[\mathrm{Fe}(\mathrm{CN})_{6}\right]$ & $\mathrm{Na}$ & {$[97,170]$} \\
\hline$(\mathrm{VO}) \mathrm{Cu}\left[\mathrm{Fe}(\mathrm{CN})_{6}\right]$ & $\mathrm{Li}$ & {$[149]$} \\
\hline $\mathrm{FeNi}\left[\mathrm{Fe}(\mathrm{CN})_{6}\right]$ & $\mathrm{Na}$ & {$[172,194,195]$} \\
\hline $\mathrm{FeNi}\left[\mathrm{Fe}(\mathrm{CN})_{6}\right]$ & $\mathrm{K}$ & {$[107,175]$} \\
\hline $\mathrm{FeNi}\left[\mathrm{Fe}(\mathrm{CN})_{6}\right]$ & Al & {$[71]$} \\
\hline $\mathrm{FeMn}\left[\mathrm{Fe}(\mathrm{CN})_{6}\right]$ & $\mathrm{Na}$ & {$[153,196-198]$} \\
\hline $\mathrm{MnNi}\left[\mathrm{Fe}(\mathrm{CN})_{6}\right]$ & $\mathrm{Na}$ & {$[84,96,140,153,171]$} \\
\hline $\mathrm{CoCu}\left[\mathrm{Fe}(\mathrm{CN})_{6}\right]$ & $\mathrm{Na}$ & {$[199,200]$} \\
\hline $\mathrm{TiFe}\left[\mathrm{Fe}(\mathrm{CN})_{6}\right]$ & $\mathrm{Li}$ & {$[176]$} \\
\hline $\mathrm{TiFe}\left[\mathrm{Fe}(\mathrm{CN})_{6}\right]$ & $\mathrm{Na}$ & [176] \\
\hline $\mathrm{MnCoNi}\left[\mathrm{Fe}(\mathrm{CN})_{6}\right]$ & $\mathrm{Na}$ & [201] \\
\hline $\mathrm{CuZn}\left[\mathrm{Fe}(\mathrm{CN})_{6}\right]$ & $\mathrm{Zn}$ & {$[178]$} \\
\hline $\operatorname{TiMn}\left[\mathrm{Fe}(\mathrm{CN})_{6}\right]$ & $\mathrm{Na}$ & [202] \\
\hline
\end{tabular}




\subsection{Objectives of this work}

Prussian blue analogues are an interesting family of materials whose electrochemical and physical properties make them intriguing candidates for nextgeneration electrode materials. In particular, their large interstitial spacing can accommodate a variety of ions including multivalent species, which can lead to batteries with higher energy densities than batteries based on monovalent cations. Furthermore, the ability to tune the properties of a PBA by varying the transition metals in the lattice opens the door to modifying a material to meet the particular needs of a specific application. The experimental studies in this dissertation build upon earlier work on PBAs and mixed metal hexacyanoferrates, reviewed above, and combine previously studied materials in new systems as a way to improve the electrochemical properties of Prussian blue analogue batteries. The objectives of these studies were to:

1. Develop non-lithium ion based systems utilizing PBA cathodes, with a particular focus on divalent ion systems. Divalent ion batteries are of great interest as they possess double the theoretical energy density of $\mathrm{Li}^{+}$batteries for equal amounts of intercalated ions.

2. Determine if the physical and electrochemical storage properties of a PBA could be improved if two binary metal hexacyanoferrates are incorporated into a hybrid metal hexacyanoferrate composite. Of particular interest were what effects Co or Ni would have on stabilizing manganese in the PBA lattice. 
These objectives were achieved by performing the investigations presented in the following chapters.

Chapter 2 of this dissertation explains the physical and electrochemical properties that are examined in evaluating a candidate redox system for battery usage, and the methods used to examine these properties.

Chapter 3 presents a calcium ion system containing a Prussian blue cathode. The results demonstrate the ability of PB to successfully intercalate and deintercalate $\mathrm{Ca}^{2+}$ ions while maintaining high specific capacities and experiencing minimal capacity fading over extended cycling.

Chapter 4 presents a study on the mixed metal system $\mathrm{KMn}_{x} \mathrm{CO}_{1-\mathrm{x}}\left[\mathrm{Fe}(\mathrm{CN})_{6}\right]$ as a cathode material for aqueous zinc ion batteries (ZIBs). In general, zinc ion batteries (ZIBs) are of interest because zinc metal can be used as an anode in aqueous chemistries, unlike many other battery chemistries including sodium ion batteries (SIBs), potassium ion batteries (KIBs) and magnesium ion batteries (MIBs). The latter are either too volatile ( $\mathrm{Na}$ and $\mathrm{K}$ ) or suffer from non-conductive oxide formation (Mg).

Chapter 5 examines the effects of coordinated and zeolitic water on the $\mathrm{Mg}^{2+}$ storage properties of copper hexacyanoferrate in a nonaqueous solvent. The inability of copper and manganese to produce a single-phase, mixed metal hexacyanoferrate will also be discussed. 
Chapter 6 explores the $\mathrm{Na}_{2} \mathrm{Mn}_{\mathrm{x}} \mathrm{Ni}_{1-\mathrm{x}}\left[\mathrm{Fe}(\mathrm{CN})_{6}\right]$ mixed metal system and its use as a cathode material for nonaqueous potassium ion batteries. The objective of this study was to increase the storage capacity of nickel hexacyanoferrate by replacing a fraction of the $\mathrm{Ni}$ atoms with $\mathrm{Mn}$, while avoiding the known sluggish kinetics of pure manganese hexacyanoferrate

Chapter 7 introduces preliminary density functional theory results for $\mathrm{Na}_{2} \mathrm{Mn}_{\mathbf{x}} \mathrm{Ni}_{1-\mathrm{x}}\left[\mathrm{Fe}(\mathrm{CN})_{6}\right]$.

Chapter 8 will provide a discussion of all of the results and their impact on the field of energy storage to conclude this investigation.

The systems investigated in chapters 3-6 are listed in Table 1.2 on the following page. 
Table 1.2 Outline of work presented in this dissertation

\section{Chapter Cathode Cation Electrolyte Contribution}
Prussian blue
$\mathrm{KFe}\left[\mathrm{Fe}(\mathrm{CN})_{6}\right.$
$\mathrm{Ca}^{2+}$
Acetonitrile
Use of calcium as the
intercalating species.

3

\begin{tabular}{|c|c|c|c|c|}
\hline 5 & $\begin{array}{c}\text { Copper } \\
\text { hexacyanoferrate } \\
\mathrm{K}_{2} \mathrm{Cu}\left[\mathrm{Fe}(\mathrm{CN})_{6}\right]\end{array}$ & $\mathrm{Mg}^{2+}$ & $\begin{array}{l}\text { Propylene } \\
\text { carbonate } \\
\text { and } \\
\text { ethylene } \\
\text { carbonate }\end{array}$ & $\begin{array}{l}\text { Investigation of the role } \\
\text { zeolitic and coordinated } \\
\text { water have on the } \\
\text { magnesium ion storage } \\
\text { properties of } \mathrm{K}_{2} \mathrm{Cu}\left[\mathrm{Fe}(\mathrm{CN})_{6}\right]\end{array}$ \\
\hline 6 & $\begin{array}{l}\text { Manganese-nickel } \\
\text { hexacyanoferrate } \\
\mathrm{K}_{2} \mathrm{Mn}_{x} \mathrm{Ni}_{1-x}\left[\mathrm{Fe}(\mathrm{CN})_{6}\right]\end{array}$ & $\mathrm{K}^{+}$ & $\begin{array}{l}\text { Propylene } \\
\text { carbonate } \\
\text { and } \\
\text { ethylene } \\
\text { carbonate }\end{array}$ & $\begin{array}{l}\text { Use of potassium as the } \\
\text { intercalating species. } \\
\text { Investigation into the } \\
\text { relationship between the } \\
\text { percentage } \mathrm{Mn} \text { and the } \\
\text { bonding properties, storage } \\
\text { capacity, and rate capability } \\
\text { of the resulting } \\
\mathrm{K}_{2} \mathrm{Mn}_{x} \mathrm{Ni}_{1-x}\left[\mathrm{Fe}(\mathrm{CN})_{6}\right]\end{array}$ \\
\hline
\end{tabular}




\section{Chapter 2.}

\section{Methods}

Redox materials that are being evaluated as candidates for batteries must be characterized in terms of their physical and electrochemical properties. Several methods are used to examine these properties.

\subsection{Physical Properties and their measurement}

As discussed earlier in the review of Prussian blue analogues, the physical properties of PBA affect their electrochemical behavior. These properties, including crystalline structure, water content, particle size and morphology, and content of transition metals, can be determined by X-ray diffraction, thermogravimetric analysis, scanning electron microscopy, energy dispersive X-ray spectroscopy, and Fourier transform infrared spectroscopy, as are discussed in section 2.2.1 through section 2.2.5.

\subsubsection{X-ray Diffraction}

Powder x-ray diffraction (XRD) is a non-destructive analytical technique used to study the crystal structure of a material. A diffraction pattern is generated by sweeping a detector over a fixed set of $2 \Theta$ angles and measuring the x-rays scattered by the sample. The angle at which the detector will observe a signal, and the intensity of that signal, are uniquely determined by the structure and elements of the material. A sample spectrum is shown in Figure 2.1. 
The relationship between the diffraction pattern of a material and its crystal structure is given by Bragg's law (equation 2.1):

$$
n \lambda=2 d \sin (\theta)
$$

where $\mathrm{n}$ is an integer, $\lambda$ is the wavelength of the incident $\mathrm{x}$-rays, $\mathrm{d}$ is the distance between atomic layers in the sample, and $\theta$ is the angle of incidence. For a given $\lambda$ and the set of interatomic spacings of a given material there is a unique set of $\theta^{\prime}$ s, making every material's diffraction pattern a sort of structural signature. However, every diffraction pattern has multiple possible crystal structures that could have generated it. Thus, in order to determine the crystal structure of a sample, additional information or a

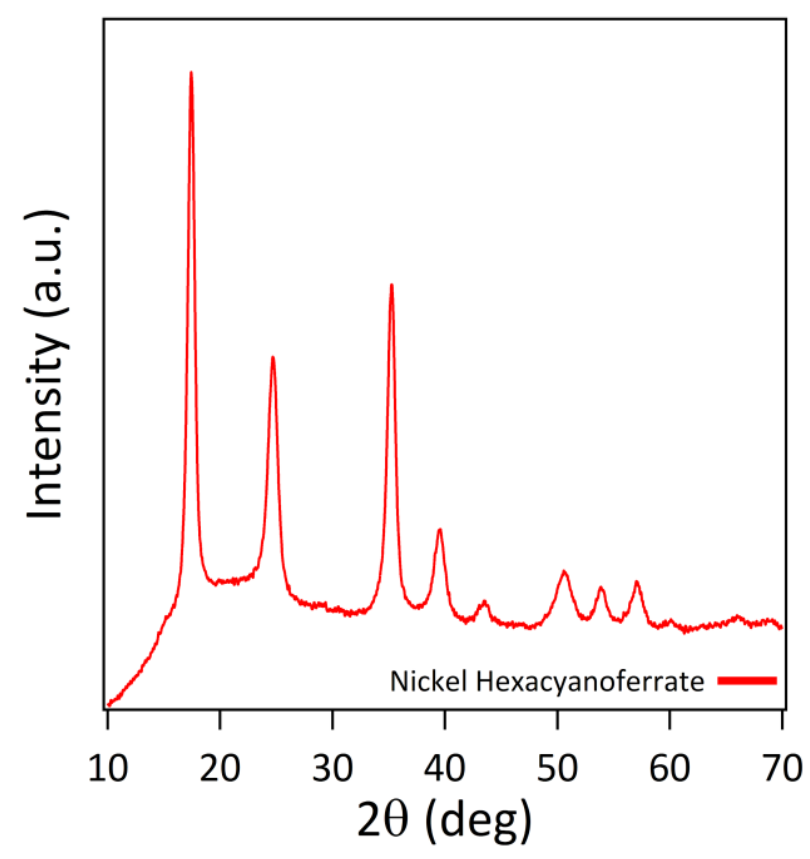

Figure 2.1 Standard powder X-ray diffraction profile 
preliminary, approximate structure is required. The majority of Prussian blue analogues form a crystal structure similar to that of Prussian blue, making structure determination possible for PBAs.

For the work presented in this dissertation, a Rigaku Ultima IV with a $\mathrm{Cu}$ Ka source was used to collect all XRD profile.

\subsubsection{Thermogravimetric Analysis}

Thermogravimetric analysis (TGA) is a quantitative analytical technique that measures the mass loss of a sample by monitoring its weight as it is heated at a constant rate. TGA measurements provide information about phenomena such as off gassing of volatile compounds, moisture content, thermal stability and decomposition kinetics. Depending on the environment in which a TGA experiment is conducted, e.g. in air, inert atmosphere or $\mathrm{O}_{2}$, different reactions can also be detected.

For the work presented in this dissertation, TGA was used to study water content before and after thermal treatment, as well as determine the thermal stability of materials.

\subsubsection{Scanning Electron Microscopy}

A scanning electron microscopy (SEM) is a type of electron microscope that produces an image by rastering a beam of incident electrons over a sample. Backscattered electrons (BSEs) are high energy electrons that reflect off atomic nuclei in the 
sample. Secondary electrons (SEs) are produced when an electron from the incident beam transfers enough energy to an atom in the sample to eject an electron from the sample. Secondary electron images provide more information about the topology of a sample, while back-scattered images offer high contrast.

For the work presented in this dissertation, back-scattered images were used because they provided more information about the particle size of the materials being examined.

\subsubsection{Energy Dispersive X-Ray Spectroscopy}

Energy dispersive $\mathrm{x}$-ray spectroscopy (EDS) is a semi-quantitative analytical technique that can accompany electron microscope imaging and provide information about the elemental composition of a sample. As secondary electrons are ejected from atoms during electron scanning, a higher energy, outer shell electron can settle into the newly generated vacancy and emit a photon with energy in the x-ray region of the spectrum, equal to the energy difference between the two electronic states. The $x$-ray energies provide signatures of the electronic structure of the emitting element and therefore allow that element to be identified.

In the work presented in this thesis, EDS was used to examine the chemical composition of mixed metal hexacyanoferrates, and to identify what ions were participating in intercalation and deintercalation during discharging and charging of electrodes. 


\subsubsection{Fourier Transform Infrared Spectroscopy}

Infrared (IR) spectroscopy probes the molecular bonds of a sample by irradiating it with infrared light and measuring the transmitted signal. Fourier transform infrared spectroscopy (FTIR) uses a broadband infrared light source and a Michelson interferometer to collect an interferogram from which an entire IR spectrum can be reconstructed by taking the Fourier transform. In practice, the interferogram is generated by shining the IR light onto a mirror with a pathlength that changes at a known frequency.

The most important IR absorption peaks for PBAs are:

1. The $\mathrm{C} \equiv \mathrm{N}$ stretching frequency (major peak between $1900-2200 \mathrm{~cm}^{-1}$ ),

2. Metal carbon stretching frequency (major peak between $500-600 \mathrm{~cm}^{-1}$ ),

3. Surface water (broad peak centered near $3350 \mathrm{~cm}^{-1}$ ),

4. Zeolitic water (sharp peak near $1600 \mathrm{~cm}^{-1}$ ), and

5. Coordinated water (shoulder near $1650 \mathrm{~cm}^{-1}$ ).

\subsection{Electrochemical Properties}

The electrical properties of candidate redox systems are quantitatively characterized by measuring specific capacity, cell potential, cycle lifetime, coulombic efficiency and rate capability. These properties are discussed below (sec. 2.2.1 sec. 2.2 .5$)$, followed by a presentation of the methods used to evaluate these properties (sec. 2.3.1- sec. 2.3.3). 


\subsubsection{Specific Capacity}

In stationary battery systems the most important measure of storage capacity is gravimetric capacity, or capacity per unit mass of active material. The theoretical gravimetric capacity $\left(\mathrm{mAh} \mathrm{g}^{-1}\right.$ ) of a material is defined as the amount of charge that can be stored per unit mass of active material. For energy stored through redox reactions, theoretical gravimetric capacity is described by

$$
\text { Capacity }=\frac{n F}{3.6 M}
$$

where Capacity is measured in $\mathrm{mAhg}^{-1}, \mathrm{n}$ is the number of moles of electrons transferred per mole of redox material, $\mathrm{F}$ is the electric charge carried by one mole of electrons (Faraday's constant), and $\mathrm{M}$ is the molar mass $\left(\mathrm{g} \cdot \mathrm{mol}^{-1}\right)$ of the redox material.

For other applications such as mobile electronics and cars, where battery size is a major consideration, volumetric capacity is also considered.

\subsubsection{Cell Electrical Potential}

The thermodynamic parameters of a battery's redox reactions can be used to predict the battery's theoretical maximum voltage, and thereby provide valuable means for estimating the potential usefulness of chemical redox systems as battery components.

The redox reactions of batteries are described thermodynamically by 


$$
\Delta G_{\text {reaction }}^{o}=\Sigma \Delta G_{f}^{o}(\text { product })-\Sigma \Delta G_{f}^{o}(\text { reactant })
$$

where $\Delta G^{\circ}$ reaction is the change in Gibbs free energy under standard conditions (of temperature and pressure), and $\Delta G_{f}^{o}$ is the Gibbs free energy of formation under standard conditions. If there is no transfer of heat from the battery to the external world, and no external pressure-volume work is done by the battery, then $\Delta G^{o}$ reaction equals the usable electrical work of the system. The total electrical work (W) done by a battery can be expressed as:

$$
W=q V
$$

where $q$ is the total charge transferred from the anode to the cathode during discharge, and $\mathrm{V}$ is the average voltage difference between anode and cathode during discharge. The charge transferred during a reaction is equal to $\mathrm{nF}$, where $\mathrm{n}$ is the number of moles of electrons transferred in the reaction, and $\mathrm{F}$ is the charge per mole of electrons (Faraday's constant). Thus, the change in Gibbs free energy of a redox reaction is related to the cell's average voltage by

$$
\Delta G=-n F|V|
$$

Rearranging, this average voltage can be expressed as:

$$
|V|=\frac{\left|\Delta G_{\text {cell }}\right|}{n F}
$$


and is called the open circuit voltage, $V_{O C V}$, when there is no external current flowing between the anode and cathode.

\subsubsection{Cycle Lifetime}

The cycle lifetime of a battery electrode or an entire cell is the number of chargedischarge cycles the system is able to complete before its capacity drops below some threshold criterion. Numerous factors can influence the cycle life of a material including structural transformations during charging/discharging, over-charging or overdischarging, current density, temperature and side reactions. When pairing energy storage with grid-scale electricity production, battery lifetime is of particular importance as any lost capacity means that additional energy will need to be produced from alternative, potentially fossil-fuel burning, sources.

\subsubsection{Coulombic Efficiency}

The coulombic efficiency of a battery is defined as the ratio of the total charge output to the total charge input as follows

$$
\text { Coulombic Efficiency }=100 \times \frac{Q_{\text {Charging }}}{Q_{\text {Discharging }}}
$$

Efficiencies are generally reported as the ratio of the specific capacity of a battery during charging to the specific capacity during discharging. An efficiency of less than $100 \%$ indicates that some side reaction is consuming energy that cannot be recovered by reversing the reaction. The initial charge discharge cycles of many battery systems deliver 
coulombic efficiencies of less than $100 \%$ due to the formation of a solid-electrolyte interphase (SEI). It is important to maintain high coulombic efficiencies over the lifetime of a battery to minimize waste energy.

\subsubsection{Rate Capability}

The rate capability, or rate performance, of a system is a measure of the relationship between the charge/discharge currents (rate) and its maximum capacity. For intercalation electrodes, the capacity decreases with increased current densities. The rate capability of a material is affected by electronic conduction in the electrode, ionic transport in the electrolyte, ionic diffusion in the active material and electrochemical reactions at the electrode/electrolyte interface [203]. All of the factors listed contribute to the total electronic and ionic resistance of a material. The rate performance of a system is less important when high power is not required.

\subsection{Measurement of Electrochemical Properties}

Cyclic voltammetry and galvanostatic charge discharge measurements, used to evaluate the electrochemical properties of candidate cathode materials, were conducted in a three-electrode configuration.

\subsubsection{Three-Electrode Measurements}

The normal set-up of a battery consists of only the anode and cathode, with current and voltage measurements taken between the two electrodes. This configuration 
introduces problems when one wants to study either the anode or cathode independent of the entire cell.

A three-electrode set-up consists of a working electrode (WE), a counter electrode (CE), and a reference electrode (RE). The RE's role is to maintain a stable potential while allowing no current to pass between it and the WE. This allows for current to flow between the WE and CE while measuring the potential of the WE with respect to the fixed reference potential. Because there is no $\mathrm{iR}$ drop across the electrode (i.e. no current flowing) and the potential does not change, it is possible to decouple the change in potential occurring at the cathode from that of the entire cell. Special care must be taken to select a counter electrode such that it is never limiting the current or potential of the cell. This is normally done by selecting a stable material, either a metal or carbon electrode, whose surface area is much greater than the WE's. Figure 2.2 shows a standard three-electrode electrochemical cell.

All electrochemical measurements in this dissertation were conducted in a three-electrode configuration with a PBA working electrode, an $\mathrm{Ag} / \mathrm{AgCl}$ reference electrode for aqueous electrolytes or an $\mathrm{Ag} / \mathrm{Ag}^{+}$reference electrode for nonaqueous electrolytes, and a carbon rod counter electrode. The $\mathrm{Ag} / \mathrm{AgCl}$ potential is well established and is not dependent on the particular system. The $\mathrm{Ag} / \mathrm{Ag}^{+}$potential is stable for a given setup, however it is dependent on the Ag concentration in the electrode as well as the 
electrolyte. Thus, $\mathrm{Ag} / \mathrm{Ag}^{+}$reference electrodes were calibrated by using the $\mathrm{Fc} / \mathrm{Fc}^{+}$ reaction given that it is system independent. [204]

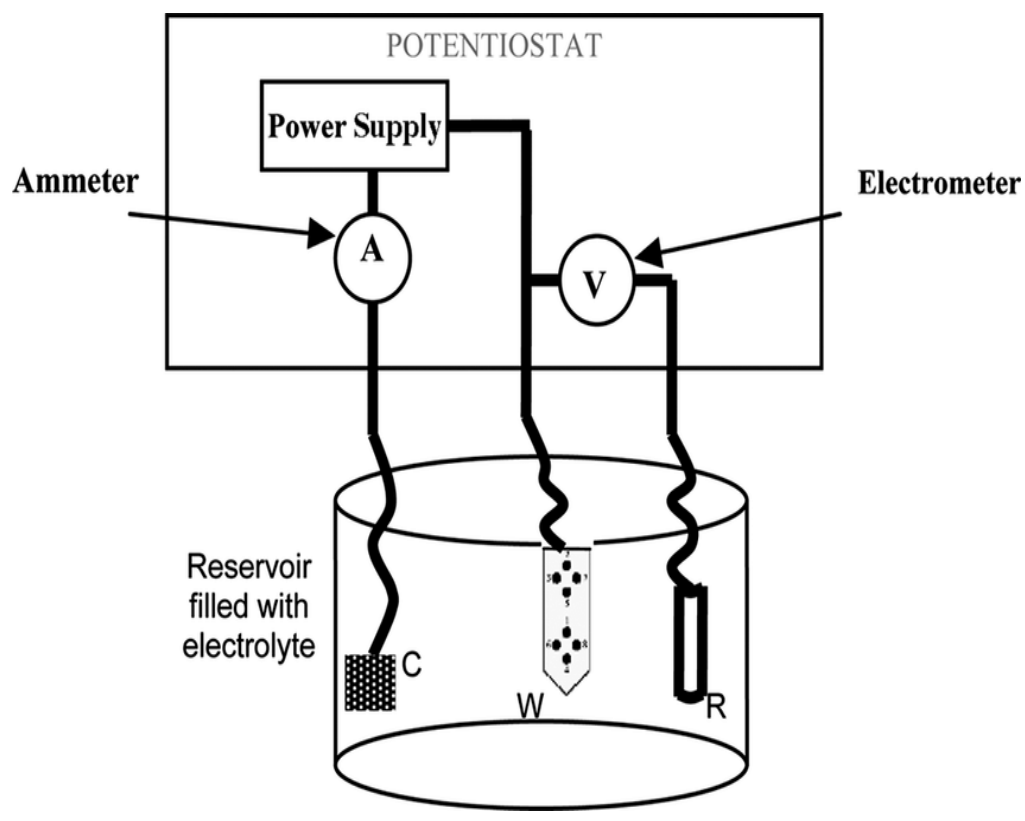

Figure 2.2 Three-electrode electrochemical cell [181]

\subsubsection{Cyclic Voltammetry}

Cyclic voltammetry (CV) is an electrochemical technique that measures the current response to a changing potential that is swept at a constant rate between a lower and an upper cutoff potential. CV is used to study the thermodynamics and kinetics of a redox reaction. For a reversible charge transfer reaction, any cathodic or anodic reaction appears as a positive peak and negative peak, respectively, in the current vs voltage graph. A typical cyclic voltammogram for a single reversible reaction is shown in Figure $2.3[205]$. 


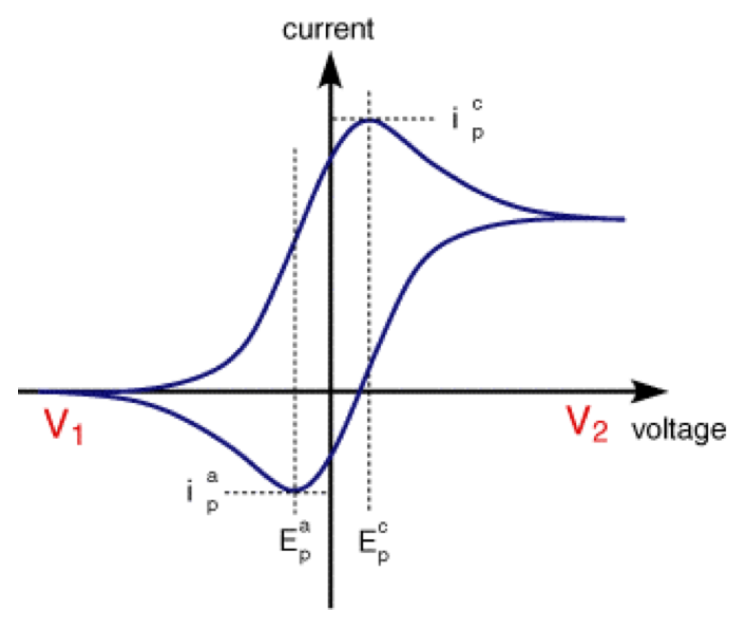

Figure 2.3 standard cyclic voltammogram for a single redox reaction [182]

The formal potential of a reaction is the mean between the cathodic and anodic peaks:

$$
E_{\frac{1}{2}}=\frac{E_{\text {cathodic }}+E_{\text {Anodic }}}{2}
$$

The kinetics of a reaction can be studied by measuring the peak anodic and cathodic currents as the scan rate is varied. For reversible redox reactions, the relationship between peak current and scan rate is described by the Randles-Sevcik equation [206]:

$$
I_{\text {peak }}=0.4463 \times \sqrt{\frac{n^{3} F^{3}}{R T}} \times \sqrt{D} \times C_{o} \times \sqrt{v}
$$

where $i_{p}$ is the peak current $(A), n$ is the number of electrons transferred in the reaction, F is Faraday's constant, $R$ is the ideal gas constant, $T$ is temperature $(K), D$ is the diffusion 
coefficient $\left(\mathrm{cm}^{2} \mathrm{sec}^{-1}\right), \mathrm{C}_{0}$ is the concentration of active sites $\left(\mathrm{mol} \mathrm{cm}{ }^{-3}\right)$, and $v$ is the cyclic voltammogram sweep rate.

In this dissertation, cyclic voltammetry was used to determine the reduction and oxidation potentials of the PBAs studied, as well as study the kinetics of ion diffusion into and out of the cathode.

\subsubsection{Galvanic Charge Discharge}

In galvanostatic charge discharge measurements, a constant current is applied between the working and counter electrodes in a three-electrode cell while the potential of the working electrode is measured with respect to the reference. The current is applied until the potential between the WE and the CE exceeds a set potential. For this dissertation, the specific capacity, rate capability, coulombic efficiencies, and cycle lifetime were all determined from galvanic charge discharge test.

Specific capacity of a cathode at a constant current is determined by:

$$
\text { Specific Capacity }=\frac{I \times t}{m}\left(m A h g^{-1}\right)
$$

where $I$ is the current applied, $\mathrm{m}$ is the mass of the active material, and $\mathrm{t}$ is the time to reach the cutoff potential. The rate capability of a material is determined by measuring the change in specific capacity as a function of charge/discharge current density. 


\section{Chapter 3.}

High performance Prussian blue as a cathode material for nonaqueous calcium ion batteries

\section{Presentation of Published work:}

Kuperman N, Padigi P, Goncher G, Evans D, Thiebes J, Solanki R. High performance Prussian Blue cathode for nonaqueous Ca-ion intercalation battery. Journal of Power Sources 2017;342:414-8. https://doi.org/10.1016/i.jpowsour.2016.12.074. [117]

\subsection{Abstract}

Potassium iron hexacyanoferrate, or Prussian blue (PB), is investigated as a cathode material for nonaqueous divalent calcium ion batteries. PB is an attractive prospect due to its high specific capacity, nontoxicity, low cost, and simple synthesis. Charge/discharge performances are examined at current densities of $23 \mathrm{mAg}^{-1}, 45 \mathrm{mAg}^{-1}$, $90 \mathrm{mAg}^{-1}$, and $125 \mathrm{mAg}^{-1}$ that produced reversible specific capacities ranging from $150 \mathrm{mAhg}^{-1}$ (at $23 \mathrm{mAg}^{-1}$ current density) to over $120 \mathrm{mAhg}^{-1}$ (at $125 \mathrm{mAg}^{-1}$ current density). These are the highest storage capacities to date for a divalent calcium ion cathode over extended period of charge/discharge cycling and are comparable in performance to monovalent intercalating ions. 


\subsection{Introduction}

Divalent ions have been of interest for rechargeable batteries for many years owing to the fact that a doubly charged ion can accept two electrons for a single ion. For intercalation type batteries, this means fewer ions would need to diffuse into a lattice for a given capacity, which could result in less severe lattice distortion and more reliable cells. The most interesting candidates for multivalent ion cells are $\mathrm{Be}^{2+}, \mathrm{Mg}^{2+}$, and $\mathrm{Ca}^{2+}\left(\right.$ and $\mathrm{Al}^{3+}$ if trivalent ions are included) due to their lightweight and small ionic radii. $\mathrm{Be}^{2+}$ can be excluded as a candidate for multivalent ion batteries due to its rarity and toxicity. Of the remaining ions, $\mathrm{Ca}^{2+}$ has the highest potential, and is very close to that of $\mathrm{Li}^{+}(-2.87 \mathrm{~V}$ vs SHE compared to $-3.04 \mathrm{~V}$ for $\mathrm{Li}$ ). This makes Ca-ions a very attractive guest species for intercalation type batteries. Early work on $\mathrm{Ca}^{2+}$ cells, however, showed that Ca metal electrodes in nonaqueous electrolytes formed a surface passivation layer that inhibited electron transfer [207-210].

Intercalation electrodes are attractive for Ca-ion batteries, where the Ca ions are not plated during discharging, but inserted into the cathode lattice followed by reduction of lattice ions. Amatucci et al. and Hayashi et al. studied the electrochemical insertion and extraction of calcium into nanocrystalline $\mathrm{V}_{2} \mathrm{O}_{5}[211]$ and $\mathrm{V}_{2} \mathrm{O}_{5}$ nanocomposites $[209,212]$ while delivering high specific capacities, $200 \mathrm{mAhg}^{-1}, 400 \mathrm{mAhg}^{-1}$, and $465 \mathrm{mAhg}^{-1}$ respectively, for a maximum of ten cycles. Very recently, a reversible capacity of 100 mAhg $^{-1}$ was achieved using a $\mathrm{CaCO}_{2} \mathrm{O}_{4}$ cathode in a completely nonaqueous system [64]. 
Prussian blue analogs $\left(\mathrm{A}_{x} \mathrm{M}\left[\mathrm{Fe}(\mathrm{CN})_{6}\right] \cdot \mathrm{nH} 2 \mathrm{O}\right.$ where $\mathrm{A}$ is an alkali metal or alkaline earth metal, and $\mathrm{M}$ is a transition metal; abbreviated PBA) have also been investigated as intercalation-based cathode materials for calcium ion batteries. $\mathrm{Ni}\left[\mathrm{Fe}(\mathrm{CN})_{6}\right]$ [87] was used as a cathode in an aqueous system and exhibited a capacity of $50 \mathrm{mAhg}^{-1}$, while in mixed solvent aqueous electrolytes $\mathrm{Co}\left[\mathrm{Fe}(\mathrm{CN})_{6}\right][65]$ and $\mathrm{Ba}\left[\mathrm{Fe}(\mathrm{CN})_{6}\right][56]$ delivered capacities of $82 \mathrm{mAhg}^{-1}$ and $55 \mathrm{mAhg}^{-1}$ respectively. Several completely nonaqueous systems with PBA cathodes have been studied, which include $\operatorname{Co}\left[\mathrm{Fe}(\mathrm{CN})_{6}\right][61], \operatorname{Ni}\left[\mathrm{Fe}(\mathrm{CN})_{6}\right][66,113]$, and $\mathrm{Mn}\left[\mathrm{Fe}(\mathrm{CN})_{6}\right][213,214]$ cathodes with maximum reversible capacities of $20 \mathrm{mAhg}^{-1}$, $60 \mathrm{mAhg}^{-1}$, and $110 \mathrm{mAhg}^{-1}$ respectively. PBA cathodes have shown good capacity retention over a large number of cycles. Only the maximum values reported in literature are listed above. In this work, we report our initial results of the performance of iron hexacyanoferrate, or Prussian blue, cathodes with Ca-ions in a nonaqueous acetonitrile (AN) electrolyte.

\subsection{Materials and methods}

PB ( $\left.\mathrm{KFe}^{3+}\left[\mathrm{Fe}^{2+}(\mathrm{CN})_{6}\right]\right)$ was synthesized using the same procedure as we have previously reported [108]. Briefly, the PB was synthesized at $60{ }^{\circ} \mathrm{C}$ by slowly adding $0.05 \mathrm{M}$ ferric nitrate in $25 \mathrm{~mL}$ deionized (DI) water to $0.1 \mathrm{M}$ potassium ferrocyanide in 25 $\mathrm{mL}$ DI water, under constant stirring. The blue precipitate was stirred for $2 \mathrm{~h}$, followed by cleaning via centrifugation at $7000 \mathrm{rpm}$ with DI water and ethanol. The precipitate was dried in an oven at $60^{\circ} \mathrm{C}$ and then annealed at $150{ }^{\circ} \mathrm{C}$ under vacuum for $24 \mathrm{~h}$ to reduce the water content of the material. 
PB cathodes were prepared by combining annealed PB powder with polyvinylidene fluoride (PVDF) which served as a binder, and multi-walled carbon nanotubes and activated carbon as conductivity enhancers in the ratio of $80: 9: 9: 2$, respectively by weight. The electrode mixture was ground using a mortar and pestle until a fine powder was achieved and then mixed with $\mathrm{N}$-methyl-2-pyrolidone (NMP) to form a paste. The paste was applied onto rectangular pieces of carbon paper and dried for two hours at $150{ }^{\circ} \mathrm{C}$ under vacuum. After cooling, the electrodes were weighed to determine the amount of active material present. The finished PB cathodes (total weight on the order of $1 \mathrm{mg}$ of active material, surface area $4 \mathrm{~cm}^{2}$ ) were weighed on an analytical balance with precision to $\pm 0.1 \mathrm{mg}$, and confirmed on another analytical balance of similar precision.

All electrochemical measurements were carried out on a Princeton Applied Research 273a potentiostat. The PB cathodes were characterized using cyclic voltammetry (CV) and galvanic cycling in a three-electrode setup with a graphite rod as a counter electrode and an $\mathrm{Ag} / \mathrm{Ag}^{+}$reference electrode in a $1 \mathrm{M} \mathrm{AgNO}_{3} /$ dry $\mathrm{AN}$ electrolyte. A ferrocene redox $\left(\mathrm{Fc} / \mathrm{Fc}^{+}\right)$reference was used in the electrolyte to calibrate the $\mathrm{Ag} / \mathrm{Ag}^{+}$ potential. The solvent used in all tests was acetonitrile which was dried prior to use by passing through a column of molecular sieves. Both the potassium ( $\mathrm{KPF}_{6}$ in dry AN) and calcium $\left(\mathrm{Ca}\left(\mathrm{ClO}_{4}\right)_{2} \mathrm{xH} 2 \mathrm{O}\right.$ in dry $\left.\mathrm{AN}\right)$ electrolytes were left over $3 \AA$ molecular sieves overnight to eliminate water. Once a cell was assembled, argon was flowed in the headspace and molecular sieves were placed in the bottom of the three-electrode cells 
to limit any additional water absorption. All sieves were activated prior to use by heating at $150^{\circ} \mathrm{C}$ in an oven overnight.

The crystallographic structure of the annealed PB powder was characterized using powder X-ray diffraction (XRD) performed on a Rigaku Ultima IV X-ray diffractometer with $\mathrm{Cu} \mathrm{K} \alpha$ radiation. Indexing and Rietveld refinement were conducted using the Fullprof crystallographic suite [215]. Morphology and particle size were investigated through scanning electron microscopy using a FEI Sirion XL30 scanning electron microscope (SEM). Elemental content of the PB cathodes was detected using energy dispersive $\mathrm{x}$-ray spectroscopy (EDX) on an Oxford Instruments EDX detector mounted on the Sirion SEM.

\subsection{Results and Discussion}

Song et al. have shown that removal of interstitial water by annealing under vacuum leads to superior electrochemical and battery performance, as well as possible structural distortions [47]. Heating Prussian blue to $150{ }^{\circ} \mathrm{C}$ eliminates most of the water from the material $[113,216]$. To confirm Prussian blue's structural stability at $150{ }^{\circ} \mathrm{C}, \mathrm{XRD}$ measurements were performed before and after annealing (Figure 3.1). The XRD patterns show no noticeable changes, indicating the material did not undergo any detectable structural changes. The annealed Prussian Blue is confirmed to have a cubic crystal structure using powder x-ray diffraction with a lattice parameter of $10.21 \AA$ and space group Pm3m (Figure 3.2). The XRD profile displays sharp and well-defined peaks indicating good crystallinity in the sample. The SEM images affirm the good crystallinity and show 


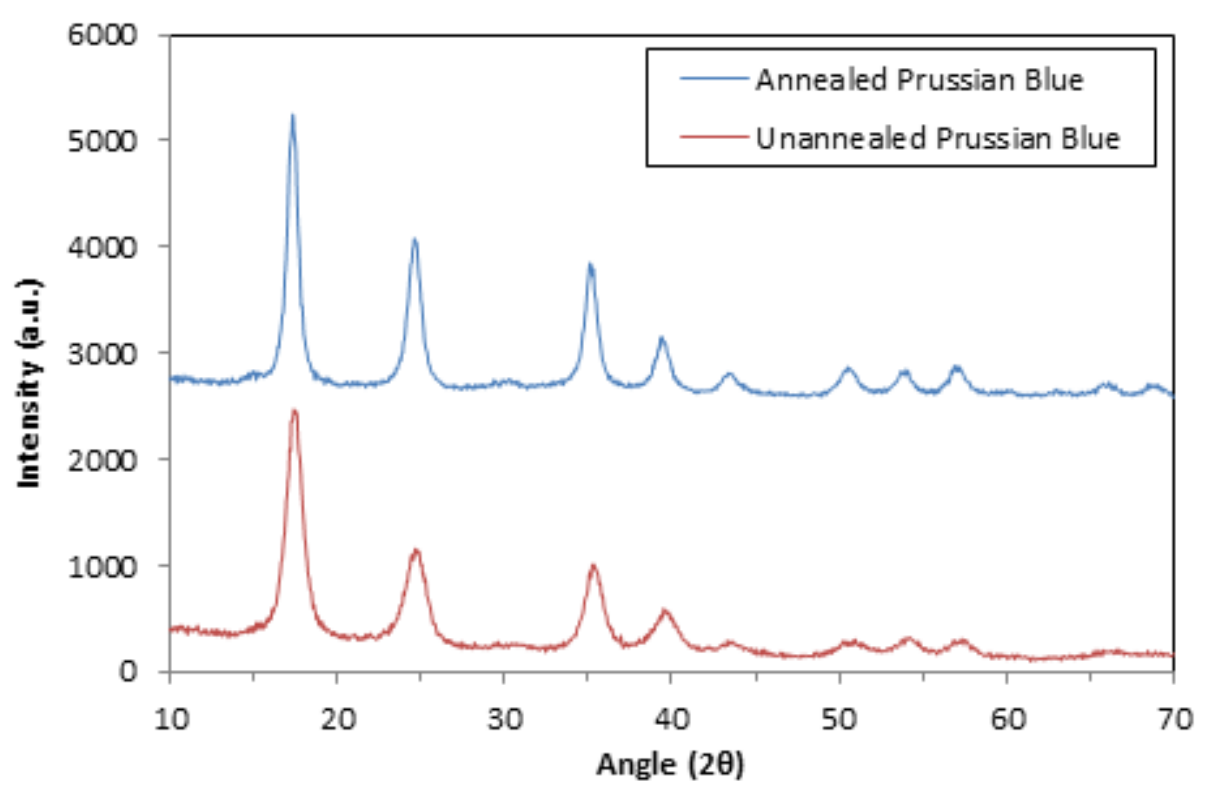

Figure 3.1 XRD pattern of pre and post annealed Prussian blue.

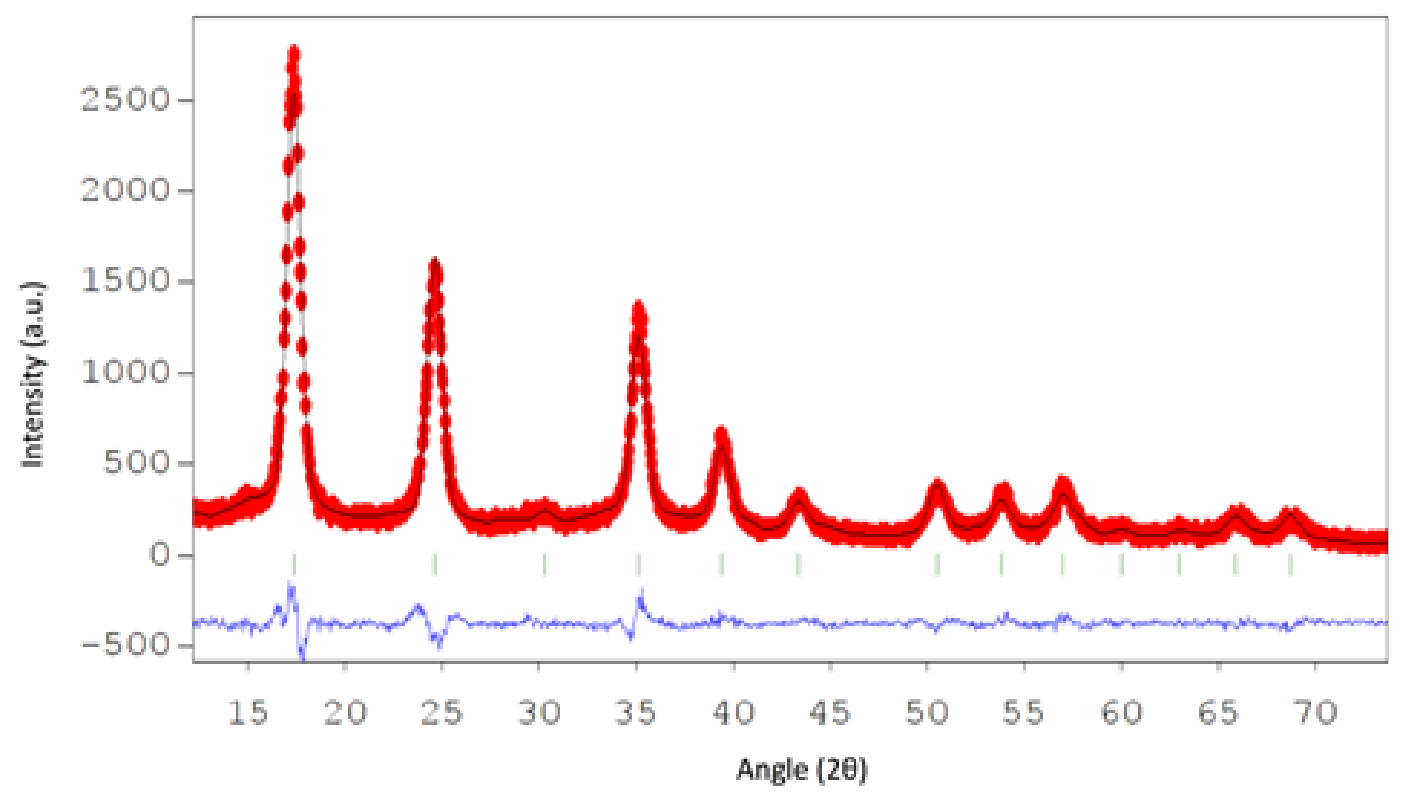

Figure 3.2 Powder XRD pattern for annealed PB. The experimental $\mathrm{x}$-ray spectrum is shown in red and the Rietveld fit with the solid black line 


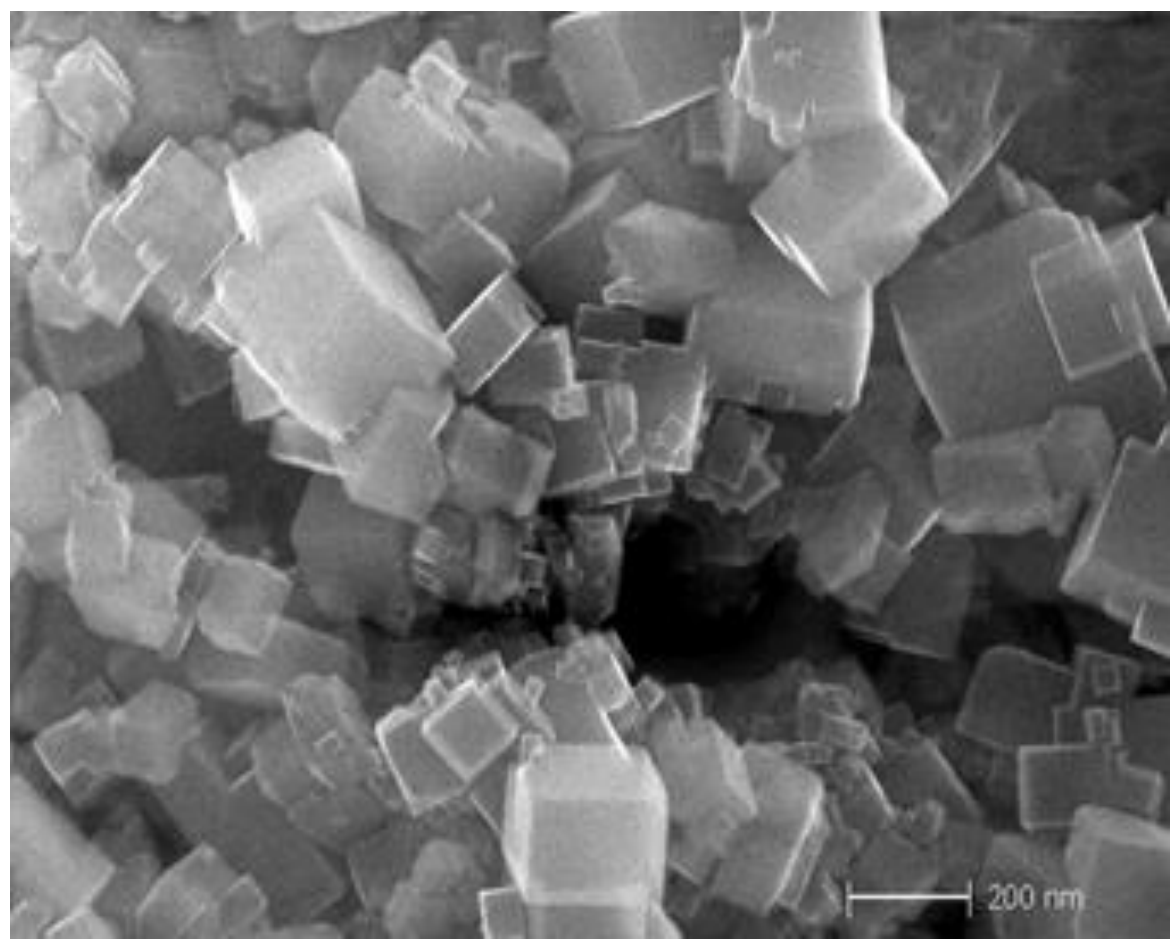

Figure 3.3 SEM image of as prepared PB nanocubes ranging between $20-200 \mathrm{~nm}$

cubic particles ranging between $20 \mathrm{~nm}$ and $200 \mathrm{~nm}$ (Figure 3.3).

All electrochemical measurements of PB cathodes were performed in a three-electrode system as described in the materials and methods. Figure 3.4 shows the cyclic voltammetry (CV) for PB with $\mathrm{Ca}\left(\mathrm{ClO}_{4}\right)_{2}$ in dry $\mathrm{AN}$ with the ferrocene reference added to the electrolyte. For our system, the measured potential offset is $68 \mathrm{mV}$ for $\mathrm{Ag} / \mathrm{Ag}^{+}$, which was then added to all measurements to plot voltages with reference to $\mathrm{Fc} / \mathrm{Fc}^{+}$. The ferrocene redox potential is roughly $2.8 \mathrm{~V}$ against $\mathrm{Ca} / \mathrm{Ca}^{+}$as reported by Lipson et al. [213]. 


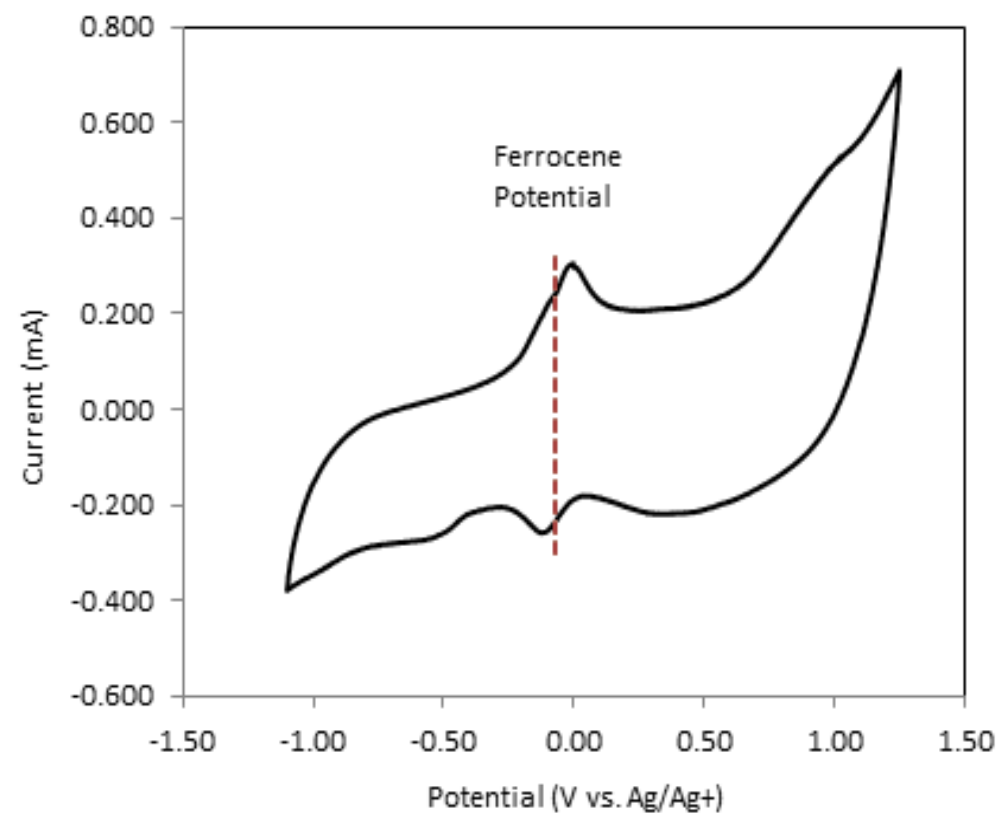

Figure 3.4 $\mathrm{CV}$ for $\mathrm{PB}$ with $\mathrm{Ca}\left(\mathrm{ClO}_{4}\right)_{2}$ in dry $\mathrm{AN}$ with the ferrocene reference added to the electrolyte. The ferrocene redox potential is $-0.068 \mathrm{~V}$ against $\mathrm{Ag} / \mathrm{Ag}^{+}$. To report everything against $\mathrm{Fc} / \mathrm{Fc}^{+}$, all potentials were adjusted by adding $68 \mathrm{mV}$ to each. The ferrocene redox potential was taken to be the half-wave potential of the $\mathrm{Fc} / \mathrm{Fc}^{+}$redox couple $\left(E_{1 / 2}\right)$. $E_{1 / 2}$ was estimated from $E_{1 / 2}=\left(E_{a p}+E_{c p}\right) / 2$, where $E_{a p}$ and $E_{c p}$ are the anodic and cathodic peak potentials, respectively

The nonaqueous potassium electrolyte $\left(\mathrm{KPF}_{6} / \mathrm{dry} \mathrm{AN}\right)$ is used as a benchmark to verify the performance of the PB cathode. Figure 3.5a shows the CV for $\mathrm{PB}$ in the $1 \mathrm{M} \mathrm{KPF}_{6}$ based electrolyte. Two well defined redox pairs are observed at $0.67 \mathrm{~V}$ and $0.44 \mathrm{~V}$, and $0.01 \mathrm{~V}$ and $0.18 \mathrm{~V}$ corresponding to both Fe ions switching oxidation states. An unidentified third anodic peak is observed in the $\mathrm{KPF}_{6}$ electrolyte at $0.24 \mathrm{~V}$ and remains for all subsequent CV tests. A similar peak also occurs when cycling the Ca-ion electrolyte and is reported by others [213]. The origin of the peak needs further exploration. 

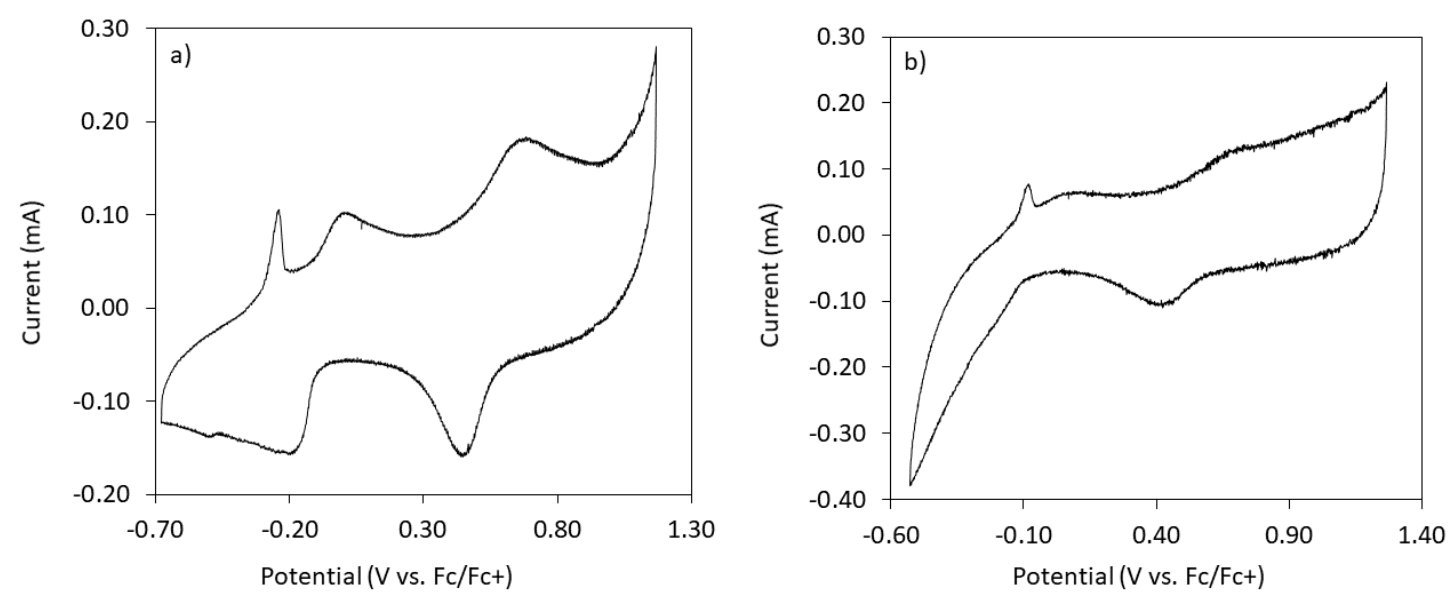

Figure 3.5 (a) $\mathrm{CV}$ of $\mathrm{PB}$ in $1 \mathrm{M} \mathrm{KPF}_{6}$ in acetonitrile at a scan rate of $0.5 \mathrm{mVs}^{-1}$. Cycled between $\left[-0.68 \mathrm{~V}, 1.17 \mathrm{~V}\right.$ ] with respect to $\mathrm{Fc} / \mathrm{Fc}^{+}$. (b) $\mathrm{CV}$ of $\mathrm{PB}$ in $1 \mathrm{M} \mathrm{Ca}\left(\mathrm{ClO}_{4}\right)_{2}$ in dry acetonitrile at a scan rate of $0.5 \mathrm{mVs}^{-1}$. Cycled between $[-0.53 \mathrm{~V}, 1.27 \mathrm{~V}]$ with respect to $\mathrm{Fc} / \mathrm{Fc}^{+}$. Reference electrode for each is $\mathrm{Ag} / \mathrm{Ag}^{+}$in acetonitrile, corrected to $\mathrm{Fc} / \mathrm{Fc}^{+}$ using a ferrocene reference.

The electrochemical properties of PB upon intercalation and deintercalation of $\mathrm{Ca}^{2+}$ were examined using the same cell geometry as for potassium, but with $1 \mathrm{M} \mathrm{Ca}\left(\mathrm{ClO}_{4}\right)_{2}$ in dry AN. The cyclic voltammogram for $\mathrm{Ca}^{2+}$ is shown in Figure 3.5b. Unlike with $\mathrm{K}^{+}$, the redox peaks of PB with Ca-ions are broad and less distinguishable. This is likely a result of higher resistance to intercalation/deintercalation of Ca-ions. The undetermined anodic peak was present again.

To determine if the new anodic peak is due to a reaction with the PB cathode, cyclic voltammetry measurements of a symmetric carbon-carbon cell with $\mathrm{Ca}\left(\mathrm{ClO}_{4}\right)_{2}$ in dry acetonitrile were conducted (Figure 3.6). Despite the absence of any PB, the peak is present. The source of the peak thus does not originate from any reaction with PB, but 


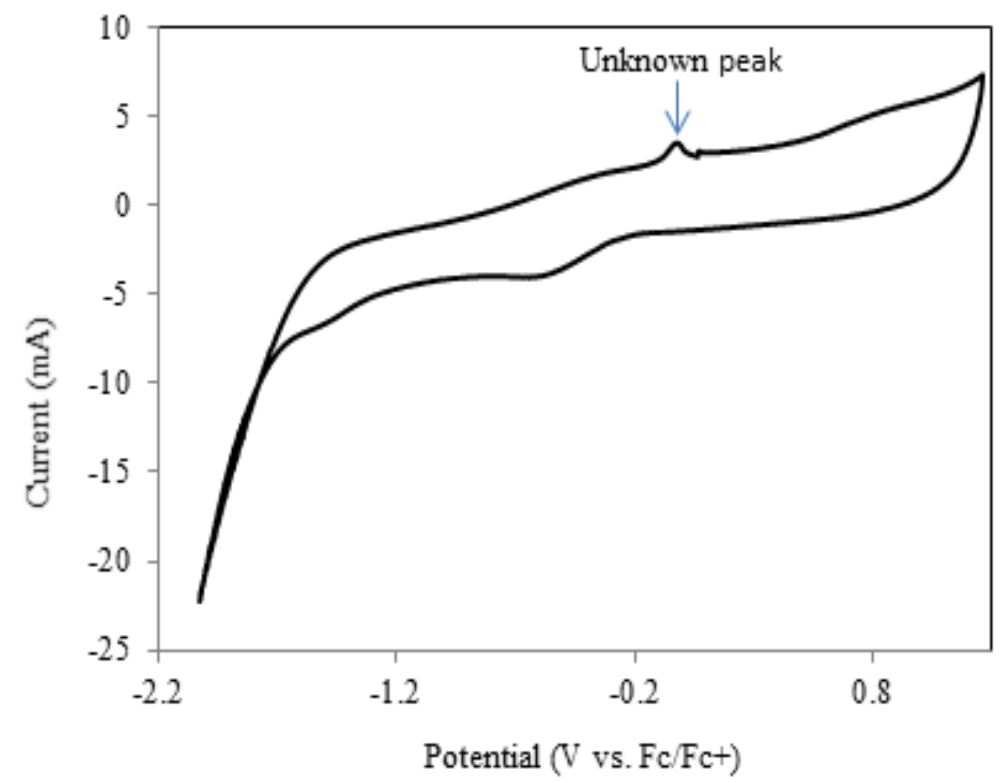

Figure 3.6 CV for carbon-carbon symmetric cell with $\mathrm{Ca}\left(\mathrm{ClO}_{4}\right)_{2}$ in dry $\mathrm{AN}$. Both the anode and the cathode were graphite rods, identical to the anodes used in the PB cells.

could possibly be attributed to formation of a surface electrolyte interphase at the anode, electrolyte decomposition, or an unknown anodic reaction.

PB cathodes were subjected to galvanostatic cycling using both $\mathrm{K}^{+}$and $\mathrm{Ca}^{2+}$ in dry acetonitrile to determine gravimetric capacities and rate capability of the active cathode material. For $\mathrm{K}^{+}$, two separate voltage plateaus are observed during both charging and discharging (Figure 3.7a). Specific gravimetric capacity is determined by taking the amount of time required to reach the upper cut-off potential for charging and lower cutoff potential for discharging, mass of the active cathode material and the applied current. The PB cathode with the $\mathrm{K}^{+}$based electrolyte demonstrates a reversible specific capacity 
of $159 \mathrm{mAhg}^{-1}$ after 10 cycles at a current density of $31 \mathrm{mAg}^{-1}$ (Figure 3.7a) [217]. The current density is determined by taking only the mass of the active material into account. Others have reported similar capacity values for sodium ions, the other highly studied monovalent ion for PBA based cathodes $[47,146,147,218,219]$.

Upon intercalation of $\mathrm{Ca}^{2+}$, a two-step redox process is observed. The plateaus on the galvanostatic graph are less defined and broader than those during charging/discharging with $\mathrm{K}^{+}$(Figure 3.7b). To study the rate capability and durability of $\mathrm{PB}$, current densities of $23 \mathrm{mAg}^{-1}, 45 \mathrm{mAg}^{-1}$, and $90 \mathrm{mAg}^{-1}$ were applied to a single PB cathode. The cell was subjected to 30 cycles at the lowest and middle current densities, and 100 cycles at the highest current density. The specific capacity at the end of the first
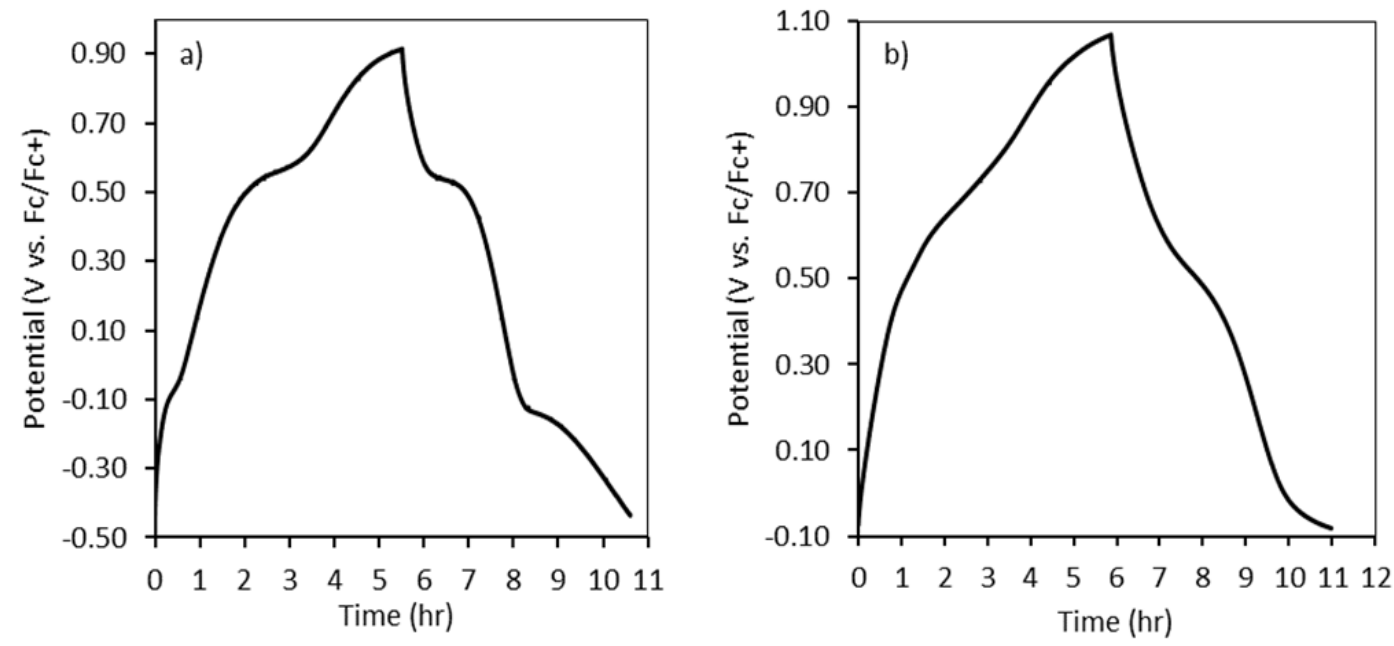

Figure 3.7 (a) Charge-discharge profile of $\mathrm{PB}$ in $1 \mathrm{M} \mathrm{KPF}_{6}$ in acetonitrile at a current density of $31 \mathrm{mAg}^{-1}$. [-.42 V, .917 V] with respect to $\mathrm{Fc} / \mathrm{Fc}^{+}$. (b) Charge-discharge profile of $\mathrm{PB}$ in $1 \mathrm{M} \mathrm{Ca}\left(\mathrm{ClO}_{4}\right)_{2}$ in acetonitrile at a current density of $23 \mathrm{mAg}^{-1}$. [-0.07 V, $1.07 \mathrm{~V}$ ] with respect to $\mathrm{Fc} / \mathrm{Fc}^{+}$. Reference electrode for each is $\mathrm{Ag} / \mathrm{Ag}^{+}$in acetonitrile, corrected to $\mathrm{Fc} / \mathrm{Fc}^{+}$using a ferrocene reference. 


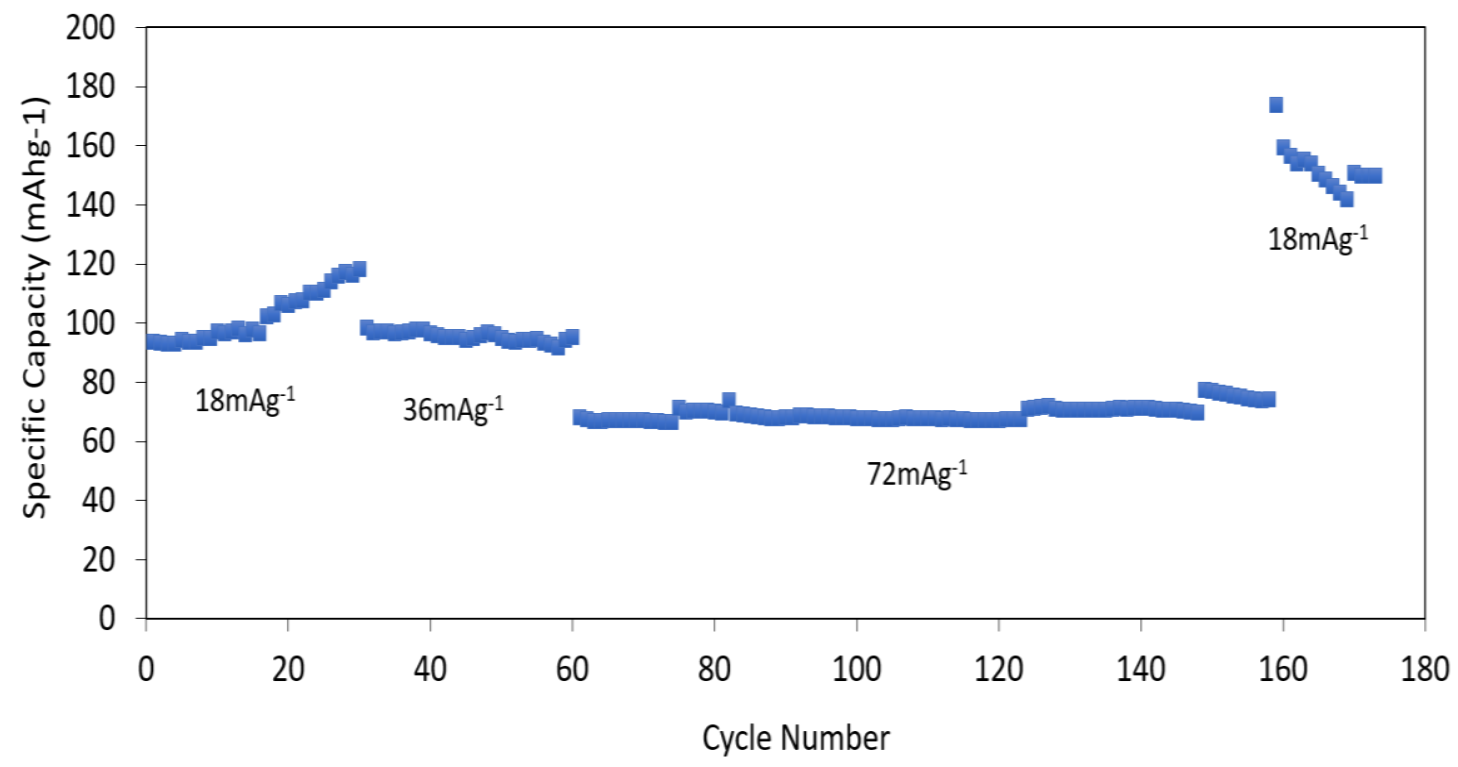

Figure 3.8 Reversible specific capacity vs. the number of charge/discharge cycles with $\mathrm{Ca}^{2+}$ at three different current densities. Cut-off voltages were $-0.07 \mathrm{~V}$ and $1.07 \mathrm{~V}$ with respect to the $\mathrm{Fc} / \mathrm{Fc}^{+}$redox couple.

cycle at $23 \mathrm{mAg}^{-1}$ is $94 \mathrm{mAhg}^{-1}$ and increases to $118 \mathrm{mAhg}^{-1}$ after completing 30 cycles. After the low current density, the cathode displays fairly constant capacity around $95 \mathrm{mAhg}^{-1}$ at the middle current density, and slightly increases from $68 \mathrm{mAhg}^{-1}$ to $74 \mathrm{mAhg}^{-1}$ after 100 cycles at the high current density (Figure 3.8). The cut-off potentials for all three current densities were $[0.07 \mathrm{~V}, 1.07 \mathrm{~V}]$ with respect to $\mathrm{Fc} / \mathrm{Fc}^{+}$. A significant increase in reversible capacity is observed over the first 30 cycles, a trend that has been witnessed before $[47,56]$. The cathode was cycled again at $23 \mathrm{mAg}^{-1}$ after completing the 100 runs at $90 \mathrm{mAg}^{-1}$. Initially the specific capacity is $173 \mathrm{mAhg}^{-1}$, but quickly drops to and stabilizes at a capacity of 150 mAhg $^{-1}$, over 15 cycles. In this work, the charge discharge reaction for $\mathrm{PB}$ with $\mathrm{Ca}^{2+}$ can be expressed as: 


$$
\begin{aligned}
& \mathrm{KFe}^{I I} \mathrm{Fe}^{I I I}(C N)_{6} \rightarrow F e^{I I I} \mathrm{Fe} e^{I I I}(C N)_{6}+K^{+}+e^{-} \\
& \mathrm{KFe}^{I I} \mathrm{Fe}^{I I I}(C N)_{6} \rightarrow F e^{I I I} \mathrm{Fe}^{I I I}(C N)_{6}+K^{+}+e^{-}
\end{aligned}
$$

Equation 3.1 represents the reaction of the first charge cycle and equation 3.2 the reaction for the subsequent discharge and charge cycles. Figure 3.9 shows the first six charge-discharge cycles for $\mathrm{PB}$ in the $1 \mathrm{M} \mathrm{Ca}\left(\mathrm{ClO}_{4}\right)_{2}$ in dry $\mathrm{AN}$ electrolyte. The first charging

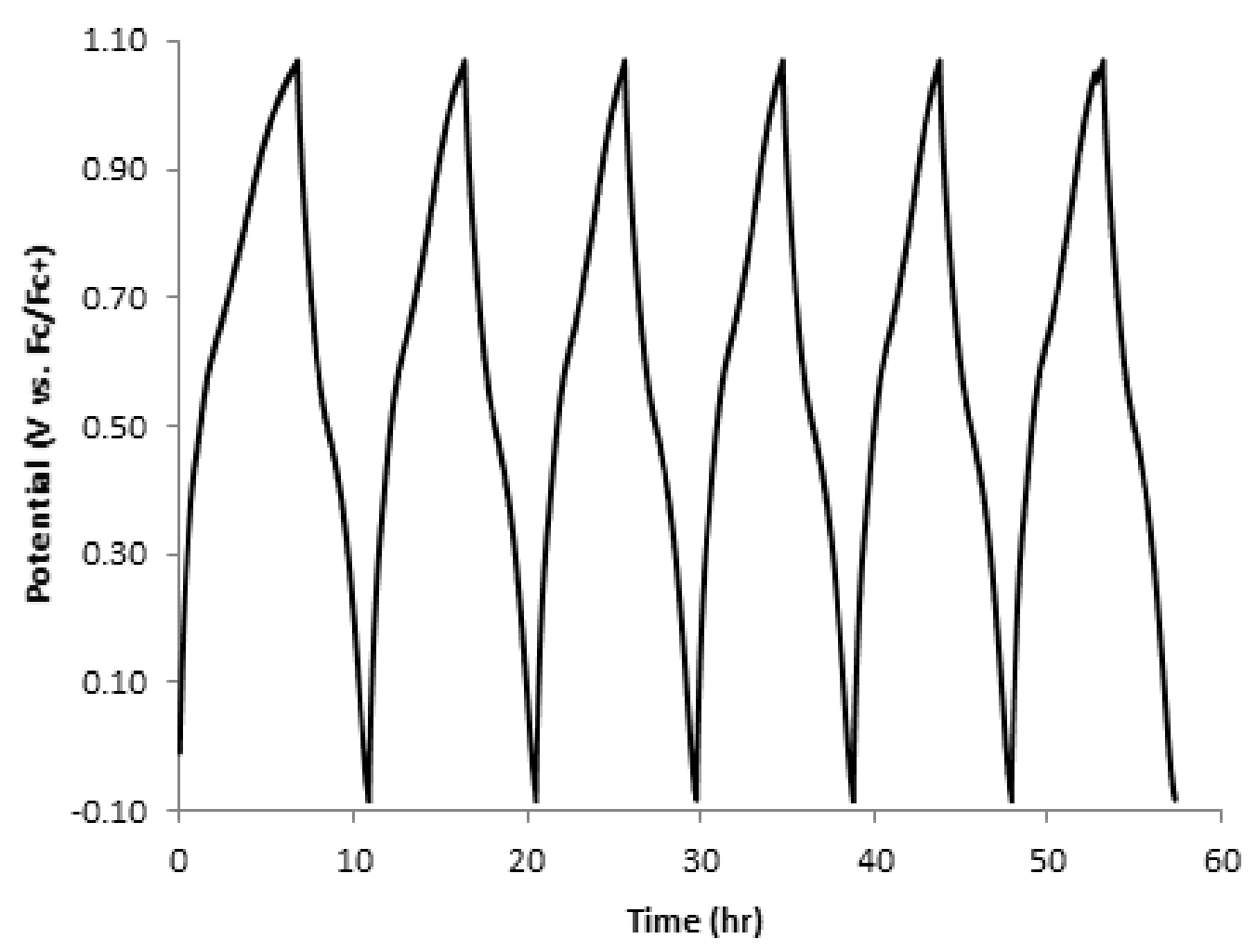

Figure 3.9 First 6 charge-discharge cycles of $\mathrm{PB}$ in $1 \mathrm{M} \mathrm{Ca}\left(\mathrm{ClO}_{4}\right)_{2}$ in acetonitrile at a current density of $23 \mathrm{mAg}^{-1}$. [-0.07 V, $\left.1.07 \mathrm{~V}\right]$ with respect to $\mathrm{Fc} / \mathrm{Fc}^{+}$. Reference electrode for each is $\mathrm{Ag} / \mathrm{Ag}^{+}$in acetonitrile, corrected to $\mathrm{Fc} / \mathrm{Fc}^{+}$using a ferrocene reference. 
cycle has a higher capacity than all subsequent cycles, which can be accounted for $\mathrm{K}^{+}$ leaving the lattice and all following cycles being due to cycling of $\mathrm{Ca}^{2+}$.

EDX spectra of an as synthesized PB electrode, fully charged electrode, and fully discharge electrode were recorded to confirm that the predominant ion intercalating into and out of the PB cathode was Ca (Figure 3.10). The large potassium peak for the as synthesized sample is expected, as potassium is present during synthesis. After cycling,

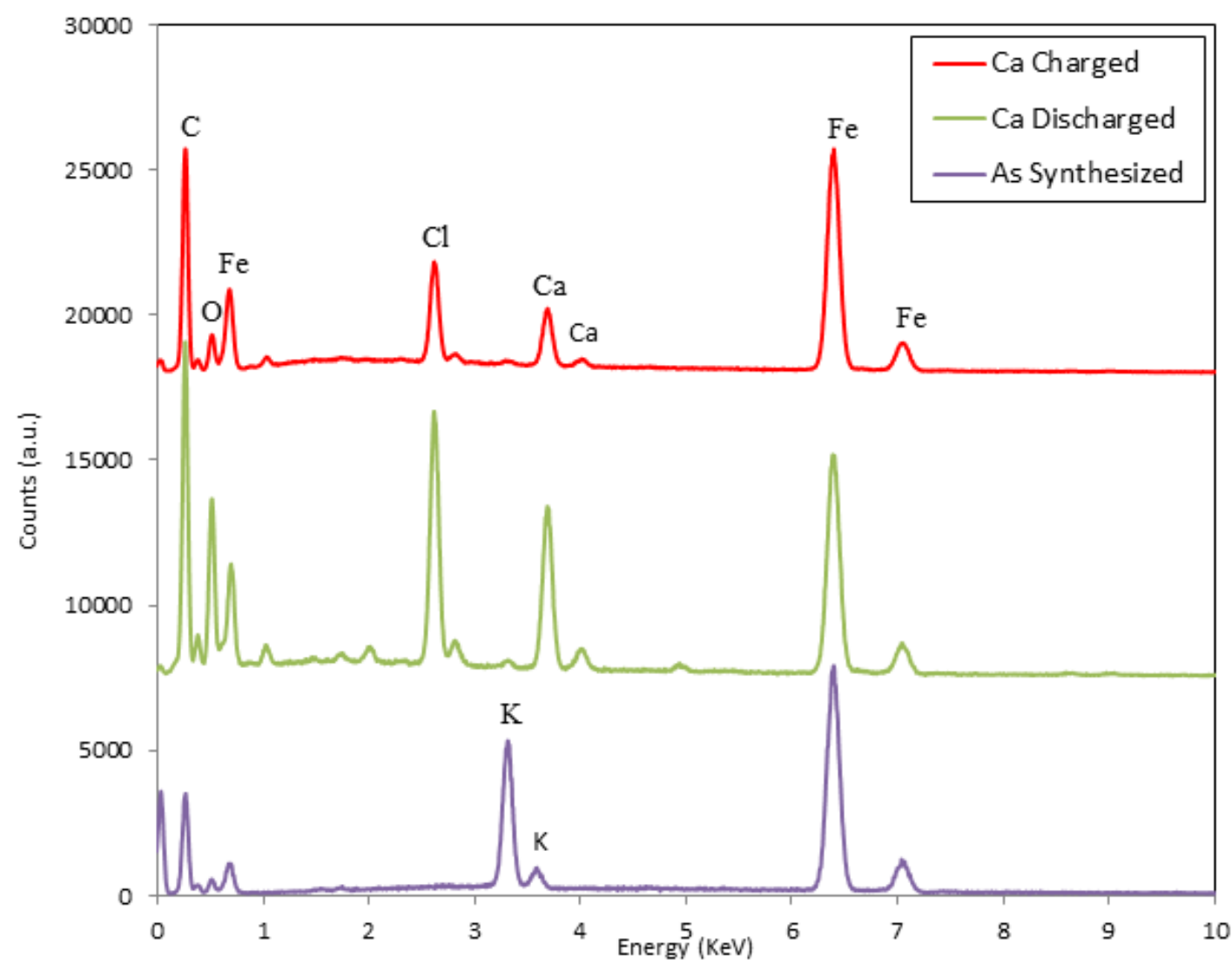

Figure 3.10 EDX spectra of an as synthesized PB electrode, fully charged electrode, and fully discharge. All spectra normalized to the Fe peak intensity for the PB after different stages of charge-discharge cycling. 
when the cathode is fully discharged, a calcium peak emerges while the potassium peak that was present initially is almost entirely gone. This indicates that after the first charge, calcium replaces potassium as the intercalating ion. During charging, the calcium peak decreases, demonstrating that calcium is reversibly intercalate into and out of PB. There is an increase in $\mathrm{Cl}$ and $\mathrm{O}$ in the discharge sample, which could be due to $\mathrm{ClO} 4$ entering the lattice.

Further galvanostatic charge/discharge tests were conducted on a new PB cathode in an identical setup as above, except the upper cut-off potential was increased from $1.07 \mathrm{~V}$ to $1.37 \mathrm{~V}$ with respect to $\mathrm{Fc} / \mathrm{Fc}^{+}$. The specific capacity over 80 charge/discharge cycles at a current density of $125 \mathrm{mAg}^{-1}$ is shown in Figure 3.11. Initially the reversible capacity is $120 \mathrm{mAhg}^{-1}$ and then drops to $103 \mathrm{mAhg}^{-1}$ after 80 cycles. After 40 cycles, the cycling was paused to check the CV profile, and then galvanic cycling was resumed. This accounts for the bump in the profile after 40 cycles. The specific capacities for both $\mathrm{PB}$ with $\mathrm{Ca}^{2+}$ tests are above the $100 \mathrm{mAhg}^{-1}$ theoretical capacity for a single step redox process, but below the theoretical capacity of $200 \mathrm{mAhg}^{-1}$ for a two-step redox reaction. This implies some of the second Fe ions are also switching redox states.

The relatively high reversible capacity of Ca-ion insertion and extraction from a Prussian Blue cathode is somewhat unexpected, given the difficulties that have been experienced with other materials over many years of research. One of the main advantages of PB over other insertion-based cathodes is the size of the lattice opening 


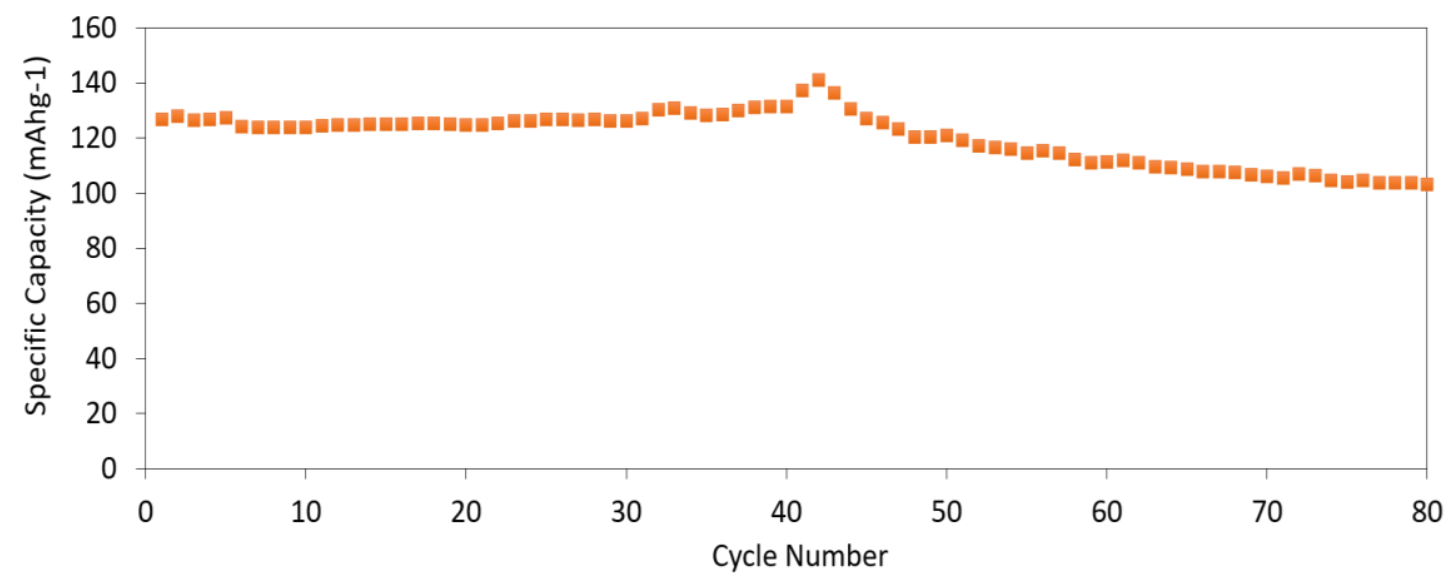

Figure 3.11 Reversible specific capacity vs. the number of charge/discharge with $\mathrm{Ca}^{2+}$ at $125 \mathrm{mAg}^{-1}$. Upper cut-off potential of $1.37 \mathrm{~V} \mathrm{vs}$. $\mathrm{Fc} / \mathrm{Fc}^{+}$.

into which ions intercalate during discharge. For PB cathodes the aperture in the lattice is approximately $0.25 \mathrm{~nm}$ based on the radius of the cyanide ion connecting the $\mathrm{Fe}^{2+}$ and $\mathrm{Fe}^{3+}$ ions in the Prussian Blue lattice (the distance between iron atoms in the lattice is 0.51 $\mathrm{nm}$ based on powder diffraction data). This is larger than most intercalation lattices, and may allow better transport. Since Ca-ions are fairly small (ionic radius $0.114 \mathrm{~nm}$ ) with a double charge, there will be strong electrostatic interactions between the Ca-ions, and the lattice, particularly the nitrogen atom in $\mathrm{CN}$ with its unbonded electron pair. Intercalation of $\mathrm{Ca}^{2+}$ into PB is energetically favorable, and occurs with minimal distortion of the lattice ( $<2 \%$ of the lattice dimension [220]). As shown in Figure 3.5a, the sites can be clearly distinguished by cyclic voltammetry with K-ions, while redox voltages for different sites with Ca-ions are not nearly as easy to distinguish. We interpret this as being due to higher resistance to movement through the lattice for the highly charged Ca-ions. 


\subsection{Conclusion}

We have shown that iron hexacyanoferrate or Prussian blue cathodes can serve as stable host lattices for reversible intercalation of $\mathrm{Ca}^{2+}$ for a potential multivalent, rechargeable battery using a nonaqueous electrolyte. A reversible capacity of $150 \mathrm{mAh}^{-1}$, $75 \%$ of the theoretical capacity for a two-step redox reaction, was achieved for a current density of $23 \mathrm{mAg}^{-1}$ and an upper cut-off potential of $1.07 \mathrm{~V}$ with respect to $\mathrm{Fc} / \mathrm{Fc}^{+}$. By increasing the upper cut-off potential to $1.37 \mathrm{~V}$, a reversible capacity of $120 \mathrm{mAhg}^{-1}$ was achieved at a current density of $125 \mathrm{mAg}^{-1}$. To date, these are the highest capacities reported over an extended number of charge discharge cycles for an intercalation-based Ca-ion battery. This work is still in progress and we expect that further optimization of the cell may lead to improved performance. 


\subsection{Additional Commentary on Published Work}

Kuperman N, Padigi P, Goncher G, Evans D, Thiebes J, Solanki R. High performance Prussian Blue cathode for nonaqueous Ca-ion intercalation battery. Journal of Power Sources 2017;342:414-8. https://doi.org/10.1016/i.jpowsour.2016.12.074. [117]

The results obtained in this study helped to accomplish the goal of developing non-lithium ion based systems utilizing a PBA cathode by demonstrating, for the first time, the suitability of $\mathrm{Ca}^{+2}$ as an electrolytic cation in the battery system consisting of a $\mathrm{Fe}\left[\mathrm{Fe}(\mathrm{CN})_{6}\right]$ cathode and acetonitrile solvent. In fact, with a specific capacity of $150 \mathrm{mAhg}^{-1}$, the PB cathode described in this work delivered the highest reported specific capacity for any calcium ion battery utilizing a PBA electrode. Divalent calcium ion batteries are of particular interest due to calcium's low cost, relative abundance (fifth most abundant element in the Earth's crust), and ability to offer double the energy density, per intercalated ion, compared to lithium ion batteries. By employing a nonaqueous chemistry, this work offers a proof of concept to future studies aimed at developing a CIB with a calcium metal anode. 


\section{Chapter 4.}

Manganese-Cobalt Hexacyanoferrate as a Cathode Material for Aqueous Zinc ion Batteries

\section{Presentation of Published Work}

Kuperman N, Hopkins M, Olson S, Goncher G, Evans D, Solanki R. Cathode Material Composed of Manganese Cobalt Hexacyanoferrate Nanoparticles for Aqueous Zinc Ion Intercalation Batteries. 2018 IEEE 13th Nanotechnology Materials and Devices Conference (NMDC), 2018, p. 1-4. https://doi.org/10.1109/NMDC.2018.8605900. [221]

\subsection{Abstract}

To accommodate the global shift towards increased energy production from renewable sources, further advancements in storage technology are needed to mitigate the intermittent nature of wind and solar. Aqueous zinc ion intercalation batteries (ZIBS) offer an inexpensive and safe alternative to the traditional lithium ion battery (LIB), making them a prime candidate for large scale storage. Metal hexacyanoferrates have been shown to be suitable cathode materials for ZIBs, allowing for the reversible insertion/extraction of the doubly charged zinc ion. In this work, we report on the performance of a cathode material composed of mixed manganese-cobalt 
hexacyanoferrate nanoparticles for a rechargeable ZIB. The cathode exhibits a reversible capacity of $111 \mathrm{mAhg}^{-1}$ at $25 \mathrm{mAg}^{-1}$ and good capacity retention after extended cycling at $100 \mathrm{mAg}^{-1}$. X-ray diffraction and SEM imaging reveal nanoparticles with a rhombohedral structure and sizes on the order of $20-60 \mathrm{~nm}$. The combination of the nontoxic hexacyanoferrate cathode, with the aqueous zinc ion electrolyte offers a promising system for large scale energy storage.

\subsection{Introduction}

In recent years, greenhouse gas emissions and global warming have become issues at the forefront of the global awareness. In 2015, the U.S. alone generated 567 terawatt hours of electricity from renewable energy sources, a $16.7 \%$ growth from the previous year [222]. This shift was mirrored worldwide as $19.3 \%$ of the global final energy consumption was provided by renewable energy [223]. However, the two main sources of renewables, solar and wind, are limited by their intermittent nature. To make these technologies viable on a large scale, novel energy storage technology is needed.

Lithium ion batteries (LIBs) have been an industry standard for energy storage due to their high gravimetric capacity, energy density, Coulombic efficiency, and long cycle lifetime. Despite their successes, the rising cost of lithium metal, as well as the toxicity and flammability of the batteries, reduce their applicability in grid scale energy storage. Aqueous zinc-ion batteries (ZIBs) are safe and nontoxic, while zinc metal and zinc salts are abundant and inexpensive, making ZIBs a potential alternative to LIBs. However, only a 
limited number of materials have been shown to reversibly intercalate zinc ions, including: $\mathrm{MnO}$ [224,225], $\mathrm{MnS}[226], \mathrm{V}_{2} \mathrm{O}_{5}[227,228]$, and Prussian blue analogues $[119,229]$.

Prussian blue (PB) and its analogues (PBAs) are mixed valence compounds with open framework structures that can accommodate a wide variety of intercalating species in the interstitial spacing $[230,231]$. They possess the general formula $A_{x} M_{1}\left[M_{2}(C N)_{6}\right]_{y} \bullet 1-y \bullet H_{2} O$ (where $A$ is an alkali cation; $M_{1}$ is the $n$-coordinated transition metal; $\left[\mathrm{M}_{2}(\mathrm{CN})_{6}\right]$ is the hexacyanometallate anion; and is a $\mathrm{M}_{2}(\mathrm{CN})_{6}$ vacancy; $0<x<2 ; 0<y<1$ ). Both transition metals can be electrochemically active in this structure, giving PBAs a high theoretical capacity $\left(171 \mathrm{mAhg}^{-1}\right.$ for Prussian blue, $\left.\mathrm{Fe}\left[\mathrm{Fe}(\mathrm{CN})_{6}\right]\right)$.

In this work, we investigate hybrid manganese-cobalt hexacyanoferrate nanoparticles and their application to aqueous zinc ion batteries. The material displays reversible zinc intercalation and delivers specific capacities of $111 \mathrm{mAhg}^{-1}$ at $25 \mathrm{mAg}^{-1}$ and $75 \mathrm{mAhg}^{-1}$ at $100 \mathrm{mAg}^{-1}$. The incorporation of manganese into the cobalt hexacyanoferrate lattice is shown to lead to improved energy storage properties.

\subsection{Experimental}

Manganese hexacyanoferrate was synthesized using the coprecipitation method described in our previous publications with slight adjustments [65,231]. An $80 \mathrm{~mL}$ aqueous solution of $\mathrm{MnCl}_{2}(40 \mathrm{mM})$, and an $80 \mathrm{~mL}$ aqueous solution of $\mathrm{K}_{4} \mathrm{Fe}(\mathrm{CN})_{6}(20 \mathrm{mM})$ 
were slowly added simultaneously and dropwise into $40 \mathrm{~mL} \mathrm{NaCl}(5 \mathrm{M}$ aq) under constant stirring and at $60^{\circ} \mathrm{C}$. The solution was stirred for two hours and the resulting precipitate was collected and washed via centrifugation with DI water and ethanol, and dried in air overnight. Once dry, the precipitate was loaded into a tube furnace and annealed under vacuum overnight at $150{ }^{\circ} \mathrm{C}$. The Annealing process has been shown to reduce interstitial water, and lead to superior electrochemical and battery performance [47].

The same procedure was followed to synthesize cobalt hexacyanoferrate and manganese-cobalt hexacyanoferrate except that $40(1-\mathrm{x}) \mathrm{mM} \mathrm{MnCl}_{2}$ and $40 \mathrm{xmM} \mathrm{moCl}_{2}$ (where $x=0.50,1.0$ ) were dissolved in a common $80 \mathrm{~mL}$ aqueous solution. The resulting materials are denoted as MnHCF, MnCoHCF0.50, and CoHCF for manganese hexacyanoferrate, manganese-cobalt hexacyanoferrate, and cobalt hexacyanoferrate, respectively.

The crystal structures of the synthesized materials were characterized using powder X-ray diffraction (XRD) performed on a Rigaku Ultima IV X-ray diffractometer with Cu K $\alpha$ radiation $(\lambda=1.54056 \AA$ ). Indexing and refinement of the structures were conducted using the Fullprof crystallographic suite [215]. Morphology and chemical composition of the nanoparticles were examined by a scanning electron microscope (SEM) and energy dispersive x-ray spectroscopy (EDS) using a Zeiss Sigma VP.

Battery cathodes were prepared by combining an annealed powder with polyvinylidene fluoride (PVDF) that served as a binder, and multi-walled carbon 
nanotubes and activated carbon as conductivity enhancers in the ratio of 80:9:9:2, respectively by weight. The combined mixture was ground using a mortar and pestle until a fine power was achieved, after which N-methyl-2-pyrolidone (NMP) was added drop by drop until a paste with paint-like consistency was formed. The electrode paste was applied to both sides of a carbon paper current collector, dried for two hours at $150{ }^{\circ} \mathrm{C}$ under vacuum, and let to cool slowly overnight while still under vacuum.

The redox potentials and electrochemical properties of the metal hexacyanoferrate cathodes were characterized using cyclic voltammetry (CV) and galvanic cycling (GC) in a three-electrode setup. Cells were assembled with a graphite rod counter electrode, $\mathrm{Ag} / \mathrm{AgCl}$ (in $3 \mathrm{M} \mathrm{NaCl}$ ) reference electrode, metal hexacyanoferrate working electrode, and $1 \mathrm{M} \mathrm{Zn}\left(\mathrm{ClO}_{4}\right)_{2}$ aqueous electrolyte.

\subsection{Results and Discussions}

\subsubsection{Structural Characterization}

The XRD pattern for each material reveals structures that differ from the wellknown face-centered cubic lattice of Prussian blue (Figure 4.1a). CoHCF and MnCoHCF0.50 both index to rhombohedral lattices with space group in good agreement with other CoHCF samples synthesized in an ion rich environment $[150,153]$. The incorporation of $\mathrm{Mn}$ into the CoHCF framework results in a decreasing refraction angle for the $<202>$ and $<404>$ peaks (Figure 4.1b). This corresponds to an increasing lattice parameter, attributed to the substitution of the smaller octahedrally coordinated, high 

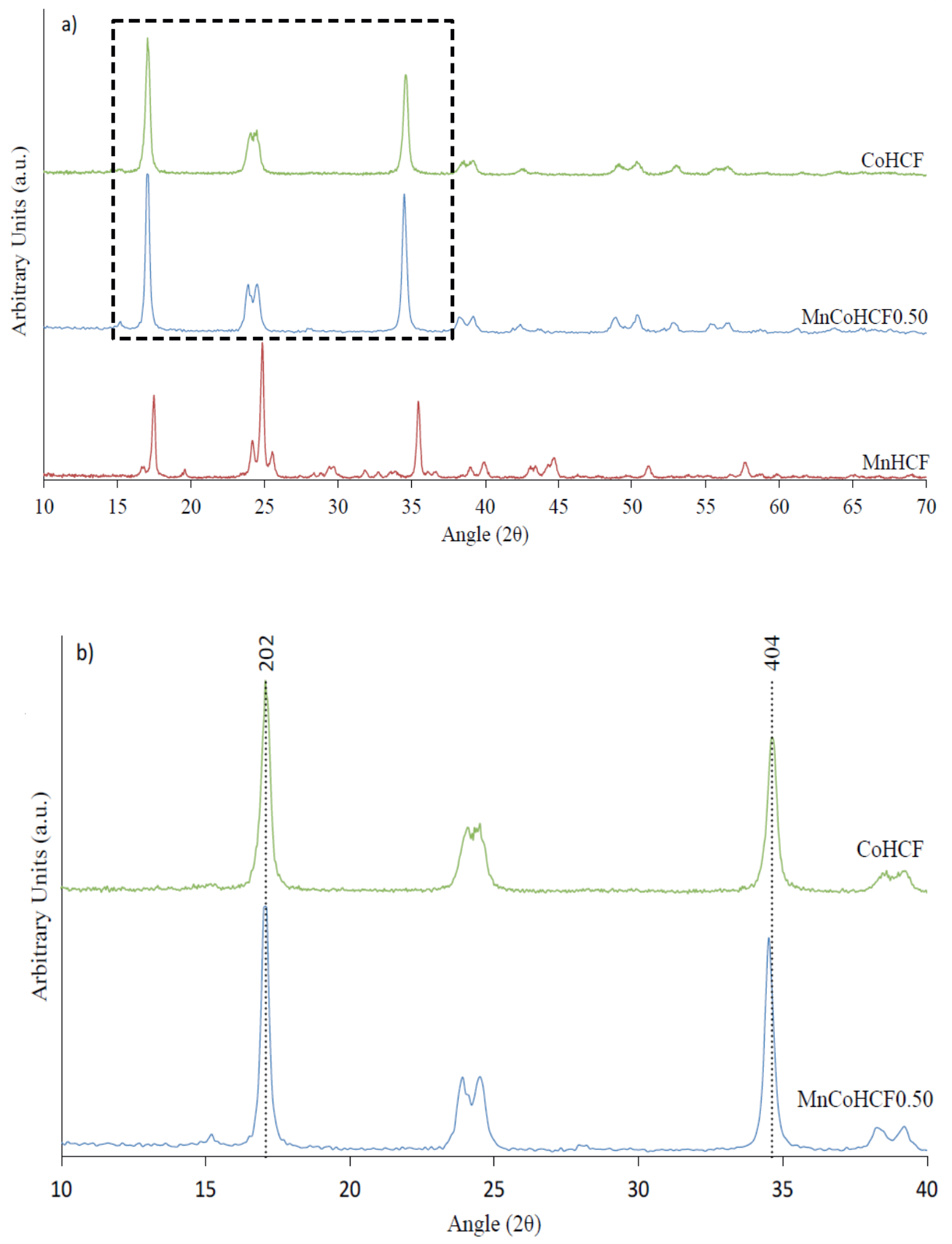

Figure 4.1 (a) XRD pattern of CoHCF, MnCoHCF0.50 and MnHCF (b) Highlighted shift in the 202 and 404 peaks for MnCoHCF0.50 
spin $\mathrm{Co}^{2+}(88.5 \mathrm{pm})$ with the large octahedrally coordinated, high spin $\mathrm{Mn}^{2+}(97 \mathrm{pm})$ $[150,232]$. Additionally, the indexing to a single rhombohedral phase for MnCoHCF0.50 indicates incorporation of both $\mathrm{Mn}$ and $\mathrm{Co}$ into the lattice instead of the formation of CoHCF and MnHCF individually. MnHCF crystallized in a monoclinic geometry, differing from the commonly reported hexagonal or cubic phases $[150,233]$. A monoclinic structure has been observed for MnHCF synthesized at an elevated temperature [234]. Cell parameters for each material, along with their respective space group, are provided in Table 4.1.

Table 4.1 Lattice parameters and space group assignment for each sample

\begin{tabular}{|c|c|c|c|c|c|c|c|c|}
\hline Material & Structure & $\begin{array}{l}\text { Space } \\
\text { Group }\end{array}$ & a & b & c & $\alpha$ & $\beta$ & $\boldsymbol{V}$ \\
\hline $\mathrm{CoHCF}$ & Hexagonal & $\mathrm{R} \overline{3} \mathrm{~m}$ & 10.502 & 10.502 & 10.114 & 90 & 90 & 90 \\
\hline MnCoHCF0.50 & Hexagonal & $\mathrm{R} \overline{3} \mathrm{~m}$ & 10.546 & 10.546 & 10.546 & 90 & 90 & 90 \\
\hline $\mathrm{MnHCF}$ & Monoclinic & $\frac{\mathrm{P} 2}{\mathrm{~m}}$ & 18.896 & 5.528 & 18.156 & 90 & 94.42 & 90 \\
\hline
\end{tabular}




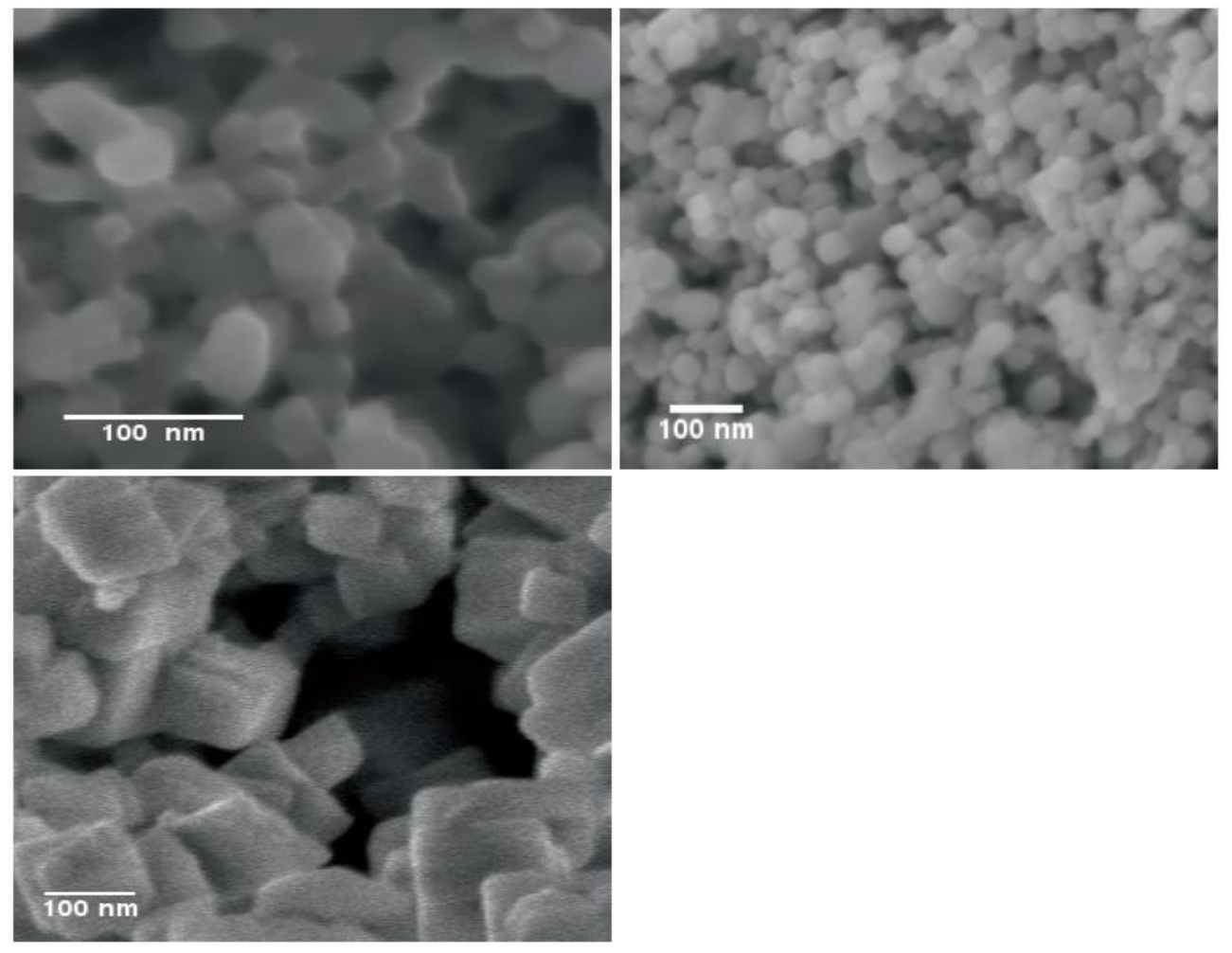

Figure 4.2 SEM images of (a) CoHCF (b) MnCoHCF0.50 (c) MnHCF

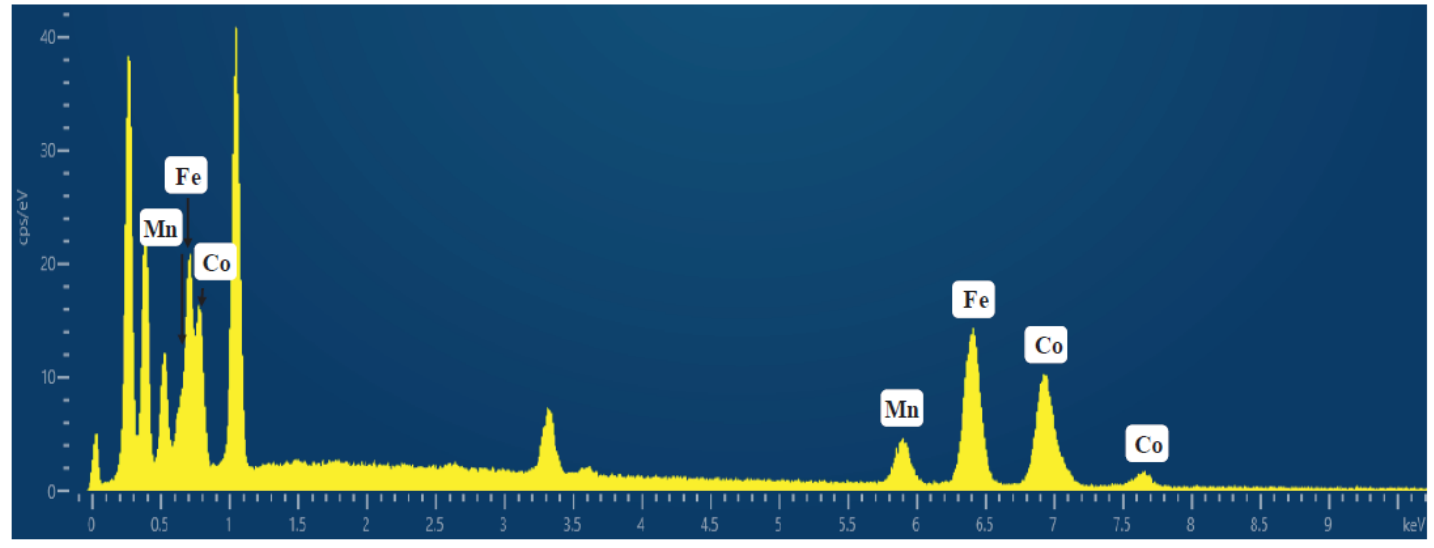

Figure 4.3 EDS spectra for MnCoHCF0.50 
SEM imaging for the CoHCF and MnCoHCF0.50 revealed nanoparticles on the order of $20-60 \mathrm{~nm}$, aggregated in larger agglomerations, while MnHCF formed nanocubes on the order of $20-100 \mathrm{~nm}$ (Figure 4.2a - c). The small size of the nanoparticles offers shorter diffusion pathways for $\mathrm{Zn}$ ions to intercalate into the bulk of the material. The EDS spectra MnCoHCF0.50 verifies the presence of $\mathrm{Mn}$ in the sample (Figure 4.3).

\subsubsection{Electrochemical Characterization}

The electrochemical redox properties of the three metal hexacyanoferrates were examined by cyclic voltammetry (scan rate of $0.5 \mathrm{mV} / \mathrm{s}$ ) that revealed reversible $\mathrm{Zn}$ intercalation within the water voltage window for CoHCF and MnCoHCF0.50 (Figure 4.4). In Figure 4.4a, one major oxidation peak at $0.81 \mathrm{~V}$, and two shoulder peaks at $0.76 \mathrm{~V}$ and $0.88 \mathrm{~V}$, and three distinct reduction peaks at $0.59 \mathrm{~V}, 0.67 \mathrm{~V}$, and $0.78 \mathrm{~V}$ for CoHCF, demonstrate the presence of multiple insertion/extraction reactions. Complex redox reactions, including the $\mathrm{Co}^{2+} / \mathrm{Co}^{3+}$ switch, have been reported with a range of intercalating ions $[87,235]$. This is in contrast to $\mathrm{CoHCF}$ and $\mathrm{Na}^{+}$where a single broad redox peak, attributed to the $\mathrm{Fe}^{2+} / \mathrm{Fe}^{3+}$ switch, is observed [236]. MnCoHCF0.50 exhibited three, well defined, oxidation peaks at $0.75 \mathrm{~V}, 0.81 \mathrm{~V}$, and $0.90 \mathrm{~V}$, and corresponding reduction peaks at $0.59 \mathrm{~V}, 0.66 \mathrm{~V}$, and $0.76 \mathrm{~V}$ with peak currents slightly larger than its CoHCF counterpart. Unlike the other two materials, MnHCF displayed irreversible electrochemical behavior in the aqueous $\mathrm{Zn}$ environment. The unstable nature of MnHCF in aqueous electrolytes has been previously reported $[179,192]$. 

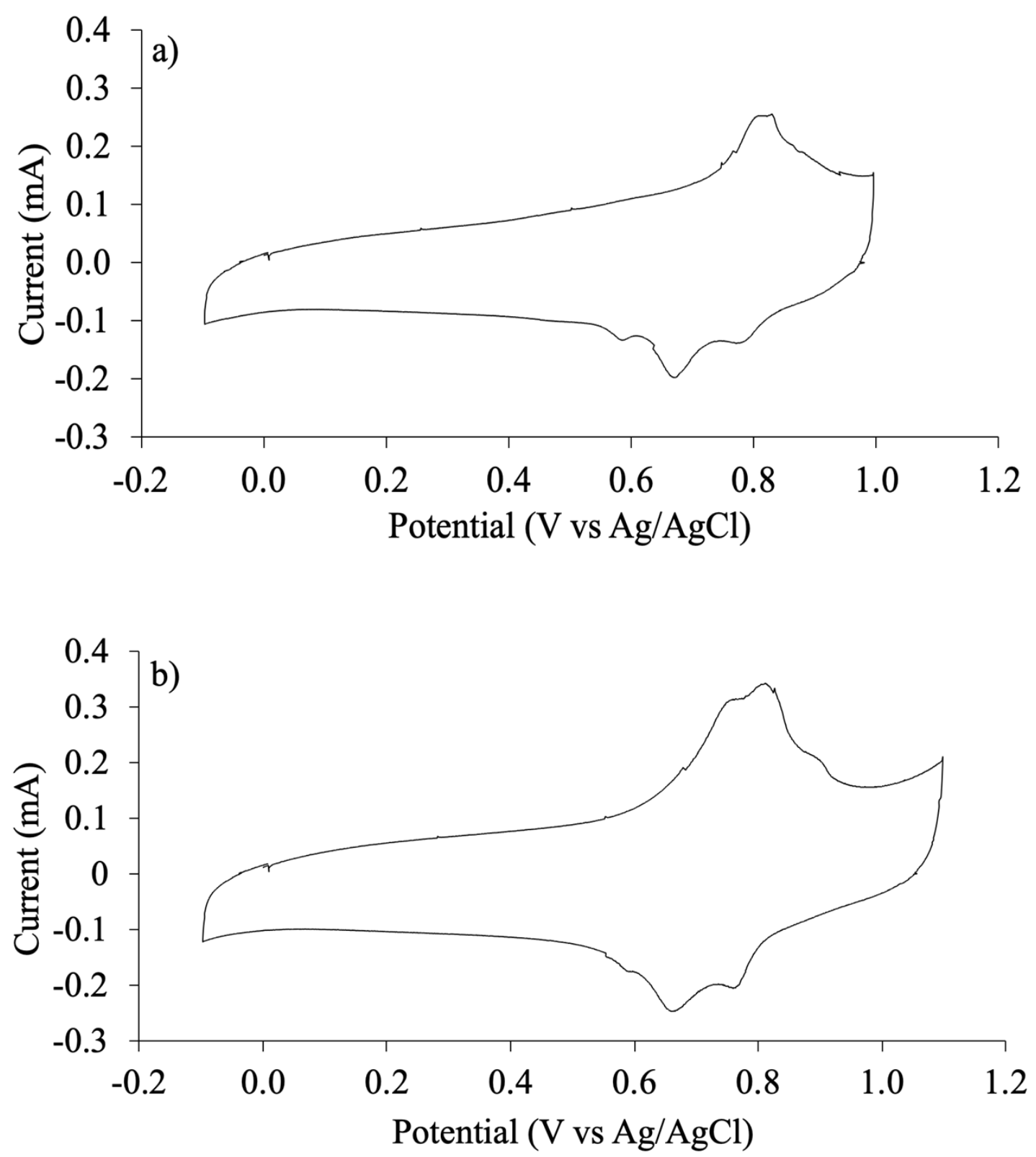

Figure 4.4. $\quad \mathrm{CV}$ profile at $25 \mathrm{mV} / \mathrm{s}$ (a) CoHCF (b) MnCoHCF0.50

Galvanic cycling (GC) was performed on MnCoHCF0.50 to further investigate the material's energy storage properties. The charge and discharge capacities of CoHCF were 
taken as baselines to better understand the impact of incorporating $\mathrm{Mn}$ into the hexacyanoferrate lattice. Figure $4.5 \mathrm{a}$ shows the GC potential profiles of CoHCF and MnCoHCF0.50 at a current density of $25 \mathrm{mAg}^{-1}$ cycled between 0.0 and $1.0 \mathrm{~V} \mathrm{vs} \mathrm{Ag} / \mathrm{AgCl}$. The plateau between $0.64 \mathrm{~V}$ and $0.9 \mathrm{~V}$ is an indication of bulk intercalation of $\mathrm{Zn}$ ions and corresponds well with the redox potentials revealed in the CV measurements. The galvanic profiles for CoHCF and MnCoHCF0.50 mirror one another, however the discharge capacity for MnCoHCF0.50 after the first cycle (111 mAhg-1) exceeds that of CoHCF $\left(82 \mathrm{mAhg}^{-1}\right)$, demonstrating the positive effect of $\mathrm{Mn}$ incorporation. The semiquantitative chemical compositional data gathered from EDS measurements suggest Co exists in a much greater quantity than Mn in MnCoHCF0.50; However, small levels of a third metal atom incorporated into the Prussian blue lattice have shown to improve the structural, electrochemical, and energy storage properties of the material [172].

Extended cycling at various current densities demonstrates the improved rate capability and high capacity retention of MnCoHCF0.50 compared to CoHCF. Figure 4.5 shows the specific capacity and coulombic efficiency at $25 \mathrm{mAg}^{-1}, 100 \mathrm{mAg}^{-1}$, and $25 \mathrm{mAg}^{-1}$ again, over an extended number of cycles. The MnCoHCF0.50 cathode delivers a discharge capacity of $111 \mathrm{mAhg}^{-1}$ with a coulombic efficiency of 92\%, whereas CoHCF delivers $82 \mathrm{mAhg}^{-1}$ with an efficiency of $92 \%$. After 15 cycles, both MnCoHCF0.50 and CoHCF see a decay in capacity (91 mAhg ${ }^{-1}$ and $75 \mathrm{mAhg}^{-1}$ respectively) while both of the coulombic efficiencies approach $100 \%$. After 100 cycles at $100 \mathrm{mAg}^{-1} \mathrm{MnCoHCF0.50}$ exhibits good rate capability and retention, delivering a specific capacity of $75 \mathrm{mAhg}^{-1}$, 
a)

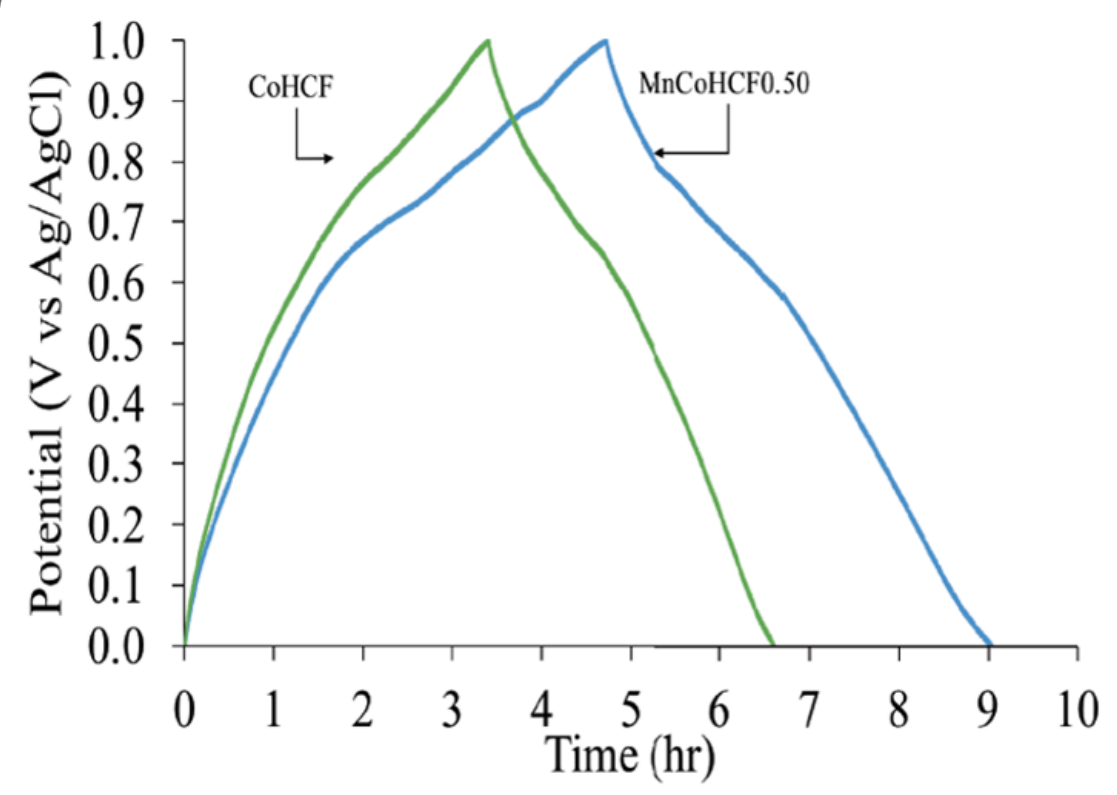

b)

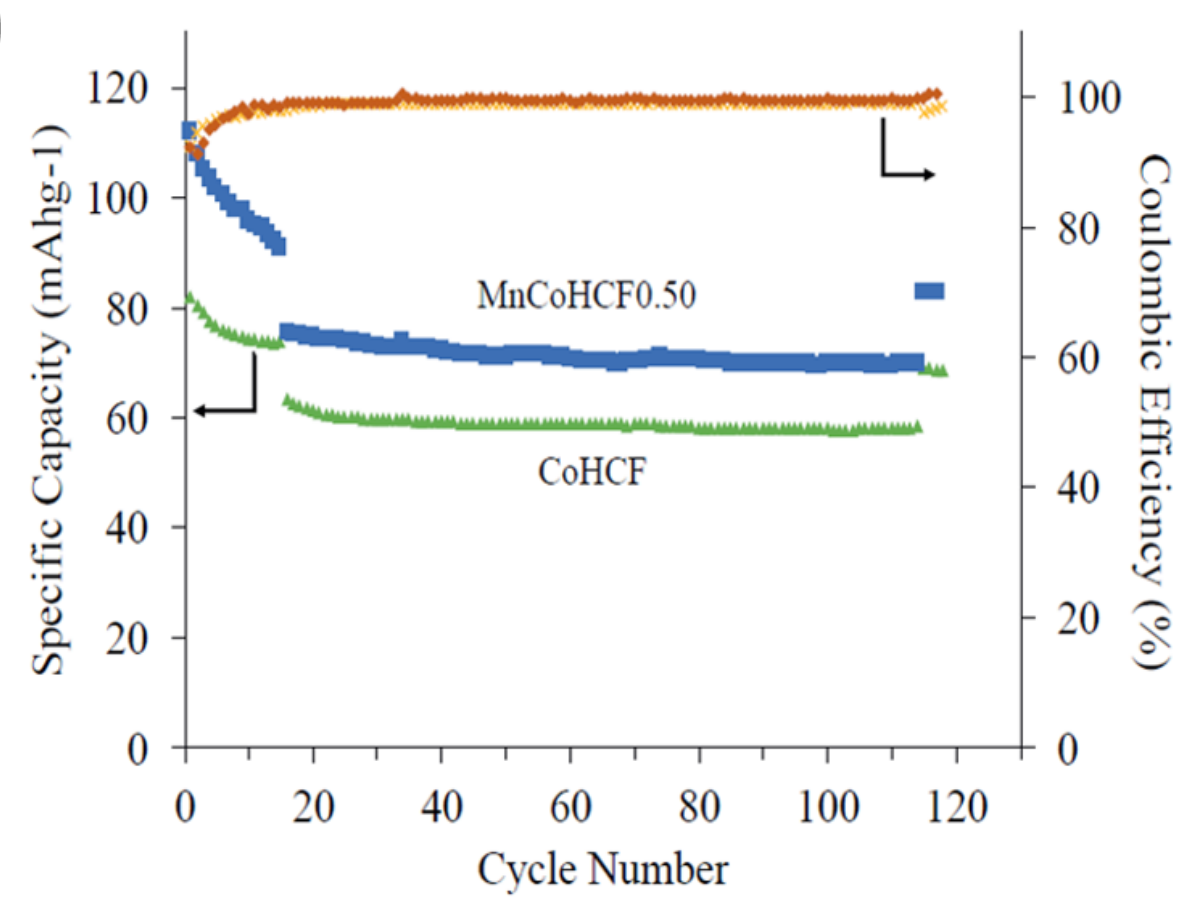

Figure 4.5 (a) 1st Galvanic Charge Discharge cycles for CoHCF and MnCoHCF0.50 (25 mA/g) (b) Specific capacity vs cycle life 
while retaining $93 \%$ of its initial capacity over 100 cycles. CoHCF shows similar capacity retention, however the delivered specific capacity is lower $\left(62 \mathrm{mAhg}^{-1}\right)$. Further confirming the stability of each material, MnCoHCF recovered $75 \%$ of its initial capacity after returning to $25 \mathrm{mAg}^{-1}$, while CoHCF delivered $93 \%$ of the starting capacity.

\subsubsection{Conclusion}

In this work, MnCoHCF0.50 was successfully synthesized. XRD analysis of MnCoHCF0.50 coupled with EDS measurements confirmed a single phase with uniform distribution of $\mathrm{Mn}$ and Co throughout. A complex insertion/extraction process was highlighted by three distinct oxidation and reduction potentials. An increase in specific capacity was achieved by the addition of $\mathrm{Mn}$ to the CoHCF lattice, resulting in a $29 \mathrm{mAhg}^{-1}$ increase when cycled at $25 \mathrm{mAg}^{-1}$. The capacity retention at an elevated current density of MnCoHCF0.50 ( $93 \%$ retention over 100 cycles at $\left.100 \mathrm{mAg}^{-1}\right)$ indicated that the material could be a promising candidate for aqueous zinc ion batteries. 


\subsection{Additional Commentary on Published Work}

Kuperman N, Hopkins M, Olson S, Goncher G, Evans D, Solanki R. Cathode Material Composed of Manganese Cobalt Hexacyanoferrate Nanoparticles for Aqueous Zinc Ion Intercalation Batteries. 2018 IEEE 13th Nanotechnology Materials and Devices Conference (NMDC), 2018, p. 1-4. https://doi.org/10.1109/NMDC.2018.8605900. [221]

The studies presented in this chapter were undertaken to:

1. Develop non-lithium ion based systems utilizing PBA cathodes, with a particular focus on divalent ion systems.

2. Determine if the electrochemical storage properties of pure cobalt hexacyanoferrate and pure manganese hexacyanoferrates could be improved by incorporating both Co and $\mathrm{Mn}$ into the same lattice.

The results obtained in this study helped to accomplish these goals by demonstrating:

1. For the first time, the successful use of $\mathrm{Zn}^{+2}$ with $\mathrm{Co}\left[\mathrm{Fe}(\mathrm{CN})_{6}\right]$ and $\mathrm{MnCo}\left[\mathrm{Fe}(\mathrm{CN})_{6}\right]$ cathodes in an aqueous solvent, and

2. Synergistic properties of $\mathrm{Mn}$ and $\mathrm{Co}$ in the mixed metal hexacyanoferrate $\mathrm{MnCo}\left[\mathrm{Fe}(\mathrm{CN})_{6}\right]$ 
The incorporation of Mn into a CoHCF lattice, producing MnCoHCF0.50, resulted in a $21 \%$ increase in reversible specific capacity in the aqueous electrolyte. Furthermore, Co stabilized the $\mathrm{Mn}-\mathrm{N} \equiv \mathrm{C}-\mathrm{Fe}$ chain and prevented dissolution into an aqueous electrolyte. However, a negative effect on electrochemical properties was observed, which was an increased capacity loss for MnCoHCF0.50 compared to CoHCF, $18 \%$ vs. $9 \%$ respectively, after the first 15 charge-discharge cycles. Two reasons zinc ion batteries of interest are their high theoretical energy densities due to $\mathrm{Zn}$ being divalent, and the ability to use zinc metal with aqueous chemistries. Aqueous systems have high safety profiles and low environmental impact, compared to nonaqueous systems. 


\section{Chapter 5.}

Copper Hexacyanoferrate as a cathode material for magnesium ion batteries.

\subsection{Prelude}

The original goal of this study was to investigate manganese-copper hexacyanoferrate (MnCuHCF) as a cathode material for magnesium ion batteries. However, XRD revealed $\mathrm{Mn}$ and $\mathrm{Cu}$ formed a multi-phase product when synthesized by coprecipitation in $5 \mathrm{M} \mathrm{NaCl}$ at $60^{\circ} \mathrm{C}$ (Figure 5.1).

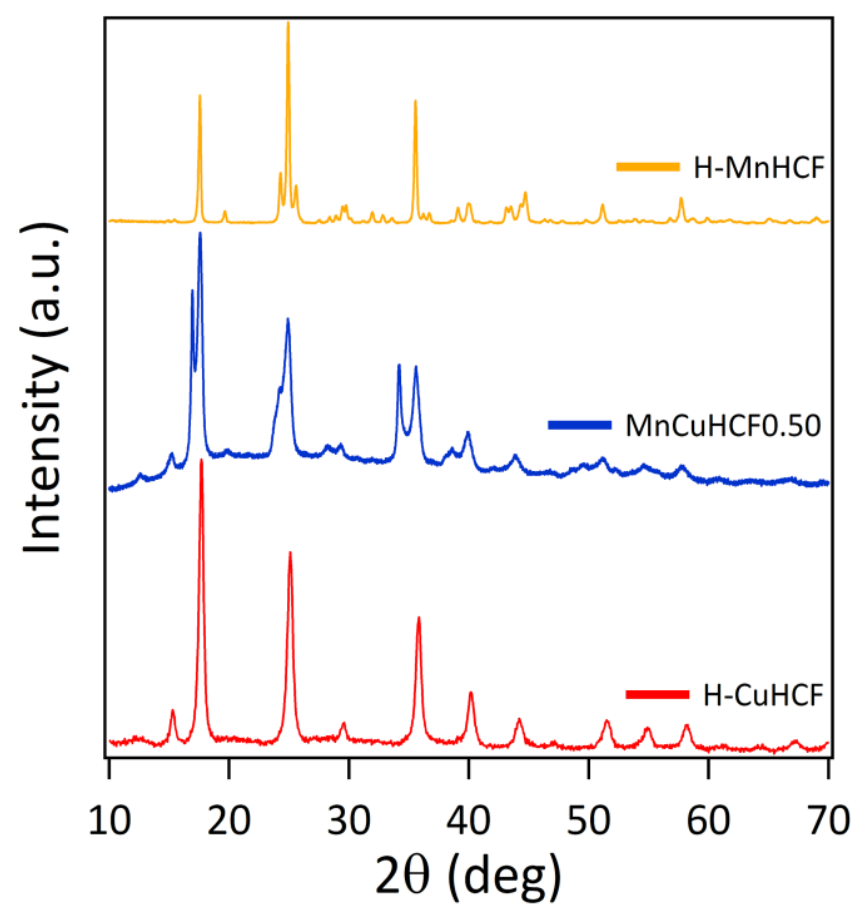

Figure 5.1 XRD profiles for the hydrated samples of copper hexacyanoferrate (CuHCF), manganese-copper hexacyanoferrate (MnCuHF0.50), and manganese hexacyanoferrate (MnHCF) 
After completing the study on copper hexacyanoferrate cathode for magnesium ion batteries, two novel hydrothermal synthesis methods were developed that produced single phased $\mathrm{Na}_{2} \mathrm{Mn}_{0.50} \mathrm{Cu}_{0.50}\left[\mathrm{Fe}(\mathrm{CN})_{6}\right]$, denoted as MnCuHCF0.50. In a typical synthesis $20 \mathrm{mM}$ of $\mathrm{CuCl}_{2} \cdot 2 \mathrm{H}_{2} \mathrm{O}$ and $20 \mathrm{mM}$ of $\mathrm{MnCl}_{2} \cdot 2 \mathrm{H}_{2} \mathrm{O}$ were dissolved in $35 \mathrm{~mL}$ of deionized (DI) water, and $20 \mathrm{mM}$ of $\mathrm{K}_{4} \mathrm{Fe}(\mathrm{CN})_{6}$ was dissolved separately in $35 \mathrm{~mL}$ of DI water. The two solutions were transferred to a $100 \mathrm{~mL}$ Teflon lined stainless steel autoclave with either $20 \mathrm{~mL}$ sodium citrate $(0.2 \mathrm{M}$ aq) or sodium sulfate $(1.5 \mathrm{M}$ aq), sealed, and maintained at $120{ }^{\circ} \mathrm{C}$ for 12 hours. The resulting was collected and washed via centrifugation with DI water followed by a final wash with ethanol.

The XRD profiles for the citrate and sulfate syntheses, denoted as C-MnCuHCF0.50 and S-MnCuHCF0.50 respectively, are shown in Figure 5.2. SEM imaging and the

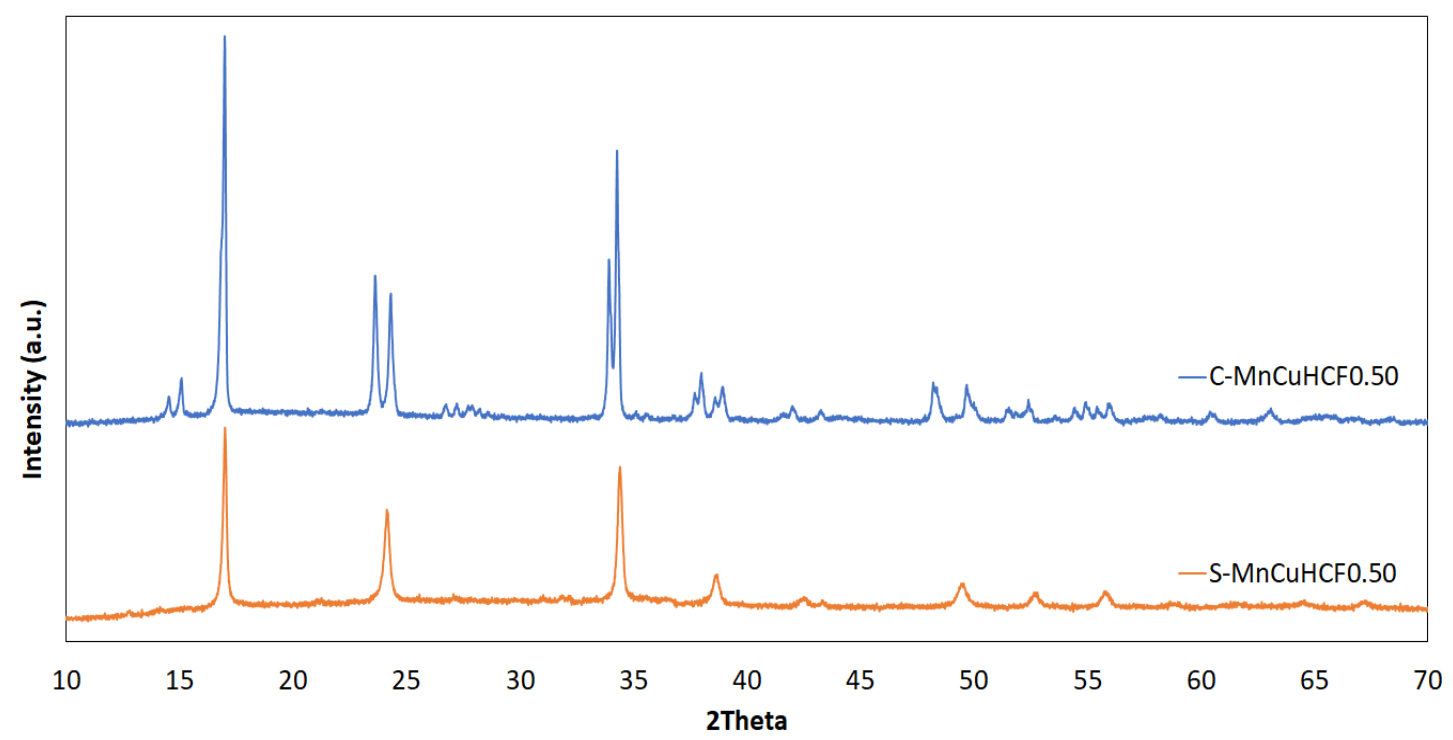

Figure 5.2 XRD profiles for hydrothermal synthesis of MnCuHCF0.50 with sodium citrate (blue) and sodium sulfate (orange). Both samples crystalized into a single phase. 
a)

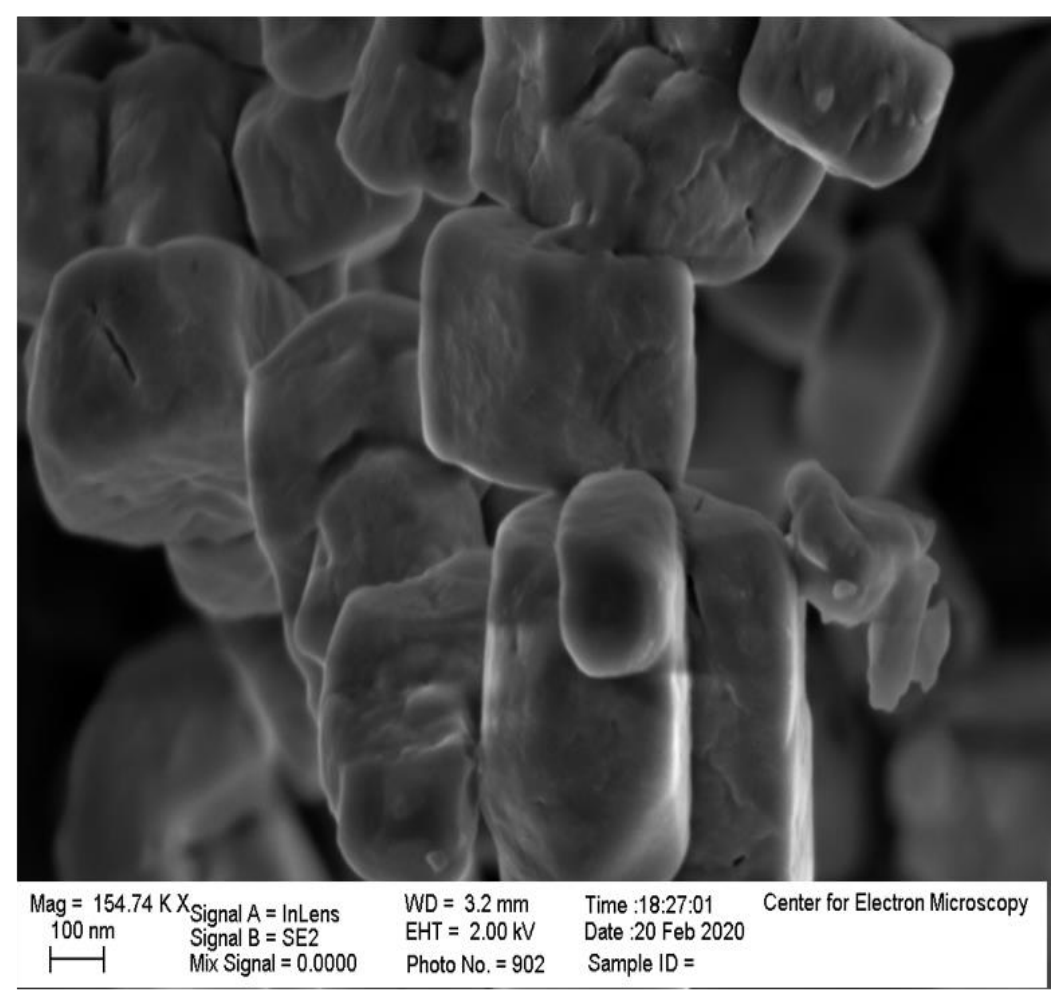

b)

EDS Layered Image 1

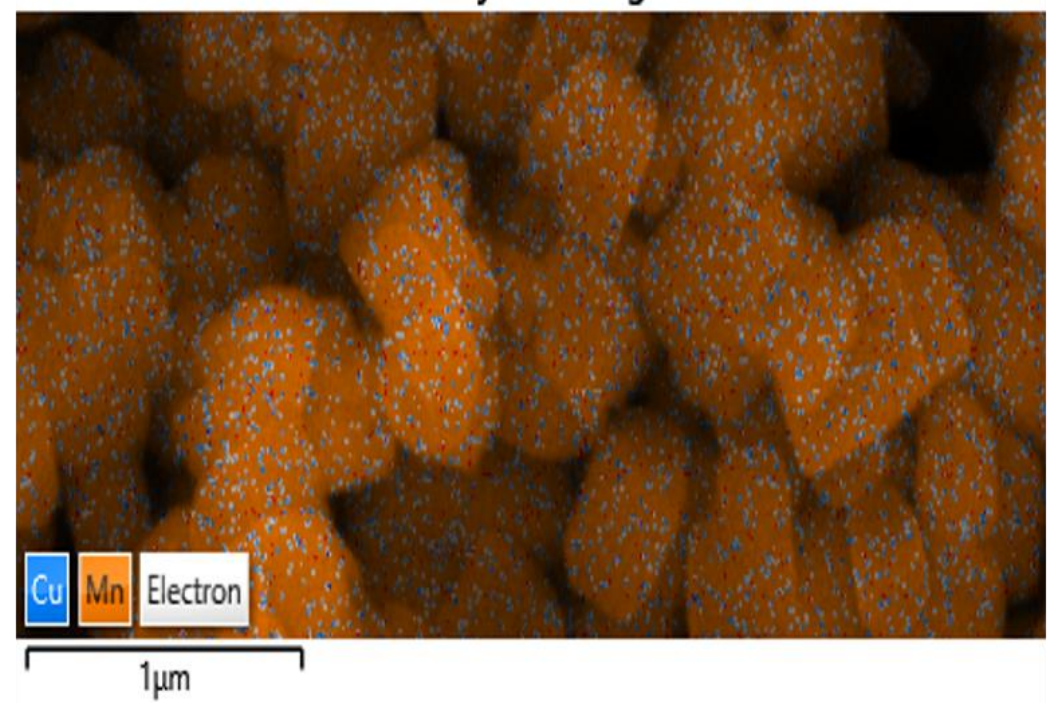

Figure $\mathbf{5 . 3}$

(a) SEM image of C-MnCuHCF0.50 (b) EDS elemental map of C-MnCuHCF0.50. 
accompanying EDS elemental map reveal an even distribution of both $\mathrm{Mn}$ and $\mathrm{Cu}$ throughout C-MnCuHCF0.50 (Figure 5.3 a,b). The higher stability constant for the copper citrate complex compared to the manganese citrate explains the higher concentration of Mn compared to $\mathrm{Cu}[237]$.

The relationship between the synthesis conditions and a mixed metal hexacyanoferrates formation offers an intriguing avenue to explore in future work. 


\section{Presentation of Published Work}

Kuperman N, Cairns A, Goncher G, Solanki R. Structural water enhanced intercalation of magnesium ions in copper hexacyanoferrate nonaqueous batteries. Electrochimica Acta 2020;362:137077. https://doi.org/10.1016/j.electacta.2020.137077. [238]

\subsection{Abstract}

In this article we investigate copper hexacyanoferrate (CuHCF) as a nonaqueous magnesium ion battery (MIB) cathode, and the positive influence of structural water on its $\mathrm{Mg}^{2+}$ storage properties. The hydrated and dehydrated forms of CuHCF $(\mathrm{H}-$ and D-CuHCF) each displayed excellent rate capabilities and extended lifetimes with zero capacity loss. However, H-CuHCF delivers a specific capacity $25 \%$ higher than that of D-CuHCF. Cyclic voltammetry and galvanostatic charge discharge reveal a redox reaction present only in the hydrated CuHCF, which accounts for $25 \%$ of its total reversible capacity $\left(63 \mathrm{mAh} \mathrm{g}^{-1}\right.$ at $\left.25 \mathrm{~mA} \mathrm{~g}^{-1}\right)$. Furthermore, ex-situ FTIR reveals that the structural water of $\mathrm{H}$-CuHCF remains in the lattice during charging/discharging. We propose that water provides partial electrostatic screening between the CuHCF lattice and Mg ions, while allowing an additional redox transition to become thermodynamically accessible. 


\subsection{Introduction}

As the overall cost of energy production from renewable sources continues to drop globally [239], a lack of robust energy storage solutions is curtailing wide scale adoption of renewables and decarbonization of the energy economy [240,241]. Rechargeable batteries are one possible solution to the demand for storage, with the lithium ion battery (LIB) being the current standard. However, due to the cost, safety concerns, and toxicity of LIBs, new battery technologies are needed to fully utilize renewable energy sources, such as wind and solar.

One promising alternative to LIBs is the divalent magnesium ion battery (MIB), as magnesium is relatively abundant, stable in air, and environmentally benign. Additionally, magnesium metal anodes possess high volumetric and gravimetric capacities (3833 mAh cm${ }^{-3}$ and $2205 \mathrm{mAh} \mathrm{g}^{-1}$ for Mg vs. $2046 \mathrm{mAh} \mathrm{cm}^{-3}$ and $3861 \mathrm{mAh} \mathrm{g}^{-1}$ for Li) and can be plated safely without dendritic growth [242-244]. Unfortunately, sluggish kinetics and high migration barriers have made the development of suitable MIB cathodes challenging [57]. Some advances have been made on MIB cathodes that are able to reversibly intercalate $\mathrm{Mg}^{2+}$, including: $\mathrm{Mg}_{x} \mathrm{Mo}_{3} \mathrm{~S}_{4}$ [243], $\mathrm{Mg}_{x} \mathrm{Cu}_{y} \mathrm{Mo}_{6} \mathrm{~S}_{8}$ [58], $\mathrm{MnO}_{2}$ [245], $\mathrm{V}_{2} \mathrm{O}_{5}[246]$, and Prussian Blue analogues (PBAs) [111,113].

Prussian Blue analogues are a family of mixed valence compounds with a general composition of $A_{x} M_{1}\left[M_{2}(C N)_{6}\right]_{y} \bullet \square_{1-y} \bullet z H_{2} O$ (where $A$ is an alkali cation; $M_{1}$ is the $\mathrm{N}$-coordinated transition metal; $\mathrm{M}_{2}(\mathrm{CN})_{6}$ is the hexacyanometallate anion; and $\square$ is a 
$\left[\mathrm{M}_{2}(\mathrm{CN})_{6}\right]^{3-/ 4-}$ vacancy; $\left.0<\mathrm{x}<2 ; 0<\mathrm{y}<1\right)$. Water molecules can be present in two unique crystallographic environments: coordinate to the unbonded $M_{1}$ atoms replacing the missing hexacyanometallate anions (coordinated water), and additional water can reside in the interstitial spacing (zeolitic water).

From neutron diffraction studies, the distinct water sites for a generic cubic PBA have been identified as: zeolitic water residing at the $8 \mathrm{c}$ position in the center of the lattice (A-site), and coordinated water at the 24e position (B-site) close to the location of the missing nitrogen as shown in Figure 5.4 [125].

There has been extensive research on PBAs for energy storage applications for both aqueous and nonaqueous systems owing to their large open framework, structural stability, high theoretical capacity $\left(170 \mathrm{mAh} \mathrm{g}^{-1}\right)$, and ability to accommodate a wide variety of intercalating species $[65,85,87,113,115,123,150,201,221,230,231,244]$.

Coordinated and zeolitic water play an integral role in the electrochemical properties of a PBA, having positive and negative effects depending on the system of interest. For aqueous electrolytes, water offers charge screening between the lattice and the intercalating ions, which allows for high ionic mobilities on the order of $10^{-7} \mathrm{~cm}^{2} \mathrm{~s}^{-1}$ [150]. Additionally, zeolitic and nitrogen coordinated water can facilitate the migration of ions in PBAs [87]. For some nonaqueous systems, the removal of water from the PBA lattice during cycling results in parasitic side reactions and structural degradation [80]. Efforts to mitigate these negative effects of water has led to considerable research on the 
(a)

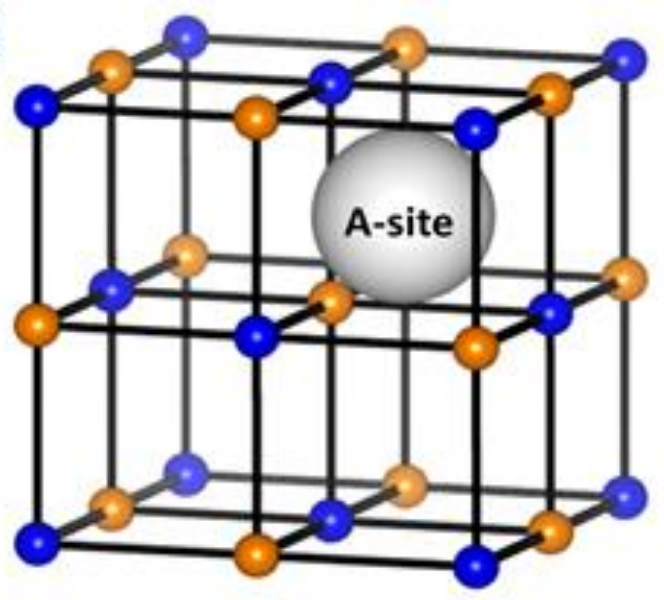

(b)
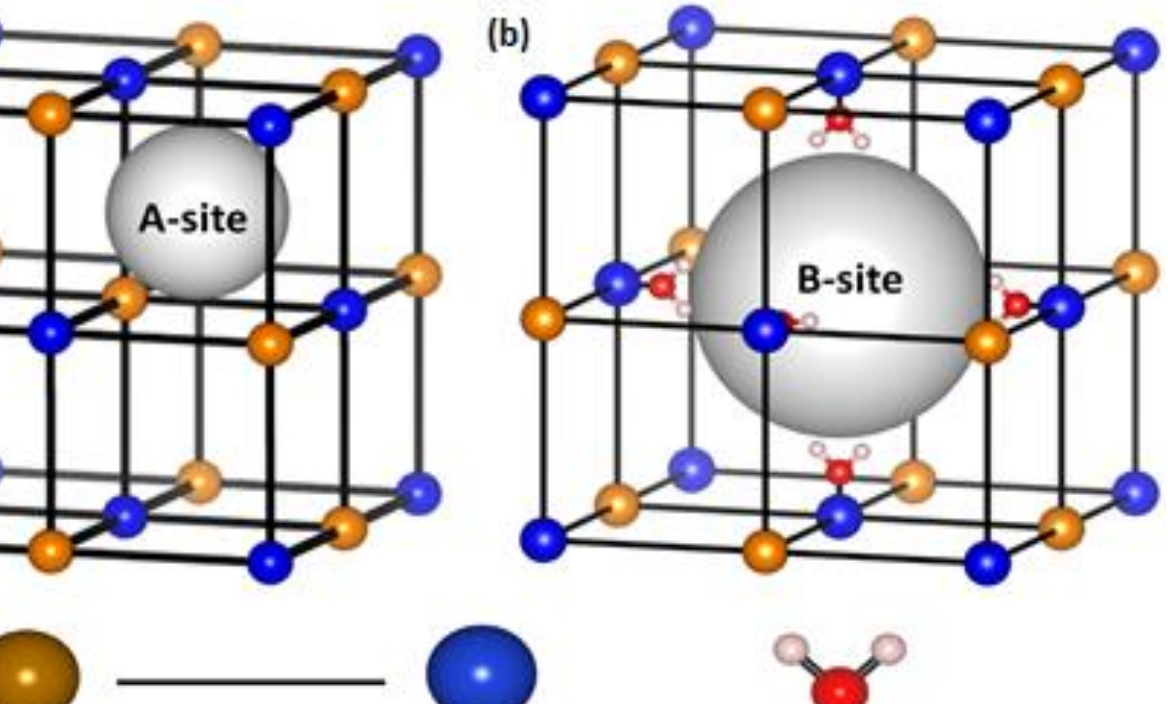

$\mathrm{Fe}$

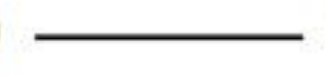

$\mathrm{C} \equiv \mathrm{N}$

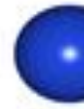

$\mathrm{Cu}$

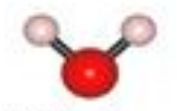

Water

Figure 5.4 Depiction of the cubic structure of CuCHF (a) A pristine lattice where intercalated ions can reside at A lattice sites (8c). (b) B lattice site (24e) of CuHCF at a $\left[\mathrm{M}_{2}(\mathrm{CN})_{6}\right]^{3-/ 4-}$ vacancy and the resulting coordinated water molecules bonded to the dangling $\mathrm{Cu}^{2+}$ atoms.

development of low vacancy materials with minimal water content $[55,201]$. However, Padigi et al. and others have demonstrated the successful use of hybrid aqueous/nonaqueous electrolytes can improve electrochemical performances and increase specific capacities by more than $45 \%[65,151]$.

In this work, we have investigated the impact of coordinated and zeolitic water on the electrochemical and energy storage properties of copper hexacyanoferrate (CuHCF), and its use as a cathode material for nonaqueous MIBs. The dehydrated copper hexacyanoferrate displays inferior electrochemical energy storage properties compared 
to the hydrated form, counter to many other PBAs whose performance improves upon the removal of water as part of the synthesis procedure $[47,55]$. Through a combination of FTIR, ex-situ energy dispersive x-ray spectroscopy (EDS), cyclic voltammetry (CV), and galvanic charge discharge we confirm the reversible intercalation of $\mathrm{Mg}^{2+}$ ions and examine the effect of zeolitic and coordinated water on $\mathrm{Mg}$ intercalation.

\subsection{Materials and Methods}

\subsubsection{Materials Synthesis:}

CuHCF was synthesized by coprecipitation similar to our previous work, with slight modification [221]. Briefly, $40 \mathrm{mM}$ of $\mathrm{CuCl}_{2} \cdot 2 \mathrm{H}_{2} \mathrm{O}$ was dissolved in $80 \mathrm{~mL}$ of deionized (DI) water, and $20 \mathrm{mM}$ of $\mathrm{K}_{4} \mathrm{Fe}(\mathrm{CN})_{6}$ was dissolved separately in $80 \mathrm{~mL}$ of DI water. The two solutions were simultaneously added dropwise into $40 \mathrm{~mL} \mathrm{NaCl}(5 \mathrm{M} \mathrm{aq})$ under constant stirring and maintained at $60^{\circ} \mathrm{C}$ for two hours. The resulting precipitate was collected and washed via centrifugation with DI water followed by a final wash with ethanol. Materials were dried under two conditions: (1) dried in air overnight, denoted as the hydrated copper hexacyanoferrate (H-CuHCF) and (2) dried in air overnight and annealed at $100^{\circ} \mathrm{C}$

under vacuum for two hours, denoted as the dehydrated copper hexacyanoferrate (D-CuHCF). The water content of these two materials differ substantially, which has a large effect on their energy storage properties. 


\subsubsection{Material Characterization:}

The crystal structure of each sample was characterized using powder x-ray diffraction (XRD) performed on a Rigaku Ultima IV X-ray diffractometer with $\mathrm{Cu} \mathrm{K \alpha}$ radiation $(\lambda=1.54056 \AA$ ). Indexing and refinement of the structures were conducted using the Fullprof crystallographic suite $[215,247]$. Morphology and chemical composition of the nanoparticles and fully assembled cathodes were examined by scanning electron microscope (SEM) and energy dispersive x-ray spectroscopy (EDS) using a Zeiss Sigma VP SEM. Thermal and water content analysis was performed using a thermogravimetric analyzer (TGA, Mettler TGA-50) from 50 to $300{ }^{\circ} \mathrm{C}$ at a heating rate of $5{ }^{\circ} \mathrm{C} \mathrm{min}-1$ under flowing $\mathrm{N}_{2}$. Fourier transform infrared spectroscopy (FTIR, Thermo Scientific Nicolet iS10 FTIR equipped with diamond ATR) in the range of $600-3800 \mathrm{~cm}^{-1}$ was used to probe the chemical environment of the cyanide ligand and determine the oxidation states of the transition metals. FTIR in the range of $90-690 \mathrm{~cm}^{-1}$ was performed on a Thermo Scientific Nicolette 6700 equipped with a DTGS detector to probe the metal-carbon and metalnitrogen bonding.

\subsubsection{Electrochemical Measurements:}

All electrochemical measurements were performed using a Gamry reference-600 potentiostat in a 3-electrode setup. Cathodes were prepared by coating a slurry of either H-CuHCF or D-CuHCF, polyvinylidene fluoride (PVDF), multi-walled carbon nanotubes, and activated carbon in the ratio of 80:9:9:2, respectively by weight in $\mathrm{N}$-methyl-2-pyrolidone (NMP) onto carbon paper. The coated electrodes were cured for two hours at $100{ }^{\circ} \mathrm{C}$ 
under vacuum prior to use. In general, cells consisted of the respective cathode, a carbon rod counter, an $\mathrm{Ag} / \mathrm{Ag}^{+}$in propylene carbonate reference, and an electrolyte of $1 \mathrm{M}$ magnesium perchlorate anhydrous, $\mathrm{Mg}\left(\mathrm{ClO}_{4}\right)_{2}$, in a mixture of propylene carbonate (PC) and ethylene carbonate (EC) $[\mathrm{PC} / \mathrm{EC}=50 / 50$ by volume]. All reference electrodes were calibrated against the $\mathrm{Fc} / \mathrm{Fc}^{+}$redox couple. Additionally, all electrolytes were dried over $3 \AA ̊$ molecular sieves to remove any residual water.

\subsection{Results and Discussion}

Powder x-ray diffraction was used to characterize changes in the crystal structure

of CuHCF after thermal treatments. The powder XRD patterns for hydrated and dehydrated CuHCF are shown in Figure 5.5a. H-CuHCF exhibits sharp peaks indicative of high crystallinity and can be indexed to the well-known face-centered cubic structure with a lattice parameter of $10.03 \AA$. After annealing at $100{ }^{\circ} \mathrm{C}$ for two hours, D-CuHCF undergoes a phase change to an orthorhombic system with lattice parameters $a=10.32 \AA, b=10.21 \AA, c=9.88 \AA$. Profile fits to the cubic and orthorhombic crystal structures are shown in Figure 5.6. PBAs are known to undergo structural distortions during thermal treatments, caused by the removal of both zeolitic and coordinated water [47]. The orthorhombic phase of D-CuHCF is consistent with other reported Prussian blue analogue systems such as $\mathrm{NiNa}_{2}\left[\mathrm{Fe}(\mathrm{CN})_{6}\right] \cdot 2 \mathrm{H}_{2} \mathrm{O}$ [248], $\mathrm{Cs}_{0.97} \mathrm{Cu}\left[\mathrm{Fe}(\mathrm{CN})_{6}\right]_{0.99} \cdot 1.1 \mathrm{H}_{2} \mathrm{O}$ [249], and $\mathrm{CoK}_{2}\left[\mathrm{Fe}(\mathrm{CN})_{6}\right] \cdot 2 \mathrm{H}_{2} \mathrm{O}[250]$. Upon dehydration at $150^{\circ} \mathrm{C}$, the CuHCF cubic or slightly distorted cubic crystal structure is no longer present indicating a breakdown of the 

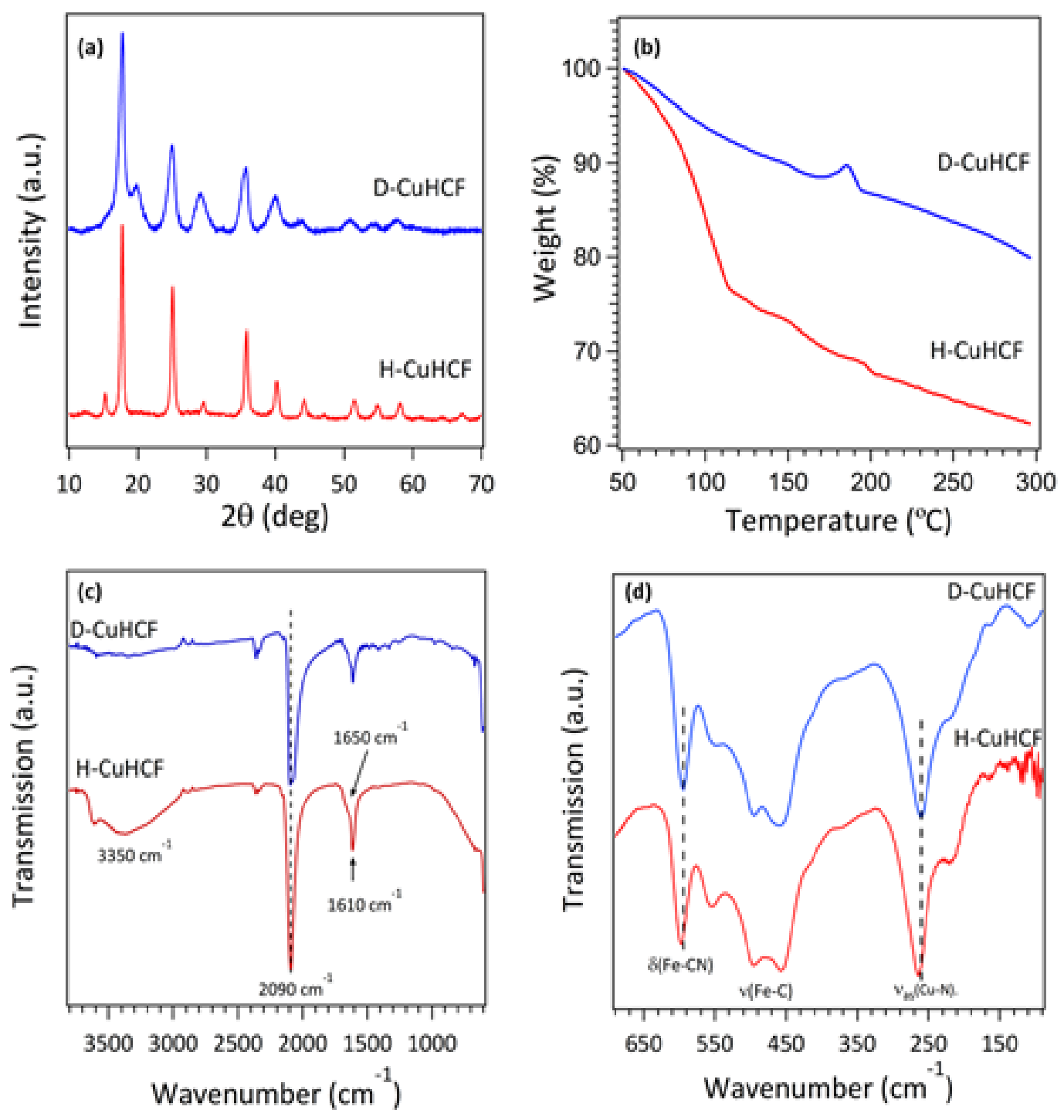

Figure 5.5 Physical characterization of H- and D-CuHCF. (a) Powder x-ray diffraction patterns for D-CuHCF and H-CuHCF. (b) Thermogravimetric curves for the CuHCF powders. $\mathrm{H}-\mathrm{CuHCF}$ undergoes a $34 \%$ mass loss due to the removal of both zeolitic and coordinated water between $50^{\circ} \mathrm{C}<\mathrm{T}<115^{\circ} \mathrm{C}$. D-CuHCF experiences an $8 \%$ mass loss over the same temperature range. (c) FTIR spectra (between $600-3800 \mathrm{~cm}^{-1}$ ) confirm the removal of surface water $\left(3350 \mathrm{~cm}^{-1}\right)$, and partial removal of coordinated and zeolitic water (1650 and $1610 \mathrm{~cm}^{-1}$, respectively). (d) FTIR spectra in the far IR range (between $90-690 \mathrm{~cm}^{-1}$ ) demonstrate the effect of dehydration on the Fe-CN and Cu$\mathrm{N}$ bond. 

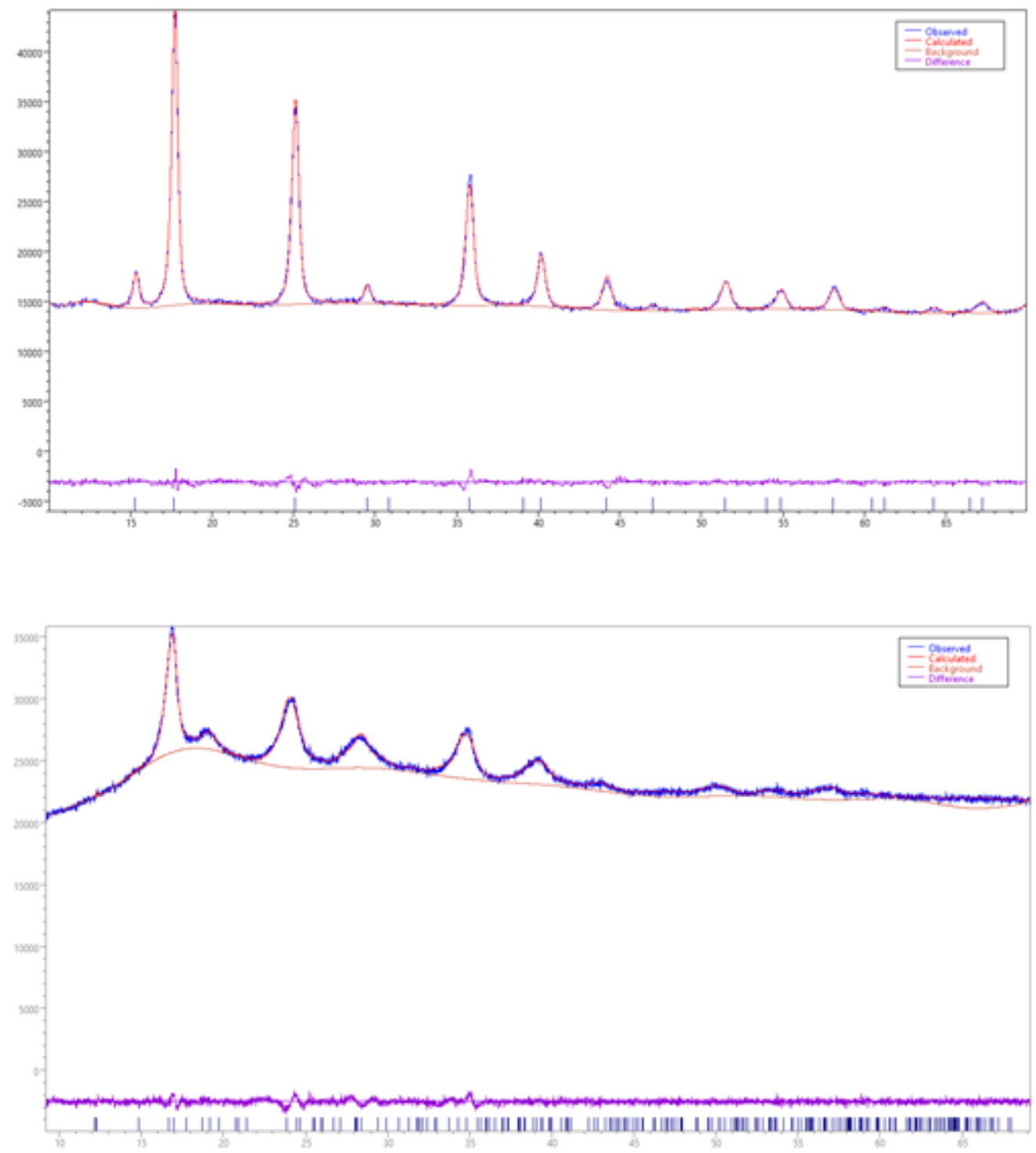

Figure 5.6 XRD profile fittings for (a) The cubic structure of H-CuHCF with lattice parameter $10.03 \AA$ (b) The orthorhombic structure of D-CuHCF with lattice parameters $a=10.32 \AA, b=10.21 \AA, c=9.88 \AA$.

material (Figure 5.7). SEM imaging reveals nanosized particles on the order of $25-100$ $\mathrm{nm}$ which aggregate into larger agglomerations (Figure 5.8). 
Levels of hydration and forms of water in each sample were evaluated with thermogravimetric analysis and FTIR. Figure 5.5b shows the TGA curves of both samples. $\mathrm{H}$-CuHCF displays a distinct mass loss step between $50^{\circ} \mathrm{C}<\mathrm{T}<115^{\circ} \mathrm{C}$, which corresponds to the removal of both zeolitic and coordinated water (34 \% mass loss) [85,251]. Above $115^{\circ} \mathrm{C}$ the material begins to gradually decompose. This behavior is similar to previous reports of copper hexacyanoferrate [85]. D-CuHCF shows an $8 \%$ weight loss between $50{ }^{\circ} \mathrm{C}<\mathrm{T}<115{ }^{\circ} \mathrm{C}$, indicating the successful removal of $67 \%$ of the coordinated and zeolitic water. The mass gain at $170^{\circ} \mathrm{C}$ for D-CuHCF is likely due to the breakdown of the hexacyanoferrate structure, followed by a secondary exothermic reaction [251]. CuHCF is

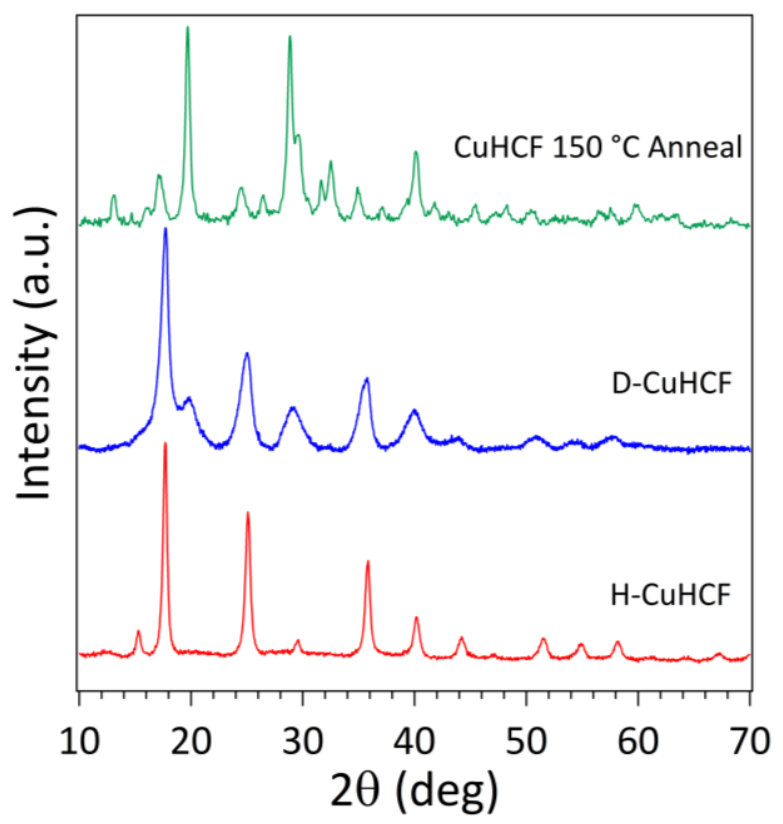

Figure 5.7 Powder x-ray diffraction patterns for CuHCF after different thermal treatments: annealed under vacuum at $150^{\circ} \mathrm{C}$, annealed under vacuum at $100{ }^{\circ} \mathrm{C}$ (D-CuHCF), untreated (H-CuHFC) and the crystalline structure breaks down after the high temperature anneal 


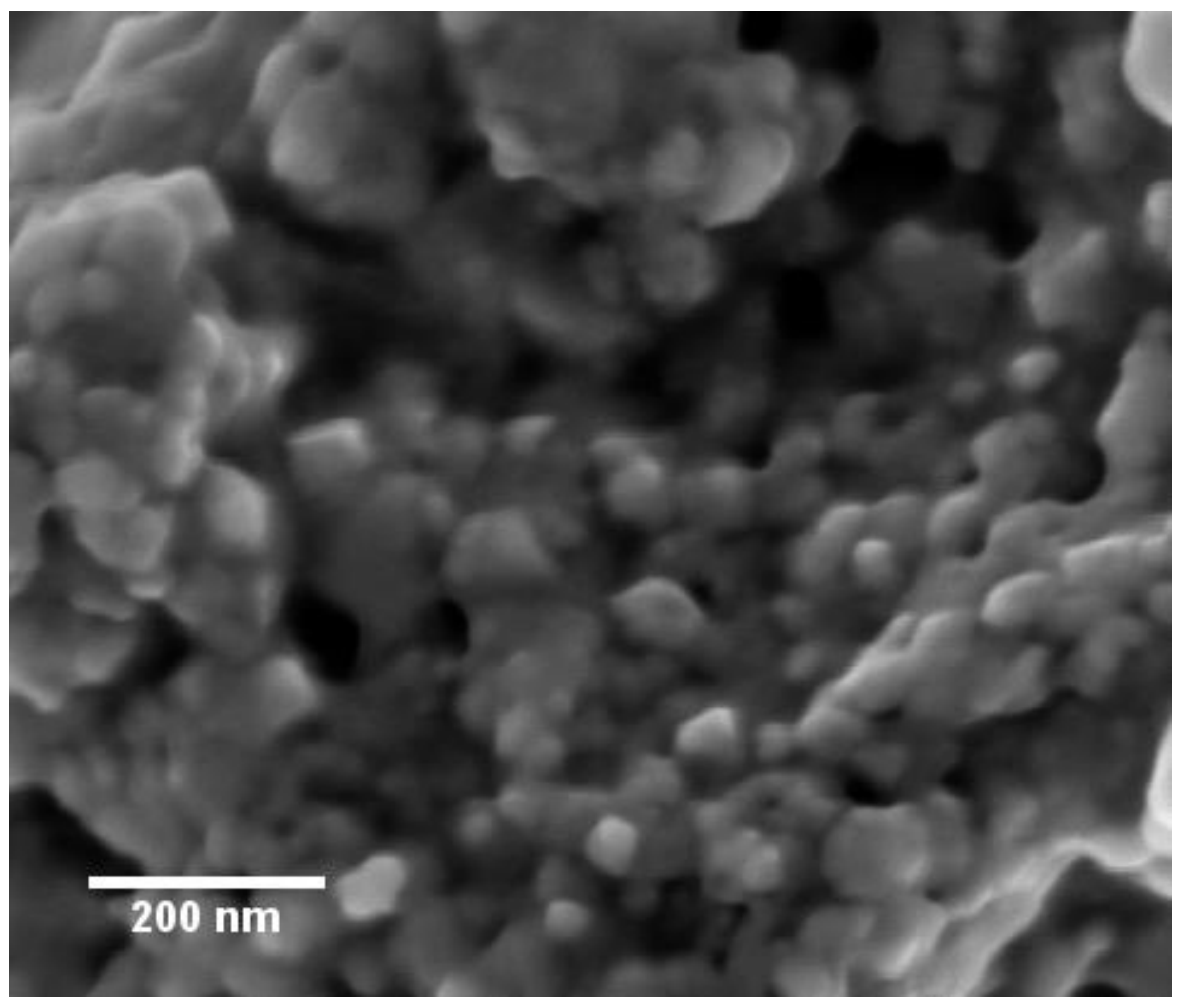

Figure 5.8 Standard SEM image of CUHCF. CuHCF crystalizes into nano-sized particles on the order of 25-100 nm, and further aggregate into large agglomerations.

known to be thermally unstable compared to other PBAs that can withstand annealing temperatures above $100{ }^{\circ} \mathrm{C}$ without any structural change or degradation [252].

The FTIR spectra in Figure 5.5c shows a large absorption peak for both $\mathrm{H}$ - and D-CuHCF at $2090 \mathrm{~cm}^{-1}$ of the CN stretching frequency, $v(C \equiv N)$, which is characteristic of $\mathrm{Cu}^{\prime \prime}-\mathrm{NC}-\mathrm{Fe}$ ". A small splitting is observed in D-CuHCF, which is attributed to the structural shift to a lower crystal symmetry [253]. Neither sample exhibits v(C三N) of Cu"-NC-Fe III (located at $2174 \mathrm{~cm}^{-1}$ ), confirming the homogeneity of the iron oxidation state in the 
as-prepared materials. For $\mathrm{H}$-CuHCF, the broad absorption peak centered at $3350 \mathrm{~cm}^{-1}$ is due to the $\mathrm{O}-\mathrm{H}$ stretching frequency of free surface water, while the bending modes of weakly bound zeolitic water and coordinated water are associated with the sharp peak $1610 \mathrm{~cm}^{-1}$ and the shoulder at $1650 \mathrm{~cm}^{-1}$, respectively [251]. Upon dehydration, the broad surface water peak is removed while the IR bands associated with both zeolitic and coordinated water are weakened, further verifying their partial removal.

The FTIR spectrum of a cured H-CuHCF electrode confirms the coordinated and zeolitic water remains in the lattice while all surface water is removed (Figure 5.9). The stability of water in the prepared electrode compared to D-CuHCF is attributed to the presence of the PVDF binder which may help trap the water within the lattice. It should be noted that curing corresponds to the heating of the entire electrode material, whereas annealing refers to exclusively heating the bare CuHCF powder.

Far IR spectra in the rage of $90-690 \mathrm{~cm}^{-1}$, shown in Figure $5.5 \mathrm{~d}$, were taken to study the relationship between coordinated and zeolitic water and the metal cyanide bonds. For $\mathrm{H}-\mathrm{CuHCF}$, the peaks at $598 \mathrm{~cm}^{-1}$ and $264 \mathrm{~cm}^{-1}$ are due to the Fe-CN linear bending and $\mathrm{Cu}-\mathrm{N}$ asymmetric stretching modes respectively [253]. The corresponding D-CuHCF bands are redshifted by $4 \mathrm{~cm}^{-1}$, indicating that the removal of water results in a weakening of the bonds. Interestingly, the Fe-C stretching modes located 491 and $452 \mathrm{~cm}^{-1}$ remain unchanged in these samples. 


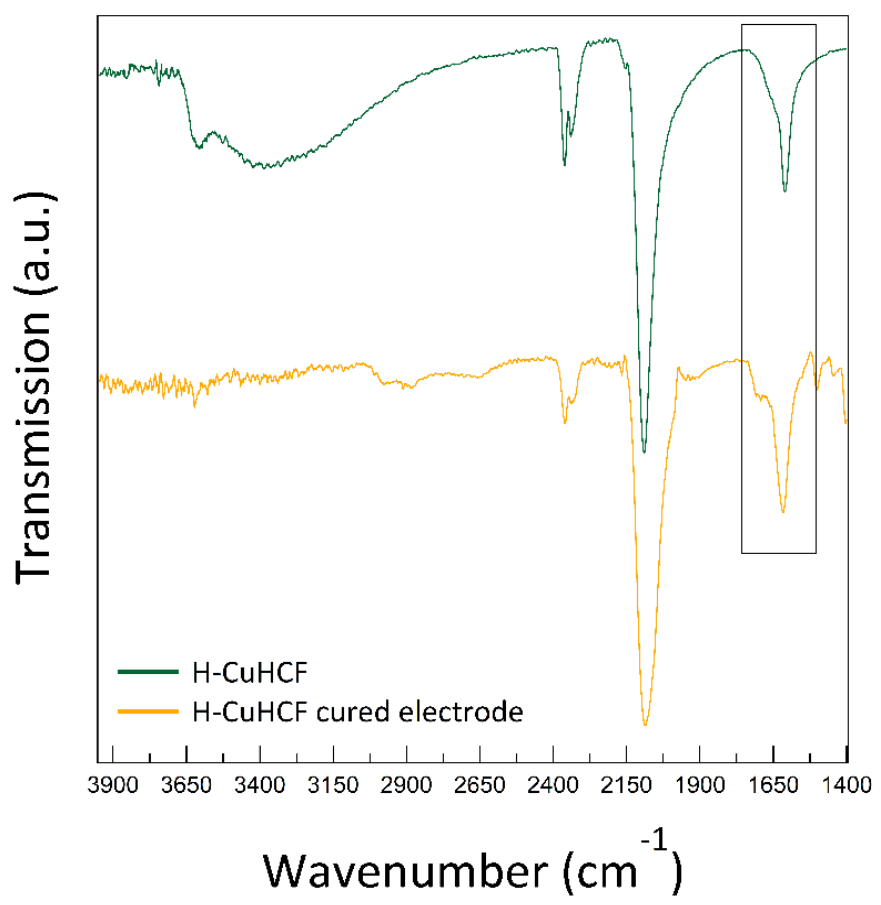

Figure 5.9 FTIR spectra of $\mathrm{H}$-CuHCF pre- and post-curing at $100{ }^{\circ} \mathrm{C}$ under vacuum, confirming coordinated and zeolitic water are not removed from the H-CuHCF electrodes. The stability of the coordinated and zeolitic water is attributed to the presence of the PVDF binder.

The redox properties of the samples upon intercalation of $\mathrm{Mg}^{2+}$ were investigated by cyclic voltammetry in a three-electrode configuration at a sweep rate of $0.5 \mathrm{mV} \mathrm{s}^{-1}$ (Figure 5.10). Electrochemical measurements were corrected using a ferrocene calibration reference (Figure 5.11). Prior to electrochemical testing, all cathodes were de-sodiated by being charged to $1.1 \mathrm{~V}$ vs $\mathrm{Fc} / \mathrm{Fc}^{+}$, rinsed, and then reassembled in a new cell with fresh electrolyte H-CuHCF displays a single, broad oxidation peak centered at $0.64 \mathrm{~V}$, ranging from $0.18 \mathrm{~V}$ to $0.90 \mathrm{~V}\left(\mathrm{vs} \mathrm{Fc} / \mathrm{Fc}^{+}\right.$) and two equally prominent reduction peaks at $0.64 \mathrm{~V}$ and $0.30 \mathrm{~V}\left(\mathrm{vs} \mathrm{Fc} / \mathrm{Fc}^{+}\right)$. A similar result has been observed for CuHCF under 
(a)

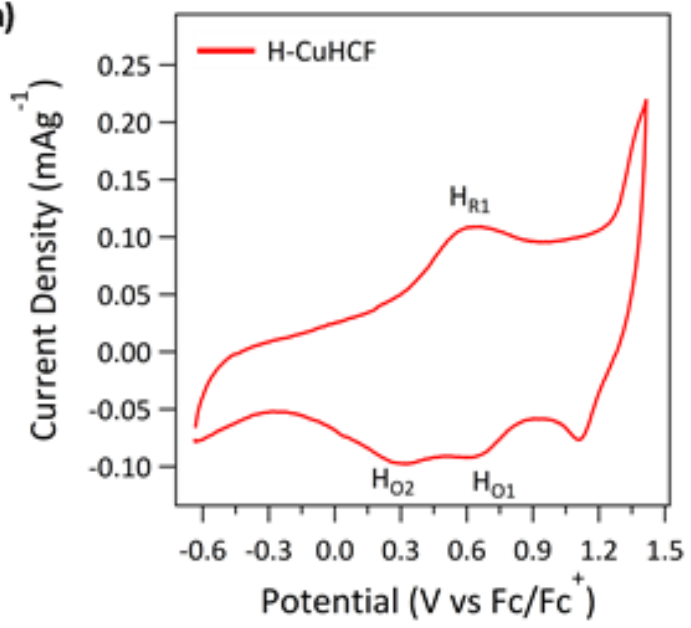

(b)

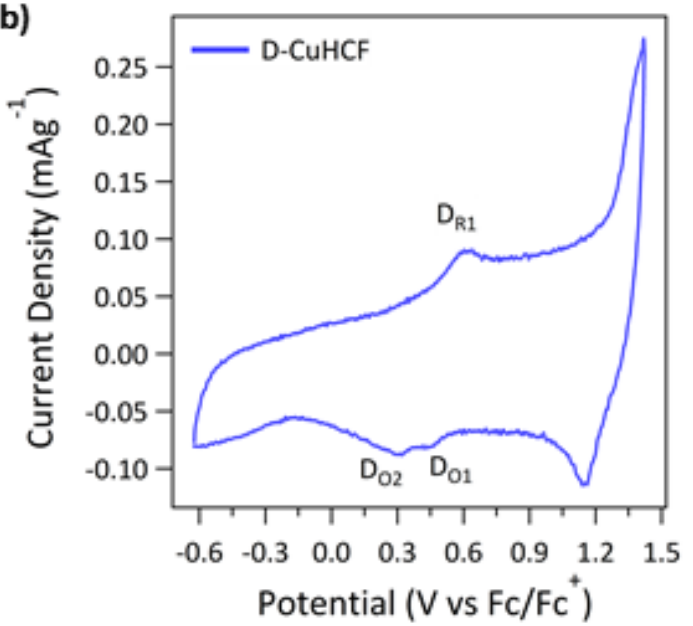

Figure 5.10 Cyclic voltammograms at a scan rate of $0.5 \mathrm{mV} \mathrm{s}^{-1}$ in $1 \mathrm{M} \mathrm{Mg}\left(\mathrm{ClO}_{4}\right)_{2}$ in $\mathrm{PC} / \mathrm{EC}=50 / 50$. (a) H-CuHCF. (b) D-CuHCF

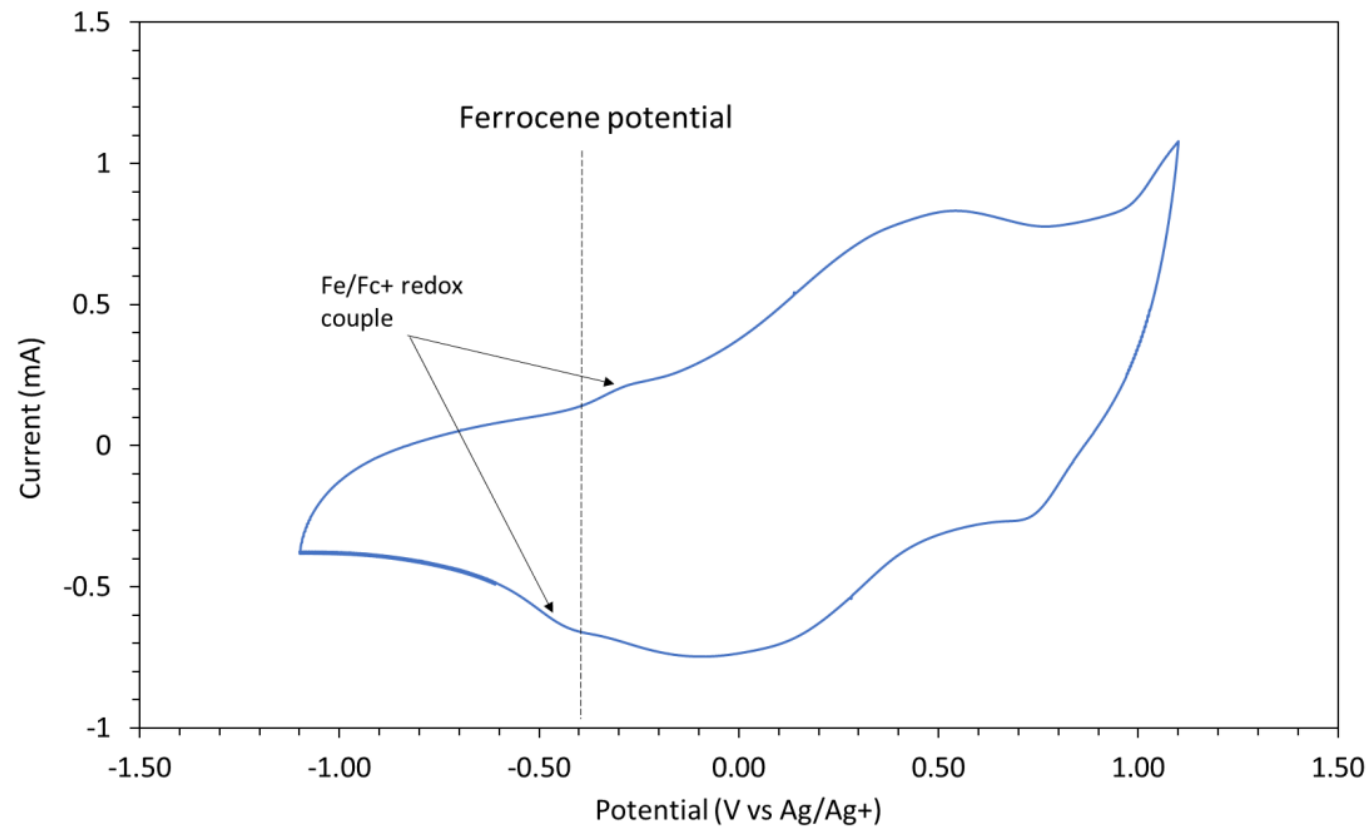

Figure 5.11 CV of $\mathrm{H}-\mathrm{CuHCF}\left(\mathrm{vs} \mathrm{Ag} / \mathrm{Ag}^{+}\right)$in $1 \mathrm{M} \mathrm{Mg}\left(\mathrm{ClO}_{4}\right)_{2}$ in $\mathrm{PC} / \mathrm{EC}=50 / 50$ with ferrocene added to calibrate the $\mathrm{Ag} / \mathrm{Ag}^{+}$pseudo-reference. The $\mathrm{Fc} / \mathrm{Fc}^{+}$potential was determined to be $-0.365 \mathrm{~V}$ vs $\mathrm{Ag} / \mathrm{Ag}^{+}$. 
a)

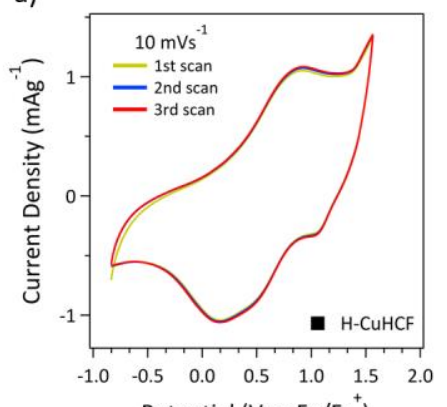

b)

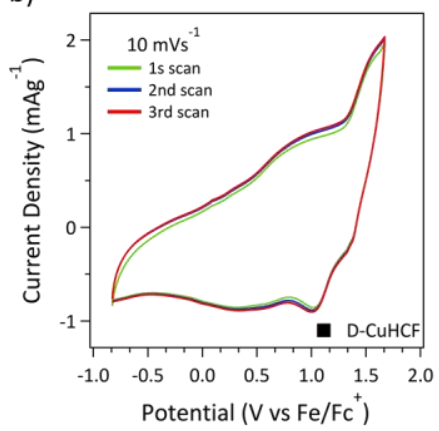

c)

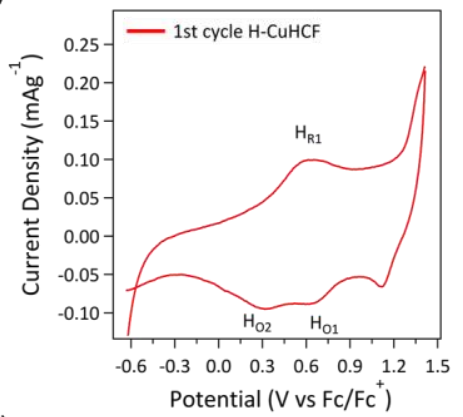

d)

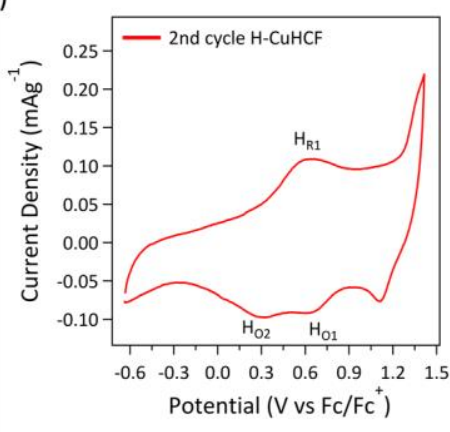

e)

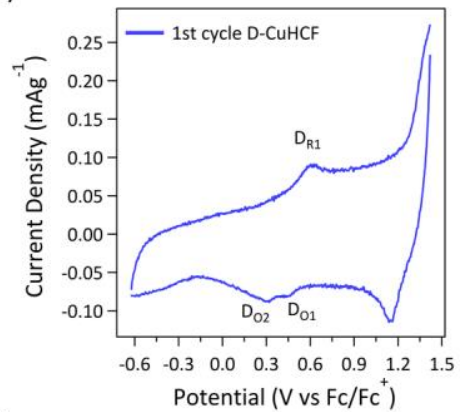

f)

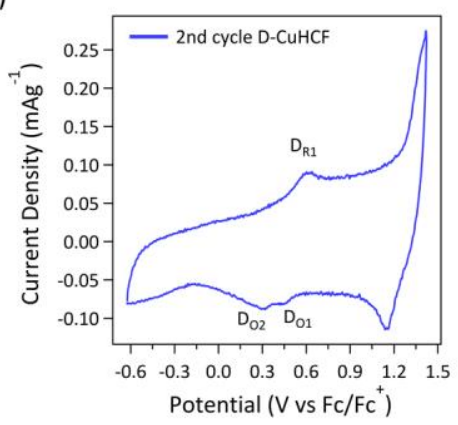

Figure 5.12 multiple cyclic voltammograms of $\mathrm{H}$ - and D-CuHCF at $10 \mathrm{mVs}^{-1}$ and $0.5 \mathrm{mVs}^{-1}$. (a) H-CuHCF at $10 \mathrm{mVs}^{-1}$ (b) D-CuHCF at $10 \mathrm{mVs}^{-1}$ (c) $1^{\text {st }}$ cycle at $0.5 \mathrm{mVs}^{-1}$ of $\mathrm{H}$-CuHCF (d) $1^{\text {st }}$ cycle at $0.5 \mathrm{mVs}^{-1}$ of D-CuHCF (e) $2^{\text {st }}$ cycle at $0.5 \mathrm{mVs}^{-1}$ of H-CuHCF (f) $2^{\text {st }}$ cycle at $0.5 \mathrm{mVs}^{-1}$ of D-CuHCF

$\mathrm{Al}^{3+}$ intercalation [123]. The oxidation and corresponding reduction peaks above $1.0 \mathrm{~V}$ for both $\mathrm{H}$ - and $\mathrm{D}-\mathrm{CuHCF}$ are not believed to be related to either $\mathrm{Cu}$ or Fe redox. However, as shown in Figure 5.12, the peaks show no degradation upon multiple cv scans at various current densities, indicating it is reversible in nature. Additionally, no electrolyte consumption is observed after extended charge/discharge testing. D-CuHCF (Figure $5.10 \mathrm{~b}$ ) exhibits similar behavior with a single oxidation peak at $0.61 \mathrm{~V}$ vs $\mathrm{Fc} / \mathrm{Fc}^{+}$and two smaller reduction peaks at $0.30 \mathrm{~V}$ and $0.46 \mathrm{~V}$ vs $\mathrm{Fc} / \mathrm{Fc}^{+}$, which align with the second oxidation peak of H-CuHCF. Additionally, the normalized, integrated current $\left(\mathrm{mC} \mathrm{g}^{-1}\right)$ for 
D-CuHCF is $43 \%$ lower than that of $\mathrm{H}-\mathrm{CuHCF}$ indicating fewer $\mathrm{Mg}^{2+}$ ions are able to enter the lattice at a scan rate of $0.5 \mathrm{mV} \mathrm{s}^{-1}$. The two oxidation peaks for CuHCF may signify that both $\mathrm{Fe}$ and $\mathrm{Cu}$ undergo reduction/oxidation or that two distinct Fe environments exist. The general electrochemical behavior of CuHCF is known to be more complex than that of other Prussian Blue analogues, as the intercalating ion can influence the activity of $\mathrm{Cu}^{2+} / \mathrm{Cu}^{+}$. Wessells et al. have reported copper inactivity during $\mathrm{Na}$ intercalation [230], while Mizuno et al. demonstrated with ex situ Mössbauer spectroscopy and X-ray absorption near edge structure (XANES) that copper can switch between $\mathrm{Cu}^{2+} / \mathrm{Cu}^{+}$during $\mathrm{Mg}^{2+}$ intercalation [111]. Also, Mullaliu et al. and others have provided further evidence for the electroactivity of copper in PBAs [254,255]. However, without additional tests, it is not possible to conclusively determine if copper is indeed undergoing redox in our samples given that the specific capacity of our material is below the theoretical capacity of Fe switching $\left(\mathrm{Fe}^{2+} / \mathrm{Fe}^{3+}\right)$.

Galvanostatic charge discharge tests at various current densities were conducted to investigate the effect of water on the electrochemical charge storage of CuHCF. Ex situ EDX measurements at different states of charge confirmed $\mathrm{Mg}^{2+}$ intercalation/deintercalation (Figure 5.13). At the lowest current density of $25 \mathrm{~mA} \mathrm{~g}^{-1}, \mathrm{H}-$ and D-CuHCF deliver reversible specific capacities of 63 and $50 \mathrm{mAh} \mathrm{g}^{-1}$ respectively (Figure 5.14a) with coulombic efficiencies of $98 \%$. The capacities are calculated using the entire mass of the cathode coating mixture, not just the active material, and are comparable to both aqueous and nonaqueous CuHCF systems $[111,115]$. The differential 
a)

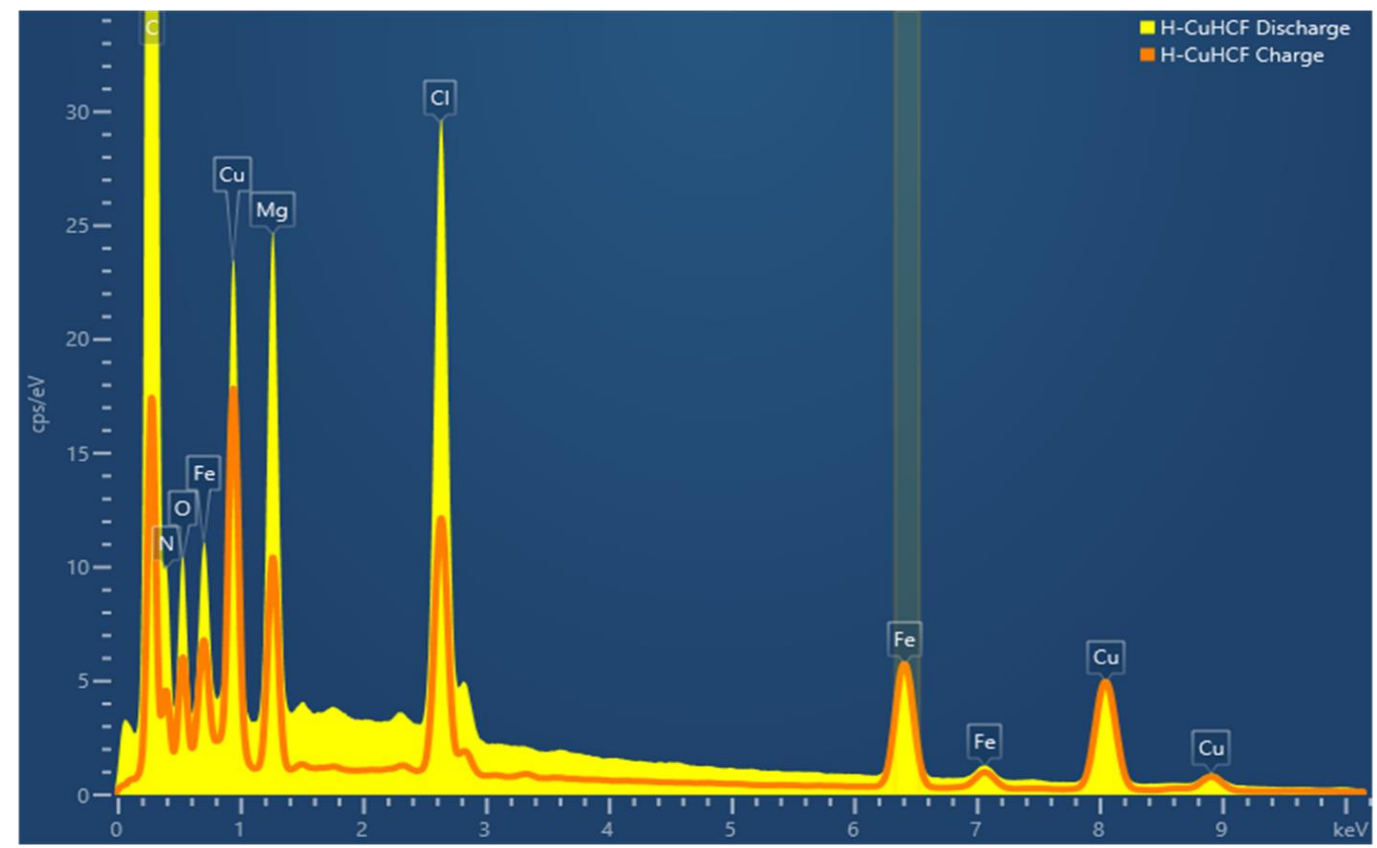

b)

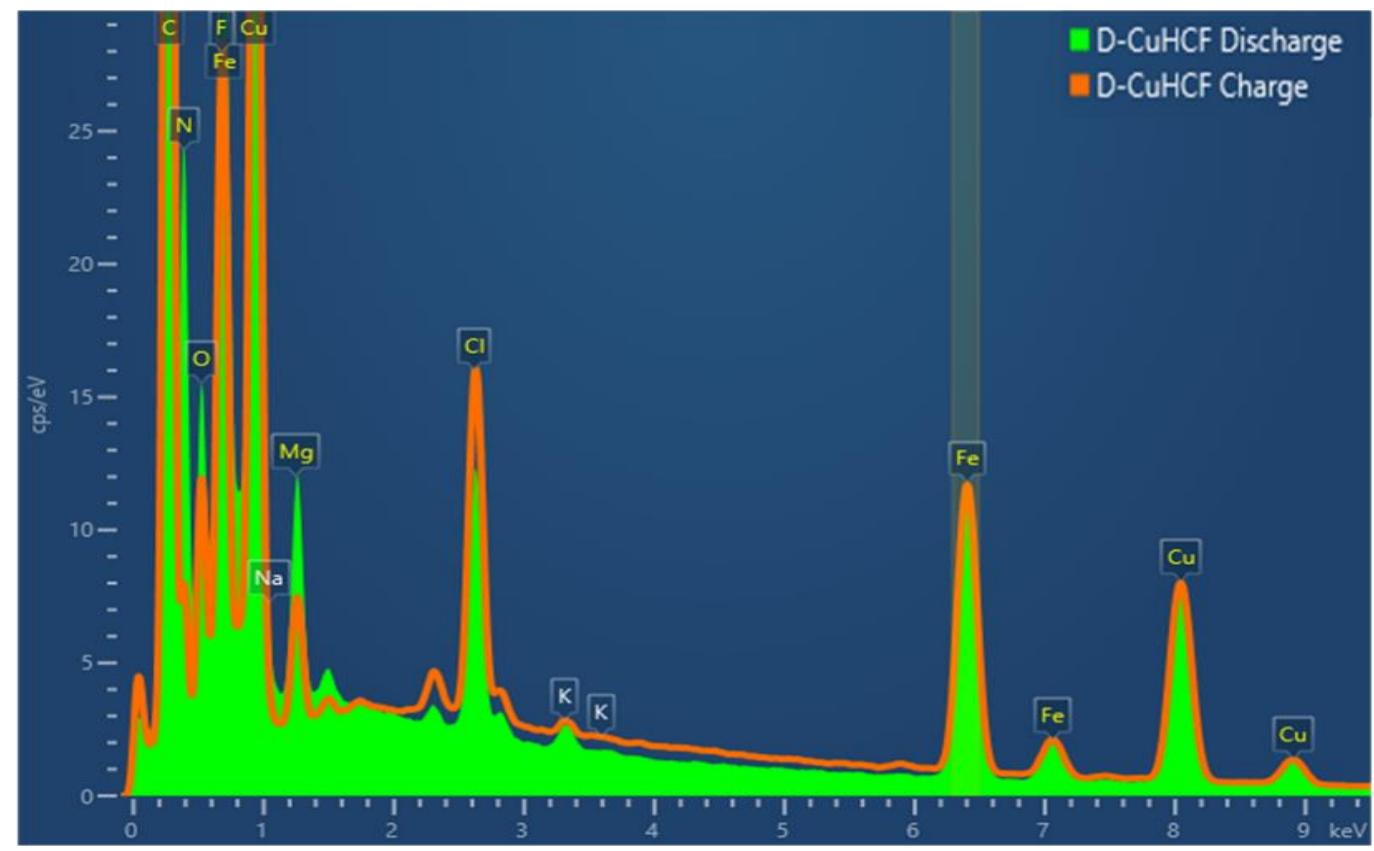

Figure 5.13 Confirmation of $\mathrm{Mg}^{2+}$ intercalation/deintercalation. Ex situ EDS spectra for fully charged and fully discharged (a) H-CuHCF (b) D-CuHCF. 

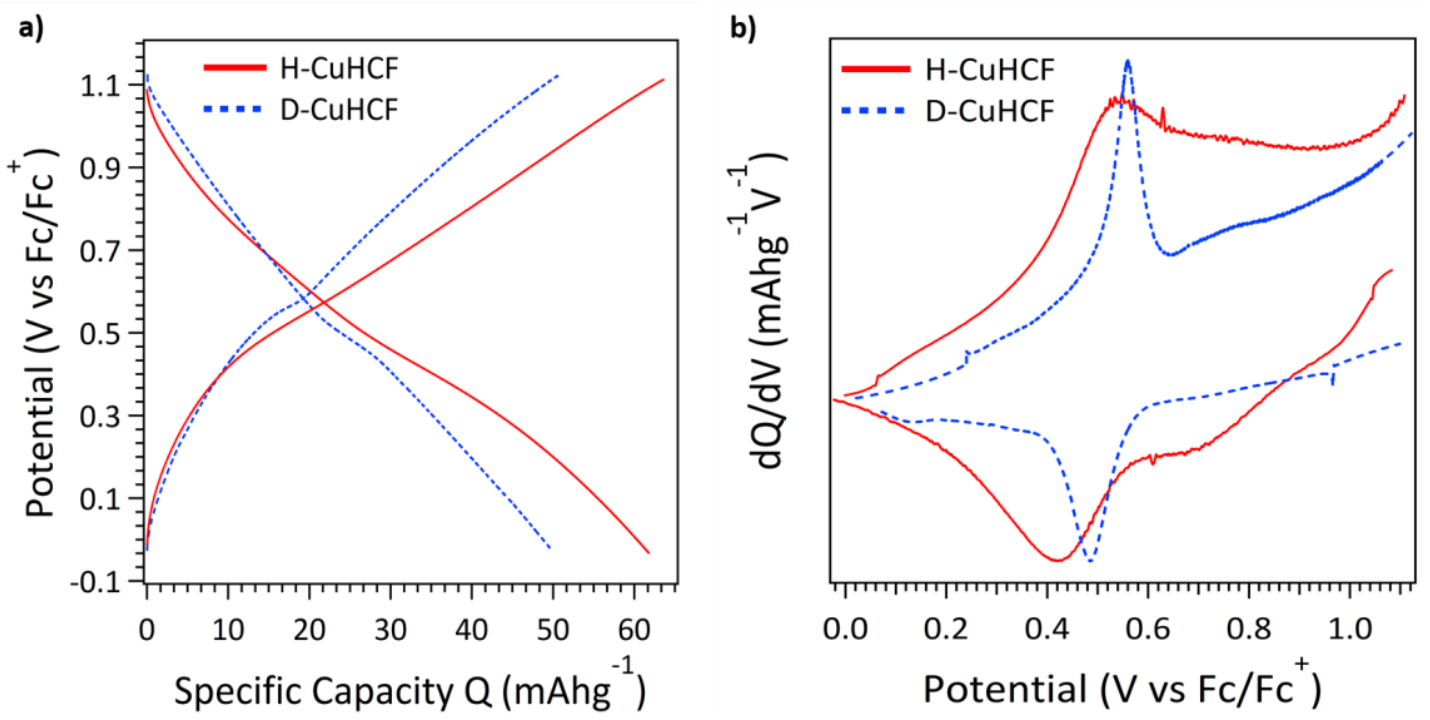

Figure 5.14 (a) Galvanostatic charge/discharge profiles of $\mathrm{H}$ - and D-CuHCF at 25 $\mathrm{mA} \mathrm{g}^{-1}$ in $1 \mathrm{M} \mathrm{Mg}\left(\mathrm{ClO}_{4}\right)_{2}$ in $\mathrm{PC} / \mathrm{EC}=50 / 50$. All current densities and capacities are calculated by considering the total mass of the electrode coating. (b) Differential capacity plots of charge/discharge profiles at $25 \mathrm{~mA} \mathrm{~g}^{-1}$. H-CuHCF exhibits two reduction steps, while $D$-CuHCF only displays a single step. The higher potential redox process observed in $\mathrm{H}$-CuHCF accounts for $25 \%$ of its total specific capacity.

capacity plots reveal a contrast in the discharge processes between the two samples. $\mathrm{H}$-CuHCF undergoes a two-step redox process at $0.53 / 0.42 \mathrm{~V}$ and $0.72 / 0.68 \mathrm{~V} \mathrm{vs} \mathrm{Fc} / \mathrm{Fc}^{+}$, whereas D-CuHCF exhibits a single step at $0.56 / 0.48 \mathrm{~V}$ vs Fc/Fc (Figure $5.14 \mathrm{~b}$ ). The oxidation and reduction potentials as determined from the differential capacity are consistent with the CV results (Figure 5.15). As only a single redox pair is observed for D-CuHCF, it can be concluded that the reaction at 0.53/0.42 V for $\mathrm{H}-\mathrm{CuHCF}$ and $0.56 / 0.48$ V for D-CuHCF corresponds to the $\mathrm{Fe}^{2+} / \mathrm{Fe}^{3+}$ switch. The higher potential redox reaction between $0.82 \mathrm{~V}\left(\mathrm{vs} \mathrm{Fc} / \mathrm{Fc}^{+}\right)$and $0.58 \mathrm{~V}\left(\mathrm{vs} \mathrm{Fc} / \mathrm{Fc}^{+}\right)$contributes $25 \%$ of $\mathrm{H}$-CuHCF's total 

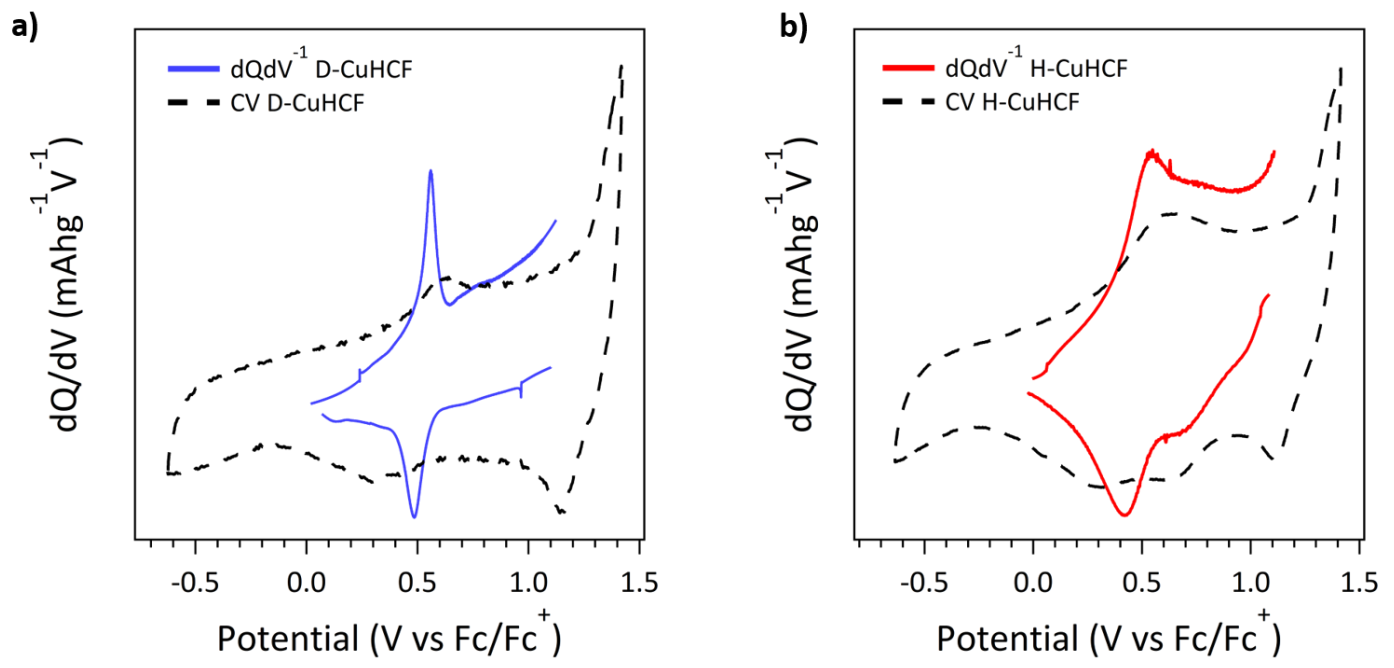

Figure 5.15 Cyclic voltammograms vs differential capacity plots for (a) D-CuHCF. (b) $\mathrm{H}$-CuHCF. The difference in redox potentials as measured by the two methods range from $1 \mathrm{mV}$ to $102 \mathrm{mV}$.
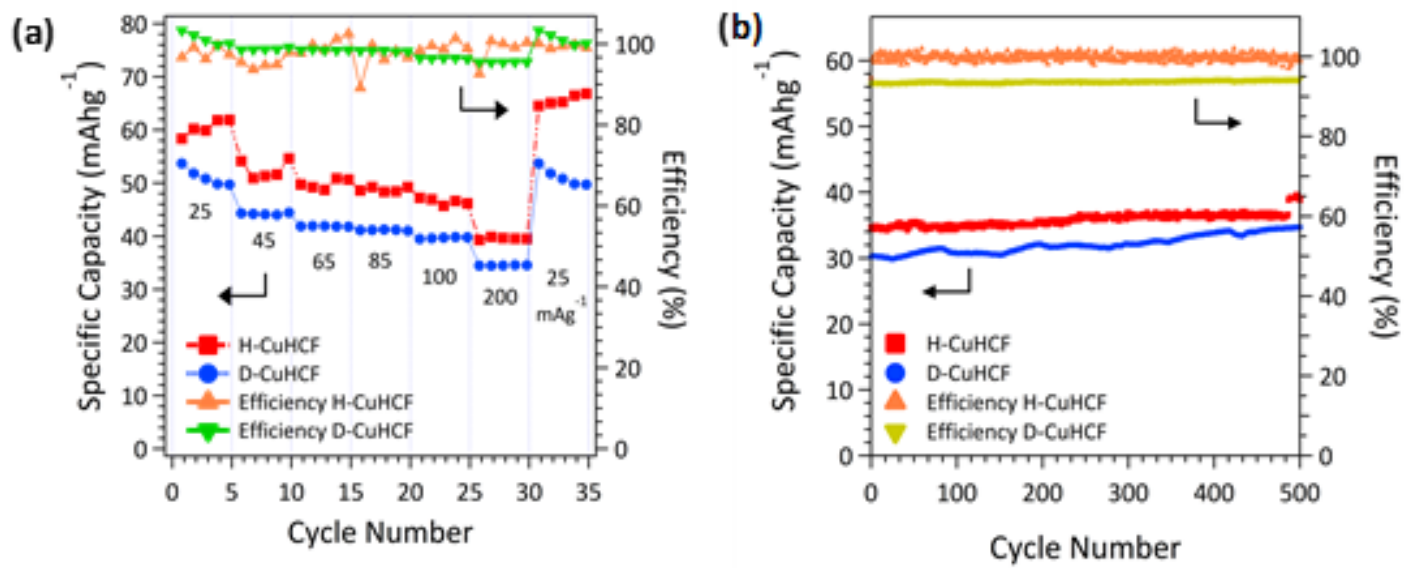

Figure 5.16 Electrochemical and charge storage characterization of $\mathrm{H}$ - and D-CuHCF in $1 \mathrm{M} \mathrm{Mg}\left(\mathrm{ClO}_{4}\right)_{2}$ in $\mathrm{PC} / \mathrm{EC}=50 / 50$. All current densities and capacities are calculated taking total electrode mass into account. (a) Rate capability tests for H- and D- CuHCF. (b) Capacity retention of $\mathrm{H}$ - and D-CuHCF cathodes over 500 cycles at $300 \mathrm{~mA} \mathrm{~g}^{-1}$. Neither sample experienced any capacity loss after the extended cycling. 
capacity and accounts for the loss of capacity upon dehydration. Despite the decrease in capacity upon dehydration the voltage hysteresis' (over potential) of the two samples, which range from 42 to $111 \mathrm{mV}$, are low for divalent ion insertion and further illustrate the superior $\mathrm{Mg}^{2+}$ kinetics of CuHCF [115].

Rate capability tests were performed at current densities of $25,45,65,85,100$, and $200 \mathrm{mAh} \mathrm{g}^{-1}$ (Figure 5.16a). Both H- and D-CuHCF display good performance, retaining over $65 \%$ of their initial capacity when the current density was increased from 25 to $200 \mathrm{~mA} \mathrm{~g}^{-1}$. Upon returning to $25 \mathrm{~mA} \mathrm{~g}^{-1}$, both samples recover $100 \%$ of their initial capacity. The corresponding discharge profiles are shown in Figure 5.17. Cycle lifetimes were examined over 500 cycles at $300 \mathrm{~mA} \mathrm{~g}^{-1}$ (Figure 5.16b). Neither H- or D-CuHCF

(a)

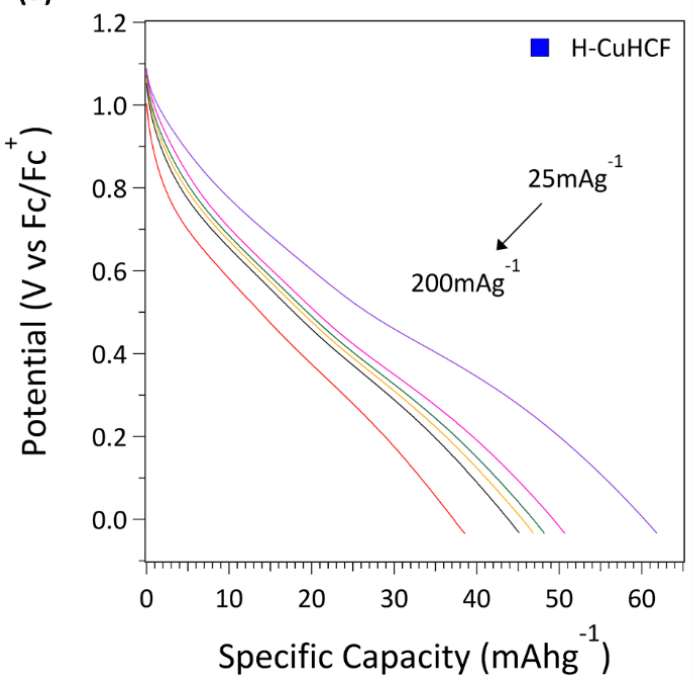

(b)

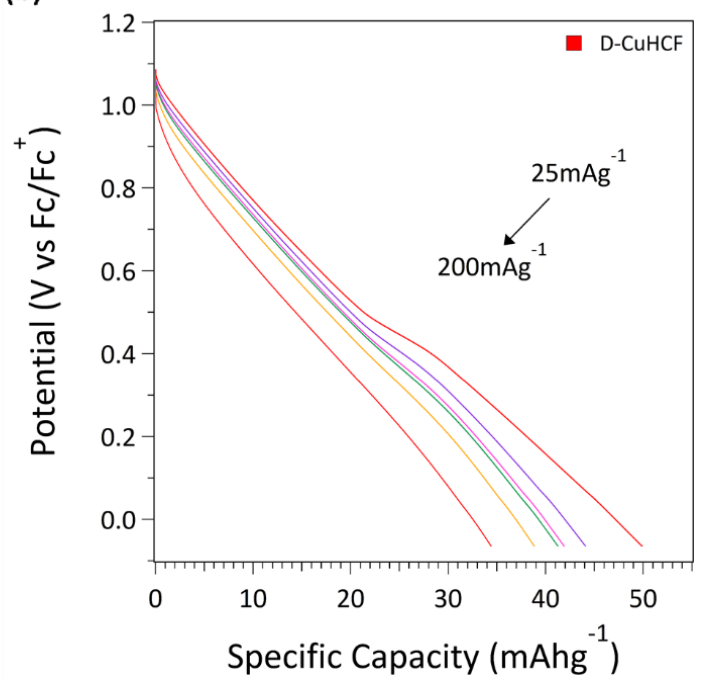

Figure 5.17 Gavanostatic discharge profiles at different current densities in $1 \mathrm{M}$ $\mathrm{Mg}\left(\mathrm{ClO}_{4}\right)_{2}$ in $\mathrm{PC} / \mathrm{EC}=50 / 50$ to determine the rate capabilities. (a) Discharge profiles of $\mathrm{H}$-CuHCF. (b) Discharge profiles of D- CuHCF. 
experienced any capacity fading over the extended testing, while delivering reversible capacity of 38 and $35 \mathrm{mAh} \mathrm{g}^{-1}$ with coulombic efficiencies of $100 \%$ and $94 \%$, respectively. The increase in reversible capacity of both samples after 500 charge/discharge cycles is thought to result from the intercalation of electrolyte into the lattice, causing the cathodes to slowly become wetted. Similar results have been reported for other PBA systems [256].

To further examine the $\mathrm{Mg}^{2+}$ insertion/extraction reaction kinetics, cyclic voltammograms at varying sweep rates from 10 to $50 \mathrm{mVs}^{-1}$ were collected (Figure $5.18 \mathrm{a}, \mathrm{d})$. The peak cathodic and anodic currents each obey a power-law relationship with respect to scan rate $(v)$ :

$$
i=a v^{b}
$$

where $\mathrm{a}$ and $\mathrm{b}$ are adjustable parameters. The exponential parameter $\mathrm{b}$ reflects the rate limiting step in the electrochemical reaction. A value of $b=0.5$ represents $a$ diffusion-controlled process, while $b=1.0$ suggests non-faradic (capacitive) behavior [257]. The $b$ parameter for each case was determined from the slopes of the logarithmic plots shown in Figure 5.18b and Figure 5.18e. b values of 0.64 and 0.59 were determined for the cathodic and anodic reactions of H-CuHCF respectively, while values of 0.57 and 0.51 were determined for D-CuHCF's cathodic and anodic reactions, respectively. All b values are close to 0.5 indicating a diffusion-limiting process for both samples, with H-CuHCF displaying slightly more pseudocapactive behavior than D-CuHCF. 
(a)

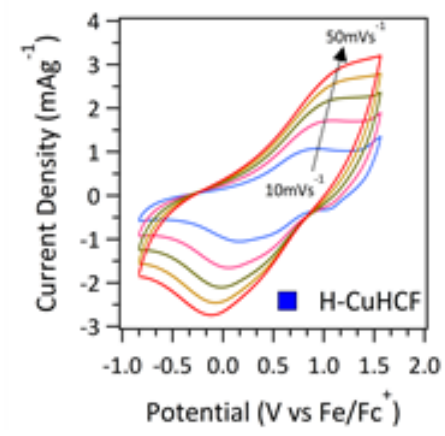

(d)

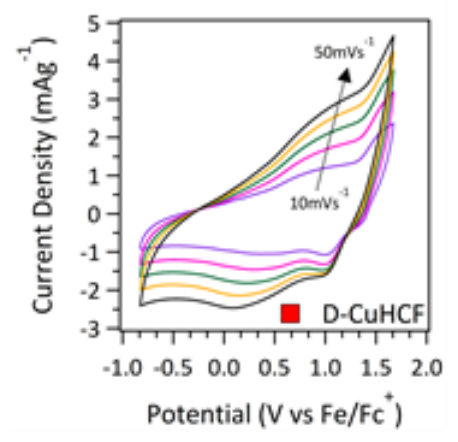

(b)

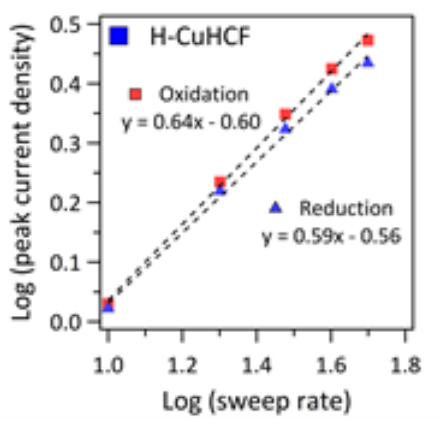

(e)

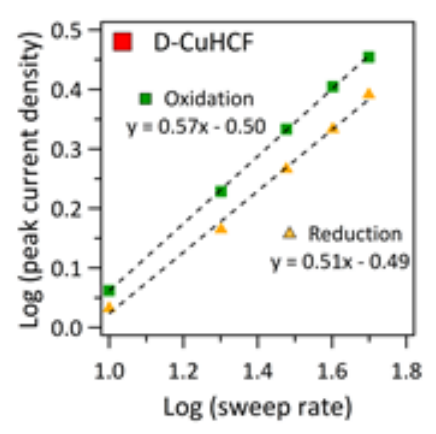

(c)

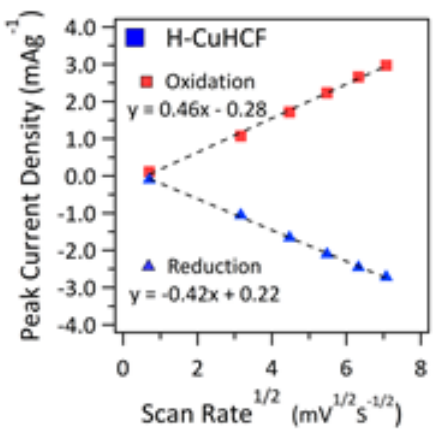

(f)

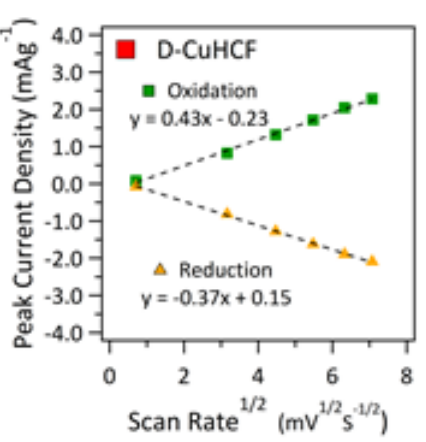

Figure 5.18 (a,d) Cyclic voltammograms of $\mathrm{H}$ - and D-CuHCF at scan rates from 10 to $50 \mathrm{mV} \mathrm{s}^{-1}$ in $1 \mathrm{M} \mathrm{Mg}\left(\mathrm{ClO}_{4}\right)_{2}$ in $\mathrm{PC} / \mathrm{EC}=50 / 50$. (b,e) the corresponding log (peak current density) vs log (sweep rate) plots used to calculate the b coefficients. (c, f) the corresponding peak current density vs square root of the scan rate plots used to estimate $\mathrm{Mg}^{2+}$ diffusion coefficients.

Diffusion coefficients were estimated by the Randles-Sevcik equation, fitted to the linear plot of peak current versus square root of the scan rate shown in Figure $5.18 \mathrm{c}$ and Figure 5.18f, which models diffusion limited quasi-reversible reactions [206]:

$$
i_{\text {peak }}=0.4463 \times \sqrt{\frac{n^{3} F^{3}}{R T}} \times \sqrt{D} \times C_{o} x \sqrt{v}
$$

where $i_{p}$ is the peak current $(A), n$ is the number of electrons transferred in the reaction, F is Faraday's constant, $R$ is the ideal gas constant, $T$ is temperature $(K), D$ is the diffusion 
coefficient $\left(\mathrm{cm}^{2} \mathrm{sec}^{-1}\right), \mathrm{C}_{0}$ is the concentration of active sites $\left(\mathrm{mol} \mathrm{cm}^{-3}\right)$, and $v$ is the cyclic voltammogram sweep rate. $C_{0}$ was estimated from the specific capacitance and density of the material. Diffusion coefficients for the oxidation $\left(D_{o x}\right)$ and reduction $\left(D_{\text {red }}\right)$ reactions of H-CuHCF were estimated to be $4.8 \times 10^{-10}$ and $4.1 \times 10^{-10} \mathrm{~cm}^{2} \mathrm{sec}^{-1}$ respectively, and $2.5 \times 10^{-10}$ and $1.8 \times 10^{-10} \mathrm{~cm}^{2} \mathrm{sec}^{-1}$ for D-CuHCF respectively, which are on the order of other nonaqueous PBA systems [77]. The similar $\mathrm{Mg}^{2+}$ diffusion kinetics and rate capability of both the hydrated and dehydrated samples highlights the importance of the shared structural properties of CuHCF, including its open framework and mechanical stability. Neither H- or D-CuHCF display any degradation after undergoing rate or lifetime tests, while delivering reversible capacities of 63 and $50 \mathrm{mAh} \mathrm{g}^{-1}$ at $25 \mathrm{~mA} \mathrm{~g}^{-1}$, respectively. The increase in capacity for H-CuHCF is attributed to the accessibility of a second redox step that accounts for $25 \%$ of its total capacity $\left(16 \mathrm{mAh} \mathrm{g}^{-1}\right)$ at $25 \mathrm{~mA} \mathrm{~g}^{-1}$.

To better understand the role of water during charging/discharging, ex situ FTIR spectra of H-CuHCF were collected (Figure 5.19). The large absorption peak at $1763 \mathrm{~cm}^{-1}$ corresponds to the $\mathrm{C}=\mathrm{O}$ stretching frequency of ethylene carbonate [258], confirming the intercalation of electrolyte into the CuHCF lattice. The zeolitic and coordinated water peak at $1628 \mathrm{~cm}^{-1}$ maintains a constant intensity between the fully charged and fully discharged states, indicating that water does not accompany $\mathrm{Mg}^{2+}$ during intercalation/deintercalation, but instead remains within the lattice. Based on this stability, it is proposed that the internal water is predominantly coordinated to the CuHCF framework at the $24 \mathrm{e}$ site. The second redox reaction and improved charge storage 


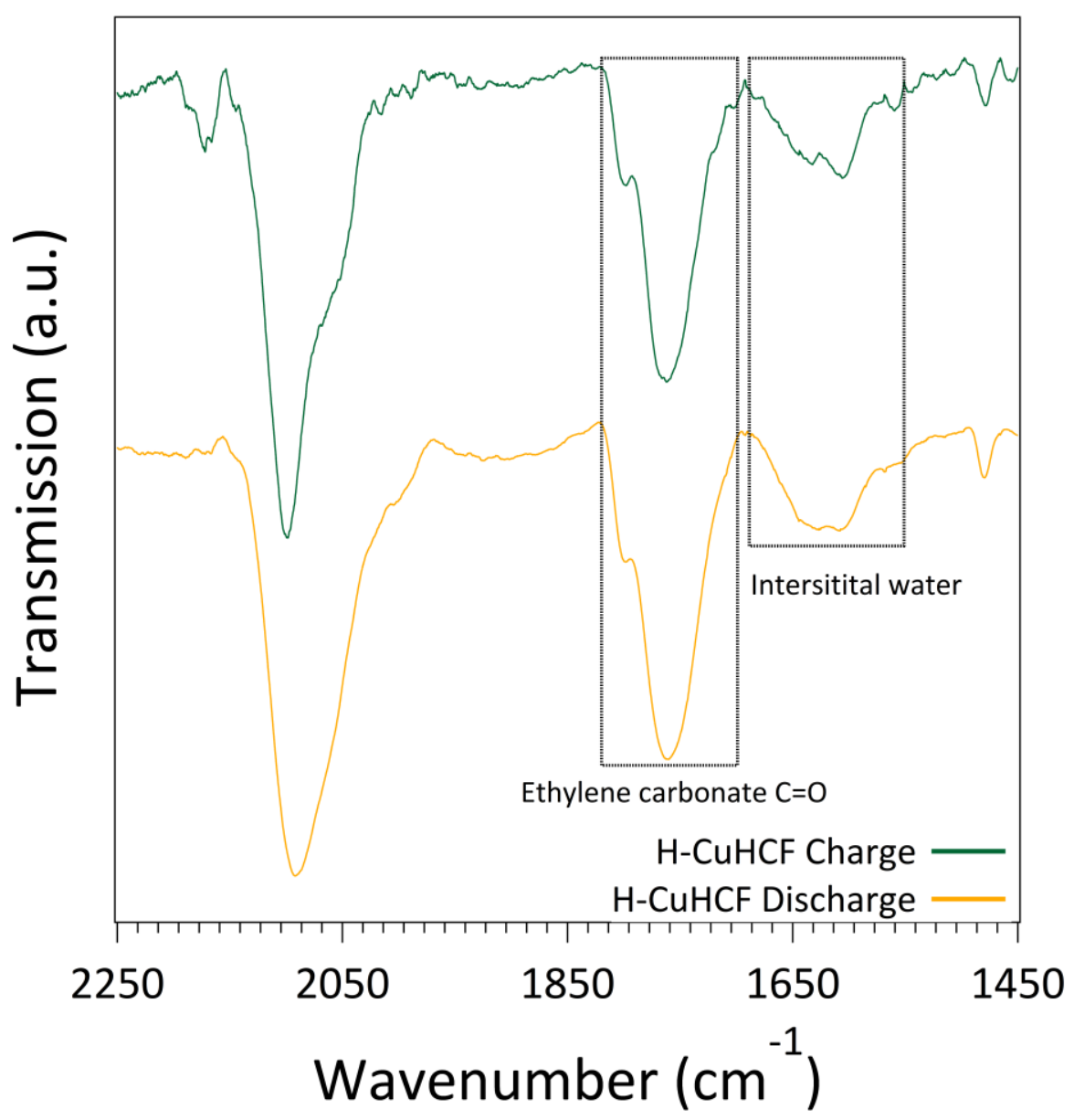

Figure 5.19 Ex situ FTIR analysis of H-CuHCF. The interstitial and zeolitic water peak at $1628 \mathrm{~cm}^{-1}$ does not change between fully charge and fully discharged, demonstrating the water does not leave the lattice.

capacity of $\mathrm{H}$-CuHCF are believed to be due to electrostatic shielding provided by the static coordinated and zeolitic water, which allows for the B lattice sites with dangling $\mathrm{Cu}$ atoms to become thermodynamically accessible [115]. The presence of water in the lattice has been proposed to have similar effects for PBAs, as well as other magnesium ion cathodes, such as: layered $\mathrm{MoO}_{2}$ [245], and $\mathrm{V}_{2} \mathrm{O}_{5}$ [246]. 


\subsection{Conclusion:}

The charge storage capacities of hydrated and dehydrated CuHCF in non-aqueous electrolytes have been investigated by characterizing the structural and electrochemical properties of hydrated and dehydrated CuHCF. Both hydrated and dehydrated CuHCF show reversible $\mathrm{Mg}^{2+}$ intercalation, and zeolitic and coordinated water content was shown to increase measured charge storage capacity by approximately $25 \%$. FTIR and TGA analysis show that thermal treatment of the bare CuHCF powder at $100{ }^{\circ} \mathrm{C}$ effectively removes $63 \%$ of the zeolitic and coordinated water molecules, while prepared $\mathrm{H}$-CuHCF electrodes are able to retain their water effectively during the curing process. This result is believed to be due to the presence of the PVDF binder, which helps keep water in the $\mathrm{H}$-CuHCF lattice. Benefiting from the stable structure and large interstitial spacing of the underlying CuHCF framework, both the hydrated and dehydrated materials exhibit excellent rate and cycle lifetime performances, neither of which show any loss of capacity after 500 cycles at $300 \mathrm{~mA} \mathrm{~g}^{-1}$. However, by maintaining its zeolitic and coordinated water, $\mathrm{H}$-CuHCF achieves a $25 \%$ increase in storage capacity. Ex situ FTIR reveals that water does not accompany $\mathrm{Mg}^{2+}$ ions during intercalation/deintercalation. We propose that the water plays a supporting role within the lattice, providing partial electrostatic screening of the divalent $\mathrm{Mg}$ ions, while also allowing a new redox transition to become thermodynamically accessible. The presence of a second redox peak in H-CuHCF accounts for the difference in storage capacity between H-CuHCF and D-CuHCF. 


\subsection{Additional Commentary on Published Work}

Kuperman N, Cairns A, Goncher G, Solanki R. Structural water enhanced intercalation of magnesium ions in copper hexacyanoferrate nonaqueous batteries. Electrochimica Acta 2020;362:137077. https://doi.org/10.1016/j.electacta.2020.137077. [238]

The studies presented in this chapter were undertaken to:

1. Develop non-lithium ion based systems utilizing PBA cathodes, with a particular focus on divalent ion systems.

2. Determine if maintaining coordinated and zeolitic water improved the magnesium ion storage properties of copper hexacyanoferrate in a nonaqueous electrolyte.

The results obtained in this study helped to accomplish these goals by expanding our knowledge of the effects of coordinated and zeolitic water in the battery system consisting of a $\mathrm{Cu}\left[\mathrm{Fe}(\mathrm{CN})_{6}\right]$ cathode with a $\mathrm{Mg}^{+2}$ cation in a non-aqueous solvent (propylene carbonate and ethylene carbonate mixture). Mizuno et al. demonstrated reversible intercalation of $\mathrm{Mg}$ into $\mathrm{CuHCF}$ in an aqueous electrolyte and reported a reversible specific capacity of $50 \mathrm{mAh} \mathrm{g}^{-1}$ [111]. The specific capacity of CuHCF in the completely nonaqueous systems reported in this work was smaller than Mizuno's value, as expected, a consequence of different ionic mobilities in the electrolyte and ionic diffusion in the PBA lattice. However, by retaining coordinated water in CuHCF, specific 
capacities for nonaqueous electrolytes were consistent with those reported by Mizuno.

The benefit of nonaqueous electrolytes is the ability to use metallic Mg anodes, which can provide significant increases in energy density. In general, $\mathrm{Mg}$ metal is not volatile in air which reduces potential catastrophic failures, and $\mathrm{Mg}$ is relatively abundant (7th most abundant element in the Earth's crust). 


\section{Chapter 6.}

Manganese-Nickel Hexacyanoferrate and its Application as a Cathode Material for Nonaqueous Potassium Ion Batteries

This chapter examines manganese-nickel hexacyanoferrate as a cathode material for nonaqueous potassium ion batteries (PIBs). Temporary closures of crucial facilities due to the COVID-19 pandemic have prolonged the completion of this study and thus a manuscript is now being prepared for submission. All experimental data have been collected and analyzed except for scanning electron microscopy, energy dispersive x-ray spectroscopy and inductively coupled plasma mass spectroscopy (ICP-MS). These final measurements will provide information on particle size and morphology, elemental distribution, and elemental composition of materials. In particular, particle size could inform the analyses of ionic diffusion and rate capability.

The following work is presented in its current form and additional comments on the potential impact of the uncollected data is at the end. 


\subsection{Introduction}

This study examines manganese-nickel hexacyanoferrate (MnNiCHF) as a cathode material for nonaqueous potassium ion batteries. Pure nickel hexacyanoferrate has the advantage of being structurally stable during discharge, but suffers from low specific capacities due to the redox inactivity of $\mathrm{Ni}$. Pure manganese hexacyanoferrate has a high theoretical capacity as $\mathrm{Mn}$ is redox active, however Jahn-Teller distortions during charging and discharging cause significant capacity loss over time [153,259-261]. Figure 6.1 presents a schematic representation of $\mathrm{NaMn}_{x} \mathrm{Ni}_{1-x}\left[\mathrm{Fe}(\mathrm{CN})_{6}\right]$.

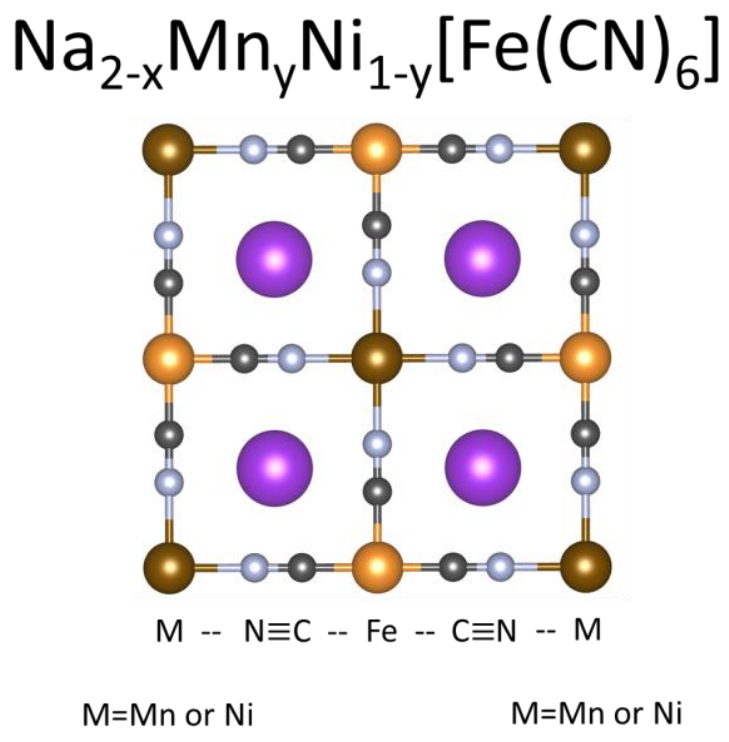

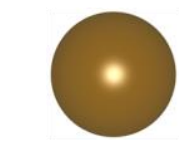

$M=$ $\mathrm{Mn}(\mathrm{HS})$ or $\mathrm{Ni}$

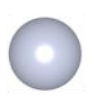

$\mathbf{N}$

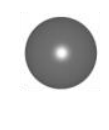

C

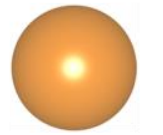

$\mathrm{Fe}$ (LS)

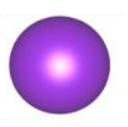

K

Figure 6.1 Schematic of $\mathrm{Na}_{2} \mathrm{Mn}_{x} \mathrm{Ni}_{1-\mathrm{x}}\left[\mathrm{Fe}(\mathrm{CN})_{6}\right]$. 
The goal of this study was to determine if the introduction of both $\mathrm{Ni}$ and $\mathrm{Mn}$ into a mixed-metal hexacyanoferrate could provide improved capacity, compared to either NiHCF or MnHCF, by combining the crystal stability provided by $\mathrm{Ni}$ atoms with the favorable redox properties provided by Mn atoms.

The materials chosen for examination are $\mathrm{Na}_{2} \mathrm{Ni}\left[\mathrm{Fe}(\mathrm{CN})_{6}\right], \mathrm{Na}_{2} \mathrm{Mn}\left[\mathrm{Fe}(\mathrm{CN})_{6}\right]$, $\mathrm{Na}_{2} \mathrm{Mn}_{0.50} \mathrm{Ni}_{0.50}\left[\mathrm{Fe}(\mathrm{CN})_{6}\right]$ and $\mathrm{Na}_{2} \mathrm{Mn}_{0.25} \mathrm{Ni}_{0.75}\left[\mathrm{Fe}(\mathrm{CN})_{6}\right]$. The latter two materials possess the same cubic crystal structure as NiHCF, eliminating the impact of crystalline phase. $\mathrm{Na}_{2} \mathrm{Mn}\left[\mathrm{Fe}(\mathrm{CN})_{6}\right]$ crystallized in a monoclinic structure, however the impact of increasing Mn concentrations occurs prior to the change in phase, allowing for trends independent of structure to be identified.

\subsection{Methods}

\subsubsection{Synthesis:}

Nickel hexacyanoferrate was synthesized via coprecipitation similar to our previous work, with slight modification [221]. Briefly, $40 \mathrm{mM}$ of $\mathrm{NiCl}_{2} \cdot 6 \mathrm{H}_{2} \mathrm{O}$ was dissolved in $80 \mathrm{~mL}$ of deionized (DI) water (solution A), and $20 \mathrm{mM}$ of $\mathrm{Na}_{4} \mathrm{Fe}(\mathrm{CN})_{6}$ was dissolved separately in $80 \mathrm{~mL}$ of DI water (solution B). Solutions A and B were simultaneously added dropwise into $40 \mathrm{~mL} \mathrm{NaCl}(5 \mathrm{M} \mathrm{aq})$ under constant stirring and maintained at $60^{\circ} \mathrm{C}$ for two hours. The resulting precipitate was collected, washed via centrifugation with DI water followed by a final wash with ethanol, and allowed to dry in air. After air drying, the resulting powder was annealed at $100^{\circ} \mathrm{C}$ under vacuum for two hours and allowed to cool 
slowly. The same procedure was followed to synthesize the mixed nickel manganese and pure manganese hexacyanoferrate powders, except that the ratio of metal chloride salts varied depending on the sample. The Ni:Mn ratios were: 1:0, 3:1, 1:1, and 0:1 denoted as NiHCF, MnNiHCF-1, MnNiHCF-2, and MnHCF respectively.

\subsubsection{Material Characterization:}

The crystal structure of each sample was characterized using powder X-ray diffraction (XRD) performed on a Rigaku Ultima IV X-ray diffractometer with $\mathrm{Cu} \mathrm{K} \alpha$ radiation $(\lambda=1.54056 \AA)$. Indexing and structure refinement were conducted using the Fullprof crystallographic suite $[215,247]$. Thermal and water content analysis was performed using a thermogravimetric analyzer (TGA, Mettler TGA-50) from 50 to $300{ }^{\circ} \mathrm{C}$ at a heating rate of $5{ }^{\circ} \mathrm{C} \mathrm{min}^{-1}$ under flowing $\mathrm{N}_{2}$. Fourier transform infrared spectroscopy (FTIR, Thermo Scientific Nicolet iS10 FTIR equipped with diamond ATR) in the range of $600-3800 \mathrm{~cm}^{-1}$ was used to probe the chemical environment of the cyanide ligand and determine the oxidation states of the transition metals. FTIR in the range of $90-690 \mathrm{~cm}^{-1}$ was performed on a Thermo Scientific Nicolette 6700 equipped with a DTGS detector to probe the metal-carbon and metal-nitrogen bonding.

\subsubsection{Electrochemical Measurements:}

Cathodes were prepared by coating a slurry of a $\mathrm{Na}_{x} \mathrm{Mn}_{y} \mathrm{Ni}_{1-y}\left[\mathrm{Fe}(\mathrm{CN})_{6}\right]$ powder, polyvinylidene fluoride (PVDF), multi-walled carbon nanotubes, and activated carbon in 
the ratio of $80: 9: 9: 2$, respectively by weight in $\mathrm{N}$-methyl-2-pyrolidone (NMP) onto carbon paper. The carbon paper was cleaned with ethanol and dried prior to use. Coated electrodes were annealed for two hours at $100{ }^{\circ} \mathrm{C}$ under vacuum prior to use. All electrochemical measurements were performed using a Gamry reference-600 potentiostat in a three-electrode setup. In general, cells consisted of the respective cathode, a carbon rod counter electrode, an $\mathrm{Ag} / \mathrm{Ag}^{+}$in propylene carbonate reference electrode, and an electrolyte of saturated potassium hexafluorophosphate (sat $\mathrm{KPF}_{6}$ ) in a mixture of propylene carbonate (PC) and ethylene carbonate (EC) $[P C / E C=50 / 50$ by volume]. All reference electrodes were calibrated against the $\mathrm{Fc} / \mathrm{Fc}^{+}$redox couple.

\subsection{Results}

The XRD patterns of the as synthesized powders are shown in Figure 6.2a. NiHCF is indexed to the well-known PBA cubic structure with lattice parameter $10.20 \AA$. Substitution of $\mathrm{Mn}$ for $\mathrm{Ni}$ causes an expansion of the lattice, observed as a downward shift in $2 \theta$ (Figure 6.2b). This is a consequence of the larger radius of high spin, octahedrally crystallized coordinated, $\mathrm{Mn}^{2+}(97 \mathrm{pm})$ compared to the octahedrally coordinated $\mathrm{Ni}^{2+}(83 \mathrm{pm})$ [232]. MnNiHCF-1, and MnNiHCF-2 are indexed to cubic systems with lattice parameters $10.27 \AA$, and $10.33 \AA$ respectively. The XRD patterns for the mixed metal samples confirm that each formed a single phase, incorporating both $\mathrm{Mn}$ and $\mathrm{Ni}$, rather than mixtures of NiHCF and MnHCF. Pure MnHCF shows a monoclinic structure with lattice parameters $a=10.54 \AA, b=7.47 \AA, c=7.41 \AA$, and $\beta=91.83^{\circ}$. MnHCF with high Na 

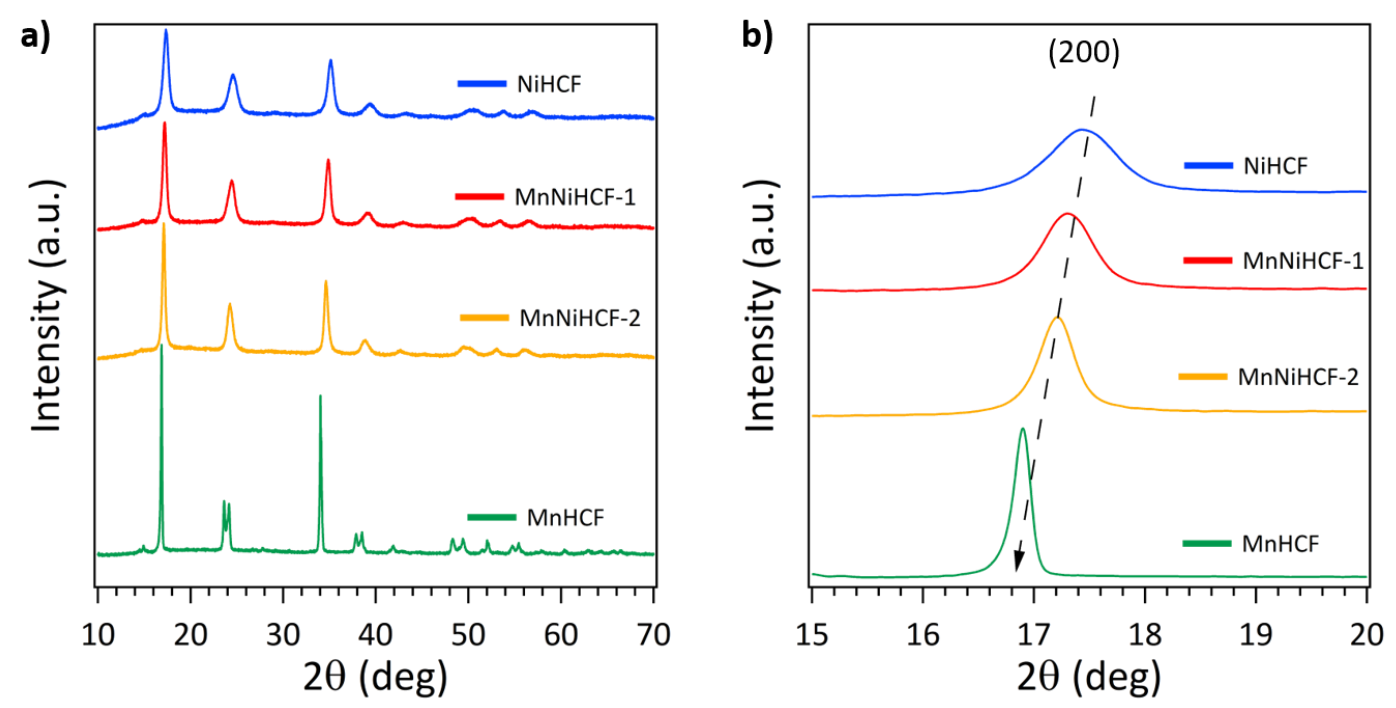

Figure 6.2 (a) XRD profile for the as-synthesized, unannealed, $\mathrm{Na}_{2} \mathrm{Mn}_{\times} \mathrm{Ni}_{1-x}\left[\mathrm{Fe}(\mathrm{CN})_{6}\right]$ powders. NiHCF, MnNiHCF-2, and MnNiHCF-2 all crystallized into a cubic structure, and MnHCF crystallized into a monoclinic structure. (b) (200) reflection for as synthesized samples. The decreasing $2 \theta$ indicates an increasing lattice parameter with increasing Mn concentration.

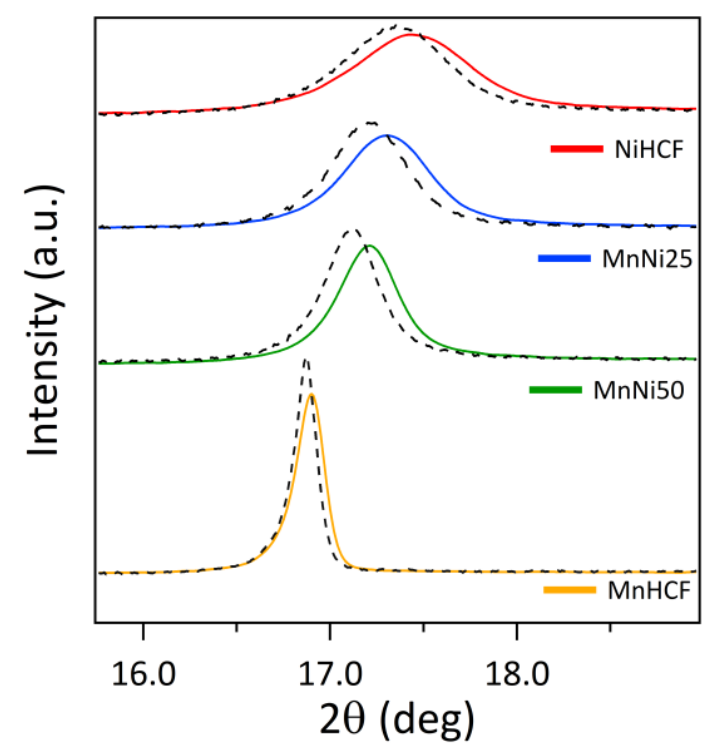

Figure 6.3 (200) reflection for the as-synthesized (dotted lines) and the annealed (solid lines) samples 
concentrations is known to undergo the observed monoclinic distortion [251,262]. XRD profiles of the annealed samples show increases in $2 \theta$ of the largest diffraction peak, which corresponds to the (200) reflection, indicating a contraction of the lattice (figure 6.3). Similar phenomena have been reported for PBAs upon the removal of interstitial and coordinated water [149]. The pre and post anneal lattice parameters presented in table 6.1.

Table 6.1 Lattice parameters for the as-synthesized and annealed $\mathrm{Na}_{2} \mathrm{Mn}_{x} \mathrm{Ni}_{1-\mathrm{x}}\left[\mathrm{Fe}(\mathrm{CN})_{6}\right]$ samples

\begin{tabular}{|c|c|c|}
\hline & As synthesized & Annealed $100^{\circ} \mathrm{C}$ \\
\hline \multirow[t]{2}{*}{$\mathrm{NiHCF}$} & $a=b=c=10.20 \AA$ & $a=b=c=10.21 \AA$ \\
\hline & $\alpha=\beta=\gamma=90^{\circ}$ & $\alpha=\beta=\gamma=90^{\circ}$ \\
\hline \multirow{2}{*}{ MnNiHCF-1 } & $a=b=c=10.27 \AA$ & $a=b=c=10.25 \AA$ \\
\hline & $\alpha=\beta=\gamma=90^{\circ}$ & $\alpha=\beta=\gamma=90^{\circ}$ \\
\hline \multirow{2}{*}{ MnNiHCF-2 } & $a=b=c=10.33 \AA$ & $a=b=c=10.32 \AA$ \\
\hline & $\alpha=\beta=\gamma=90^{\circ}$ & $\alpha=\beta=\gamma=90^{\circ}$ \\
\hline \multirow{2}{*}{$\mathrm{MnHCF}$} & $a=10.54 \AA, b=7.47 \AA, c=7.41 \AA$ & $a=10.51 \AA, b=7.45 \AA, c=7.38 \AA$ \\
\hline & $\alpha=\gamma=90^{\circ}, \beta=91.83^{\circ}$ & $\alpha=\gamma=90^{\circ}, \beta=92.01^{\circ}$ \\
\hline
\end{tabular}




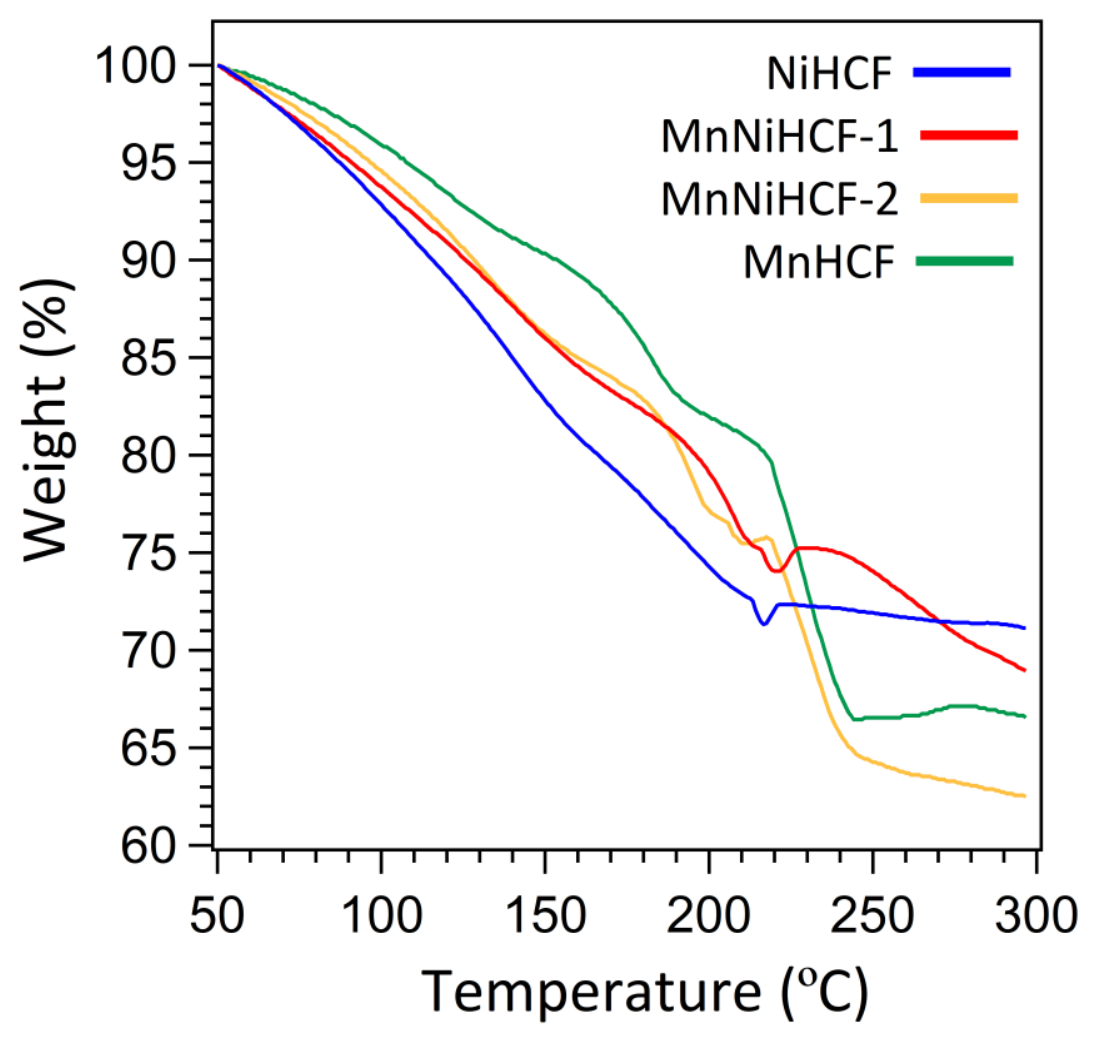

Figure 6.4 Thermogravimetric curves for as-synthesized $\mathrm{Na}_{2} \mathrm{Mn}_{x} \mathrm{Ni}_{1-\mathrm{x}}\left[\mathrm{Fe}(\mathrm{CN})_{6}\right]$ samples. The zeolitic water contentment for each sample increases with $\mathrm{Mn}$ concentration, while the percentage of coordinated water for each sample is $9 \%$.

Thermogravimetric analysis was carried out to study the water content of the $\mathrm{Na}_{2} \mathrm{Mn}_{\mathrm{x}} \mathrm{Ni}_{1-\mathrm{x}} \mathrm{HCF}$ samples. Figure 6.4 displays the TGA spectra for the as-synthesized samples, each exhibiting a multistep dehydration process. The two mass loss steps occurring between $50^{\circ} \mathrm{C}$ and $210^{\circ} \mathrm{C}$ are associated with the removal of water molecules from distinct lattice locations: the first corresponds to removal of zeolitic water and the second to the removal of coordinated water [263]. Interestingly, the amount of coordinated water is relatively consistent across all samples but the concentration of 
zeolitic water decreases with increasing manganese. After annealing, all samples show a decrease in zeolitic water content but no loss in coordinated water. TGA data is summarized in Table 6.2.

FTIR spectroscopy was applied to examine the effects of substituting $\mathrm{Mn}$, for $\mathrm{Ni}$, on the bonding characteristics of the resulting manganese-nickel hexacyanoferrate. The vibrational properties of the cyanide in a PBA are dependent on the coordinated metal atoms, their respective oxidation state(s) and electronegativities, providing individual signatures for each material [264-266]. Figure 6.5 displays spectra for the as-prepared samples.

Table 6.2 Summary of zeolitic and coordinated water content as determined by thermogravimetric analysis.

As synthesized

Zeolitic: $8 \%$

$\mathrm{NiHCF}$

Coordinated: $9 \%$

Zeolitic: $13 \%$

MnNiHCF-1

Coordinated: $9 \%$

Zeolitic: 15\%

MnNiHCF-2
Annealed $100^{\circ} \mathrm{C}$

Zeolitic: 5\%

Coordinated: $8 \%$

Zeolitic: $8 \%$

Coordinated: $9 \%$

Zeolitic: 11\%

Coordinated: $9 \%$

Zeolitic: $10 \%$

MnHCF
Zeolitic: $18 \%$

Coordinated: $9 \%$
Coordinated: $9 \%$ 
The strong absorption band in the range of $2000-2080 \mathrm{~cm}^{-1}$ is characteristic to the cyanide stretching frequency, $v(C N)$, of $\mathrm{M}^{2+}-\mathrm{NC}-\mathrm{Fe}^{2+}(\mathrm{M}=\mathrm{Ni}, \mathrm{Mn})$ [267-270]. Substitution of $\mathrm{Mn}^{2+}\left(\sigma_{\mathrm{Mn}}=\mathrm{Z} / \mathrm{r}^{2}=2.9\right)$ for $\mathrm{Ni}^{2+}\left(\sigma_{\mathrm{Ni}}=\mathrm{Z} / \mathrm{r}^{2}=4.2\right)$ lowers the effective polarizing power $\left(\sigma_{\text {eff }}=\mathrm{x}^{*} \sigma_{\mathrm{Mn}}+(1-\mathrm{x})^{*} \sigma_{\mathrm{Ni}}\right)$ of the $\mathrm{N}$-coordinated metals, inducing a redistribution of the electron density across the cyanide towards the carbon end of the ligand [84]. This shift causes the $\mathrm{CN}$ triple bond to weaken, observed as a linear decrease in $v(\mathrm{C} \equiv \mathrm{N})$ with respect to $\mathrm{Mn}$ concentration.

The broad band centered at $3350 \mathrm{~cm}^{-1}$ corresponds to the $\mathrm{O}-\mathrm{H}$ stretching frequency of free surface water, while the sharp peak at $1610 \mathrm{~cm}^{-1}$ and shoulder at 1650 $\mathrm{cm}^{-1}$ are characteristic of zeolitic water and coordinated water respectively [251]. With increasing $\mathrm{Mn}$, each water peak decreases in intensity, mirroring the TGA data and further highlighting the impact of $\mathrm{Mn}$ on the quality of the as-synthesized material. FTIR spectra of the annealed samples confirms the successful removal of the majority of surface water and partial removal of zeolitic water (Figure 6.6).

FTIR spectra in the far IR region were collected to directly probe the local environment around the carbon end of the cyanide bond (Figure 6.7). The band near 600 $\mathrm{cm}^{-1}$ is assigned to the Fe-C stretching frequency, $v(\mathrm{Fe}-\mathrm{C})$ [271]. With increasing $\mathrm{Mn}$ concentrations, the Fe-C band shifts to higher wavenumbers indicating a shortening and strengthening of the Fe- $\mathrm{C}$ bond. Both $v(\mathrm{Fe}-\mathrm{C})$ and $v(\mathrm{C} \equiv \mathrm{N})$ exhibit a linear relationship with the effective polarizating power of the $\mathrm{N}$-coordinated metals as shown in Figure 6.8. 

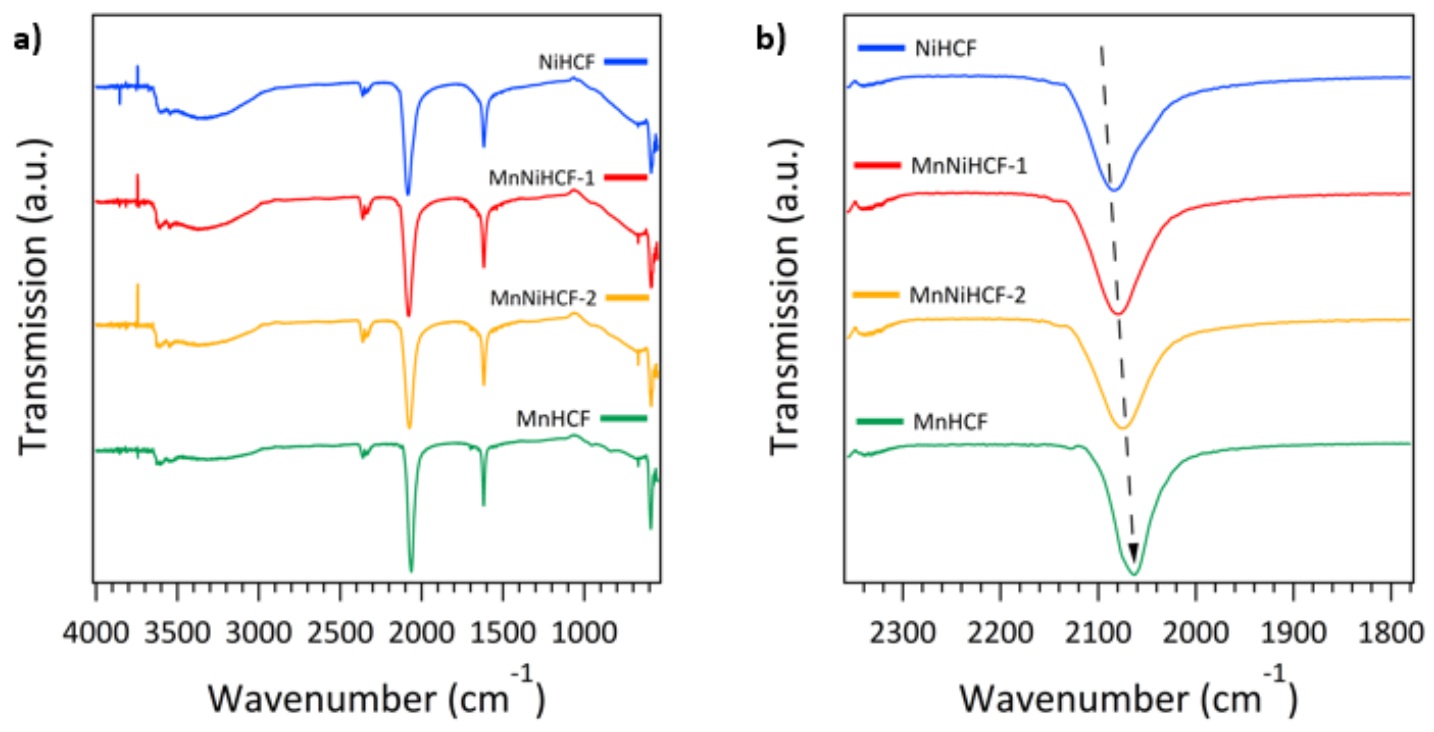

Figure 6.5 a) FTIR of the as-synthesized $\mathrm{Na}_{2} \mathrm{Mn}_{x} \mathrm{Ni}_{1-x}\left[\mathrm{Fe}(\mathrm{CN})_{6}\right]$. b) $v(\mathrm{C} \equiv \mathrm{N})$ of the as-synthesized samples. The downward shift in $v(\mathrm{C} \equiv \mathrm{N})$ with increasing $\mathrm{Mn}$ concentration indicates a weakening of the cyanide bond.

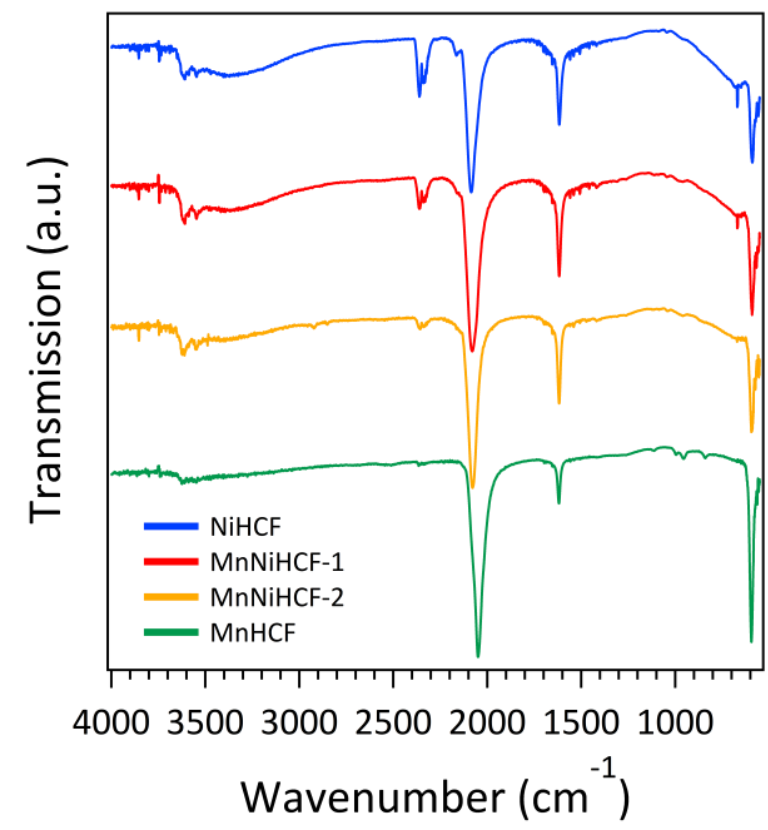

Figure 6.6 FTIR spectra of the $100{ }^{\circ} \mathrm{C}$ annealed samples of $\mathrm{Na}_{2} \mathrm{Mn}_{\times} \mathrm{Ni}_{1-x}\left[\mathrm{Fe}(\mathrm{CNN})_{6}\right]$. 

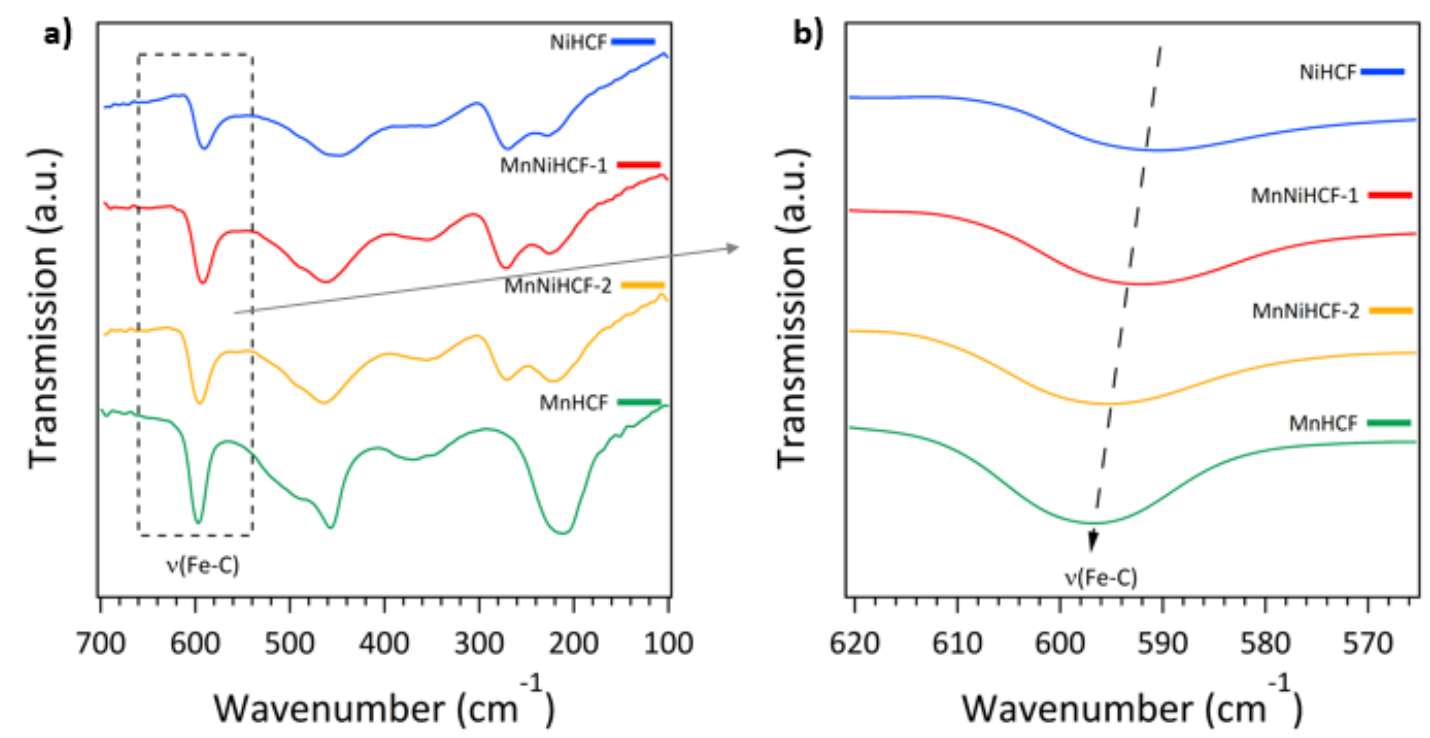

Figure 6.7 a) Far IR FTIR spectra for the as-synthesized $\mathrm{Na}_{2} \mathrm{Mn}_{x} \mathrm{Ni}_{1-x}\left[\mathrm{Fe}(\mathrm{CN})_{6}\right]$ samples. b) $v(\mathrm{Fe}-\mathrm{C})$ of the as-synthesized samples. The upward shift in $v(\mathrm{Fe}-\mathrm{C})$ with increasing $\mathrm{Mn}$ concentration indicates a strengthening of the Fe-C bond.

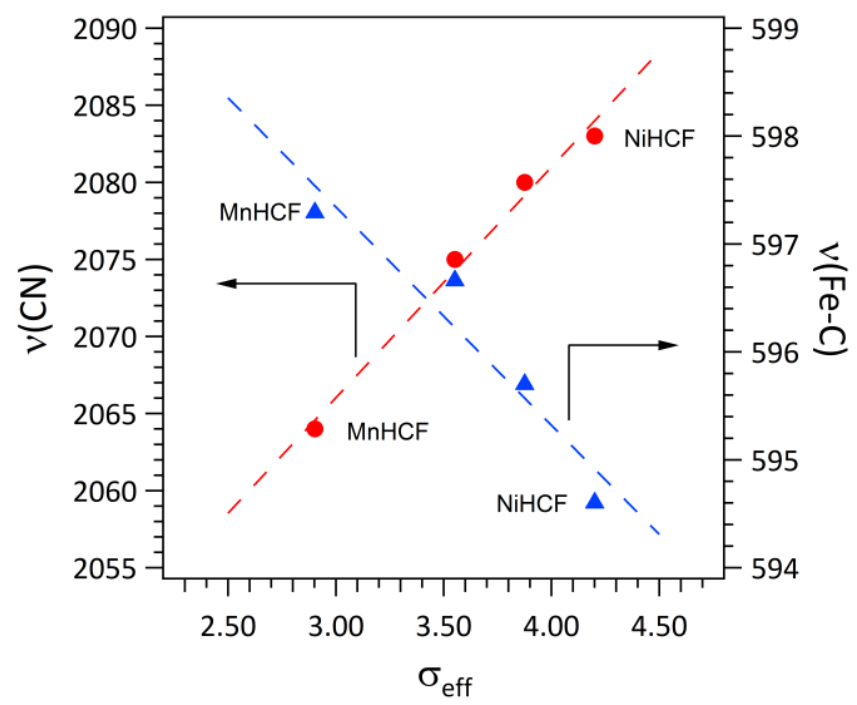

Figure 6.8 Relationships between the effective polarizing power of the nitrogen coordinated metals and the stretching frequencies for $v(\mathrm{C} \equiv \mathrm{N})$ and $v(\mathrm{Fe}-\mathrm{C})$. $\sigma_{\text {eff }}$ decreases with increasing $\mathrm{Mn}$ concentration, which in a decrease in $v(\mathrm{C} \equiv \mathrm{N})$ and increase in $v(\mathrm{Fe}-\mathrm{C})$. These trends are indicative of a weakening of the cyanide bond and a strengthening of the iron-carbon bond. 
SEM + EDS Data: These results are pending.

ICPMS Data: These results are pending.

The electrochemical performances of the $\mathrm{Mn}_{\mathrm{x}} \mathrm{Ni}_{1-\mathrm{x}} \mathrm{HCF}$ samples were examined by galvanic charge discharge and cyclic voltammetry. All measurements were conducted using a three-electrode configuration in sat $\mathrm{KPF}_{6}$ in $\mathrm{PC}$ and $\mathrm{EC}$ in a 1-to-1 ratio by volume and referenced to the $\mathrm{Fc} / \mathrm{Fc}^{+}$redox couple. As indicated by Figure 6.9 the $\mathrm{Fe}^{3+} / \mathrm{Fe}^{2+}$ discharge potential is linearly proportional to the Mn concentration as well as the ironcarbon stretching frequency, with $\mathrm{NiHCF}\left(0.35 \mathrm{~V}\right.$ vs Fc/Fc $\left.{ }^{+}\right)<\mathrm{MnNiHCF}-1\left(0.40 \mathrm{~V}\right.$ vs Fc/Fc $\left.{ }^{+}\right)$ $<\operatorname{MnNiHCF}-2\left(0.42 \mathrm{~V}\right.$ vs Fc/Fc $\left.{ }^{+}\right)<\operatorname{MnHCF}(0.48 \mathrm{~V}$ vs Fc/Fc $)$. Other reports have shown similar behavior, with the iron redox potential varying linearly with respect to changing the ratio of two $\mathrm{N}$-coordinated transition metals $[93,153]$. Figure $6.10 \mathrm{a}-\mathrm{d}$ compares the initial charge discharge profiles at $25 \mathrm{mAg}^{-1}$ of the mixed metal samples as well as the homogeneous NiHCF and MnHCF. Specific capacities of the Ni containing samples increase with $\mathrm{Mn}$ incorporation, with NiHCF, MnNiHCF-1 and MnNiHCF-2 delivering capacities of 80,103 , and $110 \mathrm{mAhg}^{-1}$ respectively. A decrease in the reversible capacity of pure MnHCF to $105 \mathrm{mAhg}^{-1}$ is observed, despite its conformity to the relationship between $\mathrm{Fe}^{2+} / \mathrm{Fe}^{3+}$ redox potential and $\mathrm{Mn}$ concentration. The increase in the specific capacities of MnNiHCF-1 and MnNiHCF-2 is ascribed to the substitution of the electroactive $\mathrm{Mn}$ for the electrochemically inactive Ni. However, the decreased capacity and increased $\mathrm{Fe}^{2+} / \mathrm{Fe}^{3+}$ redox potential of MnHCF highlights the important role both $\mathrm{Ni}$ 

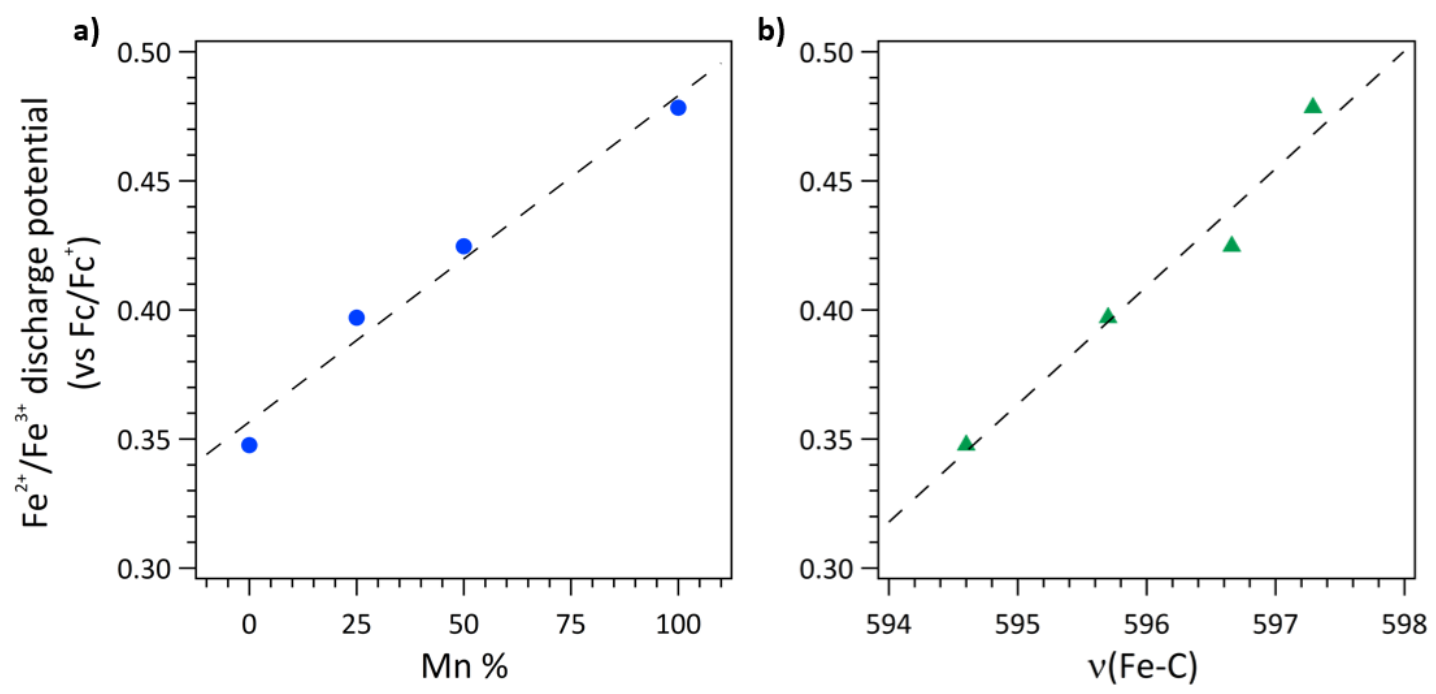

Figure 6.9 (a) Plot of $\mathrm{Fe}^{3+} / \mathrm{Fe}^{2+}$ discharge potential verses percent $\mathrm{Mn}$. (b) Plot of $\mathrm{Fe}^{3+} / \mathrm{Fe}^{2+}$ discharge potential verses $v(\mathrm{Fe}-\mathrm{C})$

and $\mathrm{Mn}$ have on modulating the electrochemical and physical properties of the resulting and increased $\mathrm{Fe}^{2+} / \mathrm{Fe}^{3+}$ redox potential of MnHCF highlights the important role both $\mathrm{Ni}$ and $\mathrm{Mn}$ have on modulating the electrochemical and physical properties of the resulting material.

Rate capability tests for each sample were conducted at $45,65,85,100$, and $200 \mathrm{mAg}^{-1}$ (Figure 6.10e). Figure $6.10 \mathrm{f}$ compares the normalized capacity $\left(\mathrm{Q} / \mathrm{Q}_{0}\right)$ of the samples as a function of current density, where $Q$ is the capacity at different current densities and $\mathrm{Q}_{0}$ is the capacity at $25 \mathrm{mAg}-1$. NiHCF, MnNiHCF-1 and MnNiHCF-2 each exhibit excellent capacity retention at increased current densities, respectively delivering 69,85 , and 90 mAhg $^{-1}$ accounting for $85 \%, 83 \%$, and $81 \%$ of their initial capacities at $200 \mathrm{mAg}^{-1}$. Additionally, all $\mathrm{Ni}$ contain samples recovered $100 \%$ of their initial capacity 

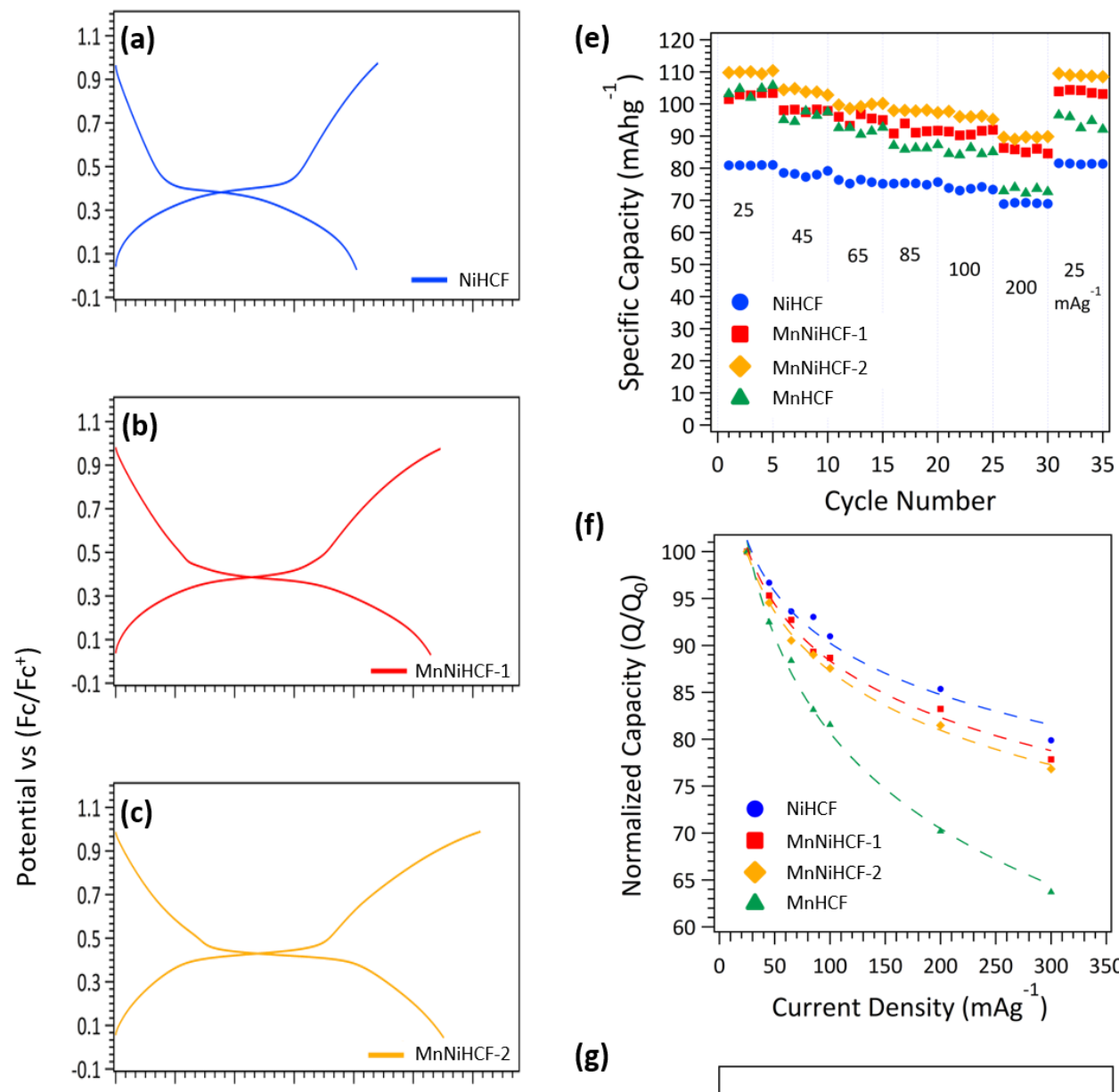

(f)

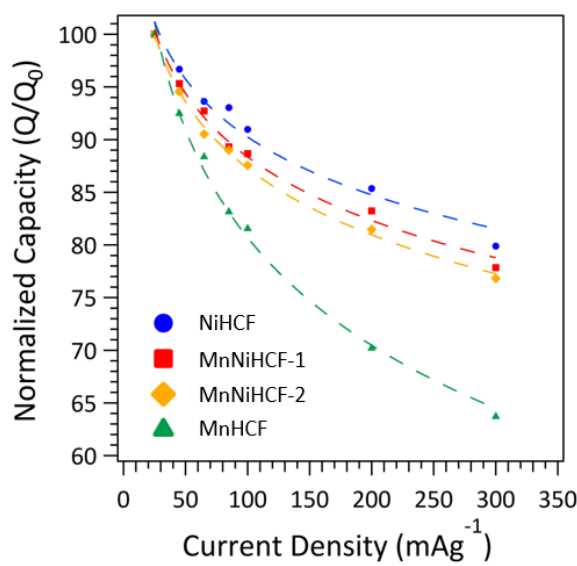

(g)

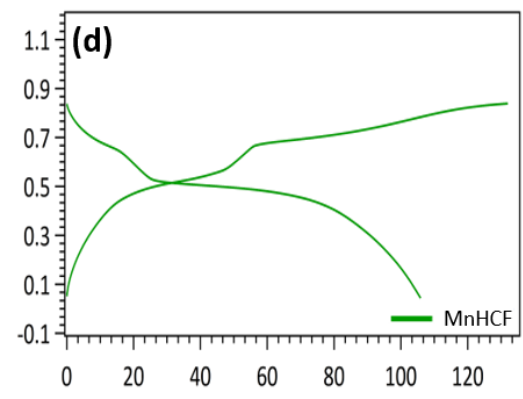

Specific Capacity Q $\left(\mathrm{mAh} \mathrm{g}^{-1}\right)$

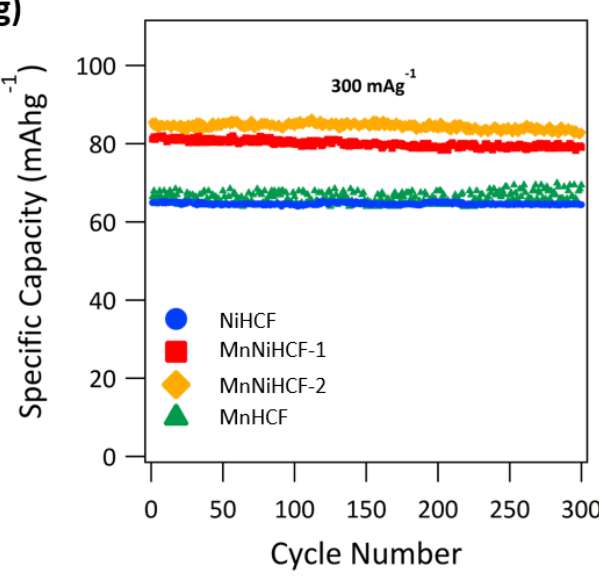

Figure 6.10 Galvanostatic charge discharge, at $25 \mathrm{mAg}^{-1}$, of a) NiHCF, b) MnNiHCF-1, c) $\mathrm{MnNiHCF}-2$, and d) MnHCF. e) Rate data for $\mathrm{Na}_{2} \mathrm{Mn}_{x} \mathrm{Ni}_{1-x}\left[\mathrm{Fe}(\mathrm{CN})_{6}\right]$. f) Normalized capacity vs current density for $\mathrm{Na}_{2} \mathrm{Mn}_{x} \mathrm{Ni}_{1-x}\left[\mathrm{Fe}(\mathrm{CN})_{6}\right]$. The rate capability of a material is inversely related to the percentage of $\mathrm{Mn}$. g) Cycle lifetimes of $\mathrm{Na}_{2} \mathrm{Mn}_{x} \mathrm{Ni}_{1-\mathrm{x}}\left[\mathrm{Fe}(\mathrm{CN})_{6}\right]$. Each cathode displays excellent performance over extended cycling at $300 \mathrm{mAg}^{-1}$. 
upon returning to $25 \mathrm{mAg}^{-1}$. The slight drop in rate performance for MnNiHCF-1 and MnNiHCF-2 exposes the adverse effect of $\mathrm{Mn}$ on the resulting materials rate capability. Pure MnHCF experiences a rapid decrease in capacity retention with increased current densities, delivering only $73 \mathrm{mAhg}^{-1}$ at $200 \mathrm{mAg}^{-1}$ (70\% of its initial capacity), and recovering only $90 \%$ of its initial capacity at $25 \mathrm{mAg}^{-1}$. Cycling stability of each material was examined over 300 cycles at $300 \mathrm{mAg}^{-1}$ (Figure 6.10g). Capacity retention was 99\% for NiHCF, $98 \%$ for MnNiHCF-1, 97\% for MnNiHCF-2, and 100\% for MnHCF. These performances underscore the reversibility of each material at high current densities.

Cyclic voltammograms at sweep rates between 0.1 and $1 \mathrm{mVs}^{-1}$ were carried out to gain further insight into $\mathrm{K}^{+}$reaction kinetics of each sample. At $0.1 \mathrm{mVs}^{-1}$, each nickel containing sample displays a single prominent redox couple associated with the $\mathrm{Fe}^{2+} / \mathrm{Fe}^{3+}$ reaction, with half potentials of $0.36,0.41,0.43 \mathrm{~V}$ vs Fc/Fc+ for NiHCF, MnNiHCF-1, and MnNiHCF-2 respectively (Figure 6.11a-c). The manganese redox reaction appears as shoulders in the MnNiHCF-1 $\left(0.47 \mathrm{~V}\right.$ vs $\left.\mathrm{Fc} / \mathrm{Fc}^{+}\right)$and MnNiHCF-2 $\left(0.55 \mathrm{~V}\right.$ vs $\left.\mathrm{Fc} / \mathrm{Fc}^{+}\right) \mathrm{CV}$ curves. Two oxidation/reduction peaks are present in the MnHCF voltammogram, with the reaction half potentials at $0.52 \mathrm{~V}$ vs $\mathrm{Fc} / \mathrm{Fc}^{+}$and $0.71 \mathrm{~V}$ vs $\mathrm{Fc} / \mathrm{Fc}^{+}$corresponding to the $\mathrm{Fe}^{2+} / \mathrm{Fe}^{3+}$ and $\mathrm{Mn}^{2+} / \mathrm{Mn}^{3+}$ redox reactions, respectively (Figure 6.11d). Figure 6.12a-d shows the cyclic voltammograms for each sample at various scan rates. The relationship between peak current and sweep rate for a reversible or quasi-reversible diffusion controlled electrochemical reaction is described by the Randles-Sevcik equation (equation 6.1) [206]: 


$$
i_{\text {peak }}=0.4463 \times \sqrt{\frac{n^{3} F^{3}}{R T}} x \sqrt{D} x C_{o} x \sqrt{v}
$$

a)

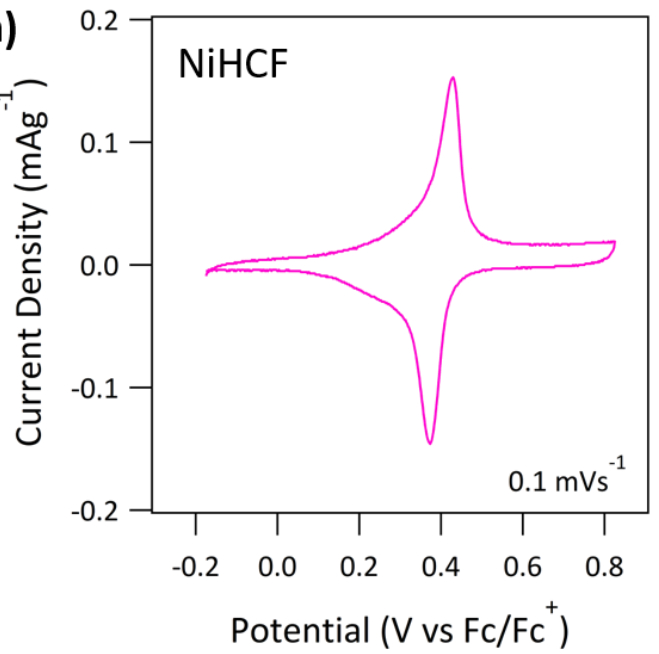

c)

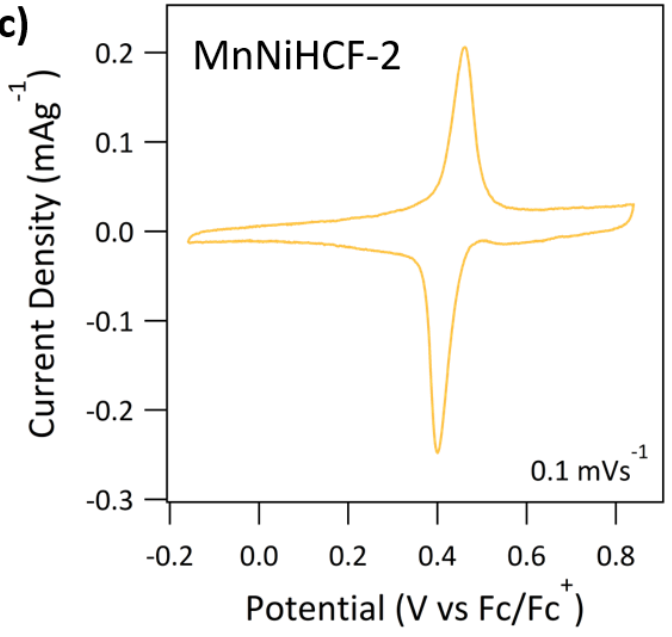

b)
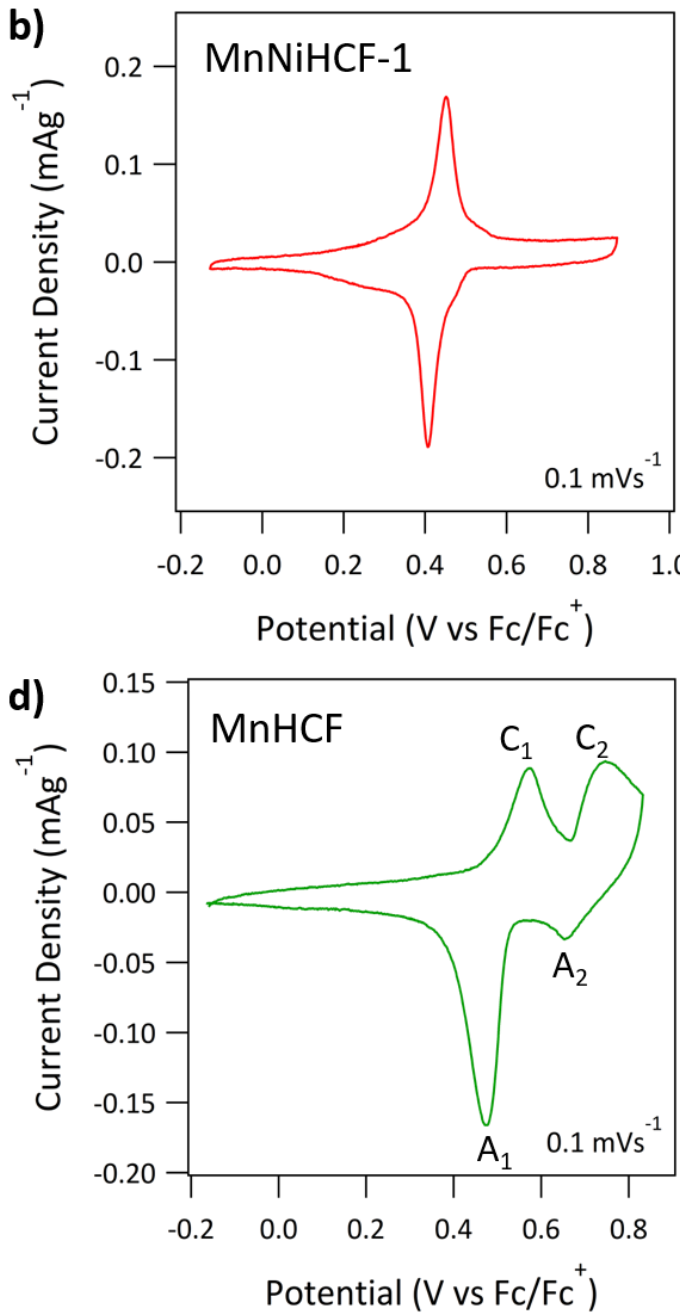

Figure 6.11 Cyclic voltammograms at $0.1 \mathrm{mV} \mathrm{s}^{-1}$ of a) NiHCF, b) MnNiHCF-1, c) MnNiHCF-2, and d) MnHCF 

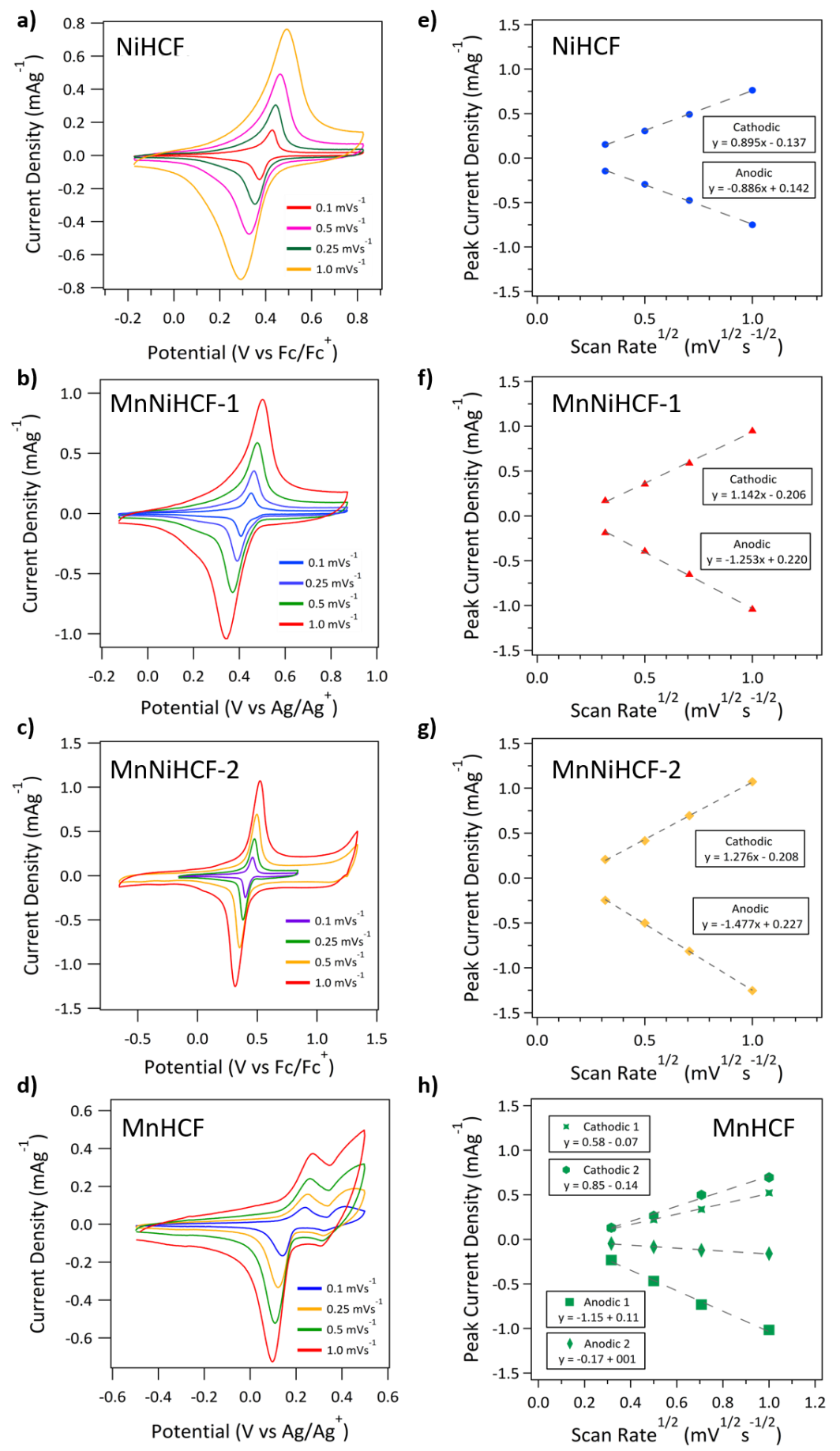

Figure 6.12 Cyclic voltammograms from $0.1-1.0 \mathrm{mV} \mathrm{s}^{-1}$ and the corresponding peak current vs (scan rate) $)^{1 / 2}$ for $(\mathbf{a}, \mathbf{e}) \mathrm{NiHCF},(\mathbf{b}, \mathbf{f}) \mathrm{MnNiHCF}-1,(\mathbf{c}, \mathbf{g}) \mathrm{MnNiHCF}-2$, and (d,h) MnHCF. 
where $i_{p}$ is the peak current $(A), n$ is the number of electrons transferred in the reaction, F is Faraday's constant, $R$ is the ideal gas constant, $T$ is temperature (K), $D$ is the diffusion coefficient $\left(\mathrm{cm}^{2} \mathrm{sec}^{-1}\right), \mathrm{C}_{0}$ is the concentration of active sites $\left(\mathrm{mol} \mathrm{cm}^{-3}\right)$, and $\mathrm{v}$ is the cyclic voltammogram sweep rate. $C_{0}$ for each material was estimated from the specific capacity of the materials. Using the slopes from the lines of best fit of the peak current $\left(I_{\text {peak }}\right)$ versus the square root of the scan rate $\left(v^{1 / 2}\right)$, diffusion coefficients for the $\mathrm{Fe}^{2+} / \mathrm{Fe}^{3+}$ oxidation/reduction reactions (Figure 6.12e-h). Table 6.3 presents the calculated diffusion coefficients. The drop in the $\mathrm{K}^{+}$diffusion for MnNiHCF-2 as well as MnHCF further demonstrates the adverse effect/impact of $\mathrm{Mn}$ on $\mathrm{K}^{+}$mobility independent of any structural shifts.

Table 6.3 Slopes determined from best fit lines in Figure $6.2 \mathrm{e}-\mathrm{h}$ and the calculated anodic and cathode $\mathrm{K}^{+}$diffusion coefficients for the $\mathrm{Fe}^{2+} / \mathrm{Fe}^{3+}$ redox reaction of $\mathrm{Mn}_{\times} \mathrm{Ni}_{1-x}[\mathrm{Fe}(\mathrm{CN}) 6]$

\begin{tabular}{ccccc}
\hline Sample & Anodic slope & Cathodic slope & $\begin{array}{c}\text { Anodic } \\
\text { diffusion coeff. }\end{array}$ & $\begin{array}{c}\text { Cathodic } \\
\text { diffusion coeff. }\end{array}$ \\
& $\frac{m A s^{1 / 2}}{m g m V^{1 / 2}}$ & $\frac{m A s^{1 / 2}}{m g m V^{1 / 2}}$ & $\frac{\mathrm{cm}^{2}}{\mathrm{~s}}$ & $\frac{\mathrm{cm}^{2}}{\mathrm{~s}}$ \\
\hline NiHCF & $-8.86 \times 10^{-4}$ & $8.95 \times 10^{-4}$ & $8.71 \times 10^{-6}$ & $8.88 \times 10^{-6}$ \\
\hline MnNiHCF-1 & $-1.25 \times 10^{-4}$ & $1.14 \times 10^{-4}$ & $8.92 \times 10^{-6}$ & $7.40 \times 10^{-6}$ \\
\hline MnNiHCF-2 & $-1.48 \times 10^{-4}$ & $1.28 \times 10^{-4}$ & $7.16 \times 10^{-6}$ & $5.35 \times 10^{-6}$ \\
\hline MnHCF & $-1.65 \times 10^{-4}$ & $8.49 \times 10^{-4}$ & $3.79 \times 10^{-8}$ & $9.98 \times 10^{-7}$
\end{tabular}




\subsection{Discussion}

The goal of this study was to determine if the introduction of both $\mathrm{Ni}$ and $\mathrm{Mn}$ into a mixed-metal hexacyanoferrate could provide improved capacity, compared to either NiHCF or MnHCF, by combining the crystal stability provided by $\mathrm{Ni}$ atoms with the favorable redox properties provided by Mn atoms.

Of the materials examined in this work, $\mathrm{Mn}_{0.50} \mathrm{Ni}_{0.50}\left[\mathrm{Fe}(\mathrm{CN})_{6}\right]$ delivers the highest specific capacity (110 mAhg ${ }^{-1}$ at $25 \mathrm{mAg}^{-1}$ ) without significant sacrifice in rate performance. This is attributed to the synergetic effects of manganese and nickel, with manganese providing addition storage capacity due to the $\mathrm{Mn}^{2+} / \mathrm{Mn}^{3+}$ transition and nickel stabilizing the overall crystal structure and in particular the $\mathrm{Mn}-\mathrm{N}-\mathrm{C}-\mathrm{Fe}$ chain. The addition of $\mathrm{Mn}$ increases the specific capacity of MnNiHCF-2 by $25 \%$ compared to pure NiHCF. The stabilization offered by nickel enables fast $\mathrm{K}^{+}$diffusion and accounts for the good rate performance of MnNiHCF-2 Both mixed manganese-nickel hexacyanoferrate samples displayed superior rate capability and cycle lifetimes compared to pure MnHCF. This result is consistent with the initial hypothesis that replacing $\mathrm{Mn}$ with $\mathrm{Ni}$ in the HCF lattice would improve electrochemical stability.

For all samples, a linear relationship between the specific capacity vs log (current density) of the sample is observed (Figure 6.13). By extrapolating the best fit curves, it is possible to obtain an approximation of the maximum achievable capacity as the current 


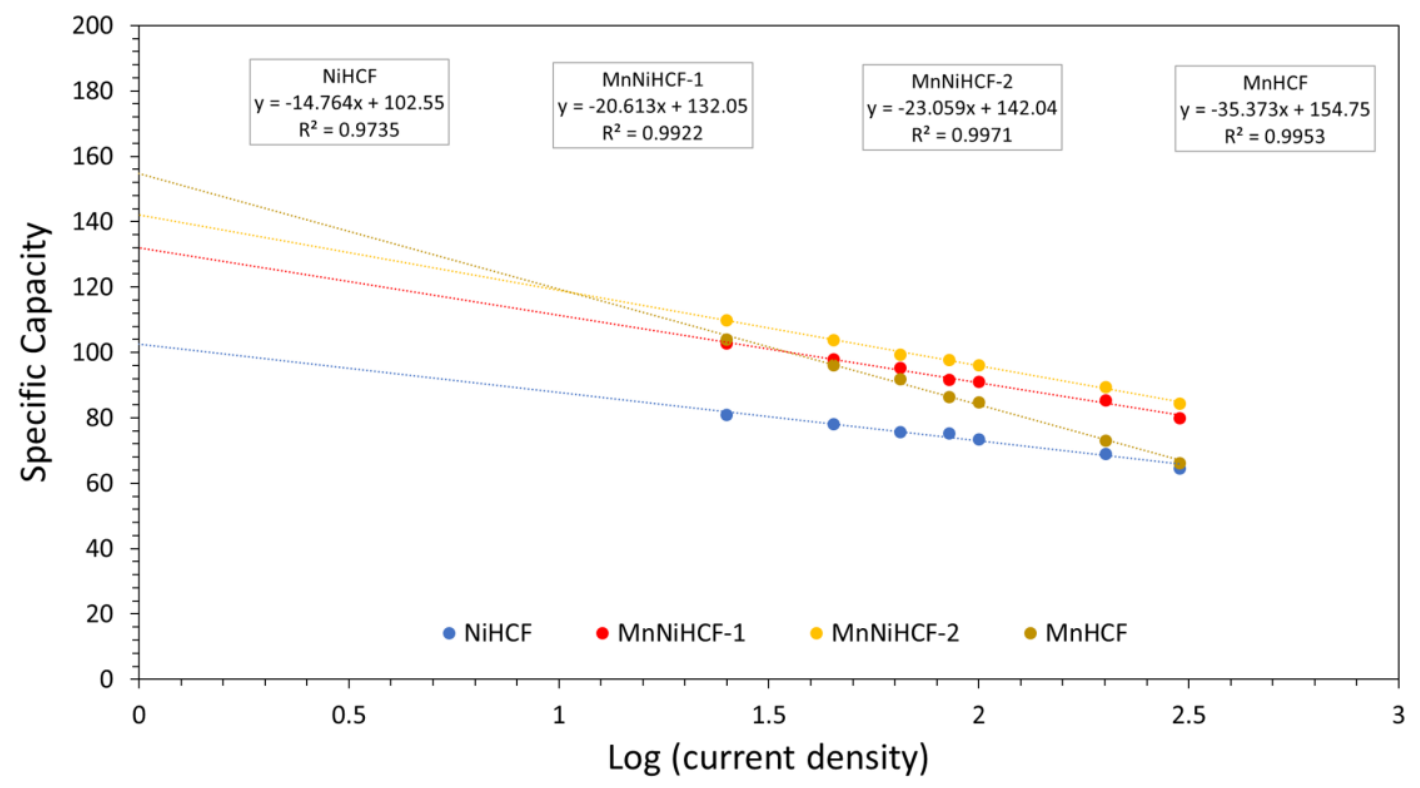

Figure 6.13 Specific capacity vs. $\log$ (current density) of $\mathrm{Na}_{2} \mathrm{Mn}_{x} \mathrm{Ni}_{1-x}\left[\mathrm{Fe}(\mathrm{CN})_{6}\right]$. The slopes provide a quantitative value related to the rate capability of the different materials. A larger slope corresponds to worse rate performance. By extrapolating the best fit lines to the $y$-intercept (zero current), a theoretical zero-current capacity can be obtained. At zero current, MnHCF has the highest theoretical capacity followed by MnNiHCF-2, MnNiHCF-1, and NiHCF, respectively.

approaches zero. These results differ from the $25 \mathrm{mAg}^{-1}$ charge/discharge capacities, with MnHCF having the largest low-current capacity followed by MnNiHCF-2, MnNiHCF-1, and lastly NiHCF. This data supports the conclusion that pure MnHCF has a lower capacity than MnNiHCF-2, at $25 \mathrm{mAg}^{-1}$, due to resistance to diffusion of the potassium cation.

In general, changing the ratio of $\mathrm{Mn}$ and $\mathrm{Ni}$ concentrations had three major effects on electrochemical performance: 
For all samples that contain $\mathrm{Ni}$, storage capacity increases with increasing $\mathrm{Mn}$ concentration. However, the capacity of pure MnHCF is lower than MnNiHCF-2.

1) Redox potential increases with increasing $M n$ concentration

2) Diffusion rates of $\mathrm{K}^{+}$decrease as $\mathrm{Mn}$ concentration increases

The first trend is attributed to the increase in redox active elements in the hexacyanoferrate lattice.

The second trend can be attributed to the modulation of the electron density across the cyanide by adjusting the effective polarization of the nitrogen coordinated metal $\left(\sigma_{\text {eff }}=x^{*} \sigma_{M n}+(1-x)^{*} \sigma_{N i}\right)$. As the concentration of $\mathrm{Mn}$ is increased the value of $\sigma_{\text {eff }}$ decreases. This results in an increase in the electron density at the carbon-Fe end of the cyanide, causing an increase in the electrical potential of the Fe [93].

Analysis of the reasons underlying the third trend will depend upon the outstanding SEM data, which will provide information on particle size. Particle size has been shown to influence the diffusion kinetics of PBAs [108,272]. 


\subsection{Additional Commentary on Manganese-Nickel Hexacyanoferrate and its Application as a Cathode Material for Nonaqueous Potassium Ion Batteries}

The studies presented in this dissertation were undertaken to:

a) Identify novel battery systems that extend beyond lithium and sodium chemistries, and

b) Provide further insights into the relationship between the metals in mixed metal hexacyanoferrates and the resulting energy storage properties.

The results obtained in this study helped to achieve these goals by:

1) Examining, for the first time, the combination of $\mathrm{Ni}_{0.75} \mathrm{Mn}_{0.25}\left[\mathrm{Fe}(\mathrm{CN})_{6}\right]$ as a cathode and $\mathrm{K}^{+}$as the electrolytic cation in a non-aqueous solvent (propylene carbonate and ethylene carbonate mixture), and

2) Examining the effects of the $\mathrm{Ni} / \mathrm{Mn}$ ratio in the battery system described above.

A synergistic effect between $\mathrm{Mn}$ and $\mathrm{Ni}$ on the electrochemical properties of the mixedmetal hexacyanoferrate $\mathrm{Na}_{2} \mathrm{Mn}_{x} \mathrm{Ni}_{1-x}\left[\mathrm{Fe}(\mathrm{CN})_{6}\right]$ was demonstrated. An inverse relationship between rate capability and storage capacity was observed, with $\mathrm{Mn}_{0.50} \mathrm{Ni}_{0.50}\left[\mathrm{Fe}(\mathrm{CN})_{6}\right]$ offering optimal pairing of storage capacity and diffusion kinetics. 


\section{Chapter 7.}

\section{Calculating Electron Density Distribution in $\mathrm{Mn}_{\mathbf{x}} \mathrm{Ni}_{1-\mathrm{x}}\left[\mathrm{Fe}(\mathrm{CN})_{6}\right]$}

The experimental IR and electrochemical data presented in chapter 6 suggest that the specific capacity and redox potential of $\mathrm{Mn}_{\mathrm{x}} \mathrm{Ni}_{1-\mathrm{x}}\left[\mathrm{Fe}(\mathrm{CN})_{6}\right]$ compounds increase as the electron density across the Fe-C-N-M' chain is drawn towards the Fe-C end. Substituting nitrogen-coordinated $\mathrm{Mn}$ for nitrogen-coordinated $\mathrm{Ni}$ causes a decrease in stretching frequency $(\boldsymbol{v})$ of the $\mathrm{C} \equiv \mathrm{N}$ bond, consistent with bond weakening, and an increase in $\boldsymbol{v}$ of the Fe-C bond, consistent with increases in bond strength and electron density. These findings suggest a shift in average electron density away from the nitrogen-bonded transition metal and towards the iron-carbon bond. This is shown schematically as:

$$
\begin{gathered}
\mathrm{Fe}-\mathrm{C} \equiv \mathrm{N}-\mathrm{Ni} \\
\mathrm{Fe} \leftarrow \mathrm{C}<\equiv \mathrm{N} \leftarrow \mathrm{Mn}
\end{gathered}
$$

in which the arrows indicate the direction of shifts in electron density as $\mathrm{Mn}$ replaces $\mathrm{Ni}$. Density functional theory (DFT) calculations were conducted to further probe the relationship between the $\mathrm{Mn}$ concentration in $\mathrm{Mn}_{\mathrm{x}} \mathrm{Ni}_{1-\mathrm{x}}\left[\mathrm{Fe}(\mathrm{CN})_{6}\right]$ and: (a) the electron density of the Fe, and (b) the Fe-C bond length.

Traditionally, the ground state electronic structure of a system can be determined by solving the non-relativistic, time independent Schrodinger equation 7.1: 


$$
\left[-\frac{\hbar^{2}}{2 m} \sum_{i} \nabla_{i}^{2}+\sum_{i} V\left(\boldsymbol{r}_{i}\right)+\sum_{i} \sum_{i, \neq j} U\left(r_{i}, r_{j}\right)\right] \Psi\left(r_{1}, \ldots, r_{N}\right)=E \Psi\left(r_{1}, \ldots, r_{N}\right)
$$

where $\nabla_{i}^{2}$ is the electron kinetic energy, $V\left(r_{i}\right)$ is the potential energy due to electronnuclei interactions, $U\left(r_{i}, r_{j}\right)$ is the potential energy term due to electron-electron interactions, and $\mathrm{E}$ is the energy of the system. In principal, all information about a system can be obtained by solving the many-body Schrodinger equation. However, a closed form analytical solution cannot be written for systems other than hydrogen, and numerical solutions are limited to systems with $\mathrm{N} \leq 20$ due to complexities arising from electronelectron interactions [273].

Density functional theory (DFT), proposed by Hohenberg and Kohn building of the work of Thomas [274] and Fermi [275], is a reformulation of quantum mechanics in which, rather than the wavefunction, the ground state electron density $n(r)$ becomes the fundamental parameter [276]. This allows an N-body problem to be constructed in terms of $\mathrm{N}$ single-body problems, in which every electron is treated as moving in a static external potential $v(r)$. By solving the self-consistent Kohn-Sham equations (equations $7.2-7.4$ ), one can find the ground state electron density for a system of non-interacting electrons in an external potential [277]:

$$
\begin{gathered}
{\left[\frac{1}{2} \nabla_{i}^{2}+v_{e f f}(r)\right] \varphi_{i}(r)=\varepsilon_{i} \varphi_{i}(r)} \\
n(r)=\sum_{i=1}^{N}\left|\varphi_{i}(r)\right|^{2}
\end{gathered}
$$




$$
V_{e f f}(r)=V(r)+V_{H}(r)+V_{x c}(r)
$$

where $\nabla_{i}^{2}$ and $V(r)$ are the same as those in the Schrodinger equation Hamiltonian, $\varphi_{i}(r)$ are the single particle Kohn-Sham wave functions (analogous to $\Psi$ ), $\mathrm{V}_{\mathrm{H}}(\mathrm{r})$ is the Hartree potential which describes the mean field potential of the electron density, and $V x c(r)$ is the local exchange-correlation potential which includes all exchange and correlation energies as well as any terms not accounted for by $V(r)$ and $V_{H}(r)$.

In practice, DFT calculations proceed through an iterative approach:

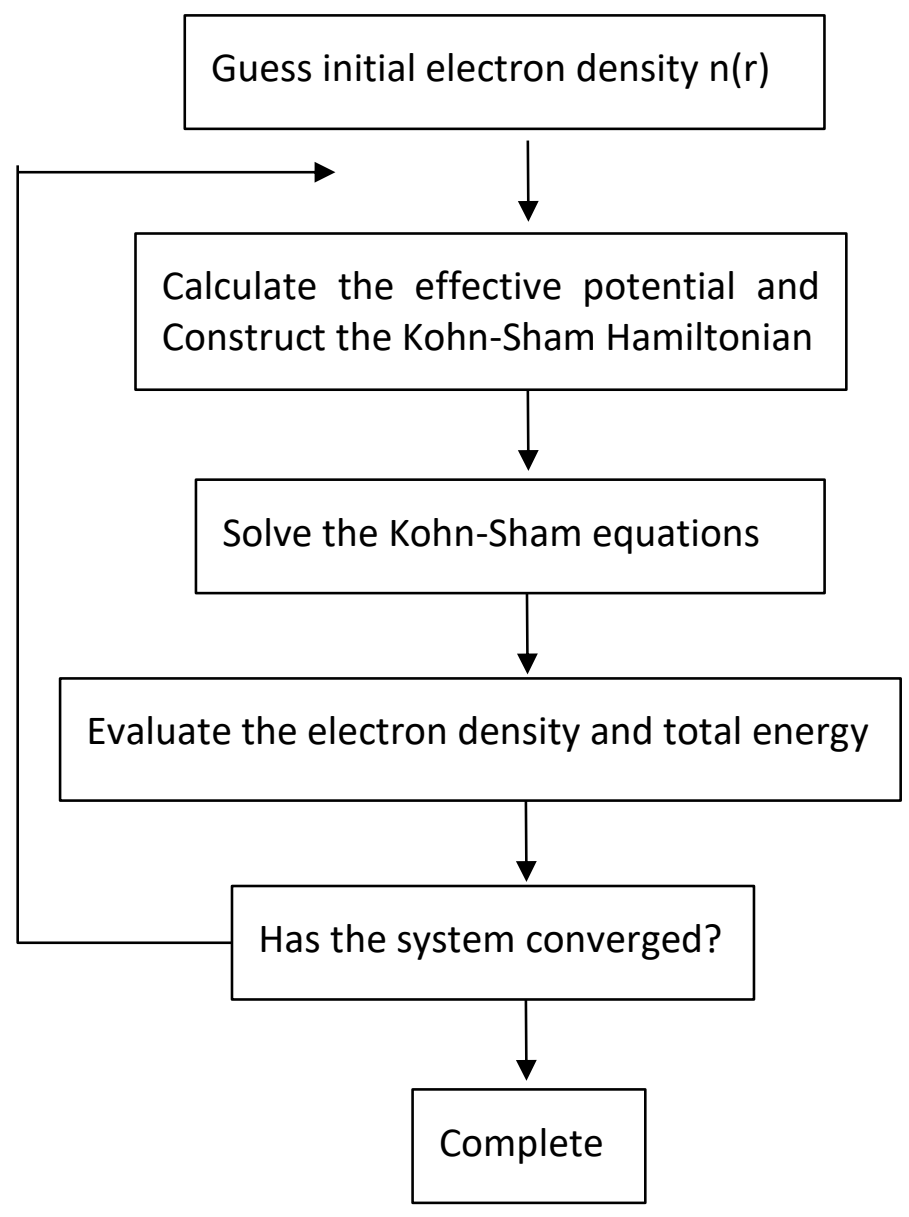




\subsection{Computational Parameters}

All DFT calculations were performed using The Vienna Ab initio Simulation Package (VASP) [278-281] on the Coeus compute cluster at Portland State University. VASP is primarily used for solid state DFT computations due to its use of the plane wave basis set, which takes advantage of the periodic structures of solids. For this work, exchange and correlation contributions were described by the generalized gradient approximation (GGA) with the Perdew-Burke-Ernzerhof (PBE) functional $[282,283]$, while the atomic cores were represented by projector augmented wave (PAW) pseudopotentials $[284,285]$. In order to account for the strongly correlated d-electrons of the transition metals, a Hubbard potential $(U)$ was applied through DFT+U $[286,287]$. U values in this work were determined by first optimizing $U_{\mathrm{Ni}}$ and $U_{\mathrm{Fe}}$ for nickel hexacyanoferrate, and then maintaining the same $U_{\mathrm{Fe}}$ while determining $U_{M n}$ in manganese hexacyanoferrate. The values for $U$ are: $U_{\mathrm{Ni}}=5.3, \mathrm{U}_{\mathrm{Mn}}=4.3$, and $\mathrm{U}_{\mathrm{Fe}}=3.9$.

Example INCAR, KPOINT, and POSCAR input files for a VASP calculation are provided in the Appendix. The INCAR file contains all of the input parameters for a calculation, telling VASP what to do. The KPOINT file determines the sampling of the Brillouin zone, and the POSCAR file contains information about the crystal structure. The other file that is require for a VASP calculation is the POTCAR file which contains the pseudopotentials and exchange-correlation functionals. All POTCAR files require a VASP license. 


\subsection{Initial results}

DFT calculations were performed for $\mathrm{Na}_{2} \mathrm{Ni}\left[\mathrm{Fe}(\mathrm{CN})_{6}\right], \mathrm{Na}_{2} \mathrm{Mn}_{25} \mathrm{Ni}_{75}\left[\mathrm{Fe}(\mathrm{CN})_{6}\right]$, $\mathrm{Na}_{2} \mathrm{Mn}_{50} \mathrm{Ni}_{50}\left[\mathrm{Fe}(\mathrm{CN})_{6}\right]$ and $\mathrm{Na}_{2} \mathrm{MnHCF}$. For simplicity, $\mathrm{Fe}(\mathrm{CN})_{6}$ vacancies, coordinated water and zeolitic water were not accounted for in the structures. The absence of these inputs was expected to cause some discrepancies between calculated and actual structures, however trends in calculated electron densities were expected to still be informative.

Prior to electronic structure calculations, the geometry and atom positions for each sample were optimized using VASP. Table 7.1 presents the calculated and experimentally determined lattice parameters for all materials. The DFT and X-ray diffraction results match well for the cubic samples, however the calculated MnHCF lattice is more distorted than the actual sample. The exaggerated distortion for the calculated MnHCF structure is attributed to the high Na content (full occupancy) and absence of interstitial water that were over-represented in the calculated structure; both of these factors are experimentally known to induce structural shifts $[260,288]$.

Charge density plots for $\mathrm{Na}_{2} \mathrm{Ni}\left[\mathrm{Fe}(\mathrm{CN})_{6}\right]$ and $\mathrm{Na}_{2} \mathrm{Mn}_{25} \mathrm{Ni}_{75}\left[\mathrm{Fe}(\mathrm{CN})_{6}\right]$ were produced to probe the effect that substitution of $\mathrm{Mn}$ for $\mathrm{Ni}$ has on the resulting material's electron distribution. Analysis of $\mathrm{Na}_{2} \mathrm{Mn}\left[\mathrm{Fe}(\mathrm{CN})_{6}\right]$ was not included because the effects of the monoclinic distortions on the electron density are unknown. 
Table 7.1 Experimental and theoretical lattice parameters for $\mathrm{Na}_{2} \mathrm{Mn}_{\times} \mathrm{Ni}_{1-\mathrm{x}}\left[\mathrm{Fe}(\mathrm{CN})_{6}\right]$

\section{Experimental Calculated}
$\mathrm{Na}_{2} \mathrm{Ni}\left[\mathrm{Fe}(\mathrm{CN})_{6}\right]$
$a=b=c=10.21 \AA$
$a=b=c=10.13 \AA$

$\mathrm{Na}_{2} \mathrm{Mn}_{25} \mathrm{Ni}_{75}\left[\mathrm{Fe}(\mathrm{CN})_{6}\right] \quad \mathrm{a}=\mathrm{b}=\mathrm{c}=10.27 \AA \quad \mathrm{a}=\mathrm{b}=\mathrm{c}=10.29 \AA$
$\mathrm{Na}_{2} \mathrm{Mn}_{50} \mathrm{Ni}_{50}\left[\mathrm{Fe}(\mathrm{CN})_{6}\right]$
$\mathrm{a}=\mathrm{b}=\mathrm{c}=10.33 \AA$
$a=b=c=10.29 \AA$

$a=10.59 \AA, b=7.58 \AA$,

$a=10.39 \AA, b=7.17 \AA$,

$c=7.36 \AA$,

$c=6.86 \AA$,

$\mathrm{Na}_{2} \mathrm{Mn}\left[\mathrm{Fe}(\mathrm{CN})_{6}\right]$

$\beta=91.55^{\circ}$

$\beta=94.53^{\circ}$

The charge density plots shown in Figure 7.1 and Figure 7.2. appear to support the hypotheses that the incorporation of $\mathrm{Mn}$ shifts the electron density towards the Fe-C end of the cyanide. For $\mathrm{Na}_{2} \mathrm{Ni}\left[\mathrm{Fe}(\mathrm{CN})_{6}\right]$, the charge density across every $\mathrm{Ni}-\mathrm{N}-\mathrm{C}-\mathrm{Fe}$ chain is equivalent, a result of the symmetry of the material (Figure 7.1). Upon substitution of Mn, a clear break in the symmetry of the electron density is observed. Figure 7.2 displays the electron density plot for of $\mathrm{Na}_{2} \mathrm{Mn}_{25} \mathrm{Ni}_{75}\left[\mathrm{Fe}(\mathrm{CN})_{6}\right]$ along the (200) plane, where two $\mathrm{Ni}$ and two $\mathrm{Mn}$ atoms are the nearest in-plane transition metals to the central Fe atom. Along the plane shown, there is a relative shift of charge density towards the Fe-C end of the cyanide in the Fe-CN-Mn chain compared to the Fe-CN-Ni chain. Additionally, the Fe-C bond length shortens from $1.893 \AA$ for Fe-CN-Ni to $1.842 \AA$ for Fe-CN-Mn, a contraction 


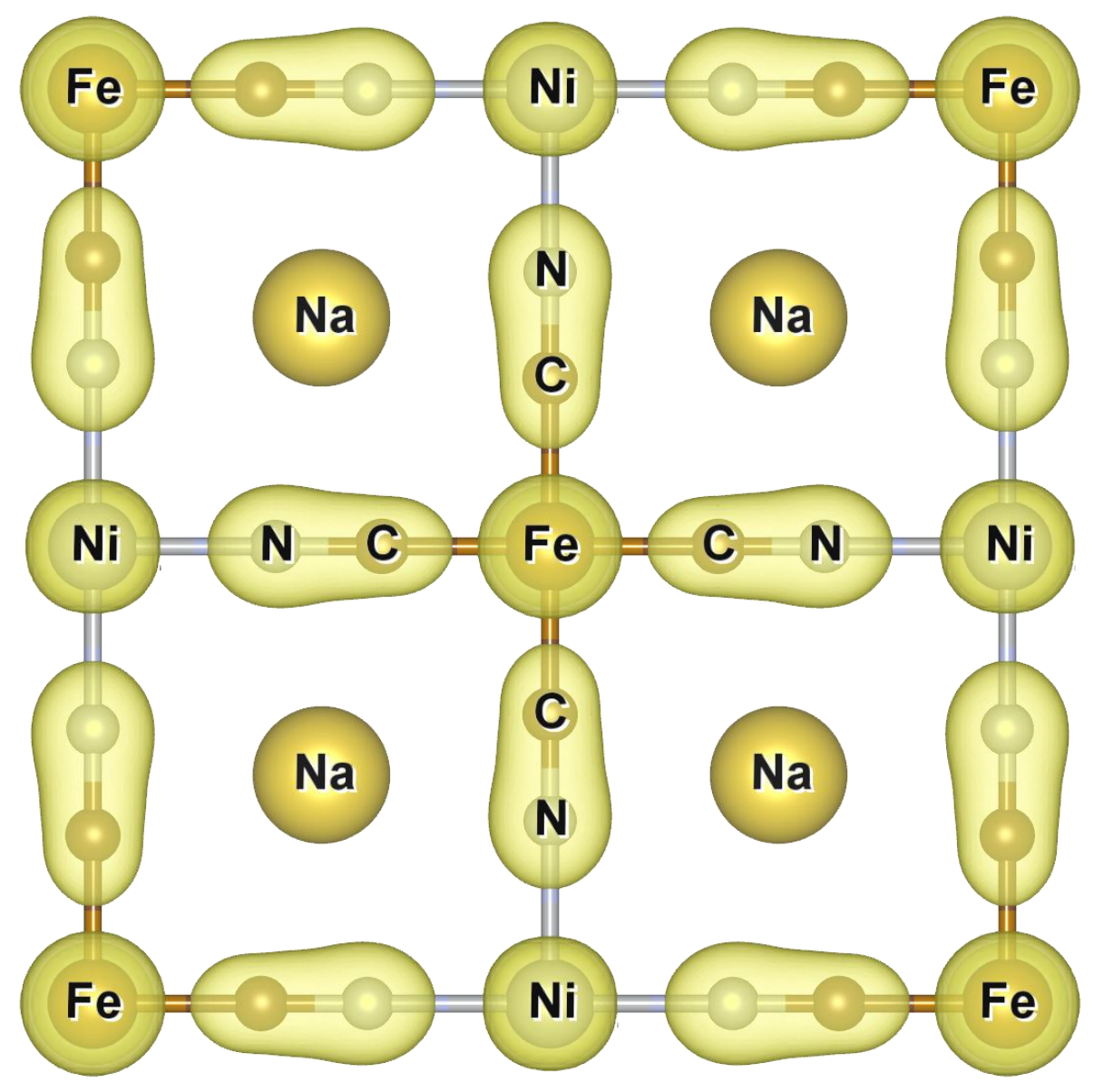

Figure 7.1 Charge density plot of $\mathrm{Na}_{2} \mathrm{Ni}\left[\mathrm{Fe}(\mathrm{CN})_{6}\right]$

of $2.7 \%$. In contrast, when the Fe atom is surrounded by $4 \mathrm{Ni}$-containing chains in the (010) plane, charge distribution between Fe and C is the again symmetric for all four carbons, as shown in Figure 7.3, similar to $\mathrm{Na}_{2} \mathrm{Ni}\left[\mathrm{Fe}(\mathrm{CN})_{6}\right]$.

The initial density functional theory calculations appear to support the hypothesis, based on the experimental results, that substitution of $\mathrm{Mn}$ for $\mathrm{Ni}$ causes a shift in the 


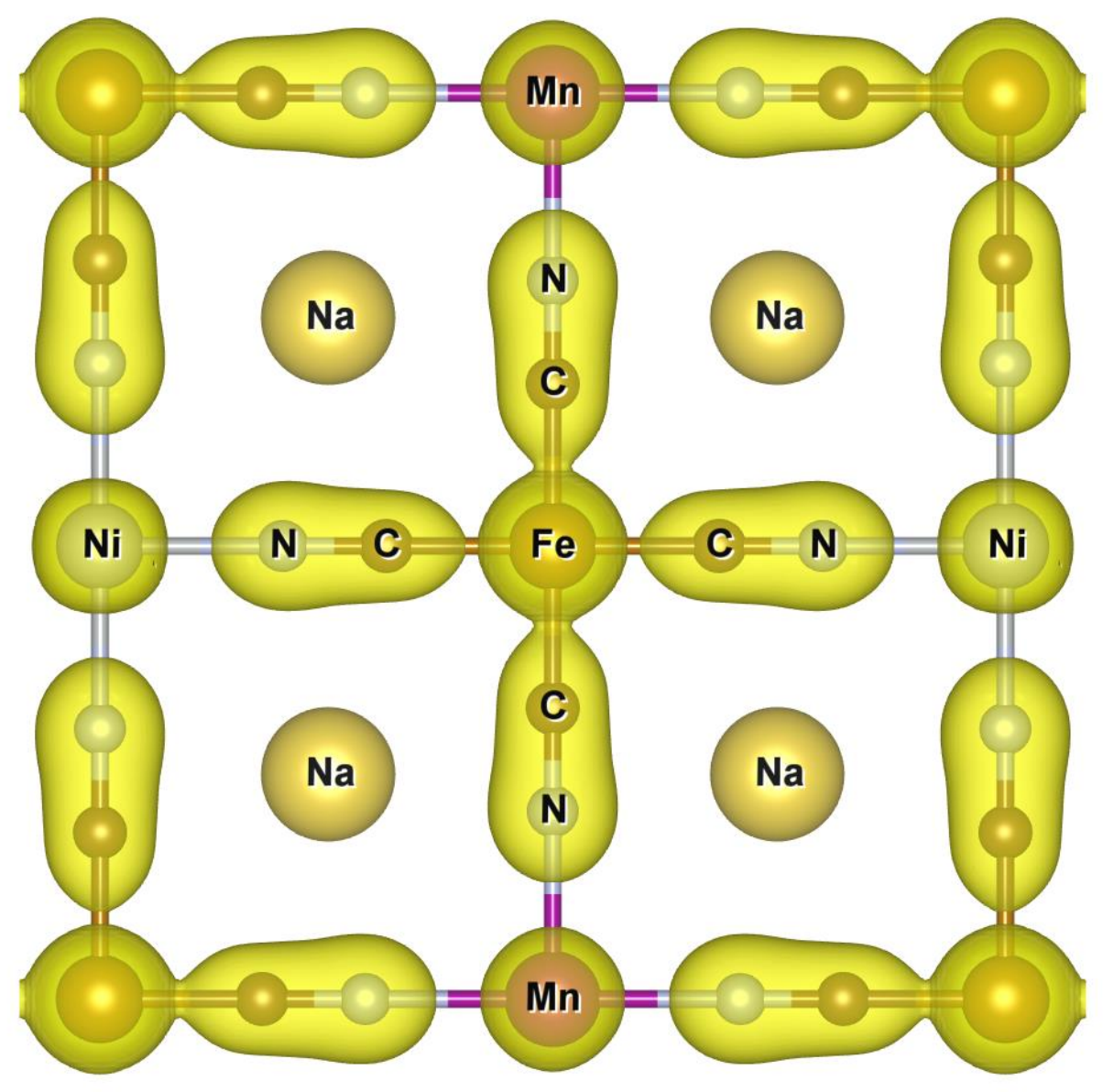

Figure 7.2 Charge density plot of $\mathrm{Na}_{2} \mathrm{Mn}_{0.25} \mathrm{Ni}_{0.75}\left[\mathrm{Fe}(\mathrm{CN})_{6}\right]$ along the (200) plane

electron density towards the Fe-C end of the cyanide. This shift is highlighted by the Fe-C bond contraction along the $\mathrm{Mn}-\mathrm{N}-\mathrm{C}-\mathrm{Fe}$ chain compared to the $\mathrm{Ni}-\mathrm{N}-\mathrm{C}-\mathrm{Fe}$ chain in $\mathrm{Na}_{2} \mathrm{Mn}_{0.25} \mathrm{Ni}_{0.75}\left[\mathrm{Fe}(\mathrm{CN})_{6}\right]$. Both of these results are consistent with the far IR absorption data presented in Figure 6.7. 


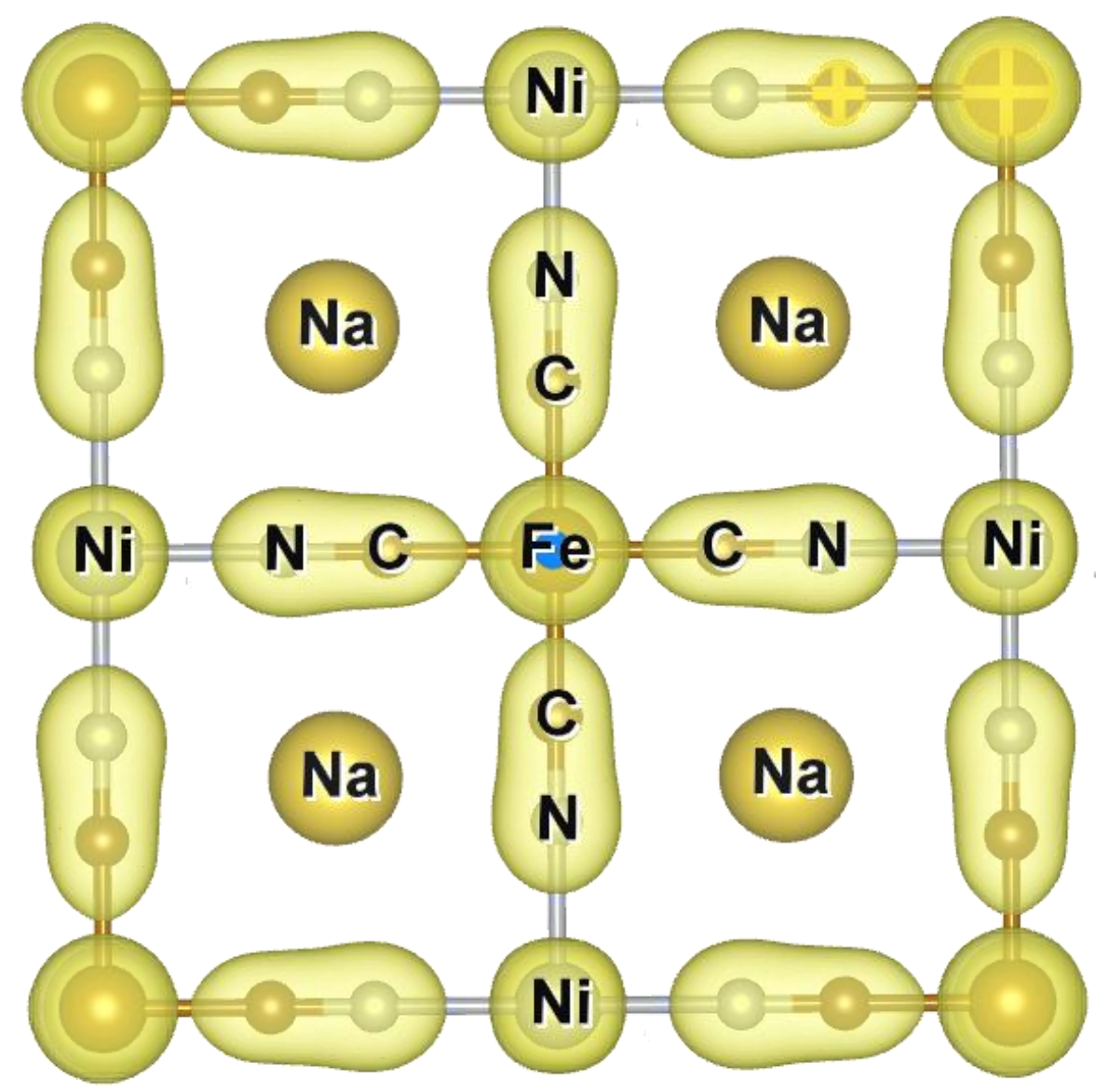

Figure 7.3 Charge density plot of $\mathrm{Na}_{2} \mathrm{Mn}_{0.25} \mathrm{Ni}_{0.75}\left[\mathrm{Fe}(\mathrm{CN})_{6}\right]$ along the (010) plane 


\section{Chapter 8.}

\section{Conclusion}

\subsection{Conclusions}

The need for innovative and novel energy storage solutions has never been greater, with the impact of global warming becoming more evident by the day. Secondary batteries are bound to be part of a larger suite of storage technologies aimed at meeting global demands for generating electricity without producing greenhouse gases. Lithium ion batteries offer high energy densities and long lifetimes, which are necessary attributes for specific applications such as powering electric vehicles and portable electronics. However, for applications where energy and power density are not the most important factors, issues surrounding the limited supply of lithium salts, safety concerns, and inclusion of toxic materials start to overshadow the benefits of lithium batteries. In particular, there is a large and growing demand for safe and inexpensive mechanisms for storing electricity produced from non- $\mathrm{CO}_{2}$ producing sources.

The work in this dissertation focused on the family of materials known as Prussian blue analogues (metal hexacyanometallates) as cathode materials for secondary battery systems. The overarching objectives were to:

1. Develop non-lithium ion based systems utilizing PBA cathodes, with a particular focus on divalent ion systems. Divalent ion batteries are of great interest as they 
possess double the theoretical energy density compared to $\mathrm{Li}^{+}$for equal amounts of intercalated ions.

2. Determine if the electrochemical storage properties of two pure binary metal hexacyanoferrates could be improved by incorporating both metals into the metal hexacyanoferrate lattice. Of particular interest was what impacts Co or Ni would have on stabilizing manganese in the PBA lattice.

Chapter 3 presented the results of investigations into the use of $\mathrm{Ca}^{2+}$ as the electrolyte in a battery system containing a Prussian blue $\left(\mathrm{Fe}^{3+}\left[\mathrm{Fe}^{2+}(\mathrm{CN})_{6}\right]\right)$ cathode and nonaqueous solvent (acetonitrile). This work demonstrated, for the first time, the suitability of $\mathrm{Ca}^{2+}$ as a cation in a battery system consisting of a $\mathrm{Fe}\left[\mathrm{Fe}(\mathrm{CN})_{6}\right]$ cathode and acetonitrile solvent. With a specific capacity of $150 \mathrm{mAhg}^{-1}$, this system delivered the highest reported specific capacity for any calcium ion battery using a Prussian Blue electrode. Calcium ion batteries are an intriguing alternative to lithium ion systems due to calcium's low cost, relative abundance (fifth most abundant element in the Earth's crust), and ability to offer double the energy density, per intercalated ion, of lithium ion batteries. By employing a nonaqueous chemistry, this work offers a proof of concept to future studies aimed at developing a CIB with a calcium metal anode.

The study presented in Chapter 4 demonstrated, for the first time, the use of $\mathrm{Zn}^{2+}$ as a reversible intercalating cation with a manganese-cobalt hexacyanoferrate cathode in an aqueous solvent. Structure analysis of MnCoHCF0.50 coupled with energy 
dispersive x-ray spectroscopy measurements confirmed a single phase with uniform distribution of $\mathrm{Mn}$ and Co throughout. A complex insertion/extraction process was highlighted by three distinct oxidation and reduction potentials. By combining manganese and cobalt the dissolution of $\mathrm{Mn}$ was prevented, while $\mathrm{Mn}$ redox provided a $21 \%$ increase $\left(29 \mathrm{mAhg}^{-1}\right)$ in storage capacity compared to CoHCF. However, the mixed metal system suffered from increased capacity loss compared to CoHCF, $18 \%$ vs. $9 \%$ respectively, after the first 15 charge-discharge cycles. In general, aqueous zinc ion batteries offer high theoretical energy densities, as zinc is a divalent ion and $\mathrm{Zn}$ metal can be utilized as an anode. Additionally, the high safety profiles and low environmental impact of aqueous systems make them ideal to pair with solar and wind energy generation.

Chapter 5 presented an examination of the effects of coordinated and zeolitic $\mathrm{H}_{2} \mathrm{O}$ on the battery system consisting of a $\mathrm{Cu}\left[\mathrm{Fe}(\mathrm{CN})_{6}\right]$ cathode in a nonaqueous $\mathrm{Mg}^{2+}$ electrolyte. Coordinated water was shown to play an important role in maximizing the specific capacity of the copper hexacyanoferrate in this system. Maintaining water within the CuHCF lattice resulted in a $25 \%$ increase in specific capacity when compared to the dehydrated sample. A nonaqueous electrolyte was chosen for this study because it is compatible with magnesium metal anodes metal, which could provide significant increases in energy density. In general, $\mathrm{Mg}$ metal is not volatile in air which reduces potential catastrophic failures, and $\mathrm{Mg}$ is relatively abundant (7th most abundant 
element in the Earth's crust). In addition, difficulties in synthesizing a single phased mixed metal system containing manganese and copper were discussed.

Chapter 6 presented the use of $\mathrm{Mn}_{x} \mathrm{Ni}_{1-\mathrm{x}}\left[\mathrm{Fe}(\mathrm{CN})_{6}\right]$ as a cathode, with $\mathrm{K}^{+}$as the intercalating cation, in a non-aqueous solvent. The objective of this study was to determine if the introduction of both $\mathrm{Ni}$ and $\mathrm{Mn}$ into a mixed-metal hexacyanoferrate could provide improved capacity, compared to either NiHCF or MnHCF, by combining the crystal stability provided by $\mathrm{Ni}$ atoms with the favorable redox properties provided by $\mathrm{Mn}$ atoms.

Pure nickel hexacyanoferrate has the advantage of being structurally stable during discharge, but suffers from low specific capacity due to the redox inactivity of $\mathrm{Ni}$. Pure manganese hexacyanoferrate has a high theoretical capacity, as $\mathrm{Mn}$ is redox active, however Jahn-Teller distortions during charging and discharging cause significant capacity loss over time [268].

Of the materials studied, $\mathrm{Na}_{2} \mathrm{Mn}_{0.50} \mathrm{Ni}_{0.50}\left[\mathrm{Fe}(\mathrm{CN})_{6}\right]$ (MnNiHCF-2) delivered the highest specific capacity $\left(110 \mathrm{mAhg}^{-1}\right.$ at $\left.25 \mathrm{mAg}^{-1}\right)$ without significant sacrifice in rate performance. This is attributed to the synergetic effects of manganese and nickel, with manganese providing addition storage capacity due to the $\mathrm{Mn}^{2+} / \mathrm{Mn}^{3+}$ transition and nickel stabilizing the overall crystal structure and in particular the Fe-C-N-Mn chain. The addition of $\mathrm{Mn}$ increases the specific capacity of MnNiHCF-2 by $25 \%$ compared to pure 
NiHCF. The stabilization offered by nickel enables fast $\mathrm{K}^{+}$diffusion and accounts for the good rate performance of $\mathrm{MnNiHCF}-2$.

More broadly, a synergistic relationship between $\mathrm{Mn}$ and $\mathrm{Ni}$ in the mixed-metal hexacyanoferrate $\mathrm{Mn}_{\mathrm{x}} \mathrm{Ni}_{1-\mathrm{x}}\left[\mathrm{Fe}(\mathrm{CN})_{6}\right]$ was demonstrated. An inverse relationship between rate capability and storage capacity was observed, with $\mathrm{Mn}_{50} \mathrm{Ni}_{50}\left[\mathrm{Fe}(\mathrm{CN})_{6}\right]$ offering optimal pairing of storage capacity and diffusion kinetics. The combination of $\mathrm{Mn}$ and $\mathrm{Ni}$ offered increased capacities compared to NiHCF while only causing minimal loss with respect to rate performances. This result is consistent with the initial hypothesis that replacing $\mathrm{Mn}$ with $\mathrm{Ni}$ in the $\mathrm{HCF}$ lattice would improve electrochemical stability.

Chapter 7 presented the results of DFT calculations of electron charge density and changes in the iron-carbon bond lengths for the $\mathrm{Na}_{2} \mathrm{Mn}_{x} \mathrm{Ni}_{1-\mathrm{x}}\left[\mathrm{Fe}(\mathrm{CN})_{6}\right]$ materials studied in chapter 6. Initial results appear to support the hypothesis proposed after analysis of the experimental data . The charge density plots of $\mathrm{Na}_{2} \mathrm{Ni}\left[\mathrm{Fe}(\mathrm{CN})_{6}\right]$ and $\mathrm{Na}_{2} \mathrm{Mn}_{0.25} \mathrm{Ni}_{0.75}\left[\mathrm{Fe}(\mathrm{CN})_{6}\right]$ demonstrate the polarization of the electron density away from the $\mathrm{Mn}$ atoms and towards the Fe-C bonds. Additionally, the optimized $\mathrm{Na}_{2} \mathrm{Mn}_{0.25} \mathrm{Ni}_{0.75}\left[\mathrm{Fe}(\mathrm{CN})_{6}\right]$ structure revealed a $2.7 \%$ decrease in the Fe-C bond length for the $\mathrm{Mn}-\mathrm{N}-\mathrm{C}-\mathrm{Fe}$ chain compared to the Ni-N-C-Fe chain. This finding further supports the conclusions drawn from the experimental FTIR data.

Collectively, the work presented in this dissertation provides novel insights into the applicability of Prussian blue analogues as cathode materials for non-lithium ion 
batteries. PBAs are promising materials as they are generally inexpensive, easy to synthesize, and can accommodate a variety of intercalating ions. Additionally, the physical and electrochemical properties of a PBA can easily be tuned for specific applications by adjusting the transition metals in the host lattice, as was shown in chapters 4 and 6.

The four intercalating ions used in this dissertation were $\mathrm{Ca}^{2+}, \mathrm{Zn}^{2+}, \mathrm{Mg}^{2+}$ and $\mathrm{K}^{+}$. Divalent ion systems, such as those in chapters 3,4 , and 5 are of great interest as they possess double the theoretical energy density compared to $\mathrm{Li}^{+}$for equal amounts of intercalated ions. Potassium ion batteries offer a high theoretical energy density resulting from the low reduction potential of potassium metal (-2.93 V verses standard hydrogen electrode), the low cost of potassium salts, and fast ionic mobilities.

\subsection{Future work}

The studies presented in this dissertation demonstrate progress towards the development of non-lithium ion batteries, and provide valuable insights into the relationships between the physical properties and storage capabilities of Prussian blue analogues. However, there is room to build on the work, focusing on three paths: continued exploration of the fundamental properties underlying the electrochemical and physical properties of mixed metal PBAs, addition of water to nonaqueous electrolytes, and application of the cathode materials presented in chapters 3-6 in a full battery.

Central to the studies of $\mathrm{Mn}_{\mathrm{x}} \mathrm{Co}_{\mathrm{x}-1}\left[\mathrm{Fe}(\mathrm{CN})_{6}\right]$ and $\mathrm{Mn}_{\mathrm{x}} \mathrm{Ni}_{1-\mathrm{x}}\left[\mathrm{Fe}(\mathrm{CN})_{6}\right]$ was the ability to stabilize $\mathrm{Mn}$ in the PBA lattice by incorporating of a third transition metal. The resulting 
mixed metal hexacyanoferrates delivered increased capacities compared to the binary parent Prussian blue analogues without significant negative consequences. To maximize the storage properties of both systems, other metal ratios should be synthesized to optimize the system. This will also provide insight into if there is a concentration of $\mathrm{Mn}$ where the Mn properties dominate and the mixed metal system becomes unstable. In addition to the two systems listed previously, $\mathrm{Mn}_{x} \mathrm{Cu}_{1-x}\left[\mathrm{Fe}(\mathrm{CN})_{6}\right]$ synthesized using the hydrothermal synthesis discussed in section 5.1 offers a rout to study an unexplored mixed metal hexacyanoferrate system.

Pairing the future experimental work with further computational modeling would allow for a deeper understanding of the relationship between the specific metals in a mix metal hexacyanoferrate and the resulting materials properties. Some next steps should be vibrational mode analysis and electronic calculations using a hybrid functional. Vibrational mode analysis of the systems studied is necessary to better understand how the $\mathrm{Ni} / \mathrm{Mn}$ ratio effects the bonding of the entire system. In addition to the cyanide bond, effects of $\mathrm{Mn}$ concentration on the nickel-nitrogen bond should be studied. Second, calculations using the hybrid functional HSEO3 [289] could provide an accurate model for the electron density and properly describe the electronic properties of the materials.

Additionally, analysis of the "chemical bonding" of the PBAs should be conducted using the local-orbital basis suite towards electron-structure reconstruction (LOBSTER), which allows for the approximation of orbital-pair interactions to generate a "bond- 
weighted" density of states. This provides information on bonding and antibonding states. Lastly, modeling of ionic diffusion pathways using the nudge elastic band method can provide important insight into the impact of $\mathrm{Mn}$ substitution on the migration of $\mathrm{K}^{+}$ ions.

Building off of the work on hydrated copper hexacyanoferrate, it would be interesting to study the system in a hybrid aqueous/nonaqueous electrolyte. Hybrid electrolytes have started to gain interest in the battery community as a way to increase ionic mobility while maintaining a wide electrochemical potential window. This approach may lead to a system with good storage properties coupled with increased power density.

Finally, the development of full batteries, a two-terminal cell without a reference electrode, is an important next step. Of particular interest is the use of metallic anodes such as $\mathrm{Zn}, \mathrm{Ca}$, and $\mathrm{Mg}$, which would provide significant increases in energy density. This would demonstrate the true applicability of the systems studied in this dissertation. 


\section{References}

[1] Kyoto Protocol to the United Nations Framework Convention on Climate Change 1997.

[2] Climate at a Glance | National Centers for Environmental Information (NCEI). NOAA National Centers for Environmental Information 2020. https://www.ncdc.noaa.gov/cag/global/timeseries/globe/land_ocean/ann/6/1880-2020 (accessed September 13, 2020).

[3] Pachauri RK, Mayer L, Intergovernmental Panel on Climate Change, editors. Climate change 2014: synthesis report. Geneva, Switzerland: Intergovernmental Panel on Climate Change; 2015.

[4] Lacis AA, Schmidt GA, Rind D, Ruedy RA. Atmospheric CO2: Principal Control Knob Governing Earth's Temperature. Science 2010;330:356-9. https://doi.org/10.1126/science.1190653.

[5] Anderson TR, Hawkins E, Jones PD. CO2, the greenhouse effect and global warming: from the pioneering work of Arrhenius and Callendar to today's Earth System Models. Endeavour 2016;40:178-87. https://doi.org/10.1016/j.endeavour.2016.07.002.

[6] World Resources Institute. CAIT Climate Data Explorer. Country Greenhouse Gas Emissions 2019. http://cait.wri.org (accessed September 13, 2020).

[7] Ritchie H, Roser M. $\mathrm{CO}_{2}$ and Greenhouse Gas Emissions. Our World in Data 2017.

[8] Pachauri RK, Meyer LA. Climate Change 2014 Synthesis Report Summary for Policymakers. Geneva, Switzerland: IPCC; 2014.

[9] Bruckner T, Bashmakov IA, Mulugetta Y, Chum H, De la Vega Navarro A, Edmonds $\mathrm{J}$, et al. Energy systems Climate Change 2014: Mitigation of Climate Change. Contribution of Working Group III to the Fifth Assessment Report of the Intergovernmental Panel on Climate Change ed OR Edenhofer et al. Cambridge and New York: Cambridge University Press Available at: Https://Www Ipcc Ch/Pdf/Assessment-Report/Ar5/Wg3/lpcc_wg3_ar5_chapter7 Pdf 2014.

[10] Secretariat R. Renewables 2020 Global Status Report. 2020.

[11] DOE OE Global Energy Storae Database. DOE OE Global Energy Storae Database 2020. https://www.sandia.gov/ess-ssl/global-energy-storage-database-home/ (accessed September 13, 2020).

[12] Koohi-Fayegh S, Rosen MA. A review of energy storage types, applications and recent developments. Journal of Energy Storage 2020;27:101047. https://doi.org/10.1016/j.est.2019.101047.

[13] World Energy Issues Monitor 2019 | Managing the Grand Energy Transition. World Energy Council 2019. https://www.worldenergy.org/publications/entry/worldenergy-issues-monitor-2019-managing-the-grand-energy-transition (accessed September 13, 2020).

[14] Penev M, Hunter C, Eichman J. Energy Storage: Days of Service Sensitivity Analysis n.d.:21. 
[15] Guerra OJ, Zhang J, Eichman J, Denholm P, Kurtz J, Hodge B-M. The value of seasonal energy storage technologies for the integration of wind and solar power. Energy Environ Sci 2020;13:1909-22. https://doi.org/10.1039/D0EE00771D.

[16] Guggenheim EA. The Conceptions of Electrical Potential Difference between Two Phases and the Individual Activities of lons. J Phys Chem 1929;33:842-9. https://doi.org/10.1021/j150300a003.

[17] Mizushima K, Jones P, Wiseman P, Goodenough JB. LixCoO2 $(0<x<-1)$ : A new cathode material for batteries of high energy density. Materials Research Bulletin 1980;15:783-789.

[18] Yoshino A, Sanechika K, Nakajima T. Secondary battery. US4668595A, 1987.

[19] Amatucci GG, Tarascon JM, Klein LC. CoO2, The End Member of the Li x CoO2 Solid Solution. J Electrochem Soc 1996;143:1114. https://doi.org/10.1149/1.1836594.

[20] Greeves N. ChemTube3D: Interactive 3D organic reaction mechanisms. Department of Chemistry, University of Liverpool; 2007.

[21] Ishizawa N, Tateishi K. Diffusion of Li atoms in LiMn2O4- A structural point of view -. Journal of the Ceramic Society of Japan 2009;117:6-14. https://doi.org/10.2109/jcersj2.117.6.

[22] Masquelier C, Padhi AK, Nanjundaswamy KS, Goodenough JB. New Cathode Materials for Rechargeable Lithium Batteries: The 3-D Framework Structures Li3Fe2(XO4)3(X=P, As). Journal of Solid State Chemistry 1998;135:228-34. https://doi.org/10.1006/jssc.1997.7629.

[23] Manthiram A, Goodenough JB. Lithium insertion into Fe2(MO4)3 frameworks: Comparison of $\mathrm{M}=\mathrm{W}$ with $\mathrm{M}=\mathrm{Mo}$. Journal of Solid State Chemistry 1987;71:34960. https://doi.org/10.1016/0022-4596(87)90242-8.

[24] Manthiram A, Goodenough JB. Lithium insertion into Fe2(SO4)3 frameworks. Journal of Power Sources 1989;26:403-8. https://doi.org/10.1016/03787753(89)80153-3.

[25] Padhi AK, Nanjundaswamy KS, Masquelier C, Goodenough JB. Mapping of Transition Metal Redox Energies in Phosphates with NASICON Structure by Lithium Intercalation. J Electrochem Soc 1997;144:2581. https://doi.org/10.1149/1.1837868.

[26] Padhi AK, Nanjundaswamy KS, Masquelier C, Okada S, Goodenough JB. Effect of Structure on the Fe3 + / Fe2 + Redox Couple in Iron Phosphates. J Electrochem Soc 1997;144:1609. https://doi.org/10.1149/1.1837649.

[27] Padhi AK, Nanjundaswamy KS, Goodenough JB. Phospho-olivines as PositiveElectrode Materials for Rechargeable Lithium Batteries. J Electrochem Soc 1997;144:1188. https://doi.org/10.1149/1.1837571.

[28] Mohamed N, K. Allam N. Recent advances in the design of cathode materials for Liion batteries. RSC Advances 2020;10:21662-85. https://doi.org/10.1039/D0RA03314F. 
[29] Ouyang C, Shi S, Wang Z, Huang X, Chen L. First-principles study of Li ion diffusion in LiFe(PO)4. Phys Rev B 2004;69:104303. https://doi.org/10.1103/PhysRevB.69.104303.

[30] Padbury R, Zhang X. Lithium-oxygen batteries-Limiting factors that affect performance. Journal of Power Sources 2011;196:4436-44. https://doi.org/10.1016/j.jpowsour.2011.01.032.

[31] Freunberger SA, Chen Y, Drewett NE, Hardwick L, Bardé F, Bruce PG. The LithiumOxygen Battery with Ether-Based Electrolytes. Angewandte Chemie International Edition 2011;50:8609-13. https://doi.org/10.1002/anie.201102357.

[32] Geng D, Ding N, Hor TSA, Chien SW, Liu Z, Wuu D, et al. From Lithium-Oxygen to Lithium-Air Batteries: Challenges and Opportunities. Advanced Energy Materials 2016;6:1502164. https://doi.org/10.1002/aenm.201502164.

[33] Asadi M, Sayahpour B, Abbasi P, Ngo AT, Karis K, Jokisaari JR, et al. A lithium-oxygen battery with a long cycle life in an air-like atmosphere. Nature 2018;555:502-6. https://doi.org/10.1038/nature25984.

[34] McCloskey BD, Bethune DS, Shelby RM, Girishkumar G, Luntz AC. Solvents' Critical Role in Nonaqueous Lithium-Oxygen Battery Electrochemistry. J Phys Chem Lett 2011;2:1161-6. https://doi.org/10.1021/jz200352v.

[35] Lu J, Jung Lee $\mathrm{Y}$, Luo X, Chun Lau K, Asadi M, Wang H-H, et al. A lithium-oxygen battery based on lithium superoxide. Nature 2016;529:377-82. https://doi.org/10.1038/nature16484.

[36] Abraham KM, Jiang Z. A Polymer Electrolyte-Based Rechargeable Lithium/Oxygen Battery. J Electrochem Soc 1996;143:1. https://doi.org/10.1149/1.1836378.

[37] Wild M, O'Neill L, Zhang T, Purkayastha R, Minton G, Marinescu M, et al. Lithium sulfur batteries, a mechanistic review. Energy \& Environmental Science 2015;8:3477-94. https://doi.org/10.1039/C5EE01388G.

[38] Ma L, Hendrickson KE, Wei S, Archer LA. Nanomaterials: Science and applications in the lithium-sulfur battery. Nano Today 2015;10:315-38. https://doi.org/10.1016/j.nantod.2015.04.011.

[39] Zhao H, Deng N, Yan J, Kang W, Ju J, Ruan Y, et al. A review on anode for lithiumsulfur batteries: Progress and prospects. Chemical Engineering Journal 2018;347:343-65. https://doi.org/10.1016/j.cej.2018.04.112.

[40] Zhang SS. Liquid electrolyte lithium/sulfur battery: Fundamental chemistry, problems, and solutions. Journal of Power Sources 2013;231:153-62. https://doi.org/10.1016/j.jpowsour.2012.12.102.

[41] Zhao H, Xu J, Yin D, Du Y. Electrolytes for Batteries with Earth-Abundant Metal Anodes. Chemistry - A European Journal 2018;24:18220-34. https://doi.org/10.1002/chem.201802438.

[42] Jiang Y, Hu M, Zhang D, Yuan T, Sun W, Xu B, et al. Transition metal oxides for high performance sodium ion battery anodes. Nano Energy 2014;5:60-6. https://doi.org/10.1016/j.nanoen.2014.02.002. 
[43] Qu B, Ma C, Ji G, Xu C, Xu J, Meng YS, et al. Layered SnS2-Reduced Graphene Oxide Composite - A High-Capacity, High-Rate, and Long-Cycle Life Sodium-Ion Battery Anode Material. Advanced Materials 2014;26:3854-9. https://doi.org/10.1002/adma.201306314.

[44] Komaba S, Yabuuchi N, Nakayama T, Ogata A, Ishikawa T, Nakai I. Study on the Reversible Electrode Reaction of Na1-xNi0.5Mn0.5O2 for a Rechargeable SodiumIon Battery. Inorg Chem 2012;51:6211-20. https://doi.org/10.1021/ic300357d.

[45] Zhou T, Pang WK, Zhang C, Yang J, Chen Z, Liu HK, et al. Enhanced Sodium-Ion Battery Performance by Structural Phase Transition from Two-Dimensional Hexagonal-SnS2 to Orthorhombic-SnS. ACS Nano 2014;8:8323-33. https://doi.org/10.1021/nn503582c.

[46] Slater MD, Kim D, Lee E, Johnson CS. Sodium-Ion Batteries. Advanced Functional Materials 2013;23:947-58. https://doi.org/10.1002/adfm.201200691.

[47] Song J, Wang L, Lu Y, Liu J, Guo B, Xiao P, et al. Removal of Interstitial H2O in Hexacyanometallates for a Superior Cathode of a Sodium-Ion Battery. Journal of the American Chemical Society 2015;137:2658-64. https://doi.org/10.1021/ja512383b.

[48] Wang L, Lu Y, Liu J, Xu M, Cheng J, Zhang D, et al. A Superior Low-Cost Cathode for a Na-Ion Battery. Angew Chem Int Ed 2013;52:1964-7. https://doi.org/10.1002/anie.201206854.

[49] Wang L, Song J, Qiao R, Wray LA, Hossain MA, Chuang Y-D, et al. Rhombohedral Prussian White as Cathode for Rechargeable Sodium-Ion Batteries. J Am Chem Soc 2015;137:2548-54. https://doi.org/10.1021/ja510347s.

[50] Dong Y, Wu Z-S, Zheng S, Wang X, Qin J, Wang S, et al. Ti3C2 MXene-Derived Sodium/Potassium Titanate Nanoribbons for High-Performance Sodium/Potassium Ion Batteries with Enhanced Capacities. ACS Nano 2017;11:4792-800. https://doi.org/10.1021/acsnano.7b01165.

[51] Luo W, Wan J, Ozdemir B, Bao W, Chen Y, Dai J, et al. Potassium Ion Batteries with Graphitic Materials. Nano Lett 2015;15:7671-7. https://doi.org/10.1021/acs.nanolett.5b03667.

[52] Pramudita JC, Sehrawat D, Goonetilleke D, Sharma N. An Initial Review of the Status of Electrode Materials for Potassium-Ion Batteries. Advanced Energy Materials 2017;7:1602911. https://doi.org/10.1002/aenm.201602911.

[53] Komaba S, Hasegawa T, Dahbi M, Kubota K. Potassium intercalation into graphite to realize high-voltage/high-power potassium-ion batteries and potassium-ion capacitors. Electrochemistry Communications 2015;60:172-5. https://doi.org/10.1016/j.elecom.2015.09.002.

[54] Zhang W, Mao J, Li S, Chen Z, Guo Z. Phosphorus-Based Alloy Materials for Advanced Potassium-Ion Battery Anode. J Am Chem Soc 2017;139:3316-9. https://doi.org/10.1021/jacs.6b12185.

[55] Zhou A, Xu Z, Gao H, Xue L, Li J, Goodenough JB. Size-, Water-, and Defect-Regulated Potassium Manganese Hexacyanoferrate with Superior Cycling Stability and Rate 
Capability for Low-Cost Sodium-Ion Batteries. Small 2019;15:1902420. https://doi.org/10.1002/smll.201902420.

[56] Padigi P, Goncher G, Evans D, Solanki R. Potassium barium hexacyanoferrate - A potential cathode material for rechargeable calcium ion batteries. Journal of Power Sources 2015;273:460-4. https://doi.org/10.1016/j.jpowsour.2014.09.101.

[57] Huie MM, Bock DC, Takeuchi ES, Marschilok AC, Takeuchi KJ. Cathode materials for magnesium and magnesium-ion based batteries. Coordination Chemistry Reviews 2015;287:15-27. https://doi.org/10.1016/j.ccr.2014.11.005.

[58] Levi E, Mitelman A, Aurbach D, Brunelli M. Structural Mechanism of the Phase Transitions in the Mg-Cu-Mo6S8 System Probed by ex Situ Synchrotron X-ray Diffraction. Chem Mater 2007;19:5131-42. https://doi.org/10.1021/cm0715489.

[59] Aurbach D, Lu Z, Schechter A, Gofer Y, Gizbar H, Turgeman R, et al. Prototype systems for rechargeable magnesium batteries. Nature 2000;407:724-7. https://doi.org/10.1038/35037553.

[60] Li Y, Nuli Y, Yang J, Yilinuer T, Wang J. MgFeSiO4 prepared via a molten salt method as a new cathode material for rechargeable magnesium batteries. Chin Sci Bull 2011;56:386-90. https://doi.org/10.1007/s11434-010-4247-4.

[61] Lu D, Liu H, Huang T, Xu Z, Ma L, Yang P, et al. Magnesium ion based organic secondary batteries. J Mater Chem A 2018;6:17297-302. https://doi.org/10.1039/C8TA05230A.

[62] Kim C, Phillips PJ, Key B, Yi T, Nordlund D, Yu Y-S, et al. Direct Observation of Reversible Magnesium Ion Intercalation into a Spinel Oxide Host. Advanced Materials 2015;27:3377-84. https://doi.org/10.1002/adma.201500083.

[63] Singh N, Arthur TS, Ling C, Matsui M, Mizuno F. A high energy-density tin anode for rechargeable magnesium-ion batteries. Chem Commun 2012;49:149-51. https://doi.org/10.1039/C2CC34673G.

[64] Cabello M, Nacimiento F, González JR, Ortiz G, Alcántara R, Lavela P, et al. Advancing towards a veritable calcium-ion battery: CaCo2O4 positive electrode material. Electrochemistry Communications 2016;67:59-64. https://doi.org/10.1016/j.elecom.2016.03.016.

[65] Padigi P, Kuperman N, Thiebes J, Goncher G, Evans D, Solanki R. Calcium Cobalt Hexacyanoferrate Cathodes for Rechargeable Divalent Ion Batteries. Journal of New Materials for Electrochemical Systems 2016;19.

[66] Tojo T, Sugiura Y, Inada R, Sakurai Y. Reversible Calcium Ion Batteries Using a Dehydrated Prussian Blue Analogue Cathode. Electrochimica Acta 2016;207:22-7. https://doi.org/10.1016/j.electacta.2016.04.159.

[67] Ponrouch A, Palacin MR. On the road toward calcium-based batteries. Current Opinion in Electrochemistry 2018;9:1-7. https://doi.org/10.1016/j.coelec.2018.02.001.

[68] Ponrouch A, Frontera C, Bardé F, Palacín MR. Towards a calcium-based rechargeable battery. Nat Mater 2016;15:169-72. https://doi.org/10.1038/nmat4462. 
[69] Wang D, Gao X, Chen Y, Jin L, Kuss C, Bruce PG. Plating and stripping calcium in an organic electrolyte. Nature Materials 2017. https://doi.org/10.1038/nmat5036.

[70] Wang M, Jiang C, Zhang S, Song X, Tang Y, Cheng H-M. Reversible calcium alloying enables a practical room-temperature rechargeable calcium-ion battery with a high discharge voltage. Nature Chemistry 2018;10:667. https://doi.org/10.1038/s41557-018-0045-4.

[71] Gao Y, Yang H, Wang X, Bai Y, Zhu N, Guo S, et al. The Compensation Effect Mechanism of Fe-Ni Mixed Prussian Blue Analogues in Aqueous Rechargeable Aluminum-Ion Batteries. ChemSusChem 2020;13:732-40. https://doi.org/10.1002/cssc.201903067.

[72] Ru Y, Zheng S, Xue H, Pang H. Potassium cobalt hexacyanoferrate nanocubic assemblies for high-performance aqueous aluminum ion batteries. Chemical Engineering Journal 2019:122853. https://doi.org/10.1016/j.cej.2019.122853.

[73] Licht S. Novel aluminum batteries: a step towards derivation of superbatteries. Colloids and Surfaces A: Physicochemical and Engineering Aspects 1998;134:2418. https://doi.org/10.1016/S0927-7757(97)00329-4.

[74] Jayaprakash N, Das SK, Archer LA. The rechargeable aluminum-ion battery. Chemical Communications 2011;47:12610. https://doi.org/10.1039/c1cc15779e.

[75] Zhang L, Chen L, Luo H, Zhou X, Liu Z. Large-Sized Few-Layer Graphene Enables an Ultrafast and Long-Life Aluminum-Ion Battery. Advanced Energy Materials 2017;7:1700034. https://doi.org/10.1002/aenm.201700034.

[76] Chen H, Guo F, Liu Y, Huang T, Zheng B, Ananth N, et al. A Defect-Free Principle for Advanced Graphene Cathode of Aluminum-Ion Battery. Advanced Materials 2017;29:1605958. https://doi.org/10.1002/adma.201605958.

[77] Wang B, Han Y, Wang X, Bahlawane N, Pan H, Yan M, et al. Prussian Blue Analogs for Rechargeable Batteries. IScience 2018;3:110-33. https://doi.org/10.1016/j.isci.2018.04.008.

[78] Ware M. Prussian Blue: Artists' Pigment and Chemists' Sponge. J Chem Educ 2008;85:612. https://doi.org/10.1021/ed085p612.

[79] Kraft A. On the discovery and history of Prussian Blue. Bull Hist Chem 2008;33:617.

[80] Hurlbutt K, Wheeler S, Capone I, Pasta M. Prussian Blue Analogs as Battery Materials. Joule 2018;2:1950-60. https://doi.org/10.1016/j.joule.2018.07.017.

[81] Keggin JF, Miles FD. Structures and Formulæ of the Prussian Blues and Related Compounds. Nature 1936;137:577-8.

[82] Wessells CD, Huggins RA, Cui Y. Copper hexacyanoferrate battery electrodes with long cycle life and high power. Nature Communications 2011;2:550. https://doi.org/10.1038/ncomms1563.

[83] Li W, Zhang F, Xiang X, Zhang X. Electrochemical Properties and Redox Mechanism of Na2Ni0.4Co0.6[Fe(CN)6] Nanocrystallites as High-Capacity Cathode for Aqueous Sodium-Ion Batteries. The Journal of Physical Chemistry C 2017;121:27805-12. https://doi.org/10.1021/acs.jpcc.7b07920. 
[84] Oliver-Tolentino M, M MG, Osiry H, Ramos-Sánchez G, González I. Electronic density distribution of $\mathrm{Mn}-\mathrm{N}$ bonds by a tuning effect through partial replacement of $\mathrm{Mn}$ by $\mathrm{Co}$ or $\mathrm{Ni}$ in a sodium-rich hexacyanoferrate and its influence on the stability as a cathode for Na-ion batteries. Dalton Transactions 2018. https://doi.org/10.1039/C8DT03595D.

[85] Pasta M, Wessells CD, Liu N, Nelson J, McDowell MT, Huggins RA, et al. Full openframework batteries for stationary energy storage. Nature Communications 2014;5. https://doi.org/10.1038/ncomms4007.

[86] Shen L, Jiang Y, Liu Y, Ma J, Sun T, Zhu N. High-stability monoclinic nickel hexacyanoferrate cathode materials for ultrafast aqueous sodium ion battery. Chemical Engineering Journal 2020;388:124228. https://doi.org/10.1016/j.cej.2020.124228.

[87] Wang RY, Wessells CD, Huggins RA, Cui Y. Highly Reversible Open Framework Nanoscale Electrodes for Divalent Ion Batteries. Nano Lett 2013;13:5748-52. https://doi.org/10.1021/nl403669a.

[88] Shen Z, Sun Y, Xie J, Liu S, Zhuang D, Zhang G, et al. Manganese hexacyanoferrate/graphene cathodes for sodium-ion batteries with superior rate capability and ultralong cycle life. Inorganic Chemistry Frontiers 2018;5:2914-20. https://doi.org/10.1039/C8QI00768C.

[89] Lee H-W, Wang RY, Pasta M, Woo Lee S, Liu N, Cui Y. Manganese hexacyanomanganate open framework as a high-capacity positive electrode material for sodium-ion batteries. Nat Commun 2014;5:5280. https://doi.org/10.1038/ncomms6280.

[90] Shen Z, Guo S, Liu C, Sun Y, Chen Z, Tu J, et al. Na-Rich Prussian White Cathodes for Long-Life Sodium-Ion Batteries. ACS Sustainable Chem Eng 2018;6:16121-9. https://doi.org/10.1021/acssuschemeng.8b02758.

[91] Xie M, Xu M, Huang Y, Chen R, Zhang X, Li L, et al. Na2NixCo1 - xFe(CN)6: A class of Prussian blue analogs with transition metal elements as cathode materials for sodium ion batteries. Electrochemistry Communications 2015;59:91-4. https://doi.org/10.1016/j.elecom.2015.07.014.

[92] Wessells CD, Peddada SV, Huggins RA, Cui Y. Nickel Hexacyanoferrate Nanoparticle Electrodes For Aqueous Sodium and Potassium Ion Batteries. Nano Lett 2011;11:5421-5. https://doi.org/10.1021/nl203193q.

[93] Li W, Zhang F, Xiang X, Zhang X. Nickel-Substituted Copper Hexacyanoferrate as a Superior Cathode for Aqueous Sodium-Ion Batteries. ChemElectroChem 2018;5:350-4. https://doi.org/10.1002/celc.201700958.

[94] Nakamoto K, Sakamoto R, Sawada Y, Ito M, Okada S. Over 2 V Aqueous Sodium-Ion Battery with Prussian Blue-Type Electrodes. Small Methods 2018:1800220. https://doi.org/10.1002/smtd.201800220.

[95] Li W, Han C, Xia Q, Zhang K, Chou S, Kang Y-M, et al. Remarkable Enhancement in Sodium-Ion Kinetics of NaFe2(CN)6 by Chemical Bonding with Graphene. Small Methods 2018;2:1700346. https://doi.org/10.1002/smtd.201700346. 
[96] Yang D, Xu J, Liao X-Z, He Y-S, Liu H, Ma Z-F. Structure optimization of Prussian blue analogue cathode materials for advanced sodium ion batteries. Chemical Communications 2014;50:13377-80. https://doi.org/10.1039/C4CC05830E.

[97] Wessells CD, McDowell MT, Peddada SV, Pasta M, Huggins RA, Cui Y. Tunable Reaction Potentials in Open Framework Nanoparticle Battery Electrodes for GridScale Energy Storage. ACS Nano 2012;6:1688-94. https://doi.org/10.1021/nn204666v.

[98] Phadke S, Mysyk R, Anouti M. Effect of cation ( $\mathrm{Li}+, \mathrm{Na}+, \mathrm{K}+, \mathrm{Rb}+, \mathrm{Cs}+$ ) in aqueous electrolyte on the electrochemical redox of Prussian blue analogue (PBA) cathodes. Journal of Energy Chemistry 2020;40:31-8. https://doi.org/10.1016/j.jechem.2019.01.025.

[99] Levin EE, Kokin AA, Presnov DE, Borzenko AG, Vassiliev SY, Nikitina VA, et al. Electrochemical Analysis of the Mechanism of Potassium-Ion Insertion into K-rich Prussian Blue Materials. ChemElectroChem 2020;7:761-9. https://doi.org/10.1002/celc.201901919.

[100] Huang B, Shao Y, Liu Y, Lu Z, Lu X, Liao S. Improving Potassium-Ion Batteries by Optimizing the Composition of Prussian Blue Cathode. ACS Appl Energy Mater 2019;2:6528-35. https://doi.org/10.1021/acsaem.9b01097.

[101] Zhang C, Xu Y, Zhou M, Liang L, Dong H, Wu M, et al. Batteries: Potassium Prussian Blue Nanoparticles: A Low-Cost Cathode Material for Potassium-Ion Batteries (Adv. Funct. Mater. 4/2017). Adv Funct Mater 2017;27:n/a-n/a. https://doi.org/10.1002/adfm.201770024.

[102] Tang Y, Li W, Feng P, Zhou M, Wang K, Jiang K. Investigation of alkali-ion (Li, Na and $\mathrm{K})$ intercalation in manganese hexacyanoferrate $\mathrm{KxMnFe}(\mathrm{CN}) 6$ as cathode material. Chemical Engineering Journal 2020;396:125269. https://doi.org/10.1016/j.cej.2020.125269.

[103] Xue L, Li Y, Gao H, Zhou W, Lü X, Kaveevivitchai W, et al. Low-Cost High-Energy Potassium Cathode. J Am Chem Soc 2017;139:2164-7. https://doi.org/10.1021/jacs.6b12598.

[104] Pei Y, Mu C, Li H, Li F, Chen J. Low-Cost K4Fe(CN)6 as a High-Voltage Cathode for Potassium-Ion Batteries. ChemSusChem 2018;11:1285-9. https://doi.org/10.1002/cssc.201800057.

[105] Sun Y, Liu C, Xie J, Zhuang D, Zheng W, Zhao X. Potassium manganese hexacyanoferrate/graphene as a high-performance cathode for potassium-ion batteries. New Journal of Chemistry 2019. https://doi.org/10.1039/C9NJ02085C.

[106] Chong S, Wu Y, Guo S, Liu Y, Cao G. Potassium nickel hexacyanoferrate as cathode for high voltage and ultralong life potassium-ion batteries. Energy Storage Materials 2019. https://doi.org/10.1016/j.ensm.2019.07.003.

[107] Chong S, Yang J, Sun L, Guo S-W, Liu Y-N, Liu HK. Potassium Nickel Iron Hexacyanoferrate as Ultra-Long Life Cathode Material for Potassium Ion Batteries with High Energy Density. ACS Nano 2020. https://doi.org/10.1021/acsnano.0c02047. 
[108] Padigi P, Thiebes J, Swan M, Goncher G, Evans D, Solanki R. Prussian Green: A High Rate Capacity Cathode for Potassium Ion Batteries. Electrochimica Acta 2015;166:32-9. https://doi.org/10.1016/j.electacta.2015.03.084.

[109] Wu X, Jian Z, Li Z, Ji X. Prussian white analogues as promising cathode for nonaqueous potassium-ion batteries. Electrochemistry Communications 2017;77:547. https://doi.org/10.1016/j.elecom.2017.02.012.

[110] Kim D-M, Kim Y, Arumugam D, Woo SW, Jo YN, Park M-S, et al. Co-intercalation of $\mathrm{Mg} 2+$ and $\mathrm{Na}+$ in Na0.69Fe2(CN)6 as a High-Voltage Cathode for Magnesium Batteries. ACS Appl Mater Interfaces 2016;8:8554-60. https://doi.org/10.1021/acsami.6b01352.

[111] Mizuno Y, Okubo M, Hosono E, Kudo T, Oh-ishi K, Okazawa A, et al. Electrochemical $\mathrm{Mg} 2+$ intercalation into a bimetallic CuFe Prussian blue analog in aqueous electrolytes. J Mater Chem A 2013;1:13055-9. https://doi.org/10.1039/C3TA13205F.

[112] Marzak P, Kosiahn M, Yun J, Bandarenka AS. Intercalation of $\mathrm{Mg} 2+$ into electrodeposited Prussian Blue Analogue thin films from aqueous electrolytes. Electrochimica Acta 2019. https://doi.org/10.1016/j.electacta.2019.03.094.

[113] Lipson AL, Han S-D, Kim S, Pan B, Sa N, Liao C, et al. Nickel hexacyanoferrate, a versatile intercalation host for divalent ions from nonaqueous electrolytes. Journal of Power Sources 2016;325:646-52. https://doi.org/10.1016/j.jpowsour.2016.06.019.

[114] Shrivastava A, Liu S, C. Smith K. Linking capacity loss and retention of nickel hexacyanoferrate to a two-site intercalation mechanism for aqueous $\mathrm{Mg} 2+$ and $\mathrm{Ca}$ $2+$ ions. Physical Chemistry Chemical Physics 2019;21:20177-88. https://doi.org/10.1039/C9CP04115J.

[115] Wang RY, Shyam B, Stone KH, Weker JN, Pasta M, Lee H-W, et al. Reversible Multivalent (Monovalent, Divalent, Trivalent) Ion Insertion in Open Framework Materials. Advanced Energy Materials 2015;5:n/a-n/a. https://doi.org/10.1002/aenm.201401869.

[116] Adil Md, Dutta PK, Mitra S. An Aqueous Ca-ion Full Cell Comprising BaHCF Cathode and MCMB Anode. ChemistrySelect 2018;3:3687-90. https://doi.org/10.1002/slct.201800419.

[117] Kuperman N, Padigi P, Goncher G, Evans D, Thiebes J, Solanki R. High performance Prussian Blue cathode for nonaqueous Ca-ion intercalation battery. Journal of Power Sources 2017;342:414-8. https://doi.org/10.1016/j.jpowsour.2016.12.074.

[118] Lu K, Song B, Zhang J, Ma H. A rechargeable Na-Zn hybrid aqueous battery fabricated with nickel hexacyanoferrate and nanostructured zinc. Journal of Power Sources 2016;321:257-63. https://doi.org/10.1016/j.jpowsour.2016.05.003.

[119] Trócoli R, La Mantia F. An Aqueous Zinc-Ion Battery Based on Copper Hexacyanoferrate. ChemSusChem 2015;8:481-5. https://doi.org/10.1002/cssc.201403143. 
[120] Jia Z, Wang B, Wang Y. Copper hexacyanoferrate with a well-defined open framework as a positive electrode for aqueous zinc ion batteries. Materials Chemistry and Physics 2015;149-150:601-6. https://doi.org/10.1016/j.matchemphys.2014.11.014.

[121] Jayalakshmi $M$, Scholz $F$. Performance characteristics of zinc hexacyanoferrate/Prussian blue and copper hexacyanoferrate/Prussian blue solid state secondary cells. Journal of Power Sources 2000;91:217-23. https://doi.org/10.1016/S0378-7753(00)00475-4.

[122] Zhang L, Chen L, Zhou X, Liu Z. Morphology-Dependent Electrochemical Performance of Zinc Hexacyanoferrate Cathode for Zinc-Ion Battery. Scientific Reports 2015;5:18263. https://doi.org/10.1038/srep18263.

[123] Liu S, Pan GL, Li GR, Gao XP. Copper hexacyanoferrate nanoparticles as cathode material for aqueous Al-ion batteries. J Mater Chem A 2015;3:959-62. https://doi.org/10.1039/C4TA04644G.

[124] Li Z, Xiang K, Xing W, Carter WC, Chiang Y-M. Reversible Aluminum-Ion Intercalation in Prussian Blue Analogs and Demonstration of a High-Power Aluminum-Ion Asymmetric Capacitor. Advanced Energy Materials 2015;5:n/a-n/a. https://doi.org/10.1002/aenm.201401410.

[125] Wardecki D, Ojwang DO, Grins J, Svensson G. Neutron Diffraction and EXAFS Studies of $\mathrm{K} 2 \mathrm{x} / 3 \mathrm{Cu}[\mathrm{Fe}(\mathrm{CN}) 6] 2 / 3 \cdot \mathrm{nH} 2 \mathrm{O}$. Crystal Growth \& Design 2017;17:1285-92. https://doi.org/10.1021/acs.cgd.6b01684.

[126] Sharma VK, Mitra S, Thakur N, Yusuf SM, Juranyi F, Mukhopadhyay R. Dynamics of water in prussian blue analogues: Neutron scattering study. Journal of Applied Physics 2014;116:034909. https://doi.org/10.1063/1.4890722.

[127] Herren F, Fischer P, Ludi A, Haelg W. Neutron diffraction study of Prussian Blue, $\mathrm{Fe} 4[\mathrm{Fe}(\mathrm{CN}) 6] 3 . x \mathrm{H} 2 \mathrm{O}$. Location of water molecules and long-range magnetic order. Inorg Chem 1980;19:956-9. https://doi.org/10.1021/ic50206a032.

[128] Lu Y, Wang L, Cheng J, Goodenough JB. Prussian blue: a new framework of electrode materials for sodium batteries. Chem Commun 2012;48:6544-6. https://doi.org/10.1039/C2CC31777J.

[129] Eftekhari A. Potassium secondary cell based on Prussian blue cathode. Journal of Power Sources 2004;126:221-8. https://doi.org/10.1016/j.jpowsour.2003.08.007.

[130] Wu X, Wu C, Wei C, Hu L, Qian J, Cao Y, et al. Highly Crystallized Na2CoFe(CN)6 with Suppressed Lattice Defects as Superior Cathode Material for Sodium-Ion Batteries. ACS Appl Mater Interfaces 2016;8:5393-9. https://doi.org/10.1021/acsami.5b12620.

[131] Yang D, XU J, Liao X-Z, Wang H, He Y-S, Ma Z-F. Prussian blue without coordinated water as a superior cathode for sodium-ion batteries. Chem Commun 2015;51:8181-4. https://doi.org/10.1039/C5CC01180A.

[132] Wu X, Luo Y, Sun M, Qian J, Cao Y, Ai X, et al. Low-defect Prussian blue nanocubes as high capacity and long life cathodes for aqueous $\mathrm{Na}$-ion batteries. Nano Energy 2015;13:117-23. https://doi.org/10.1016/j.nanoen.2015.02.006. 
[133] Paolella A, Faure C, Timoshevskii V, Marras S, Bertoni G, Guerfi A, et al. A review on hexacyanoferrate-based materials for energy storage and smart windows: challenges and perspectives. Journal of Materials Chemistry A 2017;5:18919-32. https://doi.org/10.1039/C7TA05121B.

[134] You Y, Wu X-L, Yin Y-X, Guo Y-G. High-quality Prussian blue crystals as superior cathode materials for room-temperature sodium-ion batteries. Energy Environ Sci 2014;7:1643-7. https://doi.org/10.1039/C3EE44004D.

[135] Asakura D, Okubo M, Mizuno Y, Kudo T, Zhou H, Ikedo K, et al. Fabrication of a Cyanide-Bridged Coordination Polymer Electrode for Enhanced Electrochemical Ion Storage Ability. J Phys Chem C 2012;116:8364-9. https://doi.org/10.1021/jp2118949.

[136] Zhang M, Hou C, Halder A, Ulstrup J, Chi Q. Interlocked graphene-Prussian blue hybrid composites enable multifunctional electrochemical applications. Biosensors and Bioelectronics n.d. https://doi.org/10.1016/j.bios.2016.02.044.

[137] Wang X-J, Krumeich F, Nesper R. Nanocomposite of manganese ferrocyanide and graphene: A promising cathode material for rechargeable lithium ion batteries. Electrochemistry Communications 2013;34:246-9. https://doi.org/10.1016/j.elecom.2013.06.019.

[138] Chen R, Huang Y, Xie M, Zhang Q, Zhang X, Li L, et al. Preparation of Prussian Blue Submicron Particles with a Pore Structure by Two-Step Optimization for Na-Ion Battery Cathodes. ACS Appl Mater Interfaces 2016;8:16078-86. https://doi.org/10.1021/acsami.6b04151.

[139] You Y, Yu X, Yin Y, Nam K-W, Guo Y-G. Sodium iron hexacyanoferrate with high Na content as a Na-rich cathode material for Na-ion batteries. Nano Res 2015;8:11728. https://doi.org/10.1007/s12274-014-0588-7.

[140] Chen R, Huang Y, Xie M, Wang Z, Ye Y, Li L, et al. Chemical Inhibition Method to Synthesize Highly Crystalline Prussian Blue Analogs for Sodium-lon Battery Cathodes. ACS Appl Mater Interfaces 2016;8:31669-76. https://doi.org/10.1021/acsami.6b10884.

[141] Ji Z, Han B, Liang H, Zhou C, Gao Q, Xia K, et al. On the Mechanism of the Improved Operation Voltage of Rhombohedral Nickel Hexacyanoferrate as Cathodes for Sodium-Ion Batteries. ACS Appl Mater Interfaces 2016;8:33619-25. https://doi.org/10.1021/acsami.6b11070.

[142] Liu Y, Qiao Y, Zhang W, Li Z, Ji X, Miao L, et al. Sodium storage in Na-rich NaxFeFe(CN)6 nanocubes. Nano Energy 2015;12:386-93. https://doi.org/10.1016/j.nanoen.2015.01.012.

[143] Shiba F, Fujishiro R, Kojima T, Okawa Y. Preparation of Monodisperse Cobalt(II) Hexacyanoferrate(III) Nanoparticles Using Cobalt lons Released from a Citrate Complex. J Phys Chem C 2012;116:3394-9. https://doi.org/10.1021/jp210707y.

[144] Wu X, Sun M, Guo S, Qian J, Liu Y, Cao Y, et al. Vacancy-Free Prussian Blue Nanocrystals with High Capacity and Superior Cyclability for Aqueous Sodium-Ion 
Batteries.

ChemNanoMat

2015;1:188-93.

https://doi.org/10.1002/cnma.201500021.

[145] Zhang H, Li C, Chen D, Zhao J, Jiao X, Xia Y. Facile preparation of Prussian blue analogue $\mathrm{Co} 3[\mathrm{Co}(\mathrm{CN}) 6] 2$ with fine-tuning color transition temperature as thermochromic material. CrystEngComm 2017;19:2057-64. https://doi.org/10.1039/C7CE00384F.

[146] Prabakar SJR, Jeong J, Pyo M. Highly crystalline Prussian blue/graphene composites for high-rate performance cathodes in Na-ion batteries. RSC Adv 2015;5:37545-52. https://doi.org/10.1039/C5RA04769B.

[147] Jiang Y, Yu S, Wang B, Li Y, Sun W, Lu Y, et al. Prussian Blue@C Composite as an Ultrahigh-Rate and Long-Life Sodium-Ion Battery Cathode. Adv Funct Mater 2016;26:5315-21. https://doi.org/10.1002/adfm.201600747.

[148] Yue Y, Binder AJ, Guo B, Zhang Z, Qiao Z-A, Tian C, et al. Mesoporous Prussian Blue Analogues: Template-Free Synthesis and Sodium-Ion Battery Applications. Angew Chem Int Ed 2014;53:3134-7. https://doi.org/10.1002/anie.201310679.

[149] Xie C-C, Yang D-H, Zhong M, Zhang Y-H. Improving the Performance of a Ternary Prussian Blue Analogue as Cathode of Lithium Battery via Annealing Treatment. Z Anorg Allg Chem 2016;642:289-93. https://doi.org/10.1002/zaac.201500710.

[150] Pasta M, Wang RY, Ruffo R, Qiao R, Lee H-W, Shyam B, et al. Manganese-cobalt hexacyanoferrate cathodes for sodium-ion batteries. J Mater Chem $A$ 2016;4:4211-23. https://doi.org/10.1039/C5TA10571D.

[151] Firouzi A, Qiao R, Motallebi S, Valencia CW, Israel HS, Fujimoto M, et al. Monovalent manganese based anodes and co-solvent electrolyte for stable low-cost high-rate sodium-ion batteries. Nat Commun 2018;9:1-10. https://doi.org/10.1038/s41467018-03257-1.

[152] Crumbliss AL, Lugg PS, Morosoff N. Alkali metal cation effects in a Prussian blue surface modified electrode. Inorg Chem 1984;23:4701-8. https://doi.org/10.1021/ic00194a057.

[153] Moritomo $Y$, Urase S, Shibata T. Enhanced battery performance in manganese hexacyanoferrate by partial substitution. Electrochimica Acta 2016;210:963-9. https://doi.org/10.1016/j.electacta.2016.05.205.

[154] Xiao P, Song J, Wang L, Goodenough JB, Henkelman G. Theoretical Study of the Structural Evolution of a Na2FeMn(CN)6 Cathode upon $\mathrm{Na}$ Intercalation. Chem Mater 2015;27:3763-8. https://doi.org/10.1021/acs.chemmater.5b01132.

[155] Dostal A, Kauschka G, Reddy SJ, Scholz F. Lattice contractions and expansions accompanying the electrochemical conversions of Prussian blue and the reversible and irreversible insertion of rubidium and thallium ions. Journal of Electroanalytical Chemistry 1996;406:155-63. https://doi.org/10.1016/0022-0728(95)04427-2.

[156] You Y, Wu X-L, Yin Y-X, Guo Y-G. A zero-strain insertion cathode material of nickel ferricyanide for sodium-ion batteries. J Mater Chem A 2013;1:14061-5. https://doi.org/10.1039/C3TA13223D. 
[157] Guadagnini L, Giorgetti M, Tonelli D. Pure copper vs. mixed copper and palladium hexacyanoferrates for glucose biosensing applications. J Solid State Electrochem 2013;17:2805-14. https://doi.org/10.1007/s10008-013-2193-1.

[158] Pandey PC, Panday D. Novel synthesis of nickel-iron hexacyanoferrate nanoparticles and its application in electrochemical sensing. Journal of Electroanalytical Chemistry 2016;763:63-70. https://doi.org/10.1016/j.jelechem.2015.12.048.

[159] Sharma VV, Tonelli D, Guadagnini L, Gazzano M. Copper-cobalt hexacyanoferrate modified glassy carbon electrode for an indirect electrochemical determination of mercury. Sensors and Actuators B: Chemical 2017;238:9-15. https://doi.org/10.1016/j.snb.2016.07.005.

[160] Tao W, Pan D, Liu Y, Nie L, Yao S. An amperometric hydrogen peroxide sensor based on immobilization of hemoglobin in poly(o-aminophenol) film at iron-cobalt hexacyanoferrate-modified gold electrode. Analytical Biochemistry 2005;338:33240. https://doi.org/10.1016/j.ab.2004.12.009.

[161] Gwizdałła TM. Magnetic properties of ternary Prussian Blue Analogs studied with genetic approach. Computational Materials Science 2011;50:2644-50. https://doi.org/10.1016/j.commatsci.2011.04.012.

[162] Ikeda K, Ohkoshi S, Hashimoto K. Magnetization-induced second-harmonic generation in electrochemically synthesized magnetic films of ternary metal Prussian blue analogs. Journal of Applied Physics 2003;93:1371-5. https://doi.org/10.1063/1.1536725.

[163] Pajerowski DM, Yamamoto T, Einaga Y. Photomagnetic K0.25Ni1-

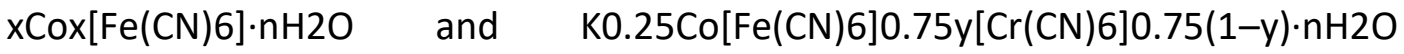
Prussian Blue Analogue Solid Solutions. Inorg Chem 2012;51:3648-55. https://doi.org/10.1021/ic202571d.

[164] Widmann A, Kahlert H, Petrovic-Prelevic I, Wulff H, Yakhmi JV, Bagkar N, et al. Structure, Insertion Electrochemistry, and Magnetic Properties of a New Type of Substitutional Solid Solutions of Copper, Nickel, and Iron Hexacyanoferrates/Hexacyanocobaltates. Inorganic Chemistry 2002;41:5706-15. https://doi.org/10.1021/ic0201654.

[165] Abbaspour A, Ghaffarinejad A. Electrocatalytic oxidation of I-cysteine with a stable copper-cobalt hexacyanoferrate electrochemically modified carbon paste electrode. Electrochimica Acta 2008;53:6643-50. https://doi.org/10.1016/j.electacta.2008.04.065.

[166] Abbaspour A, Kamyabi MA. Electrocatalytic oxidation of hydrazine on a carbon paste electrode modified by hybrid hexacyanoferrates of copper and cobalt films. Journal of Electroanalytical Chemistry 2005;576:73-83. https://doi.org/10.1016/j.jelechem.2004.10.008.

[167] Kumar AVN, Joseph J. New Zn-NiHCF Hybrid Electrochemically Formed on Glassy Carbon: Observation of Thin Layer Diffusion during Electro-Oxidation of Hydrazine. J Phys Chem C 2015;119:296-304. https://doi.org/10.1021/jp508740w. 
[168] Yu H, Jian X, Jin J, Wang F, Wang Y, Qi G. Preparation of hybrid cobalt-iron hexacyanoferrate nanoparticles modified multi-walled carbon nanotubes composite electrode and its application. Journal of Electroanalytical Chemistry 2013;700:47-53. https://doi.org/10.1016/j.jelechem.2013.03.015.

[169] Narendra Kumar AV, Harish S, Joseph J, Phani KL. Nix-Fe(1-x)Fe(CN)6 hybrid thin films electrodeposited on glassy carbon: Effect of tuning of redox potentials on the electrocatalysis of hydrogen peroxide. Journal of Electroanalytical Chemistry 2011;659:128-33. https://doi.org/10.1016/j.jelechem.2011.05.006.

[170] Hung T-F, Chou H-L, Yeh Y-W, Chang W-S, Yang C-C. Combined Experimental and Computational Studies of a Na2Ni1-xCuxFe(CN)6 Cathode with Tunable Potential for Aqueous Rechargeable Sodium-Ion Batteries. Chemistry - A European Journal 2015;21:15686-91. https://doi.org/10.1002/chem.201501485.

[171] Hu P, Peng W, Wang B, Xiao D, Ahuja U, Réthoré J, et al. Concentration-Gradient Prussian Blue Cathodes for Na-Ion Batteries. ACS Energy Lett 2020;5:100-8. https://doi.org/10.1021/acsenergylett.9b02410.

[172] Fu H, Liu C, Zhang C, Ma W, Wang K, Li Z, et al. Enhanced storage of sodium ions in Prussian blue cathode material through nickel doping. Journal of Materials Chemistry A 2017;5:9604-10. https://doi.org/10.1039/C7TA00132K.

[173] Li W, Han C, Wang W, Xia Q, Chou S, Gu Q, et al. Stress Distortion Restraint to Boost the Sodium Ion Storage Performance of a Novel Binary Hexacyanoferrate. Advanced Energy Materials 2020;10:1903006. https://doi.org/10.1002/aenm.201903006.

[174] Xu Y, Zhu Y, Chen P, Nie W, Zhou Y. Trace interstitial water removal from coppercobalt Prussian analogues by rGO coating for high performance sodium ion supercapacitor devices. Applied Surface Science 2019;481:919-25. https://doi.org/10.1016/j.apsusc.2019.03.189.

[175] Huang B, Liu Y, Lu Z, Shen M, Zhou J, Ren J, et al. Prussian Blue [K2FeFe(CN)6] Doped with Nickel as a Superior Cathode: An Efficient Strategy To Enhance Potassium Storage Performance. ACS Sustainable Chem Eng 2019;7:16659-67. https://doi.org/10.1021/acssuschemeng.9b04012.

[176] Sun X, Ji X-Y, Zhou Y-T, Shao Y, Zang Y, Wen Z-Y, et al. A new gridding cyanoferrate anode material for lithium and sodium ion batteries: Ti0.75Fe0.25[Fe(CN)6]0.96 $1.9 \mathrm{H} 20$ with excellent electrochemical properties. Journal of Power Sources 2016;314:35-8. https://doi.org/10.1016/j.jpowsour.2016.03.011.

[177] Xie C-C, Yang D-H, Zhong M, Zhang Y-H. Improving the Performance of a Ternary Prussian Blue Analogue as Cathode of Lithium Battery via Annealing Treatment. Z Anorg Allg Chem 2016;642:289-93. https://doi.org/10.1002/zaac.201500710.

[178] Kasiri G, Glenneberg J, Bani Hashemi A, Kun R, La Mantia F. Mixed copper-zinc hexacyanoferrates as cathode materials for aqueous zinc-ion batteries. Energy Storage Materials 2019. https://doi.org/10.1016/j.ensm.2019.03.006. 
[179] Bharathi S, Joseph J, Jeyakumar D, Rao GP. Modified electrodes with mixed metal hexacyanoferrates. Journal of Electroanalytical Chemistry and Interfacial Electrochemistry 1991;319:341-5. https://doi.org/10.1016/0022-0728(91)87089M.

[180] Reddy SJ, Dostal A, Scholz F. Solid state electrochemical studies of mixed nickel-iron hexacyanoferrates with the help of abrasive stripping voltammetry. Journal of Electroanalytical Chemistry 1996;403:209-12. https://doi.org/10.1016/00220728(95)04380-2.

[181] Zakharchuk NF, Naumov N, Stösser R, Schröder U, Scholz F, Mehner H. Solid state electrochemistry, X-ray powder diffraction, magnetic susceptibility, electron spin resonance, Mössbauer and diffuse reflectance spectroscopy of mixed iron(III)cadmium(II) hexacyanoferrates. J Solid State Electrochem 1999;3:264-76. https://doi.org/10.1007/s100080050157.

[182] Ishizaki M, Ono K, Suzuki K, Naito W, Kanaizuka K, Kawamoto T, et al. Fine-Tunable Electronic Energy Levels of Mixed-Metal Prussian-Blue Alloy Nanoparticles. ChemNanoMat 2017;3:288-91. https://doi.org/10.1002/cnma.201700084.

[183] Wu M-S, Lyu L-J, Syu J-H. Copper and nickel hexacyanoferrate nanostructures with graphene-coated stainless steel sheets for electrochemical supercapacitors. Journal of Power Sources 2015;297:75-82. https://doi.org/10.1016/j.jpowsour.2015.07.101.

[184] Omarova M, Koishybay A, Yesibolati N, Mentbayeva A, Umirov N, Ismailov K, et al. Nickel Hexacyanoferrate Nanoparticles as a Low Cost Cathode Material for LithiumIon Batteries. Electrochimica Acta 2015;184:58-63. https://doi.org/10.1016/j.electacta.2015.10.031.

[185] Safavi A, Kazemi SH, Kazemi H. Electrochemically deposited hybrid nickel-cobalt hexacyanoferrate nanostructures for electrochemical supercapacitors. Electrochimica Acta 2011;56:9191-6. https://doi.org/10.1016/j.electacta.2011.07.122.

[186] Xu P, Wang G, Wang H, Li Y, Miao C, Qu J, et al. K2.25Ni0.55Co0.37Fe(CN)6 nanoparticle connected by cross-linked carbon nanotubes conductive skeletons for high-performance energy storage. Chemical Engineering Journal 2017;328:834-43. https://doi.org/10.1016/j.cej.2017.07.007.

[187] Zhu X, Tao H, Li M. Co-precipitation synthesis of nickel cobalt hexacyanoferrate for binder-free high-performance supercapacitor electrodes. International Journal of Hydrogen Energy 2020. https://doi.org/10.1016/j.ijhydene.2020.02.188.

[188] Qiu X, Liu Y, Wang L, Fan L-Z. Reverse microemulsion synthesis of nickel-cobalt hexacyanoferrate/reduced graphene oxide nanocomposites for high-performance supercapacitors and sodium ion batteries. Applied Surface Science 2018;434:128592. https://doi.org/10.1016/j.apsusc.2017.11.278.

[189] Qiu Y, Lin Y, Yang H, Wang L. Ni-doped cobalt hexacyanoferrate microcubes as battery-type electrodes for aqueous electrolyte-based electrochemical 
supercapacitors. Journal of Alloys and Compounds 2019;806:1315-22. https://doi.org/10.1016/j.jallcom.2019.07.253.

[190] Okubo M, Honma I. Ternary metal Prussian blue analogue nanoparticles as cathode materials for Li-ion batteries. Dalton Trans 2013;42:15881-4. https://doi.org/10.1039/C3DT51369F.

[191] Kurihara Y, Moritomo Y. Electrochemical, structural, and electronic properties of $\mathrm{Mn}-\mathrm{Co}$ hexacyanoferrates against $\mathrm{Li}$ concentration. Jpn J Appl Phys 2014;53:067101. https://doi.org/10.7567/JJAP.53.067101.

[192] Alam Venugopal NK, Joseph J. Electrochemically formed 3D hierarchical thin films of cobalt-manganese (Co-Mn) hexacyanoferrate hybrids for electrochemical applications. Journal of Power Sources 2016;305:249-58. https://doi.org/10.1016/j.jpowsour.2015.11.088.

[193] Jiang $X$, Liu H, Song J, Yin C, Xu H. Hierarchical mesoporous octahedral $\mathrm{K} 2 \mathrm{Mn} 1-\mathrm{xCoxFe}(\mathrm{CN}) 6$ as a superior cathode material for sodium-ion batteries. J Mater Chem A 2016;4:16205-12. https://doi.org/10.1039/C6TA06658E.

[194] Yu S, Li Y, Lu Y, Xu B, Wang Q, Yan M, et al. A promising cathode material of sodium iron-nickel hexacyanoferrate for sodium ion batteries. Journal of Power Sources 2015;275:45-9. https://doi.org/10.1016/j.jpowsour.2014.10.196.

[195] Wang J, Mi C, Nie P, Dong S, Tang S, Zhang X. Sodium-rich iron hexacyanoferrate with nickel doping as a high performance cathode for aqueous sodium ion batteries. Journal of Electroanalytical Chemistry 2018. https://doi.org/10.1016/j.jelechem.2018.04.011.

[196] Kim D, Hwang T, Lim J-M, Park M-S, Cho M, Cho K. Hexacyanometallates for sodium-ion batteries: insights into higher redox potentials using $d$ electronic spin configurations. Physical Chemistry Chemical Physics 2017;19:10443-52. https://doi.org/10.1039/C7CP00378A.

[197] Gong W, Zeng R, Su S, Wan M, Rao Z, Xue L, et al. Ball-milling synthesis of ultrafine NayFexMn1-x[Fe(CN)6] as high-performance cathode in sodium-ion batteries. J Nanopart Res 2019;21:274. https://doi.org/10.1007/s11051-019-4717-9.

[198] Li W, Han C, Wang W, Xia Q, Chou S, Gu Q, et al. Stress Distortion Restraint to Boost the Sodium Ion Storage Performance of a Novel Binary Hexacyanoferrate. Advanced Energy Materials n.d.;n/a:1903006. https://doi.org/10.1002/aenm.201903006.

[199] Kim DJ, Jung YH, Bharathi KK, Je SH, Kim DK, Coskun A, et al. An Aqueous Sodium Ion Hybrid Battery Incorporating an Organic Compound and a Prussian Blue Derivative. Advanced Energy Materials 2014;4:1400133. https://doi.org/10.1002/aenm.201400133.

[200] Xu Y, Zhu Y, Chen P, Nie W, Zhou Y. Trace interstitial water removal from coppercobalt Prussian analogues by rGO coating for high performance sodium ion supercapacitor devices. Applied Surface Science 2019;481:919-25. https://doi.org/10.1016/j.apsusc.2019.03.189. 
[201] Xie B, Zuo P, Wang L, Wang J, Huo H, He M, et al. Achieving long-life prussian blue analogue cathode for $\mathrm{Na}$-ion batteries via triple-cation lattice substitution and coordinated water capture. Nano Energy 2019:S221128551930360X. https://doi.org/10.1016/j.nanoen.2019.04.059.

[202] Li J, He X, Ostendorp S, Zhang L, Hou X, Zhou D, et al. Tin modification of sodium manganese hexacyanoferrate as a superior cathode material for sodium ion batteries. Electrochimica Acta 2020;342:135928. https://doi.org/10.1016/j.electacta.2020.135928.

[203] Tian R, Park S-H, King PJ, Cunningham G, Coelho J, Nicolosi V, et al. Quantifying the factors limiting rate performance in battery electrodes. Nat Commun 2019;10:111. https://doi.org/10.1038/s41467-019-09792-9.

[204] Karp FB, Bernotski NA, Valdes TI, Bohringer KF, Ratner BD. Foreign Body Response Investigated With an Implanted Biosensor by In Situ Electrical Impedance Spectroscopy. IEEE Sensors J 2008;8:104-12. https://doi.org/10.1109/JSEN.2007.912550.

[205] Administrator. Linear Sweep and Cyclic Voltametry: The Principles 2013. https://www.ceb.cam.ac.uk/research/groups/rg-eme/Edu/linear-sweep-andcyclic-voltametry-the-principles (accessed September 20, 2020).

[206] Bard AJ, Faulkner LR. Electrochemical methods: fundamentals and applications. 2nd ed. New York: Wiley; 2001.

[207] Aurbach D, Gofer Y. The Electrochemical Behavior of Calcium Electrodes in a Few Organic Electrolytes. Journal of The Electrochemical Society 1991;138:3529-3536.

[208] Ely YE, Aurbach D. Identification of surface films formed on active metals and nonactive metal electrodes at low potentials in methyl formate solutions. Langmuir 1992;8:1845-50. https://doi.org/10.1021/la00043a026.

[209] Hayashi M, Arai H, Ohtsuka H, Sakurai Y. Electrochemical characteristics of calcium in organic electrolyte solutions and vanadium oxides as calcium hosts. Journal of Power Sources 2003;119-121:617-20. https://doi.org/10.1016/S03787753(03)00307-0.

[210] Rogosic J. Towards the development of calcium ion batteries. Ph.D. Dissertation. Massachusetts Institute of Technology, 2014.

[211] Amatucci GG, Badway F, Singhal A, Beaudoin B, Skandan G, Bowmer T, et al. Investigation of Yttrium and Polyvalent Ion Intercalation into Nanocrystalline Vanadium Oxide. ResearchGate 2001;148:A940-50. https://doi.org/10.1149/1.1383777.

[212] Bervas M, Klein L, Amatucci G. Vanadium oxide-propylene carbonate composite as a host for the intercalation of polyvalent cations. Solid State lonics 2005;176:273547. https://doi.org/10.1016/j.ssi.2005.09.009.

[213] Lipson AL, Pan B, Lapidus SH, Liao C, Vaughey JT, Ingram BJ. Rechargeable Ca-lon Batteries: A New Energy Storage System. Chem Mater 2015;27:8442-7. https://doi.org/10.1021/acs.chemmater.5b04027. 
[214] Shiga T, Kondo H, Kato $\mathrm{Y}$, Inoue M. Insertion of Calcium Ion into Prussian Blue Analogue in Nonaqueous Solutions and Its Application to a Rechargeable Battery with Dual Carriers. J Phys Chem C 2015;119:27946-53. https://doi.org/10.1021/acs.jpcc.5b10245.

[215] Rodríguez-Carvajal J. Recent advances in magnetic structure determination by neutron powder diffraction. Physica B: Condensed Matter 1993;192:55-69. https://doi.org/10.1016/0921-4526(93)90108-I.

[216] Ganguli S, Bhattacharya M. Studies of different hydrated forms of Prussian Blue. J Chem Soc, Faraday Trans 1 1983;79:1513-22. https://doi.org/10.1039/F19837901513.

[217] Kuperman N, Padigi P, Solanki R, Goncher G, Evans D, Thiebes J. Manuscript in preparation n.d.

[218] Lee H-W, Wang RY, Pasta M, Woo Lee S, Liu N, Cui Y. Manganese hexacyanomanganate open framework as a high-capacity positive electrode material for sodium-ion batteries. Nature Communications 2014;5:5280. https://doi.org/10.1038/ncomms6280.

[219] You Y, Wu X-L, Yin Y-X, Guo Y-G. High-quality Prussian blue crystals as superior cathode materials for room-temperature sodium-ion batteries. Energy Environ Sci 2014;7:1643-7. https://doi.org/10.1039/C3EE44004D.

[220] Ling C, Chen J, Mizuno F. First-Principles Study of Alkali and Alkaline Earth Ion Intercalation in Iron Hexacyanoferrate: The Important Role of Ionic Radius. J Phys Chem C 2013;117:21158-65. https://doi.org/10.1021/jp4078689.

[221] Kuperman N, Hopkins M, Olson S, Goncher G, Evans D, Solanki R. Cathode Material Composed of Manganese Cobalt Hexacyanoferrate Nanoparticles for Aqueous Zinc Ion Intercalation Batteries. 2018 IEEE 13th Nanotechnology Materials and Devices Conference (NMDC), 2018, p. 1-4. https://doi.org/10.1109/NMDC.2018.8605900.

[222] Beiter P, Tian T. 2015 renewable energy data book. National Renewable Energy Laboratory; 2016.

[223] REN21. RENEWABLES 2017 GLOBAL STATUS REPORT. Paris: REN21; 2017.

[224] Wu X, Xiang Y, Peng Q, Wu X, Li Y, Tang F, et al. Green-low-cost rechargeable aqueous zinc-ion batteries using hollow porous spinel $\mathrm{ZnMn204}$ as the cathode material. J Mater Chem A 2017;5:17990-7. https://doi.org/10.1039/C7TA00100B.

[225] Jiang B, Xu C, Wu C, Dong L, Li J, Kang F. Manganese Sesquioxide as Cathode Material for Multivalent Zinc Ion Battery with High Capacity and Long Cycle Life. Electrochimica Acta 2017;229:422-8. https://doi.org/10.1016/j.electacta.2017.01.163.

[226] Chae MS, Heo JW, Lim S-C, Hong S-T. Electrochemical Zinc-Ion Intercalation Properties and Crystal Structures of ZnMo6S8 and Zn2Mo6S8 Chevrel Phases in Aqueous Electrolytes. Inorg Chem 2016;55:3294-301. https://doi.org/10.1021/acs.inorgchem.5b02362. 
[227] He P, Quan Y, Xu X, Yan M, Yang W, An Q, et al. High-Performance Aqueous ZincIon Battery Based on Layered H2V3O8 Nanowire Cathode. Small 2017;13:n/a-n/a. https://doi.org/10.1002/smll.201702551.

[228] Alfaruqi MH, Mathew V, Song J, Kim S, Islam S, Pham DT, et al. Electrochemical Zinc Intercalation in Lithium Vanadium Oxide: A High-Capacity Zinc-Ion Battery Cathode. Chem Mater 2017;29:1684-94. https://doi.org/10.1021/acs.chemmater.6b05092.

[229] Kim D, Lee C, Jeong S. A concentrated electrolyte for zinc hexacyanoferrate electrodes in aqueous rechargeable zinc-ion batteries. IOP Conf Ser: Mater Sci Eng 2018;284:012001. https://doi.org/10.1088/1757-899X/284/1/012001.

[230] Wessells CD, Peddada SV, McDowell MT, Huggins RA, Cui Y. The effect of insertion species on nanostructured open framework hexacyanoferrate battery electrodes. Journal of The Electrochemical Society 2011;159:A98-A103.

[231] Kuperman N, Padigi P, Goncher G, Evans D, Thiebes J, Solanki R. High performance Prussian Blue cathode for nonaqueous Ca-ion intercalation battery. Journal of Power Sources 2017;342:414-8. https://doi.org/10.1016/j.jpowsour.2016.12.074.

[232] Shannon RD. Revised effective ionic radii and systematic studies of interatomic distances in halides and chalcogenides. Acta Cryst A, Acta Cryst Sect A, Acta Crystallogr A, Acta Crystallogr Sect A, Acta Crystallogr A Cryst Phys Diffr Theor Gen Crystallogr, Acta Crystallogr Sect A Cryst Phys Diffr Theor Gen Crystallogr 1976;32:751-67. https://doi.org/10.1107/S0567739476001551.

[233] Nakamoto K, Sakamoto R, Ito M, Kitajou A, Okada S. Effect of Concentrated Electrolyte on Aqueous Sodium-ion Battery with Sodium Manganese Hexacyanoferrate Cathode. Electrochemistry 2017;85:179-85. https://doi.org/10.5796/electrochemistry.85.179.

[234] Małecki G, Ratuszna A. Crystal structure of cyanometallates Me3[Co(CN)6]2 and $\mathrm{KMe}[\mathrm{Fe}(\mathrm{CN}) 6]$ with $\mathrm{Me}=\mathrm{Mn} 2+, \mathrm{Ni2}+, \mathrm{Cu} 2+$. Powder Diffraction 1999;14:25-30. https://doi.org/10.1017/S0885715600010265.

[235] Kulesza PJ, Malik MA, Miecznikowski K, Wolkiewicz A, Zamponi S, Berrettoni M, et al. Countercation-Sensitive Electrochromism of Cobalt Hexacyanoferrate Films. J Electrochem Soc 1996;143:L10-2. https://doi.org/10.1149/1.1836374.

[236] Lu K, Song B, Gao X, Dai H, Zhang J, Ma H. High-energy cobalt hexacyanoferrate and carbon micro-spheres aqueous sodium-ion capacitors. Journal of Power Sources 2016;303:347-53. https://doi.org/10.1016/j.jpowsour.2015.11.031.

[237] Pazos M, Gouveia S, Sanromán MA, Cameselle C. Electromigration of Mn, Fe, Cu and $\mathrm{Zn}$ with citric acid in contaminated clay. Journal of Environmental Science and Health, Part A 2008;43:823-31. https://doi.org/10.1080/10934520801974004.

[238] Kuperman N, Cairns A, Goncher G, Solanki R. Structural water enhanced intercalation of magnesium ions in copper hexacyanoferrate nonaqueous batteries. $\quad$ Electrochimica 2020;362:137077. https://doi.org/10.1016/j.electacta.2020.137077.

[239] Dhabi A. Renewable power generation costs in 2018. International Renewable Energy Agency; 2019. 
[240] Comello S, Reichelstein S. The emergence of cost effective battery storage. Nat Commun 2019;10:1-9. https://doi.org/10.1038/s41467-019-09988-z.

[241] Arbabzadeh M, Sioshansi R, Johnson JX, Keoleian GA. The role of energy storage in deep decarbonization of electricity production. Nat Commun 2019;10:1-11. https://doi.org/10.1038/s41467-019-11161-5.

[242] Matsui M. Study on electrochemically deposited Mg metal. Journal of Power Sources 2011;196:7048-55. https://doi.org/10.1016/j.jpowsour.2010.11.141.

[243] Aurbach D, Lu Z, Schechter A, Gofer Y, Gizbar H, Turgeman R, et al. Prototype systems for rechargeable magnesium batteries. Nature 2000;407:724-7. https://doi.org/10.1038/35037553.

[244] Sun X, Duffort V, Nazar LF. Prussian Blue Mg-Li Hybrid Batteries. Advanced Science 2016;3:1600044. https://doi.org/10.1002/advs.201600044.

[245] Nam KW, Kim S, Lee S, Salama M, Shterenberg I, Gofer Y, et al. The High Performance of Crystal Water Containing Manganese Birnessite Cathodes for Magnesium Batteries. Nano Lett 2015;15:4071-9. https://doi.org/10.1021/acs.nanolett.5b01109.

[246] Deng X, Xu Y, An Q, Xiong F, Tan S, Wu L, et al. Manganese ion pre-intercalated hydrated vanadium oxide as a high-performance cathode for magnesium ion batteries. Journal of Materials Chemistry A 2019;7:10644-50. https://doi.org/10.1039/C8TA11236C.

[247] FULLPROF: A Program for Rietveld Refinement and Pattern Matching Analysis. n.d.

[248] Martínez-Garcia R, Reguera E, Balmaseda J, Ramos G, Yee-Madeira H. On the crystal structures of some nickel hexacyanoferrates (II,III). Powder Diffr 2004;19:284-91. https://doi.org/10.1154/1.1757448.

[249] Matsuda T, Kim J, Moritomo Y. Control of the alkali cation alignment in Prussian blue framework. Dalton Trans 2012;41:7620-3. https://doi.org/10.1039/C2DT12296K.

[250] Martínez-García R, Knobel M, Balmaseda J, Yee-Madeira H, Reguera E. Mixed valence states in cobalt iron cyanide. Journal of Physics and Chemistry of Solids 2007;68:290-8. https://doi.org/10.1016/j.jpcs.2006.11.008.

[251] Åkerblom IE, Ojwang DO, Grins J, Svensson G. A thermogravimetric study of thermal dehydration of copper hexacyanoferrate by means of model-free kinetic analysis. J Therm Anal Calorim 2017;129:721-31. https://doi.org/10.1007/s10973017-6280-x.

[252] Avila M, Reguera L, Rodríguez-Hernández J, Balmaseda J, Reguera E. Porous framework of $\mathrm{T} 2[\mathrm{Fe}(\mathrm{CN}) 6] \cdot \mathrm{xH} 2 \mathrm{O}$ with $\mathrm{T}=\mathrm{Co}, \mathrm{Ni}, \mathrm{Cu}, \mathrm{Zn}$, and $\mathrm{H} 2$ storage. Journal of Solid State Chemistry 2008;181:2899-907. https://doi.org/10.1016/j.jssc.2008.07.030.

[253] Mink J, Stirling A, Ojwang DO, Svensson G, Mihály J, Németh C, et al. Vibrational properties and bonding analysis of copper hexacyanoferrate complexes in solid state. Applied Spectroscopy Reviews 2018;0:1-56. https://doi.org/10.1080/05704928.2018.1459659. 
[254] Mullaliu A, Aquilanti G, Conti P, Plaisier JR, Fehse M, Stievano L, et al. Copper Electroactivity in Prussian Blue Based Cathode Disclosed by Operando XAS. J Phys Chem C 2018. https://doi.org/10.1021/acs.jpcc.8b03429.

[255] Makowski O, Stroka J, Kulesza PJ, Malik MA, Galus Z. Electrochemical identity of copper hexacyanoferrate in the solid-state: evidence for the presence and redox activity of both iron and copper ionic sites. Journal of Electroanalytical Chemistry 2002;532:157-64. https://doi.org/10.1016/S0022-0728(02)00965-8.

[256] Wu Y, Li C, Yan W, Liang S, Wang P, Wang J, et al. Achieving high-performance Prussian blue analogue cathode with ultra-stable redox reaction for ammonium ion storage. Nanoscale Horizons 2019. https://doi.org/10.1039/C8NH00484F.

[257] Liu J, Wang J, Xu C, Jiang H, Li C, Zhang L, et al. Advanced Energy Storage Devices: Basic Principles, Analytical Methods, and Rational Materials Design. Advanced Science 2018;5:1700322. https://doi.org/10.1002/advs.201700322.

[258] Saqib N, Ganim CM, Shelton AE, Porter JM. On the Decomposition of CarbonateBased Lithium-Ion Battery Electrolytes Studied Using Operando Infrared Spectroscopy. J Electrochem Soc 2018;165:A4051. https://doi.org/10.1149/2.1051816jes.

[259] Mullaliu A, Gaboardi M, Plaisier JR, Passerini S, Giorgetti M. Lattice Compensation to Jahn-Teller Distortion in Na-Rich Manganese Hexacyanoferrate for Li-lon Storage: An Operando Study. ACS Appl Energy Mater 2020;3:5728-33. https://doi.org/10.1021/acsaem.0c00669.

[260] Mullaliu A, Aquilanti G, Conti P, Giorgetti M, Passerini S. Effect of Water and AlkaliIon Content on the Structure of Manganese(II) Hexacyanoferrate(II) by a Joint Operando X-ray Absorption Spectroscopy and Chemometric Approach. ChemSusChem 2020;13:608-15. https://doi.org/10.1002/cssc.201902802.

[261] Mullaliu A, Asenbauer J, Aquilanti G, Passerini S, Giorgetti M. Highlighting the Reversible Manganese Electroactivity in Na-Rich Manganese Hexacyanoferrate Material for Li- and Na-Ion Storage. Small Methods 2020;4:1900529. https://doi.org/10.1002/smtd.201900529.

[262] Oliver-Tolentino MA, Vázquez-Samperio J, Arellano-Ahumada SN, Guzmán-Vargas A, Ramírez-Rosales D, Wang JA, et al. Enhancement of Stability by Positive Disruptive Effect on Mn-Fe Charge Transfer in Vacancy-Free Mn-Co Hexacyanoferrate Through a Charge/Discharge Process in Aqueous Na-lon Batteries. J Phys Chem C 2018;122:20602-10. https://doi.org/10.1021/acs.jpcc.8b05506.

[263] Wheeler S, Capone I, Day S, Tang C, Pasta M. Low-Potential Prussian Blue Analogues for Sodium-Ion Batteries: Manganese Hexacyanochromate. Chem Mater 2019;31:2619-26. https://doi.org/10.1021/acs.chemmater.9b00471.

[264] Scholz F, Dostal A. The formal potentials of solid metal hexacyanometalates. Angewandte Chemie International Edition in English 1996;34:2685-2687. 
[265] Ghosh SN. Infrared spectra of the Prussian blue analogs. Journal of Inorganic and Nuclear Chemistry 1974;36:2465-6. https://doi.org/10.1016/00221902(74)80454-9.

[266] Kettle SFA, Diana E, Marchese EMC, Boccaleri E, Stanghellini PL. The vibrational spectra of the cyanide ligand revisited: the $v(C N)$ infrared and Raman spectroscopy of Prussian blue and its analogues. J Raman Spectrosc 2011;42:2006-14. https://doi.org/10.1002/jrs.2944.

[267] Tokoro H, Miyashita S, Hashimoto K, Ohkoshi S. Huge thermal hysteresis loop and a hidden stable phase in a charge-transfer phase transition of Rb $0.64 \mathrm{Mn}$ [ Fe ( CN

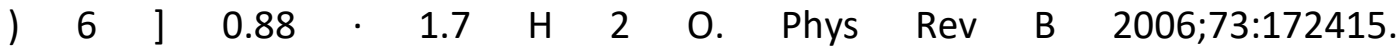
https://doi.org/10.1103/PhysRevB.73.172415.

[268] Tang Y, Li W, Feng P, Zhou M, Wang K, Wang Y, et al. High-Performance Manganese Hexacyanoferrate with Cubic Structure as Superior Cathode Material for SodiumIon Batteries. Advanced Functional Materials n.d.;n/a:1908754. https://doi.org/10.1002/adfm.201908754.

[269] Xu Y, Chang M, Fang C, Liu Y, Qiu Y, Ou M, et al. In Situ FTIR-Assisted Synthesis of Nickel Hexacyanoferrate Cathodes for Long-Life Sodium-Ion Batteries. ACS Appl Mater Interfaces 2019;11:29985-92. https://doi.org/10.1021/acsami.9b10312.

[270] Gerber SJ, Erasmus E. Electronic effects of metal hexacyanoferrates: An XPS and FTIR study. Materials Chemistry and Physics 2018;203:73-81. https://doi.org/10.1016/j.matchemphys.2017.09.029.

[271] Andrew Lin K-Y, Chen B-J, Chen C-K. Evaluating Prussian blue analogues M II3 [M III (CN) 6 ] 2 ( $\mathrm{M} I I=\mathrm{Co}, \mathrm{Cu}, \mathrm{Fe}, \mathrm{Mn}, \mathrm{Ni} ; \mathrm{M} \mathrm{III}=\mathrm{Co}, \mathrm{Fe})$ as activators for peroxymonosulfate in water. RSC Advances 2016;6:92923-33. https://doi.org/10.1039/C6RA16011E.

[272] Ming H, Torad NLK, Chiang Y-D, Wu KC-W, Yamauchi Y. Size- and shape-controlled synthesis of Prussian Blue nanoparticles by a polyvinylpyrrolidone-assisted crystallization $\quad$ process. CrystEngComm 2012;14:3387-96. https://doi.org/10.1039/C2CE25040C.

[273] Kohn W. Nobel Lecture: Electronic structure of matter-wave functions and density functionals. Reviews of Modern Physics 1999;71:1253.

[274] Thomas LH. The calculation of atomic fields. Mathematical Proceedings of the Cambridge Philosophical Society 1927;23:542-8. https://doi.org/10.1017/S0305004100011683.

[275] Fermi E. Un metodo statistico per la determinazione di alcune priorieta dell'atome. Rend Accad Naz Lincei 1927;6:32.

[276] Hohenberg P, Kohn W. Inhomogeneous Electron Gas. Phys Rev 1964;136:B864-71. https://doi.org/10.1103/PhysRev.136.B864.

[277] Kohn W, Sham U. Self-Consistent Equations Including Exchange and Correlation Effects. Phys Rev 1965;140:A1133-8. https://doi.org/10.1103/PhysRev.140.A1133.

[278] Kresse G, Hafner J. Ab initio molecular dynamics for liquid metals. Phys Rev B 1993;47:558-61. https://doi.org/10.1103/PhysRevB.47.558. 
[279] Kresse G, Hafner J. Ab initio molecular-dynamics simulation of the liquid-metal-amorphous-semiconductor transition in germanium. Phys Rev B 1994;49:1425169. https://doi.org/10.1103/PhysRevB.49.14251.

[280] Kresse G, Furthmüller J. Efficiency of ab-initio total energy calculations for metals and semiconductors using a plane-wave basis set. Computational Materials Science 1996;6:15-50. https://doi.org/10.1016/0927-0256(96)00008-0.

[281] Kresse G, Furthmüller J. Efficient iterative schemes for ab initio total-energy calculations using a plane-wave basis set. Phys Rev B 1996;54:11169-86. https://doi.org/10.1103/PhysRevB.54.11169.

[282] Perdew JP, Burke K, Ernzerhof M. Generalized Gradient Approximation Made Simple. Phys Rev Lett 1996;77:3865-8. https://doi.org/10.1103/PhysRevLett.77.3865.

[283] Perdew JP, Burke K, Ernzerhof M. Generalized Gradient Approximation Made Simple [Phys. Rev. Lett. 77, 3865 (1996)]. Phys Rev Lett 1997;78:1396-1396. https://doi.org/10.1103/PhysRevLett.78.1396.

[284] Kresse G, Joubert D. From ultrasoft pseudopotentials to the projector augmentedwave method. Phys Rev B 1999;59:1758-75. https://doi.org/10.1103/PhysRevB.59.1758.

[285] Blöchl PE. Projector augmented-wave method. Phys Rev B 1994;50:17953-79. https://doi.org/10.1103/PhysRevB.50.17953.

[286] Anisimov VI, Zaanen J, Andersen OK. Band theory and Mott insulators: Hubbard U instead of Stoner I. Phys Rev B 1991;44:943-54. https://doi.org/10.1103/PhysRevB.44.943.

[287] Anisimov VI, Solovyev IV, Korotin MA, Czyżyk MT, Sawatzky GA. Density-functional theory and NiO photoemission spectra. Phys Rev B 1993;48:16929-34. https://doi.org/10.1103/PhysRevB.48.16929.

[288] Jiang L, Lu Y, Zhao C, Liu L, Zhang J, Zhang Q, et al. Building aqueous K-ion batteries for energy storage. Nat Energy 2019. https://doi.org/10.1038/s41560-019-0388-0.

[289] Heyd J, Scuseria GE, Ernzerhof M. Hybrid functionals based on a screened Coulomb potential. The Journal of Chemical Physics 2003;118:8207-15. https://doi.org/10.1063/1.1564060.

[290] The VASP Manual - Vaspwiki n.d. https://www.vasp.at/wiki/index.php/The_VASP_Manual (accessed September 21, 2020). 


\section{Appendices}

\section{Appendix A: INCAR}

For a full list of all INCAR parameters can be found at the VASP wiki [290].

$\begin{array}{ll}\text { ISTART }=0 & \text { \# O for start, } 1 \text { for continuation } \\ \text { ICHARG }=0 & \text { \# O for start, } 1 \text { for continuation, } 11 \text { for DOS calculation }\end{array}$

ISPIN = 2 \# Turns spin polarization calculations on

NUPDOWN = $14 \quad$ \# Sets the difference between the number of electrons in the up and down spin components.

MAGMOM $=4 * 0.048 * 0.08 * .02 * 2.02 * 5.0 \quad$ \# Specifies the initial magnetic moment for each atom

LASPH $=$.TRUE. \#Includes non-spherical contributions from the gradient corrections inside the PAW spheres

ISYM = 2 \# Determines the way VASP treats symmetry

\# PBE + U calculation:

LDAU $=$. TRUE. $\#$ Switch on $\angle D A+U$

LDAUTYPE $=2$ \# LSDA + U Dudarev's approach = type 2 in vasp

\# Add on-site interaction for the respective atoms (same order as in POSCAR)

\# Only the difference $U-J$ is meaningful!!! $U$ and J do not enter separately in the calculation.

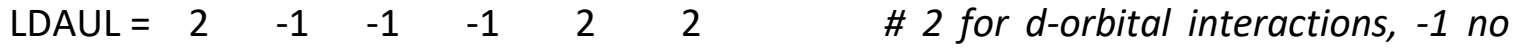
on-site interaction 
LDAUU $=\begin{array}{lllllll}3.9 & 0.0 & 0.0 & 0.0 & 5.3 & 4.3 & \text { \# Define U-parameters for on-site Coulomb }\end{array}$ interaction

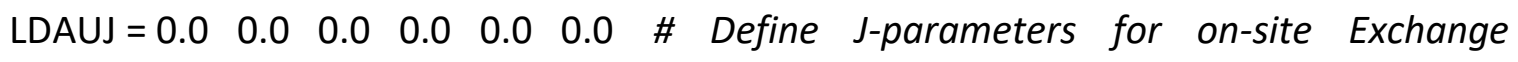
interaction

LDAUPRINT = 2 \# to print occupation matrix in OUTCAR

LMAXMIX $=4 \quad$ \# in the case of $L D A+U$ calculations $L M A X M I X$ must be increased to 4 for $d$-electrons

\# Accuracy:

ENCUT $=600 \quad$ \# energy cutoff for optimization

PREC = Accurate \# Specifies the "precision" mode

ADDGRID = .TRUE. \# Adds additional grid for evaluation of augmentation charges

ISMEAR = -5 \# determines how the partial occupancies fnk are set for each orbital.

\# 0 = gaussian smearing, -5 = tetrahedron method with Blöchl corrections

\# electronic convergence

$\mathrm{EDIFF}=1 \mathrm{E}-6 \quad$ \# maximal energy difference for stopping electronic relaxation

$\mathrm{NELMDL}=-5$ \# specifies the number of non-selfconsistent steps at the beginning. The negative number denotes the delay is only performed in the first ionic step

NELMIN = 8 \# minimum number of electronic steps

$\mathrm{NELM}=100 \quad$ \# maximum number of electronic steps

\# ionic convergence

IBRION = 2 \# determines how the ions are updated and moved. 
\# 1 = quasi-newton algorithm, 2 = conjugate gradient algorithm, -1 = no update, used for non-self consistent and DOS calculations

EDIFFG $=-0.001 \quad$ \# defines the break condition for the ionic relaxation loop. If the change in the total (free) energy is smaller than EDIFFG between two ionic steps relaxation will be stopped.

NSW $=200 \quad$ \#maximum number of ionic steps

ISIF = 3 \# Determines which degrees-of-freedom are allowed to change in relaxation. 2 = just position, 3 = position, cell shape, cell volume.

POTIM $=0.1 \quad$ \# sets the step width scaling (ionic relaxations).

\# For local charges and magnetization

LORBIT = 11 \# gives magnetic moments and DOS

LAECHG = .TRUE. \# for Bader Charge analysis

LWAVE $=$.TRUE. \# write WAVECAR file 


\section{Appendix B: KPOINT}

The descriptions of each line in the following KPOINT file is reproduced from the VASP wiki [290]:

- 1: Header

- 2: Specifies the $\mathrm{k}$ mesh generation scheme. 0 denotes automatic

- 3: Specifies either Gamma-centered or Monkhorst-Pack grid

- 4: Number of subdivisions in each direction

- 5: Shift of the mesh

Auto

0

Monkhorst-Pack

888

0.00 .00 .0 


\section{Appendix C: INCAR}

The descriptions of each line in the following POSCAR file is reproduced from the VASP wiki [290]:

- 1: Header or comments

- 2: overall scaling constant

- 3-5: Bravis matrix

- 6: Name(s) of atom(s)

- 7: Number of the atoms (of each atom type)

- 8: Specifies which coordinate system is used ("cartesian" or "direct")

- 9 - end: Positions of atoms

$\mathrm{NiHCF}$

1.0

$\begin{array}{ccr}10.2200000000 & 0.0000000000 & 0.0000000000 \\ 0.0000000000 & 10.2200000000 & 0.0000000000 \\ 0.0000000000 & 0.0000000000 & 10.2200000000\end{array}$

Fe $\mathrm{N} \quad \mathrm{C} \quad \mathrm{K}$ Ni

$\begin{array}{lllll}4 & 24 & 24 & 8 & 4\end{array}$

Direct

$\begin{array}{lll}0.000000000 & 0.500000000 & 0.000000000 \\ 0.000000000 & 0.000000000 & 0.500000000 \\ 0.500000000 & 0.000000000 & 0.000000000 \\ 0.500000000 & 0.500000000 & 0.500000000 \\ 0.200900641 & 0.000000000 & 0.000000000 \\ 0.799099359 & 0.000000000 & 0.000000000 \\ 0.000000000 & 0.200900641 & 0.000000000 \\ 0.000000000 & 0.799099359 & 0.000000000 \\ 0.000000000 & 0.000000000 & 0.200900641 \\ 0.000000000 & 0.000000000 & 0.799099359 \\ 0.200900641 & 0.500000000 & 0.500000000 \\ 0.799099359 & 0.500000000 & 0.500000000 \\ 0.000000000 & 0.700900594 & 0.500000000 \\ 0.000000000 & 0.299099359 & 0.500000000 \\ 0.000000000 & 0.500000000 & 0.700900594 \\ 0.000000000 & 0.500000000 & 0.299099359 \\ 0.700900594 & 0.000000000 & 0.500000000\end{array}$




$\begin{array}{rrr}0.299099359 & 0.000000000 & 0.500000000 \\ 0.500000000 & 0.200900641 & 0.500000000 \\ 0.500000000 & 0.799099359 & 0.500000000 \\ 0.500000000 & 0.000000000 & 0.700900594 \\ 0.500000000 & 0.000000000 & 0.299099359 \\ 0.700900594 & 0.500000000 & 0.000000000 \\ 0.299099359 & 0.500000000 & 0.000000000 \\ 0.500000000 & 0.700900594 & 0.000000000 \\ 0.500000000 & 0.299099359 & 0.000000000 \\ 0.500000000 & 0.500000000 & 0.200900641 \\ 0.500000000 & 0.500000000 & 0.799099359 \\ 0.316067871 & 0.000000000 & 0.000000000 \\ 0.683932106 & 0.000000000 & 0.000000000 \\ 0.000000000 & 0.316067871 & 0.000000000 \\ 0.000000000 & 0.683932106 & 0.000000000 \\ 0.000000000 & 0.000000000 & 0.316067871 \\ 0.000000000 & 0.000000000 & 0.683932106 \\ 0.316067871 & 0.500000000 & 0.500000000 \\ 0.683932106 & 0.500000000 & 0.500000000 \\ -0.000000000 & 0.816067894 & 0.50000000 \\ 0.000000000 & 0.183932129 & 0.500000000 \\ -0.000000000 & 0.500000000 & 0.816067894 \\ 0.000000000 & 0.500000000 & 0.183932129 \\ 0.816067894 & 0.000000000 & 0.500000000 \\ 0.183932129 & 0.000000000 & 0.500000000 \\ 0.500000000 & 0.316067871 & 0.500000000 \\ 0.500000000 & 0.683932106 & 0.500000000 \\ 0.500000000 & -0.000000000 & 0.816067894 \\ 0.500000000 & 0.000000000 & 0.183932129 \\ 0.816067894 & 0.500000000 & 0.000000000 \\ 0.183932129 & 0.500000000 & 0.000000000 \\ 0.500000000 & 0.816067894 & 0.000000000 \\ 0.500000000 & 0.183932129 & 0.000000000 \\ 0.500000000 & 0.500000000 & 0.316067871 \\ 0.500000000 & 0.500000000 & 0.683932106 \\ 0.750000000 & 0.750000000 & 0.750000000 \\ 0.250000000 & 0.250000000 & 0.750000000 \\ 0.250000000 & 0.750000000 & 0.250000000 \\ 0.750000000 & 0.250000000 & 0.250000000 \\ 0.750000000 & 0.750000000 & 0.250000000 \\ 0.750000000 & 0.250000000 & 0.750000000 \\ 0.250000000 & 0.750000000 & 0.750000000\end{array}$




$\begin{array}{lll}0.250000000 & 0.250000000 & 0.250000000 \\ 0.000000000 & 0.000000000 & 0.000000000 \\ 0.000000000 & 0.500000000 & 0.500000000 \\ 0.500000000 & 0.000000000 & 0.500000000 \\ 0.500000000 & 0.500000000 & 0.000000000\end{array}$

